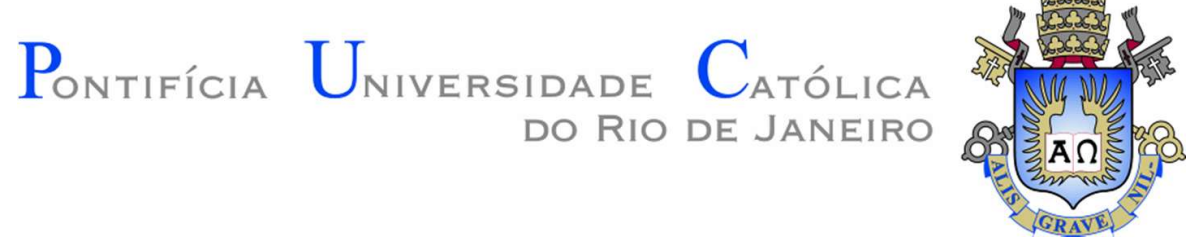

Thiago dos Santos Pereira

\author{
Injeção de Soluções Poliméricas
}

em Arenitos

Dissertação de mestrado

Dissertação apresentada ao Programa de Pósgraduação em Engenharia Mecânica da PUC-Rio como requisito parcial para obtenção do grau de Mestre em Engenharia Mecânica.

Orientador: Prof. Márcio da Silveira Carvalho

Rio de Janeiro

Abril de 2019 


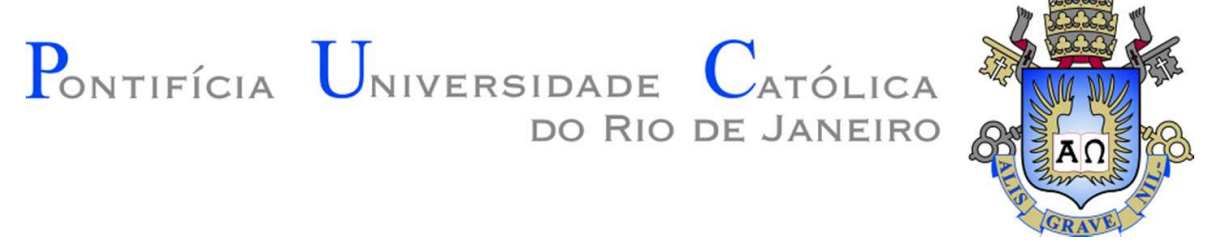

Thiago dos Santos Pereira

\title{
Injeção de Soluções Poliméricas \\ em Arenitos
}

Dissertação apresentada como requisito parcial para obtenção do grau de Mestre pelo Programa de Pósgraduação em Engenharia Mecânica da PUC-Rio. Aprovada pela comissão examinadora abaixo.

\author{
Prof. Márcio da Silveira Carvalho \\ Orientador \\ Departamento de Engenharia Mecânica - PUC-Rio
}

Prof. Marcos Vitor Barbosa Machado Departamento de Engenharia Mecânica - PUC-Rio

Prof. Antonio Luiz Serra de Souza Departamento de Engenharia Civil - PUC-Rio

Rio de Janeiro, 05 de Abril de 2019. 
Todos os direitos reservados.

Thiago dos Santos Pereira

Bacharel em Engenharia de Petróleo pela Pontifícia Universidade Católica do Rio de Janeiro.

Ficha Catalográfica

Pereira, Thiago dos Santos

Injeção de soluções poliméricas em arenitos / Thiago dos Santos Pereira ; orientador: Márcio da Silveira Carvalho. - 2019.

167 f. : il. color. ; $30 \mathrm{~cm}$

Dissertação (mestrado)-Pontifícia Universidade Católica do Rio de Janeiro, Departamento de Engenharia Mecânica, 2019.

Inclui bibliografia

1. Engenharia Mecânica - Teses. 2. Soluções poliméricas. 3. Recuperação avançada. 4. Adsorção. 5. Retenção. 6. Arenitos. I. Carvalho, Márcio da Silveira. II. Pontifícia Universidade Católica do Rio de Janeiro. Departamento de Engenharia Mecânica. III. Título. 
A todos que contribuíram com esse trabalho. 


\section{Agradecimentos}

Agradeço a sorte que sempre me acompanhou desde o meu primeiro momento de minha existência.

A sorte de ter nascido em uma família maravilhosa que sempre me proporcionou tudo e me deu liberdade para voar.

A sorte de ter saúde.

A sorte de ter conhecido, e conhecer, pessoas incríveis que fizeram diferença no meu caminhar.

A sorte no amor.

A sorte de poder contribuir, mesmo que minimamente, para o nosso processo de evolução e para a ciência.

A todos vocês, minha admiração e gratidão.

O presente trabalho foi realizado com apoio da Coordenação de Aperfeiçoamento de Pessoal de Nível Superior - Brasil (CAPES) - Código de Financiamento 001. 


\section{Resumo}

Pereira, Thiago dos Santos; Carvalho, Márcio da Silveira (Orientador). Injeção de Soluções Poliméricas em Arenitos. Rio de Janeiro, 2019. 167p. Dissertação de Mestrado - Departamento de Engenharia Mecânica, Pontifícia Universidade Católica do Rio de Janeiro

A adição de polímeros à água de injeção é um dos métodos de recuperação avançada mais utilizados devido a capacidade desses compostos, de alta massa molar, de aumentar, de maneira significativa, a viscosidade da solução mesmo em baixas concentrações. O incremento na viscosidade da solução possibilita a diminuição da razão de mobilidade entre os fluidos, melhorando o deslocamento do óleo. Porém, há uma infinidade de fatores relacionados ao uso dessas substâncias que podem modificar significativamente as características originais do meio poroso, afetando permanentemente a produtividade do reservatório. De maneira a tentar entender melhor esses mecanismos, realizou-se neste estudo a revisão das características relacionadas à injeção de soluções poliméricas, e efetuou-se uma análise experimental para estudar os processos de adsorção polimérica e recuperação de óleo. Utilizou-se três tipos de amostras de rochas com diferentes características petrofísicas. Primeiramente foram realizados testes de adsorção de polímeros nas formações em condições de trabalho específicas através do Two Slug Method. Em seguida, realizou-se um estudo do processo de recuperação de óleo através da injeção de diferentes fases aquosas: água com composição semelhante a do campo de Peregrino, solução polimérica de HPAM e solução de glicerina com água com a mesma viscosidade da solução polimérica. Os resultados mostraram a eficiência do Two Slug Method em testes de adsorção e da utilização de soluções poliméricas nos processos de recuperação de óleo.

\section{Palavras Chaves:}

Soluções Poliméricas, Recuperação Avançada, Adsorção, Retenção, Arenitos. 


\begin{abstract}
Pereira, Thiago dos Santos; Carvalho, Márcio da Silveira (Advisor). Polymer Flooding in Sandstone Cores. Rio de Janeiro, 2019. 167p. MSc. Dissertation - Departamento de Engenharia Mecânica, Pontifícia Universidade Católica do Rio de Janeiro.
\end{abstract}

The addition of polymers to the injection water is one of the most used oil enhanced recovery method because of the ability of these compounds to increase the viscosity of the solution even at low concentrations. This increase of the water phase viscosity promotes the reduction of the mobility ratio between fluids, improving the displacement of oil. However, there is a large number of factors related to the use of these substances that can significantly modify the original characteristics of the porous medium, affecting the useful life of the oil field. In order to better understand these mechanisms, a review of the characteristics related to polymer-flooding, and an experimental analysis were carried out to verify polymer adsorption mechanism and oil recovery processes. Three types of core samples with different petrophysical characteristics were used. Tests were carried out to study polymer adsorption on formations under specific working conditions by using the Two Slug Method. Then, oil recovery tests were performed with the injection of different water phases: water with composition similar to Peregrino field water, polymer solution and glycerol- water solution with the same viscosity of the polymer solution. Results showed the efficiency of the Two Slug Method in adsorption tests and the use of polymer solutions in oil recovery processes.

\title{
Keywords:
}

Polymer Solutions, Enhanced Oil Recovery, Adsorption, Retention, Sandstones. 


\section{Sumário}

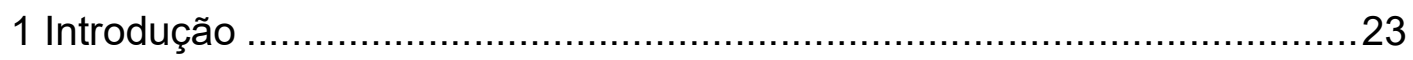

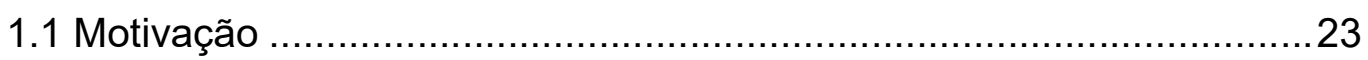

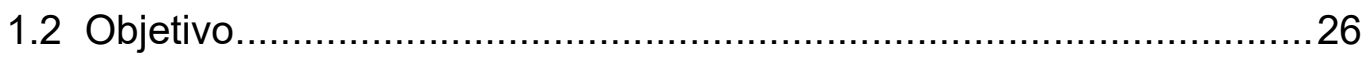

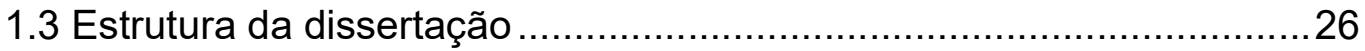

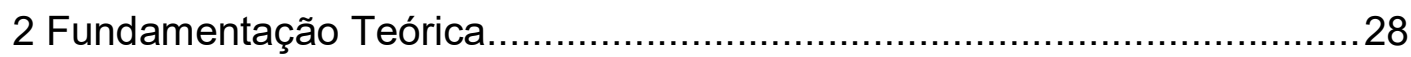

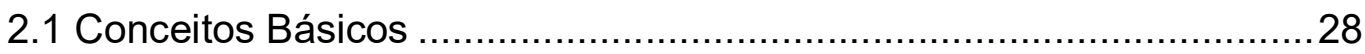

2.1.2 Conceitos Básicos Relacionados às Propriedades das Rochas ...29

2.1.3 Conceitos Básicos Relacionados aos Fluidos ..............................34

2.2 Conceitos Básicos em Engenharia de Petróleo ..................................38

2.2.1 Processos de Recuperação ............................................. 38

2.3 Conceitos Específicos do Experimento........................................ 41

2.3.1 Two Slug Method ........................................................ 42

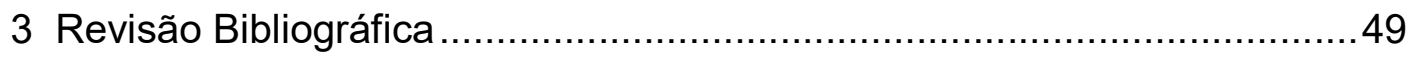

3.1 Vantagens e Desvantagens na Utilização de Soluções Poliméricas como Método de Recuperação ..............................................................50

3.2 Tipos de Polímeros ............................................................ 51

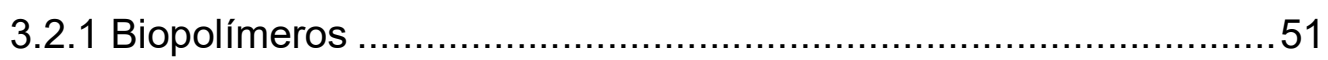

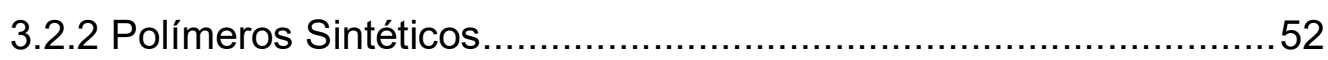

3.3 Critério de Seleção de Polímeros ............................................... 54

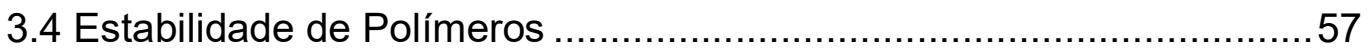

3.4.1 Degradação Química ........................................................ 58

3.4.2 Degradação Mecânica .....................................................6 60

3.4.3 Degradação Biológica ....................................................60 
3.5 Mecanismos de Retenção de Polímeros

3.5.1 Retenção Hidrodinâmica ..................................................... 62

3.5.2 Aprisionamento Mecânico ............................................ 62

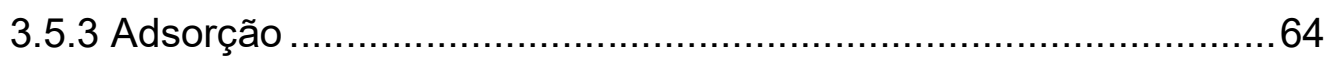

4 Procedimento Experimental ............................................................ 67

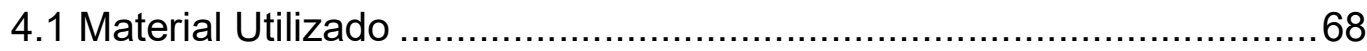

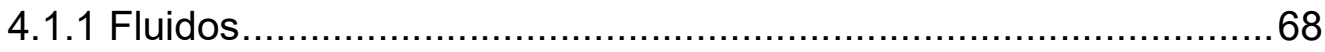

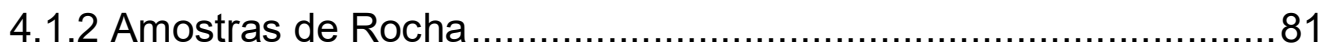

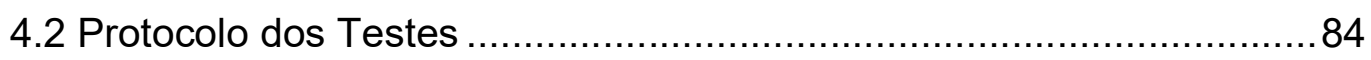

4.2.1 Procedimentos Primários ..................................................... 84

4.2.2 Adsorção de Polímeros ........................................................... 85

4.2.3 Recuperação de Óleo com Água de Peregrino, Solução de Glicerina e Solução Polimérica ..........................................................90

4.2.3.1 Aparato Experimental ................................................ 90

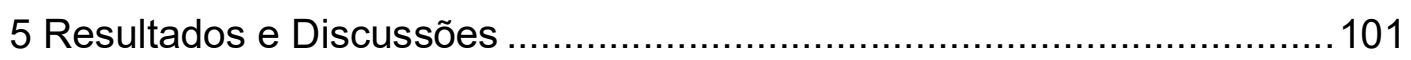

5.1 Resultados dos Procedimentos de Adsorção .................................101

5.1.1 Gray Berea (GBT2) ....................................................... 101

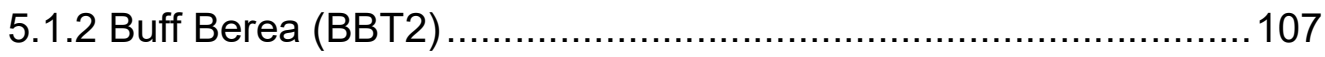

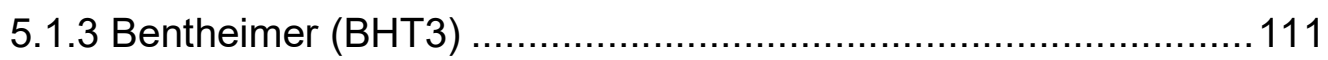

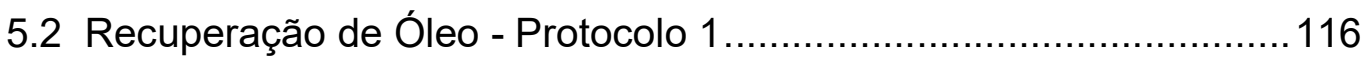

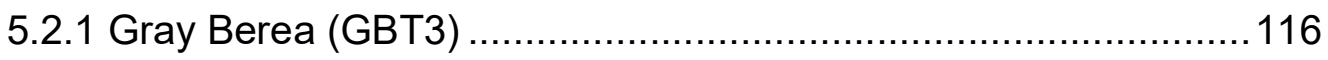

5.2.2 Buff Berea (BBT3) …...................................................... 125

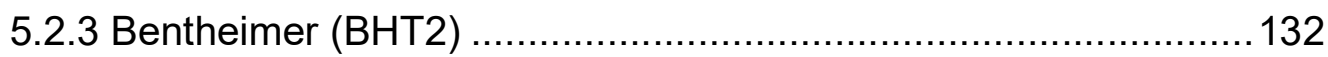

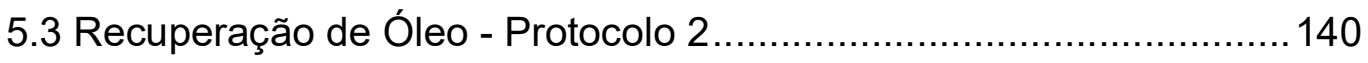

5.3.1 Gray Berea (GBTH3) ............................................. 141 


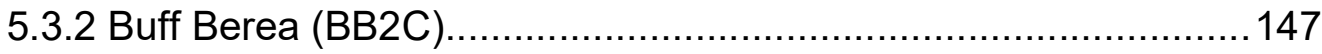

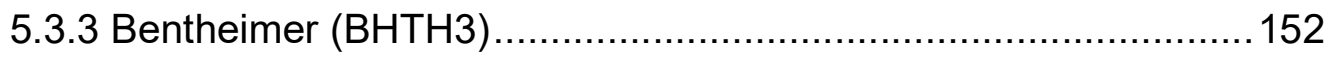

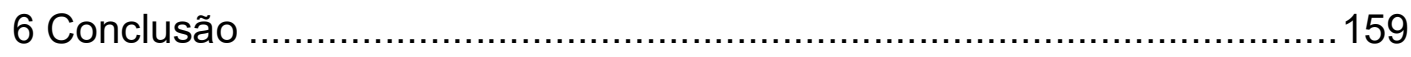

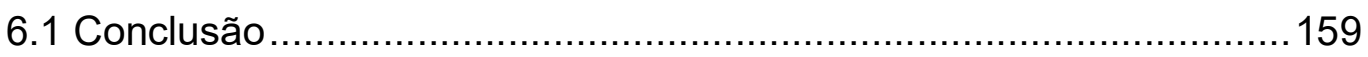

6.2 Sugestões e Recomendações .....................................................160

Referências Bibliográficas ............................................................ 162 


\section{Índice de Figuras}

Figura 1- Consumo mundial de energia. (BP Energy Review, 2018)...........23

Figura 2 - Curva de permeabilidade relativa (SANSONE, 2014) ..................32

Figura 3 - Contato de um fluido em superfícies de diferentes molhabilidades

(CAO, 2010).

Figura 4 - Esquema macroscópico de descolamento de fluido com injeção de solução polimérica (b) e de solução salina (a). (SHENG, 2011). 36

Figura 5 - Comportamento reológico de fluidos sob taxa de cisalhamento variável (GUTIÉRREZ, 2018).

Figura 6 - Aparato experimental utilizado por Lotsch em 1985 (LOTSCH et al., 1985).

Figura 7 - Sequência de injeção do Two Slug Method.

Figura 8 - Esquema experimental utilizado por Sandengen (2017) e utilizado

no presente trabalho. (SANDENGEN et al., 2017). .43

Figura 9 - Tubo capilar para medida de concentração. .45

Figura 10- Perfis de pressão e condutividade do Two Slug Method (SANDENGEN et al., 2017). 45

Figura 11 - a) Cálculo do volume de poro inacessível. b) Cálculo da massa de polímero adsorvido (figura adaptada de SANDENGEN et al., 2017). Figura 12 - Estrutura principal da goma xantana (BENTO, 2016; adaptado de SORBIE, 1991) .52

Figura 13 - Estrutura da cadeia de HPAM (Adaptado de BENTO, 2016)......54 Figura 14 - Resumo sobre os critérios de seleção para injeção de polímeros (SHENG, 2015).

Figura 15 - Efeito da presença de oxigênio em HPAM a $90^{\circ} \mathrm{C}: 1$, baixo nível de oxigênio; 2, ar; 3, oxigênio (Adaptado de LUO et al., 2006).

Figura 16 - Mecanismos de retenção polimérica (Adaptado de SZABO, 1975).

Figura 17 - Adsorção de HPAM para diferentes graus de hidrólise (Adaptado de MACWILLIANS, 1973). 65 
Figura 18 - Relação entre adsorção e concentração da solução polimérica (Adaptado de SHENG, 2010.).

Figura 19 - a) Sistema de filtração da solução polimérica. b) e c) Detalhe do filtro de $5 \square \mathrm{m}$.

Figura 20 - Procedimento de troca de atmosfera para manipulação da solução polimérica.

Figura 21 - Face de injeção das amostras manchadas por óxido provenientes das partes metálicas.

Figura 22 - Caracterização reológica da solução polimérica AN125VHM de 1g/L (1000 ppm) (dados de viscosidade).

Figura 23 - Caracterização reológica da solução polimérica AN125VHM de 1g/L (1000 ppm) (dados de tensão de cisalhamento).

Figura 24 - Análise do ajuste do modelo matemático de Cross e seus

devidos índices. .76

Figura 25 - Caracterização reológica do AGECOM 500PS (Viscosidade). ...80 Figura 26 - Caracterização reológica do AGECOM 500PS (Tensão de Cisalhamento) .80

Figura 27 - Esquema do aparato experimental utilizado para os testes de adsorção. .86

Figura 28 - Esquema do procedimento de adsorção polimérica. .89

Figura 29 - Esquema do aparato experimental utilizado para os testes de adsorção.

Figura 30 - Esquema do protocolo 1 de recuperação de óleo. .99

Figura 31 - Esquema do protocolo 2 de recuperação de óleo. 100

Figura 32 - Curva de permeabilidade da amostra GBT2. 102

Figura 33 - Diferencial de pressão através da amostra GBT2 104

Figura 34 - Perfis de condutividade e diferencial de pressão no capilar pósamostra GBT2. 106

Figura 35 - Curvas de permeabilidade absoluta inicial e final da amostra BBT2. 107

Figura 36 - Diferencial de pressão através da amostra BBT2. 109 
Figura 37 - Perfis de condutividade e diferencial de pressão no capilar pósamostra BBT2.

Figura 38 - Curvas de permeabilidade absoluta inicial e final da amostra BHT3.

Figura 39 - Diferencial de pressão através da amostra BHT3

Figura 40 - Perfis de condutividade e diferencial de pressão no capilar pósamostra BHT3.

Figura 41 - Curva de permeabilidade absoluta inicial da amostra GBT3 ...117

Figura 42- Diferencial de pressão através da amostra GBT3.

Figura 43 - Curva de volume de óleo produzido com água de Peregrino,

solução de glicerina e solução polimérica da amostra GBT3.

Figura 44 - Curva de fator de recuperação com água de Peregrino, solução

de glicerina e solução polimérica da amostra GBT3. 124

Figura 45- Curva de permeabilidade absoluta inicial da amostra BBT3......126

Figura 46 - Diferencial de pressão através da amostra BBT3. 126

Figura 47 - Curva de volume de óleo produzido com água de Peregrino, solução de glicerina e solução polimérica da amostra BBT3.

Figura 48 - Curva de fator de recuperação com água de Peregrino, solução

de glicerina e solução polimérica da amostra BBT3.

Figura 49 - Curva de permeabilidade absoluta inicial da amostra BHT2 .... 133

Figura 50 - Diferencial de pressão através da amostra BHT2.

Figura 51 - Curva de volume de óleo produzido com água de Peregrino,

solução de glicerina e solução polimérica da amostra BHT2.

Figura 52 - Curva de fator de recuperação com água de Peregrino, solução de glicerina e solução polimérica da amostra BHT2.

Figura 53 - Curva de permeabilidade absoluta inicial da amostra GBTH3. . 142

Figura 54 - Diferencial de pressão através da amostra GBTH3.

Figura 55 - Curva de volume de óleo produzido com água de Peregrino,

solução de glicerina e solução polimérica da amostra GBTH3.

Figura 56 - Curva de fator de recuperação com água de Peregrino e solução polimérica da amostra GBTH3. 
Figura 57 - Curva de permeabilidade absoluta inicial da amostra BB2C. ...148

Figura 58 - Diferencial de pressão através da amostra BB2C...................148

Figura 59 - Curva de volume de óleo produzido com água de Peregrino,

solução de glicerina e solução polimérica da amostra BB2C.

Figura 60 - Curva de fator de recuperação com água de Peregrino e solução

polimérica da amostra BB2C

Figura 61 - Curva de permeabilidade absoluta inicial da amostra BHTH3. . 153

Figura 62 - Diferencial de pressão através da amostra BHTH3.

Figura 63 - Curva de volume de óleo produzido com água de Peregrino,

solução de glicerina e solução polimérica da amostra BHTH3.

Figura 64 - Curva de fator de recuperação com água de Peregrino e solução

polimérica da amostra BHTH3. 


\section{Índice de Tabelas}

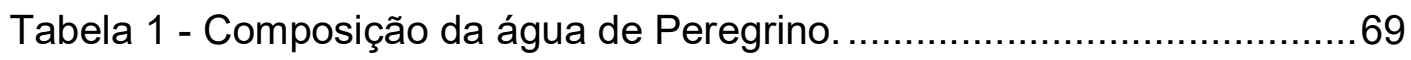

Tabela 2 - Reologia Água de Peregrino. ................................................ 70

Tabela 3 - Reologia viscosímetro capilar da solução polimérica AN125VHM

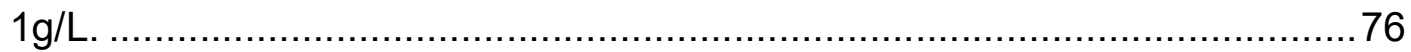

Tabela 4 - Dados reômetro rotacional. .......................................................

Tabela 5 - Reologia do óleo AGECOM 500PS obtido em viscosímetro capilar.

Tabela 6 - Características das amostras disponíveis para teste (Kocurek Industries INC).

Tabela 7 - Caracterização mineralógica da Gray Berea (Kocurek Industries INC).

Tabela 8 - Caracterização mineralógica da Buff Berea (Kocurek Industries INC).

Tabela 9 - Caracterização mineralógica da Bentheimer (Kocurek Industries

INC).

Tabela 10 - Características e propriedades petrofísicas da amosta GBT2.102

Tabela 11 - Permeabilidade inicial, intermediária e final da amostra GBT2.104

Tabela 12 - Valores de material polimérico adsorvido e volume de poro inacessível da amostra BBT3.

Tabela 13 - Características e propriedades petrofísicas da amostra BBT2.107

Tabela 14 - Valores de permeabilidades da amostra BBT2. 108

Tabela 15 - Valores de material polimérico adsorvido e volume de poro inacessível da amostra BBT2.

Tabela 16 - Características e propriedades petrofísicas da amostra BHT3.111

Tabela 17 - Valores de permeabilidade absoluta da amostra BHT3.

Tabela 18 - Valores de material polimérico adsorvido e volume de poro inacessível da amostra BHT3.

Tabela 19 - Características e propriedades petrofísicas da amostra GBT3.116

Tabela 20 - Dados da fase 2 (injeção de óleo) da amostra GBT3 
Tabela 21 - Dados da fase 3 (injeção de água) da amostra GBT3.

Tabela 22 - Dados da fase 4 (injeção de óleo) da amostra GBT3.

Tabela 23 - Dados reológicos para produção da solução de glicerina para a amostra GBT3.

Tabela 24 - Dados das fases 5 e 6 (injeção de solução aquosa de glicerina seguida de água) da amostra GBT3.

Tabela 25 - Dados da fase 7 (injeção de óleo) da amostra GBT3

Tabela 26 - Dados das fases 8 e 9 (injeção de solução polimérica seguida de água) da amostra GBT3.

Tabela 27 - Características e propriedades petrofísicas da amostra BBT3.125

Tabela 28 - Dados da fase 2 (injeção de óleo) da amostra BBT3.

Tabela 29 - Dados da fase 3 (injeção de água) da amostra BBT3.

Tabela 30 - Dados reológicos para produção da solução de glicerina para a amostra BBT3. 128

Tabela 31 - Dados da fase 4 (injeção de óleo) da amostra BBT3 128

Tabela 32 - Dados das fases 5 e 6 (injeção de solução aquosa de glicerina seguida de água) da amostra BBT3. 129

Tabela 33 - Dados da fase 7 (injeção de óleo) da amostra BBT3. 130

Tabela 34 - Dados das fases 8 e 9 (injeção de solução polimérica seguida de água) da amostra BBT3.

Tabela 35 - Características e propriedades petrofísicas da amostra BHT2 132

Tabela 36 - Dados da fase 2 (injeção de óleo) da amostra BHT2.

Tabela 37 - Dados da fase 3 (injeção de água) da amostra BHT2. 135

Tabela 38 - Dados reológicos para produção da solução de glicerina para a amostra BHT2.

Tabela 39 - Dados da fase 4 (injeção de óleo) da amostra BHT2. 136

Tabela 40 - Dados das fases 5 e 6 (injeção de solução aquosa de glicerina seguida de água) da amostra BHT2.

Tabela 41 - Dados da fase 7 (injeção de óleo) da amostra BHT2. 137

Tabela 42 - Dados das fases 8 e 9 (injeção de solução polimérica seguida de água) da amostra BHT2. 138 
Tabela 43 - Características e propriedades petrofísicas da amostra GBTH3.

Tabela 44 - Dados da fase 2 (injeção de óleo) da amostra GBTH3 ............143

Tabela 45 - Dados da fase 3 (injeção de água) da amostra GBTH3...........143

Tabela 46 - Dados da fase 4 (injeção de óleo) da amostra GBTH3............144

Tabela 47- Dados das fases 5 e 6 (injeção de solução polimérica seguida de

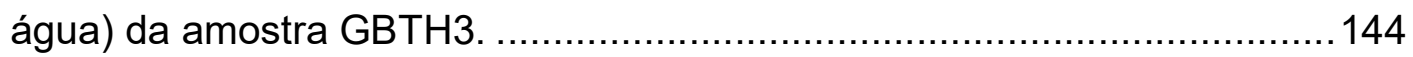

Tabela 48 - Características e propriedades petrofísicas da amostra BB2C.147

Tabela 49 - Dados da fase 2 (injeção de óleo) da amostra BB2C...............149

Tabela 50 - Dados da fase 3 (injeção de água) da amostra BB2C. ........... 149

Tabela 51 - Dados da fase 4 (injeção de óleo) da amostra BB2C...............150

Tabela 52 - Dados das fases 5 e 6 (injeção de solução polimérica seguida de

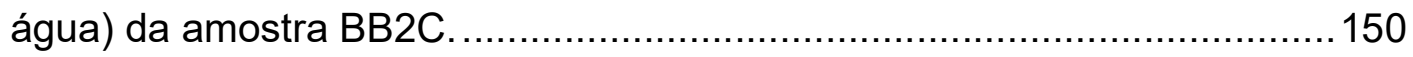

Tabela 53 - Características e propriedades petrofísicas da amostra BHTH3.

Tabela 54 - Dados da fase 2 (injeção de óleo) da amostra BHTH3 ...........154

Tabela 55 - Dados da fase 3 (injeção de água) da amostra BHTH3...........155

Tabela 56 - Dados da fase 4 (injeção de óleo) da amostra BHTH3. ...........155

Tabela 57 - Dados das fases 5 e 6 (injeção de solução polimérica seguida de

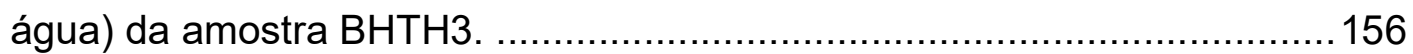

Tabela 58 - Síntese dos resultados experimentais..................................158 


\section{Nomenclatura}

$\Delta P \quad$ : Gradiente de pressão entre dois pontos de tomada de pressão.

$\Delta P_{w} \quad:$ Gradiente de pressão entre dois pontos de tomada de pressão devido a injeção de água.

$\Phi \quad$ : Porosidade.

$\dot{\gamma} \quad$ : Taxa de cisalhamento.

$\mu \quad$ : Viscosidade dinâmica do fluido.

$\mu_{o} \quad$ : Viscosidade do óleo.

$\mu_{p} \quad$ : Viscosidade da solução polimérica.

$\mu_{w} \quad$ : Viscosidade dinâmica da água.

$\eta \quad$ : Viscosidade aparente.

$v \quad$ : Viscosidade cinemática.

$\theta \quad$ : Ângulo de contato.

$\rho \quad$ : Densidade do fluido.

$\rho_{w} \quad$ : Densidade da água de Peregrino.

$\tau \quad$ : Massa de polímero adsorvido.

$\lambda_{o} \quad$ : Mobilidade do óleo.

$\lambda_{p} \quad$ : Mobilidade da solução polimérica.

$\lambda_{w} \quad$ : Mobilidade da água.

$\lambda_{w 1} \quad$ : Mobilidade da solução salina antes da injeção da solução polimérica.

$\lambda_{w 2} \quad$ : Mobilidade da solução salina após a injeção da solução polimérica.

A : Área da seção transversal que o fluido escoa.

$C_{\text {pol }}$ : Concentração da solução polimérica.

$k \quad$ : Permeabilidade absoluta.

$k 1 \quad$ : Permeabilidade absoluta inicial.

$k 2 \quad$ : Permeabilidade absoluta final. 


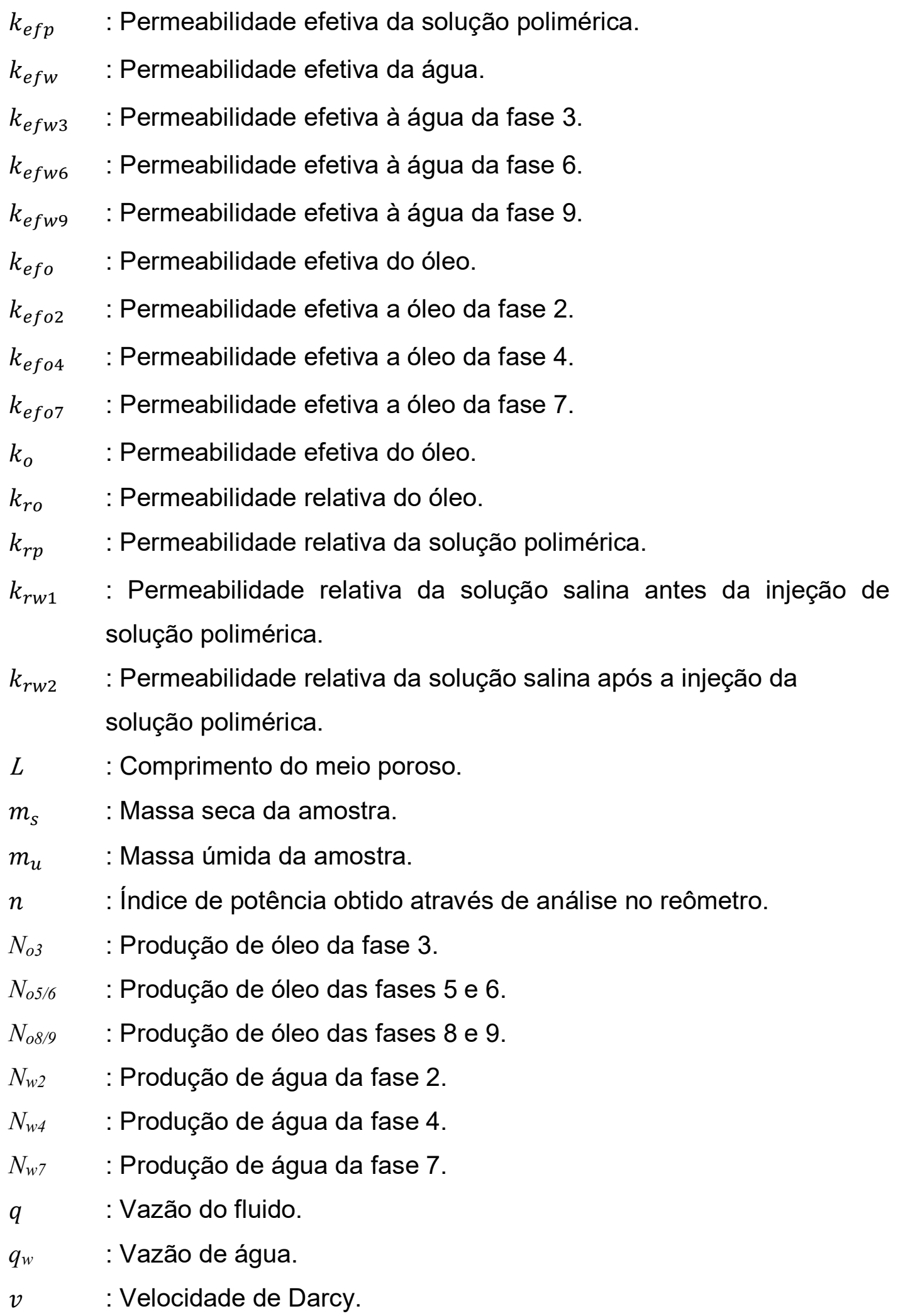


$V_{a d s} \quad$ : Volume de solução polimérica correspondente a massa de polímero adsorvida, ou seja, o volume entre os perfis dos bancos de polímero 1 e 2 no ponto de inflexão

$V_{f} \quad$ : Volume do fluido.

$V_{v} \quad$ : Volume de vazios.

$V_{p} \quad$ : Volume poroso.

$V_{t} \quad$ : Volume total.

$S_{f} \quad$ : Saturação dos fluidos.

Sofz : Saturação de óleo final da fase 2.

Sof3 : Saturação de óleo final da fase 3.

Soft $\quad$ : Saturação de óleo final da fase 4.

Sof6 : Saturação de óleo inicial da fase 6

Sof7 : Saturação de óleo final da fase 7.

Soi3 : Saturação de óleo inicial da fase 3.

Soi4 : Saturação de óleo inicial da fase 4.

Soi5 : Saturação de óleo inicial da fase 5.

Soir : Saturação de óleo inicial da fase 7.

Sois : Saturação de óleo inicial da fase 8.

Sor3 : Saturação de óleo residual da fase 3.

$S_{W} \quad$ : Saturação de água.

$S_{w f 1} \quad$ : Saturação de água final da fase 1.

$S_{w f 2} \quad$ : Saturação de água final da fase 2.

$S_{w f 3} \quad$ : Saturação de água final da fase 3.

$S_{w f 4} \quad$ : Saturação de água final da fase 4.

$S_{\text {wfG }}$ : Saturação de água final da fase 6.

$S_{w f 7} \quad$ : Saturação de água final da fase 7.

$S_{\text {wiz }} \quad$ : Saturação de água inicial da fase 3.

$S_{\text {wit }} \quad$ : Saturação de água inicial da fase 4.

$S_{\text {wi5 }} \quad$ : Saturação de água inicial da fase 5.

$S_{w i 7} \quad$ : Saturação de água inicial da fase 7. 
$S_{\text {wis }} \quad$ : Saturação de água inicial da fase 8.

Vof2 : Volume de óleo final da fase 2.

$V_{o f 3} \quad$ : Volume de óleo final da fase 3.

$V_{\text {oft }} \quad$ : Volume de óleo final da fase 4.

Vof6 : Volume de óleo final da fase 6.

Vof7 : Volume de óleo final da fase 7.

$V_{\text {ofg }} \quad$ : Volume de óleo final da fase 9.

$V_{o i 3} \quad$ : Volume de óleo inicial da fase 3.

$V_{o i 4} \quad$ : Volume de óleo inicial da fase 4.

Voig : Volume de óleo inicial da fase 6.

$V_{o i 7} \quad$ : Volume de óleo inicial da fase 7.

Voig : Volume de óleo inicial da fase 9.

$V_{w f 2} \quad$ : Volume de água final da fase 2.

$V_{w f 3} \quad$ : Volume de água final da fase 3.

$V_{w f 4} \quad$ : Volume de água final da fase 4.

$V_{w f 6} \quad$ : Volume de água final da fase 6.

$V_{w f 7} \quad$ : Volume de óleo final da fase 7.

$V_{w f g} \quad$ : Volume de água final da fase 9.

$V_{w i 2} \quad$ : Volume de água inicial da fase 2.

$V_{\text {wi3 }} \quad$ : Volume de água inicial da fase 3.

$V_{\text {wi4 }} \quad$ : Volume de água inicial da fase 4.

$V_{\text {wib }} \quad$ : Volume de água inicial da fase 6.

$V_{w i 7} \quad$ : Volume de óleo inicial da fase 7.

$V_{w i 9} \quad$ : Volume de água inicial da fase 9.

ANP : Agência Nacional do Petróleo.

CFS : Core flooding system.

EOR : Enhanced oil recovery.

HPAM : Poliacrilamida parcialmente hidrolisada.

IOR : Improved oil recovery.

PAM : Poliacrilamida. 


$\begin{array}{ll}\text { PPM } & \text { : Parte por milhão. } \\ \text { PW } & \text { : Água de Peregrino. } \\ \text { RPM } & \text { : Rotações por minuto. } \\ \text { RF } & \text { : Fator de resistência. } \\ \text { RRF } & \text { : Fator de resistência residual. } \\ \text { TF } & : \text { Taxa de filtragem. } \\ \text { VP } & \text { : Volume poroso. } \\ \text { WF1 } & : \text { Water Flooding } 1 . \\ \text { WF2 } & : \text { Water Flooding } 2 . \\ \text { WF3 } & : \text { Water Flooding } 3 .\end{array}$




\section{Introdução}

\section{1}

\section{Motivação}

A indústria do petróleo viveu por muitos anos momentos de glória. Esse cenário era fomentado por diversas condições, entre elas as recorrentes descobertas de novas reservas, que promoveram uma abundância de óleo; o alto valor de mercado dos combustíveis derivados dessa matriz; e, ainda, as questões ambientais não estavam com a atual evidência. Com o passar do tempo, surgiram alguns momentos turbulentos e nos últimos anos a indústria vive uma das etapas mais delicadas de sua história, porém, como mostrado na Fig. 1, ainda é uma das principais fontes energéticas que está sustentando o aumento gradativo da demanda mundial de energia.

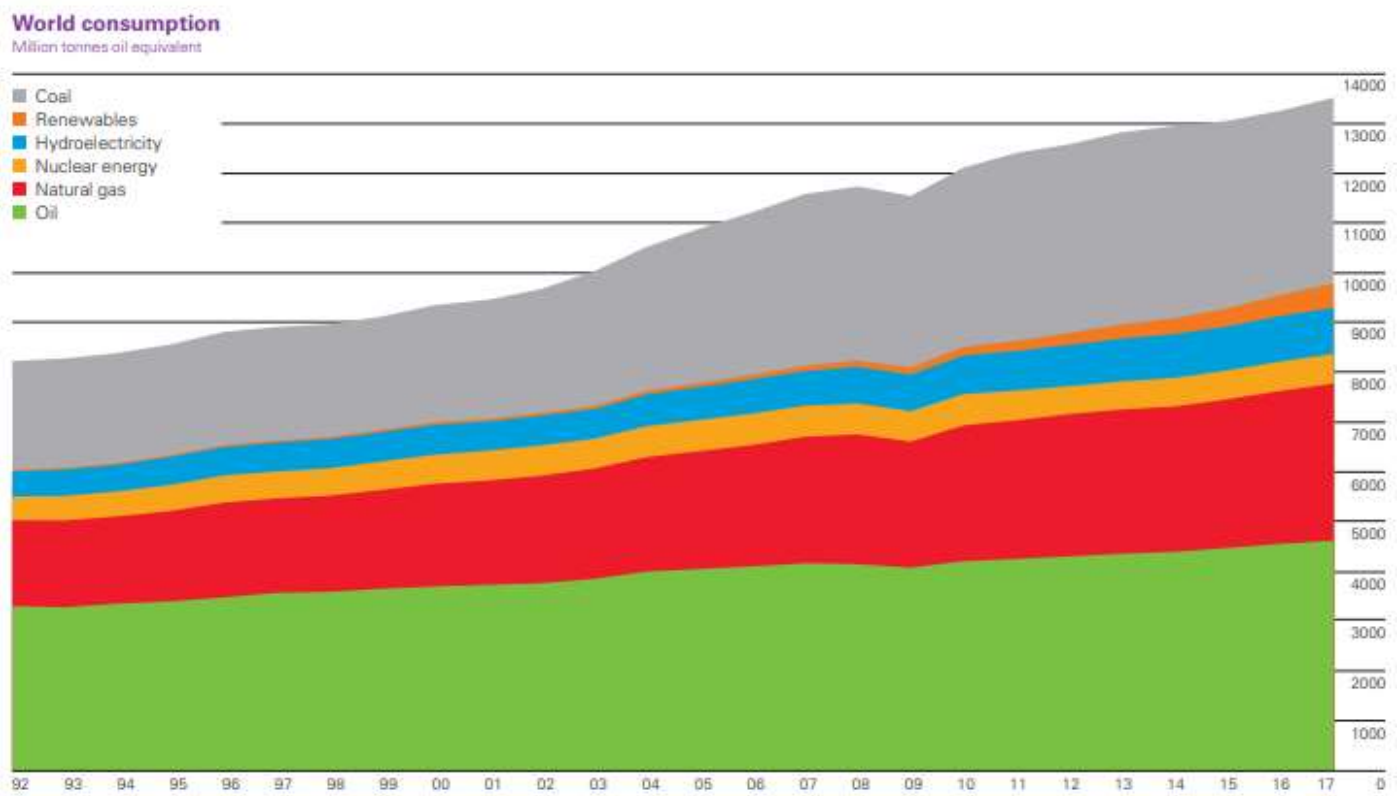

Figura 1- Consumo mundial de energia. (BP Energy Review, 2018). 
Estudos projetam que essa demanda continuará crescendo vigorosamente (BP Energy Review, 2018). O desenvolvimento de fontes renováveis é uma realidade, contudo ainda ocupa uma parcela muito pequena no fornecimento de energia devido aos inúmeros desafios técnicos de aplicação. Para muitos segmentos, a utilização de combustíveis fósseis continua sendo o meio mais simples e barato, principalmente pela sua facilidade de armazenamento, dando continuidade no consumo de uma matériaprima de quantidade limitada.

Atualmente, grande parte dos reservatórios que iniciaram as operações nas décadas passadas já se encontram em processo de declínio de produção. Esse fator, somado às incertezas de novas regiões para a extração, está mobilizando as empresas a buscarem o aprimoramento de técnicas de recuperação de petróleo.

Mesmo já possuindo um altíssimo padrão tecnológico, os métodos de recuperação estão sendo constantemente refinados e reajustados à nova realidade. A principal finalidade é obter um melhor aproveitamento das reservas já existentes, de maneira a reduzir o percentual de óleo remanescente, como também minimizar os custos de produção e impactos ao meio ambiente.

Nos métodos convencionais de recuperação, também conhecidos como recuperação primária e secundária, os fatores de recuperação variam de 20 a 40\% do total de óleo presente no reservatório. Esses, na maioria dos casos, mesmo com um baixo custo de operação, não se mostram mais vantajosos em determinados tipos de reservatórios. Dentre as principais razões estão a baixa eficiência de varrido ocasionado pela alta razão de mobilidade entre a água e o óleo, além de apresentarem problemas ambientais devido à grande quantidade de água utilizada para produzir um volume pequeno de óleo em fases mais avançadas do projeto. Visto isso, torna-se necessário a utilização de técnicas avançadas para um melhor aproveitamento de tempo, material utilizado e volume de óleo recuperado.

Nos processos de recuperação melhorada, enhanced oil recovery (EOR), o fator de recuperação pode chegar aos $60 \%$, e um dos métodos mais comuns é a injeção de químicos, como soluções poliméricas. 
O uso de polímeros vem crescendo nos últimos anos devido ao melhor conhecimento dos efeitos ocasionados no reservatório. Usualmente eles são adicionados à solução aquosa de injeção, e devido ao seu poder viscosificante são capazes, com pequenas quantidades, de aumentar a viscosidade da solução tornando a razão de mobilidade entre os fluidos deslocante (água) e deslocado (óleo) menor, melhorando, dessa maneira, a eficiência de varrido e deslocamento, e aumentando o volume de óleo recuperado. Entretanto, mesmo com o fato da utilização desse produto ter se mostrado bastante vantajosa em diferentes reservatórios de petróleo em todo o mundo, é necessário o conhecimento das consequências dessa técnica no meio poroso.

Apesar dos muitos benefícios que a injeção de polímero traz à recuperação de óleo, esse recurso não pode ser aplicado indiscriminadamente, pois é muito dependente das características do reservatório. Há uma infinidade de fatores relacionados ao uso desse produto que podem modificar significativamente as características originais da rocha e do meio poroso, afetando permanentemente a produtividade do reservatório.

Um dos efeitos conhecidos é a retenção polimérica, que resulta em uma redução da permeabilidade da rocha. Esse dano de formação, quando não devidamente calculado, pode levar a perda de injetividade, o que é uma desvantagem importante no processo de recuperação do óleo. Por outro lado, a alteração dessa propriedade da rocha pode ser benéfica para a recuperação do óleo, de maneira a reduzir ou, até mesmo, bloquear caminhos de fluxo preferenciais, forçando o fluido deslocante a penetrar por novas vias.

Dessa forma, torna-se necessária a avaliação de todos esses fatores em trabalhos experimentais de laboratório antes da aplicação em campo, a fím de compreender o processo e evitar surpresas durante a injeção das soluções. Assim, realizou-se neste estudo a revisão das características relacionadas à injeção de soluções poliméricas, e efetuou-se uma análise experimental para estudar os processos de retenção polimérica e recuperação de óleo. 


\section{2}

\section{Objetivo}

O objetivo do estudo proposto é determinar experimentalmente a variação no fator de recuperação final de óleo, e os efeitos causados nas características originais da rocha pela injeção de solução polimérica. Ainda, aplicar a metodologia em diferentes tipos de rocha, de diferentes características petrofísicas. Por fim, estabelecer uma comparação entre as metodologias de recuperação utilizando duas diferentes soluções, uma que modifique as características da rocha pelo processo de retenção e outra que não interaja, significativamente, com a formação. Para isso, serão analisados dois diferentes cenários: o processo de recuperação com solução polimérica e o processo de recuperação com solução de água e glicerina com a mesma viscosidade da solução polimérica.

O trabalho foi realizado em um simulador de fluxo, o Core Flooding System (CFS). Através desse equipamento é possível realizar, de maneira próxima às condições encontradas em reservatórios de petróleo, experimentos de fluxo em amostras de rocha. Os fluidos e corpos de prova utilizados também foram escolhidos para representar a realidade das operações.

Espera-se que os resultados desse trabalho possam contribuir para o melhor entendimento e aprimoramento da utilização das técnicas de injeção de polímeros na recuperação de petróleo.

\section{3}

\section{Estrutura da dissertação}

O trabalho desenvolvido está dividido em 6 capítulos.

O capítulo 1 apresenta, de maneira geral, uma introdução do assunto que está sendo estudado, o trabalho que será realizado, bem como parte de sua motivação. 
O capítulo 2 traz um resumo teórico dos principais assuntos que serão abordados durante o texto, para que o leitor possa entender e acompanhar o desenvolvimento do estudo de maneira mais clara.

No capítulo 3 estão dispostas as principais informações sobre a utilização de soluções poliméricas na recuperação de óleo.

O capítulo 4 expõe, detalhadamente, toda a parte referente aos experimentos. As metodologias utilizadas, os esquemas dos circuitos experimentais, e o passo a passo de tudo que foi realizado durante os testes.

No capítulo 5 são encontrados os resultados obtidos durante os testes realizados no laboratório e uma breve discussão sobre cada um.

O capítulo 6 apresenta as conclusões e sugestões para melhoria e continuidade do trabalho desenvolvido. 
2

Fundamentação Teórica

\section{1}

\section{Conceitos Básicos}

Para uma melhor compreensão das informações contidas neste documento, é de fundamental importância que o leitor tenha noção dos conceitos básicos que serão apresentados nesta seção. Quando necessário, os tópicos presentes aqui serão abordados com maior profundidade nos capítulos seguintes.

Diferentemente do senso popular, o petróleo não se encontra em grandes cavernas ou piscinas subterrâneas, ele está alocado em rochas porosas, chamadas rochas reservatório. Essas formações possuem características que se assemelham a uma esponja, com poros de diferentes tamanhos e formatos nos quais diversos tipos de fluidos podem estar contidos.

O escoamento em meios porosos é uma ciência extremamente complexa e dependente de fatores relacionados às propriedades físicas e químicas, tanto das rochas quanto dos fluidos. No processo de produção de um reservatório de petróleo, o entendimento e domínio dessas características e conceitos são vitais para o desenvolvimento e otimização das técnicas e métodos de recuperação. 


\subsection{2}

\section{Conceitos Básicos Relacionados às Propriedades das Rochas}

\subsubsection{1}

\section{Porosidade}

A porosidade $(\Phi)$ é um dos conceitos mais simples e também um dos mais importantes no estudo de reservatórios. Ela é definida como a razão entre o volume de vazios contidos na rocha $\left(V_{v}\right)$, igualmente conhecido como volume poroso $\left(V_{p}\right)$, pelo volume total $\left(V_{t}\right)$ da mesma, como mostrado na Eq. 1. O volume total é a soma do volume de poros e o volume de sólido (SORBIE, 1991; THOMAS, 2004; ROSA et al., 2006).

$$
\Phi=\frac{V_{v}}{V_{t}}
$$

Existem alguns fatores que influenciam diretamente essa propriedade, deixando a rocha mais ou menos porosa, tais como: arranjo, forma, tamanho e seleção dos grãos e a presença de materiais cimentantes (ROSA et al., 2006).

\subsubsection{2}

\section{Saturação}

A saturação dos fluidos $\left(S_{f}\right)$ presentes no reservatório é definida através da Eq. 2. É a razão entre o volume do fluido $\left(V_{f}\right)$ em questão e o volume poroso $\left(V_{p}\right)$ de uma determinada região do reservatório (ROSA et al., 2006).

$$
S_{f}=\frac{V_{f}}{V_{p}}
$$




\subsubsection{3}

\section{Permeabilidade}

Essa propriedade está relacionada à capacidade do meio poroso de permitir o fluido escoar através dele. Para que uma rocha possa permitir o deslocamento do fluido através dela, precisa haver conectividade entre os poros presentes nela. Quanto maior a conectividade, maior será o valor de permeabilidade da formação (SORBIE, 1991; THOMAS, 2004; ROSA et al., 2006).

Há três classificações para a permeabilidade. A primeira é a permeabilidade absoluta ou especifica, que acontece quando o meio poroso está saturado por somente um fluido. Vale lembrar que essa é uma propriedade do meio poroso e independente do fluido utilizado, desde que esse fluido não modifique as características do meio. $\mathrm{O}$ conceito de permeabilidade absoluta para escoamento horizontal linear está descrito na lei de Darcy, Eq. 3 (THOMAS, 2004; ROSA et al., 2006).

$$
q=\frac{k A \Delta P}{\mu L}
$$

Sendo:

- $\quad k-$ a permeabilidade absoluta (Darcy);

- $\quad q$ - a vazão do fluido $\left(\mathrm{cm}^{3} / \mathrm{s}\right)$;

- $A$ - a área da seção transversal que o fluido escoa $\left(\mathrm{cm}^{2}\right)$;

- $\quad \mu$ - a viscosidade dinâmica do fluido $(\mathrm{cP})$;

- $\Delta P-o$ gradiente de pressão entre dois pontos de tomada de pressão (atm);

- $\quad L-$ o comprimento do meio poroso $(\mathrm{cm})$.

A segunda classificação é a permeabilidade efetiva. Ela existe quando há dois ou mais fluidos ocupando os poros da rocha. Nesse cenário, quando os fluidos estão escoando, a presença de um exerce certa influência no fluxo do outro. Dessa forma, essa propriedade apresenta a capacidade do meio poroso em permitir o escoamento de 
um determinado fluido na presença de outro. A permeabilidade efetiva sempre será menor que a permeabilidade absoluta e diretamente proporcional à saturação de cada fluido (THOMAS, 2004; ROSA et al., 2006).

$$
q_{w}=\frac{k_{e f w} A \Delta P_{w}}{\mu_{w} L}
$$

A Eq. 4, mostra a permeabilidade efetiva da água. Sendo:

- $\quad k_{e f w}-$ a permeabilidade efetiva da água (Darcy);

- $\mathrm{q}_{\mathrm{w}}$ - a vazão de água $\left(\mathrm{cm}^{3} / \mathrm{s}\right)$;

- $A-$ a área da seção transversal que a água escoa $\left(\mathrm{cm}^{2}\right)$;

- $\quad \mu_{w}$ - a viscosidade dinâmica da água (cP);

- $\Delta P_{w}-$ o gradiente de pressão entre dois pontos de tomada de pressão devido a injeção de água (atm);

- $\quad L-$ o comprimento do meio poroso $(\mathrm{cm})$.

A terceira classificação é a permeabilidade relativa, que é definida pela razão entre a permeabilidade efetiva do fluido a uma determinada saturação e a permeabilidade absoluta do meio, como descreve a Eq. 5 (THOMAS, 2004; ROSA et al., 2006).

$$
k_{\text {ro }}=\frac{k_{r o}}{k}
$$

Sendo:

- $\quad k_{r o}-$ a permeabilidade relativa do óleo;

- $\quad k_{o}$ - a permeabilidade efetiva do óleo; 
- $\quad k$-a permeabilidade absoluta da amostra.

A permeabilidade relativa ocorre sempre na presença de dois ou mais fluidos no escoamento.

O gráfico apresentado na Fig. 2 é utilizado para mostrar as principais características da curva de permeabilidade relativa.

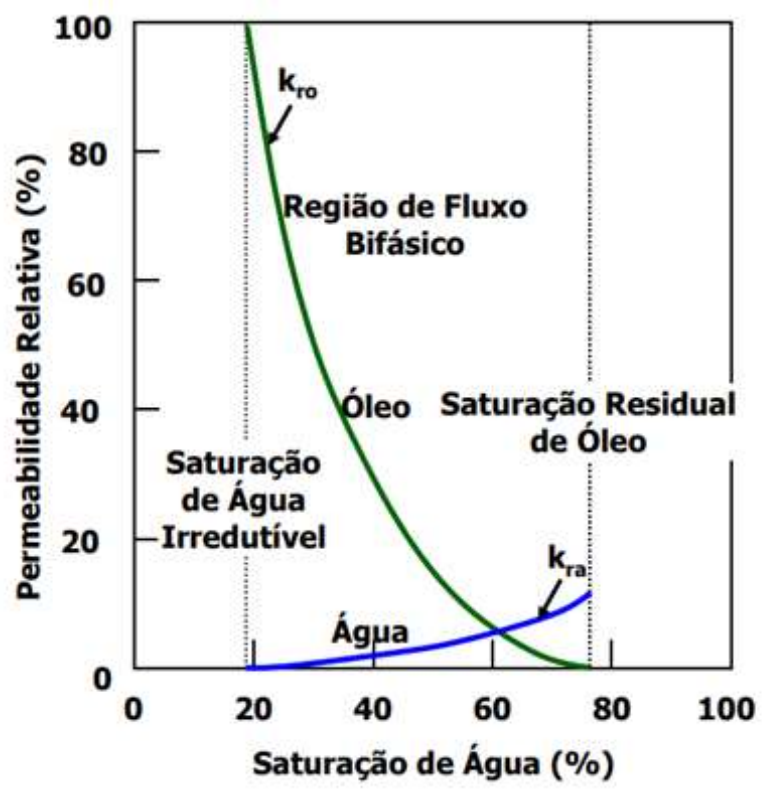

Figura 2 - Curva de permeabilidade relativa (SANSONE, 2014).

Através dessas curvas é possível notar o comportamento inverso de permeabilidade entre os dois fluidos presentes. Outros dois importantes parâmetros que podem ser obtidos através dessas curvas são a saturação de água conata (irredutível), que equivale a saturação abaixo da qual a fase aquosa torna-se imóvel, e consequentemente ao menor valor de saturação encontrado no reservatório, e a saturação de óleo residual, que é relacionada ao volume de óleo que não é possível ser deslocado. 


\subsubsection{4}

\section{Molhabilidade}

A molhabilidade refere-se à capacidade de um fluido de estar em contato com uma determinada superfície. Quando um fluido toca uma superfície qualquer ocorre um equilíbrio de forças relacionadas às tensões interfaciais ${ }^{1}$ (ROSA et al., 2006).

A maneira mais simples de identificar a molhabilidade de uma rocha é através do ângulo de contato formado entre o fluido mais denso e a rocha. Quando esse ângulo $(\theta)$ de contato é menor que $90^{\circ}$, significa que a rocha é molhável ao fluido mais denso, caso o ângulo seja maior que $90^{\circ}$, fluido menos denso molha preferencialmente a rocha (THOMAS, 2004; ROSA et al., 2006; CAO, 2010).
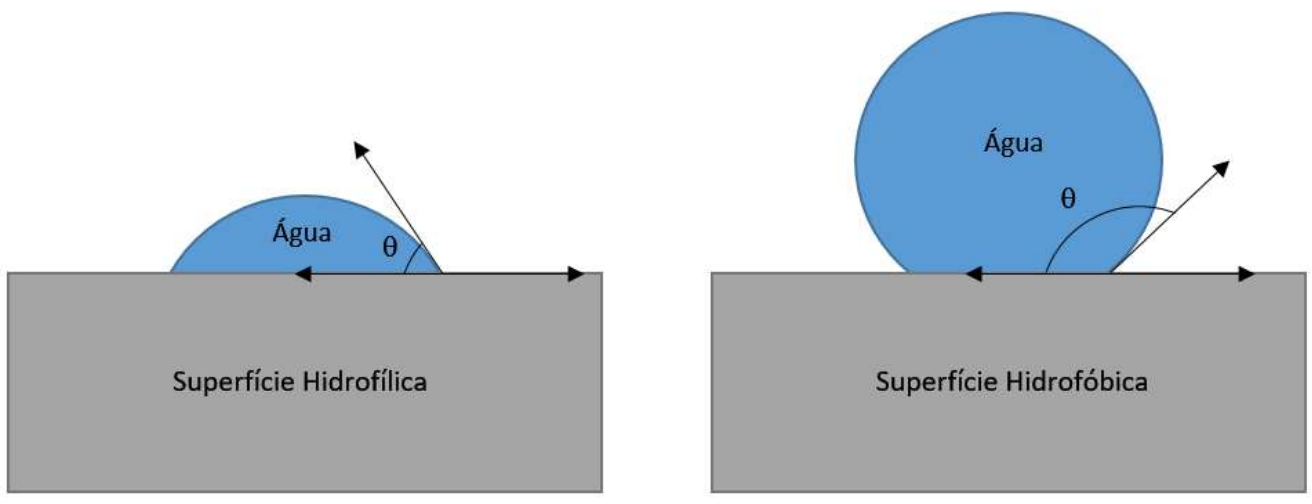

Figura 3 - Contato de um fluido em superfícies de diferentes molhabilidades (CAO, 2010).

A Fig. 3 mostra o contato da água com superfícies de diferentes molhabilidades. A superfície da esquerda apresenta um ângulo de contato com o fluido menor que $90^{\circ}$, isso significa que é uma superfície molhável à água, também conhecida como hidrofílica. A superfície da direita apresenta um ângulo de contato maior que $90^{\circ}$, logo não é molhável à água. Esse tipo de superfície também é conhecida como hidrofóbica.

\footnotetext{
${ }^{1}$ Efeito físico que ocorre na interface entre duas substâncias quaisquer.
} 


\subsubsection{4}

\section{Embebição e Drenagem}

O processo de embebição ocorre quando há um aumento da saturação do fluido ao qual a superfície é preferencialmente molhável. Por outro lado, quando há uma redução da saturação desse fluido, diz-se que houve o processo de drenagem (THOMAS, 2004; ROSA et al., 2006; RIOS, 2014).

\subsection{3}

\section{Conceitos Básicos Relacionados aos Fluidos}

\subsubsection{1}

\section{Mobilidade}

A mobilidade $(\lambda)$ de um determinado fluido se define através da razão entre a sua permeabilidade efetiva e sua viscosidade (ROSA et al., 2006).

$$
\lambda_{o}=\frac{k_{e f o}}{\mu_{o}}
$$

A Eq. 6 apresenta a mobilidade do óleo. Sendo:

. $\lambda_{o}-$ a mobilidade do óleo;

- $k_{e f o}$ - a permeabilidade efetiva do óleo $(\mathrm{mD})$;

- $\mu_{o}-\mathrm{a}$ viscosidade do óleo (cP).

Dentro desse conceito existe também a ideia de razão de mobilidade, que ocorre quando há a presença de dois fluidos, um deslocante e um outro que está sendo deslocado. Nesse caso, a mobilidade do fluido deslocante encontra-se no numerador, enquanto que a do deslocado encontra-se no denominador. 


$$
\mathrm{M}=\frac{\lambda_{w}}{\lambda_{o}}
$$

$$
\mathrm{M}=\frac{\frac{k_{w}}{\mu_{w}}}{\frac{k_{o}}{\mu_{o}}}
$$

As Eq. 7 e 8 mostram como exemplo a água sendo o fluido deslocante e o óleo, o fluido a ser deslocado. Logo, tem-se:

- $\quad \lambda_{w}-$ a mobilidade da água;

- $\quad k_{e f w}$ - a permeabilidade efetiva a água $(\mathrm{mD})$;

- $\quad \mu_{w}-$ a viscosidade da água (cp);

- $\lambda_{o}-$ a mobilidade do óleo;

- $k_{o}$ - a permeabilidade efetiva do óleo $(\mathrm{mD})$;

- $\mu_{o}-$ a viscosidade do óleo (cp).

A razão de mobilidade irá determinar a eficiência do deslocamento dos fluidos presentes no reservatório. Quando a razão de mobilidade apresenta valores muito elevados (maiores que 50), significa que a varredura não será muito proveitosa devido a não uniformidade do deslocamento. Essa diferença de mobilidade faz com que o fluido deslocante passe através do fluido deslocado, criando caminhos preferenciais, evitando, dessa maneira, que muitas áreas do reservatório tenham contato com o fluido que está sendo injetado (SORBIE, 1991; SHENG, 2011). A Fig. 4 mostra um esquema macroscópico de deslocamento com cenários de diferentes razões de mobilidade. Percebe-se que o volume recuperado devido a injeção da solução de maior viscosidade, Fig. 4b, é muito maior. 


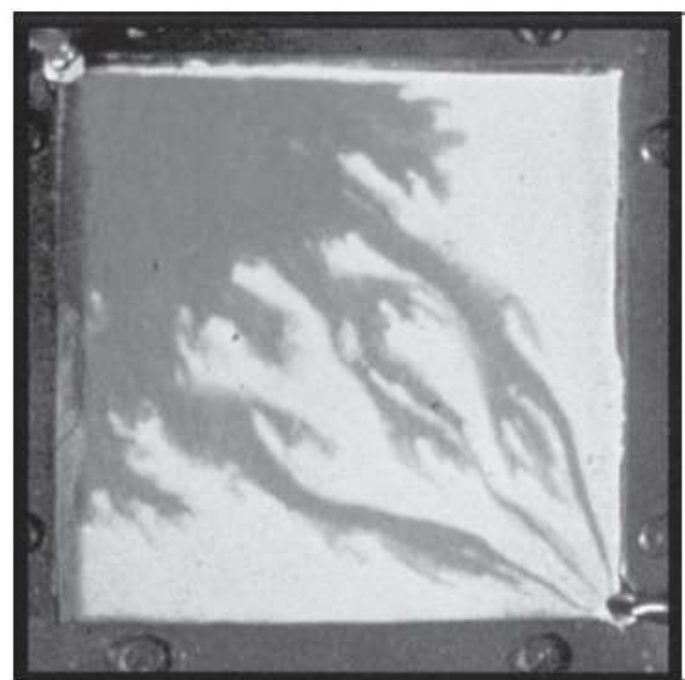

(a)

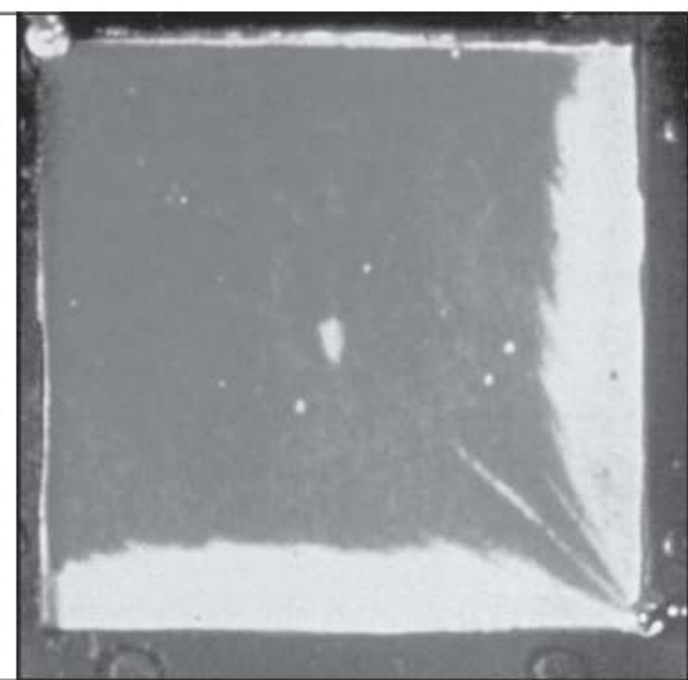

(b)

Figura 4 - Esquema macroscópico de descolamento de fluido com injeção de solução polimérica (b) e de solução salina (a). (SHENG, 2011).

\subsubsection{2}

\section{Viscosidade}

Viscosidade de um fluido é a propriedade física que caracteriza a resistência ao escoamento (BIRD, 1987). Essa propriedade possui uma relação direta com as forças intermoleculares do fluido, quanto maior a natureza da força intermolecular, maior será a força necessária para quebrar interações, resultando em uma maior resistência ao deslocamento. Isso explica o comportamento de grande parte dos fluidos frente à variação de temperatura. Com o aumento da temperatura, as moléculas apresentam maiores energias de rotação e translação, facilitando a quebra das ligações intermoleculares e diminuindo a viscosidade do fluido.

A viscosidade é definida como a razão da tensão de cisalhamento pela taxa de deformação do fluido. A proporcionalidade entre esses dois termos define se o fluido é Newtoniano ou não Newtoniano (BIRD, 1987).

Fluidos Newtonianos são aqueles que a tensão de cisalhamento é linearmente proporcional à taxa de deformação. Quando a linearidade não é observada, emprega-se a expressão "não Newtoniano" aos fluidos. Neste caso, a viscosidade varia com a taxa 
de deformação. Fluidos não Newtonianos são divididos em pseudoplásticos, quando a viscosidade diminui com o aumento da taxa de deformação, ou dilatantes, quando a viscosidade aumenta com o aumento da taxa de deformação. As Fig. 5a e 5b, mostram as relações entre viscosidade, tensão cisalhante e taxa de cisalhamento para fluidos newtonianos e não newtonianos (BIRD, 1987; GUTIÉRREZ, 2018).
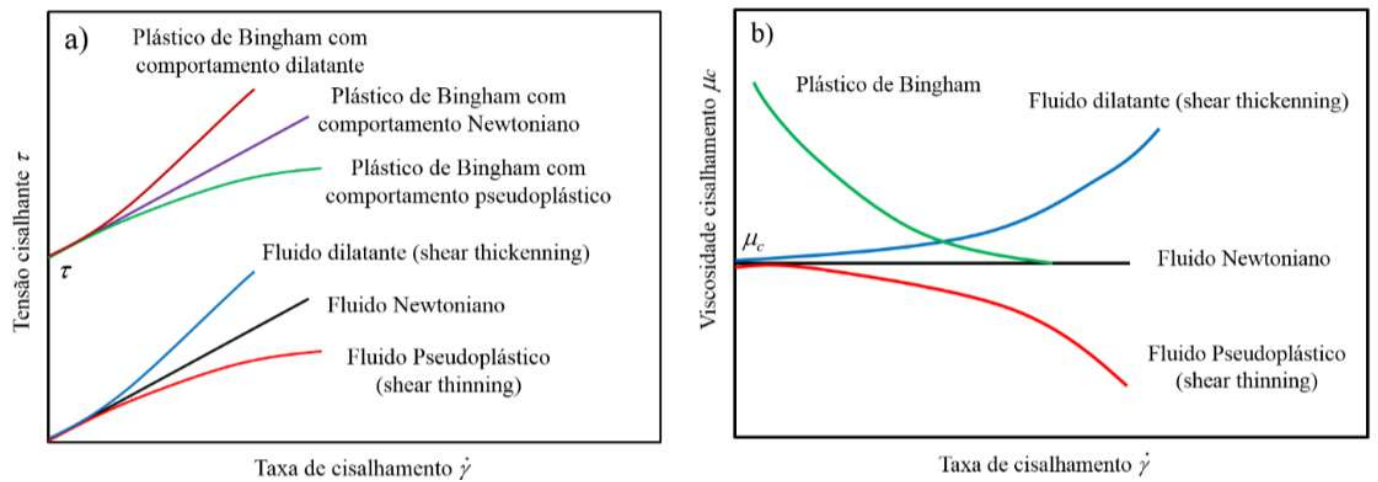

Figura 5 - Comportamento reológico de fluidos sob taxa de cisalhamento variável (GUTIÉRREZ, 2018).

Dentro desse tema ainda existem os conceitos de viscosidade dinâmica $(\mu)$, viscosidade cinemática $(v)$ e viscosidade aparente. A primeira, também conhecida como viscosidade absoluta, é definida em termos da força requerida para movimentar uma unidade de área a uma unidade de distância. A segunda é a relação entre a viscosidade dinâmica e a densidade do fluido ( $\rho)$. A Eq. 9 demonstra a relação entre esses dois parâmetros. Como visto anteriormente, os fluidos não Newtonianos apresentam uma relação de dependência entre a viscosidade e a taxa de deformação, ou seja, para cada taxa de cisalhamento haverá um valor diferente de viscosidade, nesse sentido o valor pontual dessa propriedade passa ser denominado como viscosidade aparente $(\eta)$.

$$
\mu=\nu \rho
$$




\section{2}

\section{Conceitos Básicos em Engenharia de Petróleo}

\subsection{1}

\section{Processos de Recuperação}

O processo de produção de um reservatório de petróleo pode ser dividido em três momentos diferentes: recuperação primária, recuperação secundária e a recuperação avançada (terciária). Embora os nomes pareçam obedecer a uma determinada sequência de eventos, esses processos não necessariamente possuem uma ordem cronológica a ser seguida. O método a ser escolhido irá depender do tipo de reservatório e fluido que será extraído (THOMAS, 2004, RIOS, 2014; BENTO, 2016).

Existem dois termos que são muito utilizados nas fases de recuperação de petróleo que costumam ser muito confundidos. Ainda hoje os conceitos das expressões improved oil recovery (IOR) e enhanced oil recovery (EOR) parecem não ser um consenso entre diversos autores. Sheng (2011) propõe uma definição que também será adotada pelo presente estudo. Segundo o autor, IOR se refere a qualquer tipo de processo para melhorar a recuperação de óleo, tais como: injeção de água, estimulação de poço, injeção de gases imiscíveis, etc. Já nos procedimentos de EOR estariam os recursos que modificam as interações rocha/fluidos originais também com a finalidade de incentivar a recuperação do óleo, como: combustão in situ, injeção de fluidos miscíveis, injeção de químicos, etc. Nesse contexto, as técnicas de EOR também estariam englobadas no termo IOR (SHENG, 2011).

\subsubsection{1}

\section{Processos de Recuperação Primária}

Os fluidos que estão contidos nos poros da rocha reservatório possuem uma certa quantidade de energia associada, que é conhecida como energia primária ou natural. Ela é o resultado de todas as ações e circunstâncias sofridas pela rocha durante 
o processo de formação e migração do fluido, e também a principal responsável pelo processo de recuperação primária (SORBIE, 1991).

Durante a produção do reservatório, é necessário que algum material ocupe o espaço poroso previamente ocupado pelo fluido que será produzido. Segundo Rosa (2006), existem dois principais efeitos responsáveis pelo deslocamento do fluido. O primeiro é a descompressão, causando a expansão dos fluidos presentes no reservatório e, simultaneamente, a diminuição do volume poroso. O segundo é o deslocamento de um outro fluido presente nos arredores do reservatório.

Na maioria das vezes o reservatório não é capaz de manter por muito tempo a sua energia original a ponto de promover a produção dos fluidos. Além disso, ao longo do processo de produção a pressão interna do reservatório vai diminuindo, fazendo com que o gás que está associado ao líquido seja liberado, levando ao aparecimento de uma nova fase, que poderá trazer prejuízos na produção. Nesses casos são necessários mecanismos de auxílio para dar continuidade ao procedimento de deslocamento do material que está armazenado (SORBIE, 1991; ROSA, 2006).

\subsubsection{2}

\section{Processos de Recuperação Secundária}

O processo de recuperação secundária se caracteriza pela injeção de fluidos que já estavam presentes no reservatório, água ou gás, ou que estejam disponíveis em localidades próximas. Esses fluidos são injetados em poços chamados de poços injetores, que são localizados à margem dos poços produtores.

A injeção de água é um dos métodos mais utilizados devido ao seu menor custo, alta disponibilidade e capacidade de varredura para determinados tipos de óleo, porém essa técnica possui algumas limitações.

Desde o aparecimento dessa técnica, na década de 50, um dos maiores problemas relacionados a injeção de água é devido às razões de mobilidade desfavoráveis. Por ter maior mobilidade, a água passa através de bancos de óleo, criando caminhos preferenciais e não o deslocando por completo. $\mathrm{O}$ resultado desse 
processo é uma antecipada produção de água e grandes regiões de óleo não varridas (SORBIE, 1991).

De acordo com a Agência Nacional do Petróleo (ANP), o método mais utilizado na Bacia de Campos, que é responsável por grande parte da produção brasileira de hidrocarbonetos, foi a injeção de água. A maioria desses poços já se encontram com um volume de produção de água maior que o de óleo, com isso há a necessidade de métodos auxiliares para recuperar o óleo remanescente (FERREIRA, 2016).

\subsubsection{3}

\section{Processos de Recuperação Avançada}

Os métodos de recuperação avançada surgiram com o propósito de dar continuidade ao processo de produção em reservatórios que já se encontravam em estágio avançado de produção, porém muitos dos métodos podem ser utilizados desde o início da produção. A utilização adiantada desses métodos está se tornando cada vez mais comum devido aos bons resultados apresentados na recuperação de óleo. Standnes e Skjevrak (2014) realizaram uma revisão de 72 projetos de injeção de soluções poliméricas e concluíram que quando utilizados de maneira secundária, ou seja, substituindo a injeção de água, os casos de sucesso foram mais constantes.

A aplicação dessas técnicas em ambientes offshore é mais limitada que em ambientes terrestres devido a restrições de espaço nas unidades de produção, aspectos logísticos e características do reservatório, porém, como citado anteriormente, no caso brasileiro esses poços possuem grande importância na contribuição da produção nacional, tornando imprescindível o desenvolvimento dessas técnicas e novas medidas de implantação. Os métodos especiais mais utilizados na recuperação avançada são:

1. Métodos miscíveis - Nos métodos miscíveis estão presentes a injeção de hidrocarbonetos e a injeção de $\mathrm{CO}_{2}$. Esse processo visa reduzir as forças capilares e interfaciais do óleo presente no reservatório, facilitando seu deslocamento, através da injeção de fluidos miscíveis (ROSA et al., 2006). 
2. Métodos térmicos - Os métodos térmicos são subdivididos em injeção de água quente, vapor d'água ou combustão in situ (ROSA et al., 2006). O principal objetivo é reduzir a viscosidade de óleos muito viscosos, possibilitando um melhor escoamento através do reservatório e do poço até a superfície.

3. Métodos químicos - Os métodos químicos são os mais utilizados e apresentam diferentes técnicas com variadas finalidades. Nele estão consideradas a injeção de polímeros, a injeção de solução micelar, a injeção de solução alcalina e a injeção de solução tensoativas (surfactantes) (ROSA et al., 2006; VIANNA, 2016). O tema injeção de polímeros, que é o foco desse trabalho, será melhor desenvolvido no capítulo 3 .

\section{3}

\section{Conceitos Específicos do Experimento}

O experimento realizado para quantificar o material polimérico adsorvido no meio poroso possui alguns procedimentos simples, porém não triviais. Para que o entendimento dos experimentos seja por completo é importante a elucidação destes conceitos que serão apresentados a seguir.

O dispositivo utilizado nos experimentos é o Core Flooding System. Trata-se de um conjunto de equipamentos capazes de simular as condições de pressão e temperatura encontradas nos reservatórios localizados em campos de petróleo.

O método empregado para essa tarefa foi o de dois bancos, ou Two Slug Method, utilizado por Lotsch et al. (1985) para investigar o volume de poros inacessível resultante do processo de adsorção polimérica nas paredes do meio poroso. A partir dessa concepção, diversos outros autores utilizaram a mesma técnica para calcular a massa de polímero que foi retida pela formação após a passagem de um banco de solução polimérica e verificar alterações na razão de mobilidade e permeabilidade das rochas. O procedimento é realizado através da leitura de isotermas formadas pelo diferencial de pressão e salinidade, como será mostrado a seguir. 


\subsection{1}

\section{Two Slug Method}

Dominguez \& Willhite (1977) desenvolveram um aparato capaz de acompanhar a concentração da solução polimérica durante o processo de injeção em amostras de rocha. Através de sinais fornecidos pelos equipamentos era possível traçar perfil de concentração e relacioná-los aos processos de retenção polimérica.

Lotsch et al. (1985) utilizaram um esquema parecido, exposto na Fig. 6, para realizar um estudo das consequências da injeção de solução polimérica em meios porosos. O experimento foi realizado com a utilização do Two Slug Method, que consiste na injeção de dois bancos de solução polimérica intercalados por um banco de solução salina como ilustrado na Fig. 7. As características de retenção podem ser determinadas através dos perfis gerados pela passagem das soluções na amostra de rocha.

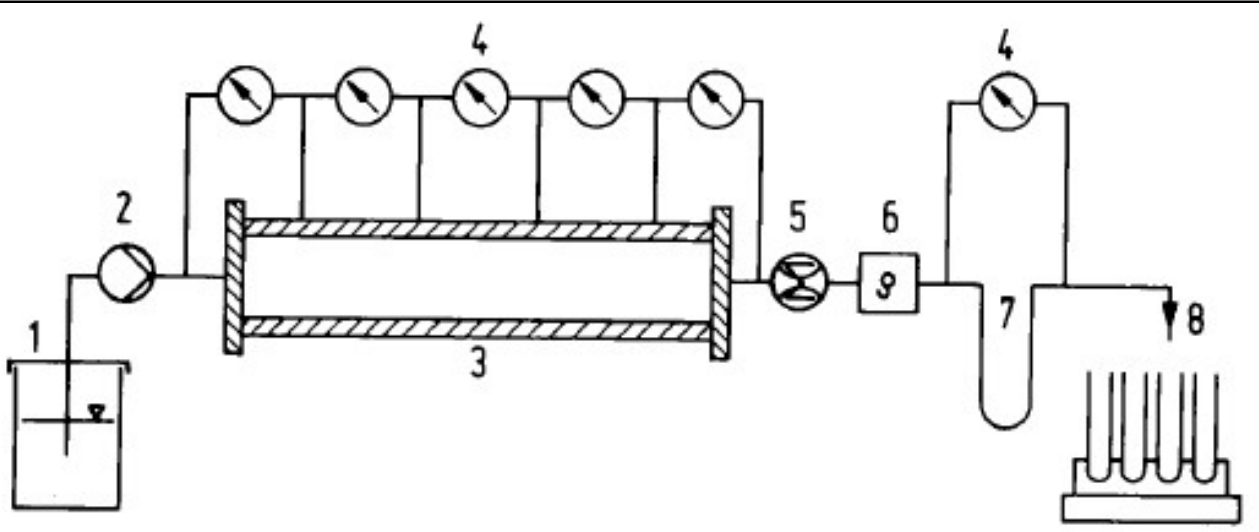

1 Buffer Vessel

2 Constant Rate Pump

3 Core Holder

4 Differential Pressure Transducer
5 Volume Counter

6 Density Measuring Devic

7 Capillary Viscosimeter

8 Fraction Collector

Figura 6 - Aparato experimental utilizado por Lotsch em 1985 (LOTSCH et al., 1985). 


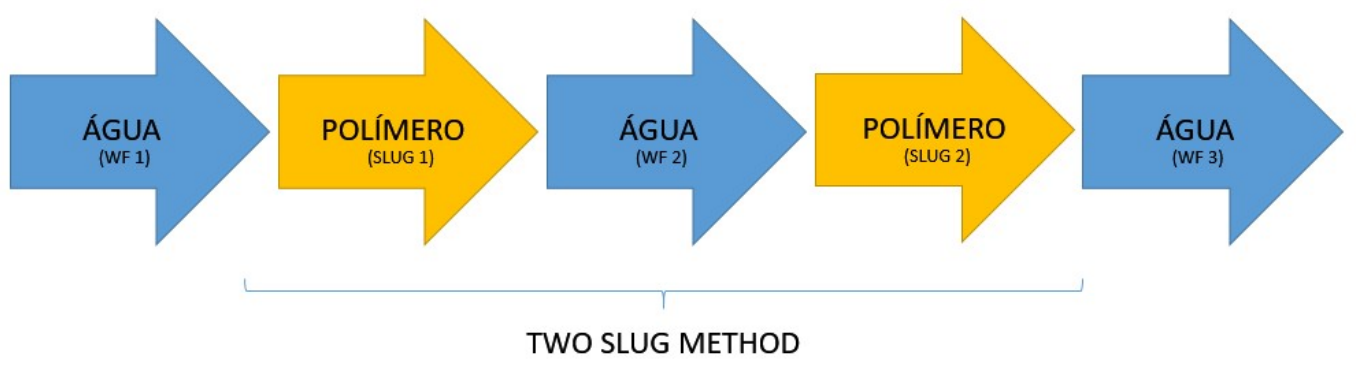

Figura 7 - Sequência de injeção do Two Slug Method.

Sandengen et al. (2017) apresentaram no $19^{\text {th }}$ Simpósio Europeu de Recuperação Melhorada de Óleo um estudo sobre a adsorção polimérica em meios porosos, no qual foi utilizado uma variação do esquema apresentado por Lotsch (1985).

As principais diferenças foram no sistema de aquisição de dados da concentração da solução polimérica e no traçador utilizado. O presente trabalho utilizou o mesmo mecanismo operado por Sandengen (2017), apresentado na Fig. 8, com isso o processo do Two Slug Method será explicado através dele.

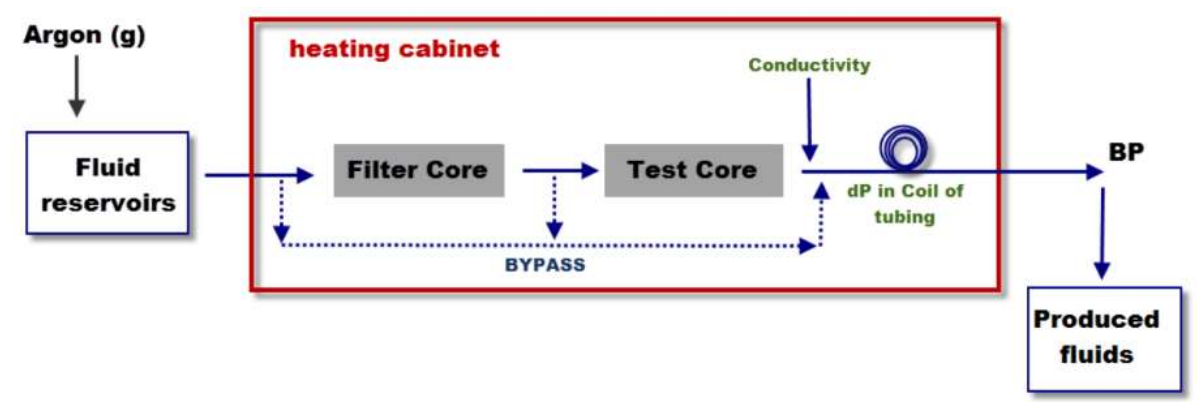

Figura 8 - Esquema experimental utilizado por Sandengen (2017) e utilizado no presente trabalho. (SANDENGEN et al., 2017).

Primeiramente a amostra é saturada com água do mar. Essa etapa tem como objetivo remover qualquer presença de ar que possa ter penetrado na amostra durante 
o posicionamento dela no porta-amostra. Nessa primeira etapa, também é realizada a curva de permeabilidade absoluta inicial da amostra.

$\mathrm{Na}$ sequência, ocorre a primeira injeção de solução polimérica, a qual, teoricamente, será responsável por toda adsorção do polímero nas paredes do meio poroso. O processo de adsorção de polímeros em rochas é considerado como um processo irreversível, portanto, uma vez que a partícula polimérica tenha sido adsorvida ela permanecerá permanentemente na formação.

Após isso, é realizada outra injeção de água do mar. A finalidade dessa fase é remover o polímero não adsorvido que ficou retido na amostra. A injeção deve durar o bastante para garantir que tudo foi retirado. Usualmente esse ponto é obtido quando o diferencial de pressão entre a entrada e saída da amostra se mantém constante.

Em seguida, é a vez da injeção do segundo banco de solução polimérica. Nesse período, espera-se que não ocorra mais nenhuma retenção polimérica por adsorção, pois as paredes já estão saturadas pela injeção do primeiro banco. A quinta e última fase tem a função combinada do primeiro e segundo banco de água.

Inicialmente o papel dessa injeção é de limpar o material polimérico retido na amostra resultante da injeção do segundo banco de polímero. Novamente, a duração da limpeza será até o diferencial de pressão se mostrar estável. Logo após, é realizado o procedimento para obtenção da curva de permeabilidade final. É importante que esse segundo processo de determinação da permeabilidade da amostra utilize valores de vazão decrescentes, sempre menores que a utilizada nas injeções das soluções poliméricas, pois a adsorção é proporcional à velocidade do fluxo.

Durante as diferentes etapas do experimento, a concentração de polímero na saída do meio poroso é determinada através da medida do diferencial de pressão do escoamento através de um tubo capilar (Fig. 9) localizado logo após o meio poroso. Esse diferencial de pressão é linearmente proporcional a viscosidade da solução polimérica. Devido as baixas concentrações usadas, assumiu-se uma variação linear entre a viscosidade, e consequentemente o diferencial de pressão, e a concentração. 
Assim, o menor diferencial de pressão corresponde ao escoamento da solução polimérica na concentração injetada.

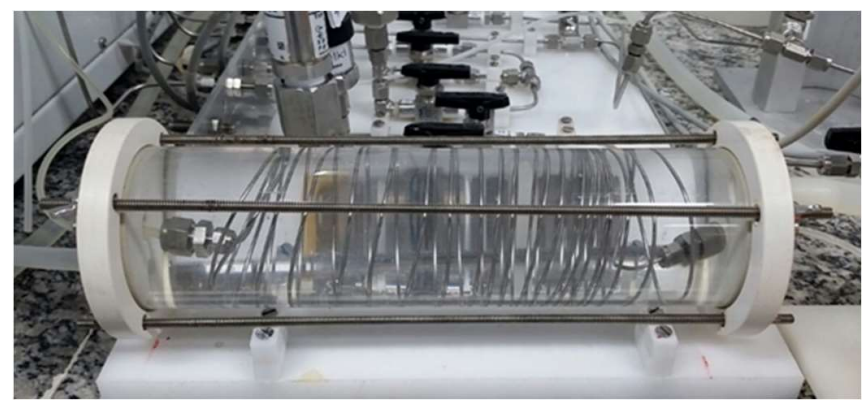

Figura 9 - Tubo capilar para medida de concentração.

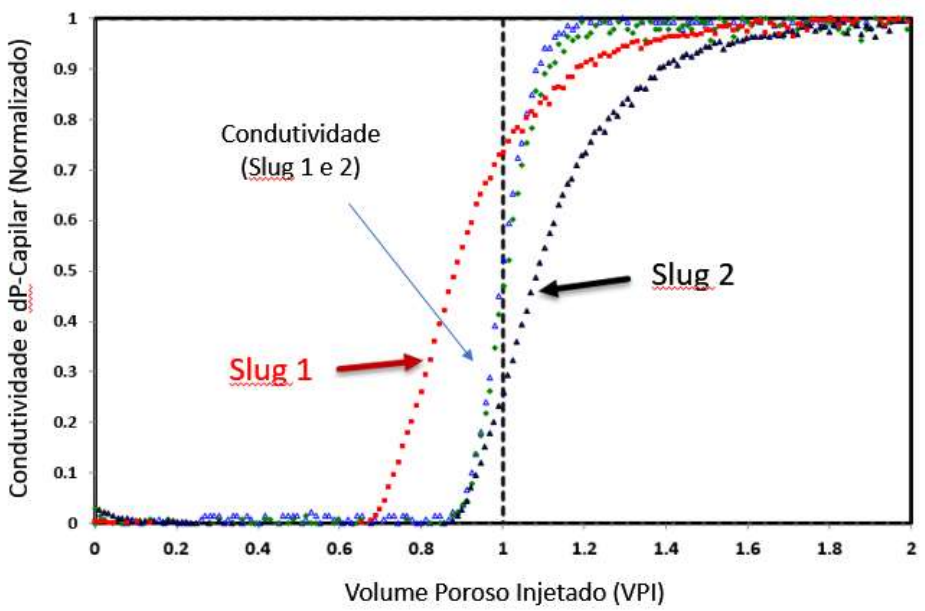

Figura 10- Perfis de pressão e condutividade do Two Slug Method (SANDENGEN et al., 2017).

A Fig. 10 apresenta a variação do diferencial de pressão no tubo capilar com o tempo de injeção, representado de forma adimensional pelo volume poroso injetado, para os dois bancos de solução polimérica injetado.

O outro perfil apresentado na Fig. 10 é referente ao sinal originado pelo traçador. Enquanto Lotsch (1985) utilizou como traçador a diferença de densidade entre os fluidos, Sandengen (2017) utilizou soluções de diferentes concentrações salinas, desse modo o sinal do traçador era adquirido através de um condutivímetro. $\mathrm{O}$ traçador tem como finalidade orientar o pesquisador sobre o posicionamento da frente 
dos fluidos dentro do sistema, pois mesmo havendo o processo de retenção polimérica na amostra a solução será filtrada, mas continuará fluindo normalmente.

Para atingir essa diferença de salinidade, utilizou-se uma solução salina com $100 \%$ de sua concentração para a fabricação da solução polimérica, e para a água de injeção a solução foi diluída em 70\%. Essa diferença de salinidade foi suficiente para criar os perfis de condutividade, que também assumiu uma relação linear entre os valores máximos e mínimos das soluções.

Os dados de condutividade (traçador) e concentração do efluente durante a injeção dos bancos de solução poliméricas são usados para determinar a quantidade de material adsorvido nas paredes da rocha e o volume de poro inacessível, que representa o volume dos poros não varridos pela solução polimérica. $\mathrm{O}$ volume é determinado pela diferença do volume poroso injetado da curva de pressão do segundo banco e a curva de condutividade no ponto de inflexão (condutividade normalizada igual a 0,5 ), como mostrado na Fig. 11a. A massa de polímero adsorvido $(\tau)$ é calculada pelo Eq. 10 (SANDENGEN, 2017).

$$
\tau=\frac{V_{a d s} C_{p o l}}{m_{\text {roch }}}
$$

Sendo:

$V_{a d s}-\mathrm{O}$ volume de solução polimérica correspondente a massa de polímero adsorvida, ou seja, o volume entre os perfis dos bancos de polímero 1 e $2(\mathrm{~mL})$, determinado também no ponto de inflexão;

$C_{p o l}$ - Concentração da solução polimérica $(\mathrm{mg} / \mathrm{mL})$;

$m_{\text {rocha }}$ - A massa seca da amostra (mg). 

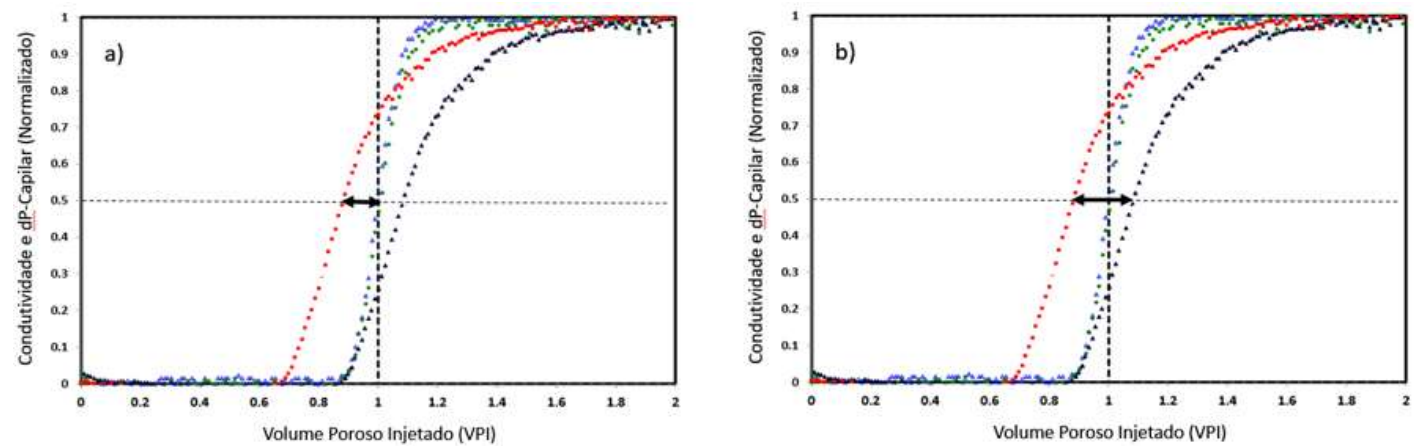

Figura 11 - a) Cálculo do volume de poro inacessível. b) Cálculo da massa de polímero adsorvido (figura adaptada de SANDENGEN et al., 2017).

Outras propriedades importantes no estudo dos efeitos de injeção polimérica são os fatores de redução de mobilidade, como o fator de resistência e o fator de resistência residual.

O fator de resistência representa a redução na mobilidade da solução polimérica devido ao aumento da viscosidade e a redução na permeabilidade quando comparado com a solução salina. O cálculo do fator de resistência está descrito na Eq. 11 (LOTSCH, 1985).

$$
R F=\frac{\lambda_{w 1}}{\lambda_{p}}=\frac{k_{r w 1}}{\mu_{w}} \times \frac{\mu_{p}}{k_{r p}}
$$

Sendo:

- $\lambda_{w 1}-$ a mobilidade da solução salina antes da injeção de solução polimérica $(\mathrm{mD} / \mathrm{cP})$;

- $\lambda_{p}$ - a mobilidade da solução polimérica $(\mathrm{mD} / \mathrm{cP})$;

- $\quad k_{r w 1}$ - a permeabilidade relativa da solução salina antes da injeção de solução polimérica $(\mathrm{mD})$;

- $\quad k_{r p}$ - a permeabilidade relativa da solução polimérica $(\mathrm{mD})$; 
- $\quad \mu_{w}$ - a viscosidade da solução salina (cP);

- $\mu_{p}$ - a viscosidade da solução polimérica (cP).

Já o fator de resistência residual (RRF) refere-se ao efeito da redução da permeabilidade causado pela injeção da solução polimérica, e é calculado a partir da razão de mobilidade entre duas fases de injeção de água como mostrado na Eq. 12 (LOTSCH, 1985). Como as viscosidades das soluções são iguais, torna-se apenas uma razão das permeabilidades.

$$
R R F=\frac{\lambda_{w 1}}{\lambda_{w 2}}=\frac{k_{r w 1}}{\mu_{w 1}} \times \frac{\mu_{w 2}}{k_{r w 2}}=\frac{k_{r w 1}}{k_{r w 2}}
$$

Sendo:

· $\quad \lambda_{w 1}-$ a mobilidade da solução salina antes da injeção da solução polimérica $(\mathrm{mD} / \mathrm{cP})$;

- $\lambda_{w 2}$ - a mobilidade da solução salina após a injeção da solução polimérica $(\mathrm{mD} / \mathrm{cP})$;

- $k_{r w 1}$ - a permeabilidade relativa da solução salina antes da injeção de solução polimérica $(\mathrm{mD})$;

- $k_{r w 2}$ - a permeabilidade relativa da solução salina após a injeção da solução polimérica $(\mathrm{mD})$. 


\section{3}

\section{Revisão Bibliográfica}

Devido à complexidade do assunto, fez-se necessário a criação deste capítulo para abordar os principais tópicos sobre os polímeros e sua utilização nos processos de recuperação de petróleo.

O termo polímero deriva do grego, poli "muitas" e meros "partes". São macromoléculas formadas por unidades que se repetem na ordem de milhões, chamadas de monômeros. Essa repetição é resultante de reações de polimerização, que são capazes de formar compostos com massa molecular na ordem de milhões (ROSA et al., 2006).

O início da utilização de polímeros em processos industriais data do início do século XIX, desde então o seu poder viscosificante vem sendo altamente requisitado para diversas finalidades. Na indústria do petróleo sua utilização começou em meados dos anos 60, a partir dessa data muitos estudos foram realizados (CHALLA, 1993; SHENG, 2011).

Os tópicos a seguir trazem, de maneira sintetizada, algumas características e a evolução das técnicas de utilização desse produto que se tornou o método químico mais utilizado em todo o mundo. As informações que serão expostas neste capítulo abordarão com mais constância as propriedades relacionadas às poliacrilamidas parcialmente hidrolisadas, que foi o polímero utilizado pelo autor. 


\section{1}

\section{Vantagens e Desvantagens na Utilização de Soluções Poliméricas como Método de Recuperação}

Somente em processos relacionados à indústria do petróleo, a utilização de soluções poliméricas engloba trabalhos que vão desde a perfuração de poços até à recuperação avançada do óleo. Há muitas vantagens e desvantagem relacionados à essa técnica, porém para manter o foco do estudo, serão apenas abordados os aspectos relativos à recuperação de óleo.

Dentre as principais vantagens destacam-se:

- São compostos de alta massa molar relativa capazes de aumentar, de maneira significativa, a viscosidade da água de injeção mesmo em baixas concentrações (THOMAS, 2004; VIANNA, 2016);

- O comportamento de fluido não Newtoniano apresentado por grande parte das soluções poliméricas também é uma vantagem muito importante. A capacidade em apresentar diferentes valores de viscosidade para diferentes situações mostra-se muito interessante, auxiliando no processo de injeção, ao terem a viscosidade da solução ao passarem por regiões mais estreitas, e no deslocamento de óleo ao atravessarem regiões de maior dimensão, a viscosidade elevada melhoraria o deslocamento do óleo;

- Podem alterar a permeabilidade da formação, forçando a passagem de fluido por zonas que não haviam sido alagadas, melhorando a varredura final (SORBIE, 1991);

- Ausência de características tóxicas e corrosivas em alguns tipos de polímeros, beneficiando o meio ambiente e os equipamentos de produção (ROSA et al., 2006).

Quantos as desvantagens, sobressaem-se:

Alta taxa de degradação química, bacteriana, térmica ou mecânica de alguns compostos (SORBIE, 1991; SHENG 2011); 
- A potencial redução da permeabilidade, que pode ser interessante em alguns casos, contudo, pode ocasionar o bloqueio total de poros, resultando em uma acentuação da perda de injetividade que já ocorre devido ao aumento da viscosidade do fluido (ROSA et al., 2006);

- Dificuldades logísticas para implementação da técnica em ambiente offshore (FERREIRA, 2016).

\section{2}

\section{Tipos de Polímeros}

Os polímeros são divididos em basicamente dois grupos: os biopolímeros polissacarídeos e os polímeros sintéticos, duas classes que possuem estruturas diferentes e, consequentemente, resultados distintos quando misturados a soluções aquosas.

\subsection{1}

\section{Biopolímeros}

Os biopolímeros são formados por microorganismos vivos, encontrados na natureza, e são resultado de um processo de fermentação microbiológica (FOGAÇA, 2014, VIANNA, 2016). Possuem peso molecular e estrutura menores que os polímeros sintéticos (HUSEYNLI, 2013). A principal vantagem é o alto poder viscosificante, mesmo em soluções de alta salinidade, que reduz a quantidade de material a ser utilizado para obter o mesmo valor de viscosidade que os polímeros sintéticos. Além disso, apresentam elevada resistência à degradação mecânica (MACHADO, 2016). O polímero natural mais conhecido e tratado na literatura de mecanismos de recuperação é a goma xantana, cuja construção dá-se a partir de 3 tipos de monômeros de sacarídeos: monose, glucose e ácido glucorânico (BENTO, 2015). 
A solução aquosa de goma xantana apresenta-se como um fluido não Newtoniano, tendo comportamento pseudoplástico. Sua molécula possui uma estrutura rígida e mais ramificada em comparação às moléculas de HPAM, porém são altamente vulneráveis ao ataque de bactérias (BENTO, 2015; LAKE, 1989; SHENG, 2011). A Fig. 12 apresenta a estrutura principal da goma xantana.

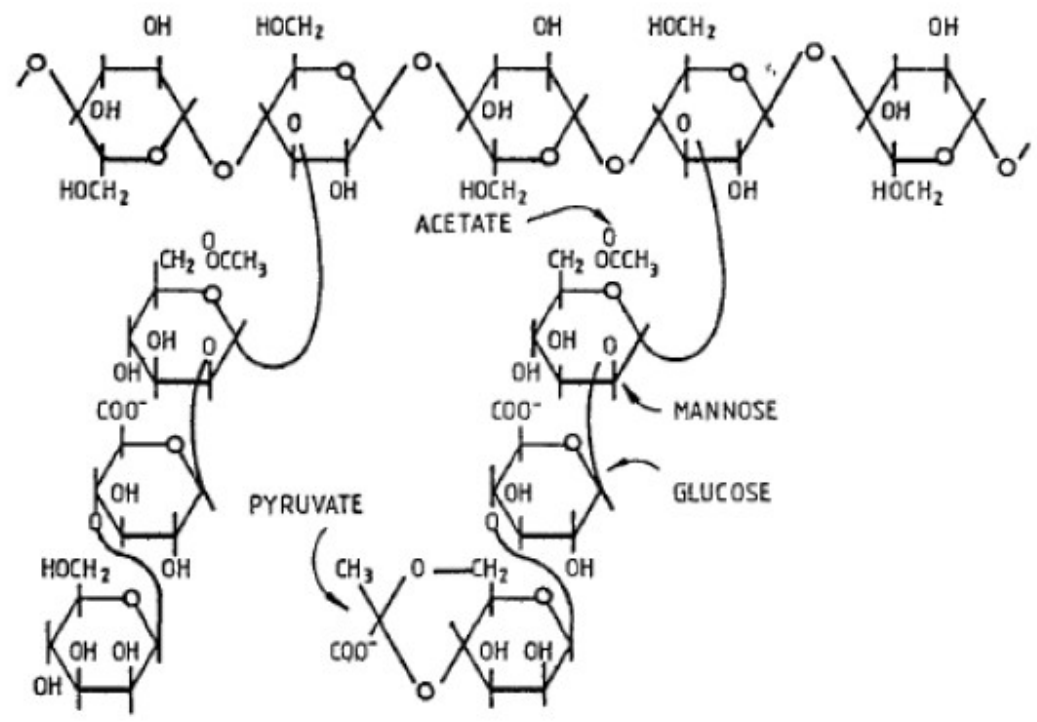

Figura 12 - Estrutura principal da goma xantana (BENTO, 2016; adaptado de SORBIE, 1991).

\subsection{2}

\section{Polímeros Sintéticos}

Os polímeros sintéticos são produzidos de forma artificial com estruturas parecidas com as de origem natural. Eles surgiram com o propósito de aumentar a oferta do produto e suprir a alta demanda do mercado. Possuem um custo de produção inferior ao dos biopolímeros (BENTO, 2016; SHENG, 2011). Atualmente, o polímero sintético mais utilizado na indústria petrolífera é a poliacrilamida (PAM), na sua forma parcialmente hidrolisada (HPAM) (SORBIE, 1991). 


\subsubsection{1}

\section{Poliacrilamida Parcialmente Hidrolisada (HPAM)}

A acrilamida, unidade monomérica da poliacrilamida, é formada, sinteticamente, a partir de propileno, oxigênio e nitrogênio. Após as reações de polimerização, surge a poliacrilamida, polímero sintético que possui fortes pontes de nitrogênio, linearidade e alto peso molecular. Posteriormente, ela pode ser modificada por hidrólise parcial, convertendo alguns grupos de amida $\left(\mathrm{CONH}_{2}\right)$ em grupos carboxílicos $\left(\mathrm{COO}^{-}\right)$, resultando na forma de poliacrilamidas parcialmente hidrolisadas (HPAM) (BENTO, 2016; SHENG, 2011; SORBIE, 1991).

O grau de hidrólise é a fração molar dos grupos de amida que são convertidos por hidrólise. Esse número, que em produtos comerciais pode variar de $15 \%$ a $35 \%$, é calculado para otimizar algumas propriedades como a solubilidade em água, viscosidade e retenção do polímero, que serão importantes para a adsorção e estabilidade frente ao cisalhamento e temperatura. O grau de adsorção dos polímeros é inversamente proporcional ao grau de hidrólise, ou seja, quando o grau de hidrólise é elevado, a tendência a retenção polimérica por adsorção diminui, assim como também há uma redução da estabilidade química devido ao alto nível do grupo $\mathrm{COO}^{-}$e baixa presença dos grupos de $\mathrm{CONH}_{2}$. Um dos motivos do processo de hidrólise nas poliacrilamidas é justamente o fato desse polímero possuir alto nível de adsorção (BENTO, 2016; SHENG, 2011; SORBIE, 1991).

A solução de HPAM apresenta o comportamento de um fluido não Newtoniano, tendo sua viscosidade diminuída com o aumento da taxa de cisalhamento, como foi visto com a goma xantana. Porém, diferentemente deste polímero, em meio aquoso a HPAM apresenta estrutura flexível (RIOS, 2014; SHENG, 2011).

As poliacrilamidas ganharam importância e visibilidade na indústria do petróleo em virtude da sua alta estabilidade biológica e química quando comparada aos biopolímeros (ROSIMIERE, 2015; LAKE, 1989).

A Fig. 13 mostra a estrutura da cadeia da poliacrilamida parcialmente hidrolisada e da poliacrilamida, no detalhe. 

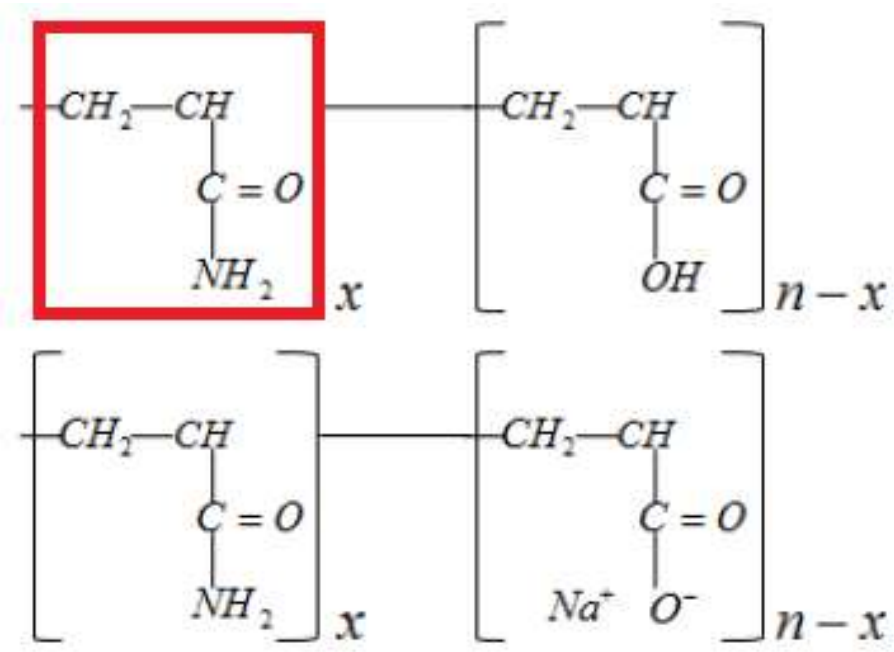

Figura 13 - Estrutura da cadeia de HPAM (Adaptado de BENTO, 2016).

\section{3}

\section{Critério de Seleção de Polímeros}

A injeção de polímeros, embora seja o método químico mais popular, nem sempre é o mais indicado a ser utilizado. Ainda assim, quando a utilização dessa técnica é possível, é preciso uma análise minuciosa do material que será empregado.

Além das propriedades dos fluidos, como grau API, viscosidade, composição e salinidade da água de formação, cada reservatório possui uma complexidade diferente. Nesse contexto, parâmetros como a temperatura da zona produtora, a permeabilidade, a composição mineralógica e o grau de heterogeneidade da formação são os principais pontos que devem ser avaliados (SORBIE, 1991; ROSA, 2006; RIOS, 2014).

O estudo sobre os critérios de seleção de polímeros já foi realizado por muitos autores, os quais apresentam um certo grau de coerência nos resultados e especificidades para algumas características e aplicações. Porém, são poucos os critérios que podem ser fixados, pois a criação de novos produtos com diferentes características promove uma continuidade no processo de evolução das técnicas e de conhecimento sobre os polímeros. 
O primeiro critério, que é um consenso dentre quase todos os autores, trata-se da temperatura a qual a solução polimérica será exposta. Esse é um dos principais fatores responsáveis pelo aceleramento de degradação química do polímero. Com isso, a utilização de polímeros em temperaturas muito elevadas deve ser evitada. Recomenda-se que os valores de trabalho sejam abaixo de $80^{\circ} \mathrm{C}$, limitando-se o uso em 95 C (SORBIE, 1991; TABER, 1997a, 1997b). Porém, alguns fornecedores desses químicos citam a viabilidade dessa técnica em temperaturas mais elevadas, podendo chegar a $120^{\circ} \mathrm{C}(\mathrm{SHENG}, 2011)$. A temperatura média entre os 171 projetos revisados por Taber (1997a, 1997b) é de $49^{\circ} \mathrm{C}$. Outra observação referente à temperatura citada por Ashby \& Jones (2006) é que com o aumento da temperatura os efeitos das forças de Van der Waals são reduzidos, isso diminui a atração entre as cadeias poliméricas, resultando em uma diminuição da viscosidade da solução.

Muitos autores tomam a profundidade da zona de injeção como um critério de seleção. Segundo Sheng (2015), essa escolha torna-se redundante, visto que o aumento da profundidade está relacionado, quase sempre, apenas com o aumento da temperatura.

Outro fator é a permeabilidade da formação, que devido ao tamanho das cadeias poliméricas não pode apresentar valores muito baixos. Formações pouco permeáveis podem ocasionar uma retenção mecânica muito grande do polímero injetado, ocasionando o entupimento e bloqueio dos canais. Segundo Sorbie (1991), para que a injeção de polímeros seja possível, os valores de permeabilidade devem ser superiores a 20mD. Segundo Taber (1997a), a permeabilidade mínima para utilização dessa técnica seria de $10 \mathrm{mD}$. Ainda segundo o autor, a média dos valores de permeabilidades nos projetos avaliados por ele é de $800 \mathrm{mD}$.

A composição mineralógica da formação dita como será a interação entre as cadeias da solução polimérica e as paredes do meio poroso. Essa relação é diretamente proporcional à quantidade de material que será adsorvido pelas paredes. Formações com alto teor de argila e rochas carbonáticas apresentam grandes retenções, com isso a utilização em arenitos é mais indicada. Outro fator é o alto grau de heterogeneidade 
das formações carbonáticas, o que não proporciona a otimização da injeção de material polimérico (SHENG, 2011).

Sheng (2011) ressalta a importância da salinidade e bivalência da água de formação. Em pequenos reservatórios, após o longo tempo de injeção de água realizado durante a recuperação secundária, a composição da água de formação torna-se muito próxima da água que está sendo injetada, que provavelmente será utilizada como solvente da solução polimérica. Nesse caso, o efeito da água original do reservatório no polímero será menor. Caso a diferença de salinidade e bivalência entre as duas soluções seja muito grande, para evitar que a solução polimérica seja afetada, é possível realizar uma pré-lavagem da região que ocorrerá a injeção. Os valores recomendados por Al-Bahar (2004) para salinidade e dureza são de 50000 ppm e 1000 ppm, respectivamente. Porém, vale ressaltar que cada produto possui uma característica diferente, logo esses limites são variáveis.

A viscosidade do óleo também é uma propriedade importante e dependente do projeto que está sendo realizado. Chang (1978) cita que no caso de outras características serem favoráveis, é possível a aplicação de polímeros em um intervalo maior de viscosidades mínima e máxima, mas que a faixa ideal seria para óleos entre 5cP e 125cP. Já Rosa et al. (2006), cita uma faixa ótima indo de 5cP a 40cP. Para Taber (1997a), os limites mínimos e máximos para utilização de polímeros seriam 10 e 150cP, respectivamente. Sorbie (1991) define como $30 \mathrm{cP}$. A utilização desse método de recuperação em reservatórios com óleos muito viscosos é uma nova tendência, que embora alguns casos de sucesso tenham ocorrido, ainda há muito o que avançar.

Como visto, muito já foi estudado e aplicado até o momento sobre a utilização da injeção de polímeros como método de recuperação de óleo, porém a todo momento novos limites e possibilidades de aplicação são descobertos, mostrando que ainda há muito a ser pesquisado. Sheng et al. (2015) realizaram uma revisão sobre os principais estudos realizados sobre os critérios de seleção para utilização de polímeros, com dados de campo e laboratoriais. A Fig. 14 resume as informações trazidas pelos autores durante décadas de pesquisas sobre esse assunto. 


\begin{tabular}{|c|c|c|c|c|c|c|c|c|c|c|c|c|}
\hline $\begin{array}{c}\text { Proposed } \\
\text { by }\end{array}$ & $k(\mathrm{md})$ & $\begin{array}{c}T_{r} \\
\left({ }^{\circ} \mathrm{C}\right)\end{array}$ & $\begin{array}{c}\text { water-salinity } \\
\text { (TDS, ppm) }\end{array}$ & $\begin{array}{c}\text { Divalent } \\
\text { (ppm) }\end{array}$ & Lithology & Clay & $\mu_{o}(\mathrm{cp})$ & $\begin{array}{c}S_{o} \\
\text { (fraction) }\end{array}$ & Aquifer & Gas Cap & $\begin{array}{c}\text { API } \\
\text { Gravity }\end{array}$ & $\begin{array}{l}\text { Depth } \\
\text { (ft) }\end{array}$ \\
\hline NPC 1976 & $\geq 20$ & $\leq 93.3$ & & & NC & & $\leq 200$ & $\begin{array}{c}\left(S_{o}-\right. \\
\left.S_{o r}\right)>0.1 \\
\end{array}$ & $\begin{array}{c}\text { None to } \\
\text { minor }\end{array}$ & $\begin{array}{c}\text { None to } \\
\text { minor }\end{array}$ & & \\
\hline $\begin{array}{l}\text { Brashear } \\
\text { and } \\
\text { Kuuskraa } \\
1978\end{array}$ & $>20$ & $<93.3$ & 50,000 & 1,000 & Sandstone & Low & $<20$ & $>0.25$ & $\begin{array}{l}\text { None to } \\
\text { week }\end{array}$ & $\begin{array}{l}\text { None to } \\
\text { week }\end{array}$ & $>15$ & NC \\
\hline $\begin{array}{l}\text { Chang } \\
1978 \\
\end{array}$ & $>20$ & $<93.3$ & & & $\begin{array}{c}\text { Sandstone } \\
\text { preferred }\end{array}$ & & $<200$ & $\begin{array}{c}\left(S_{0}\right. \\
\left.S_{0 r}\right)>0.1 \\
\end{array}$ & None & None & & \\
\hline $\begin{array}{l}\text { Carcoana } \\
1982 \\
\end{array}$ & $>50$ & $<80$ & Low & Low & Sandstone & & $50-80$ & $>0.3$ & Weak & Week & $25-35$ & $<6,561$ \\
\hline $\begin{array}{l}\text { NPC } \\
1984^{* *}\end{array}$ & $>10$ & $<121$ & $<200,000$ & & $\begin{array}{c}\text { Sandstone } \\
\text { and } \\
\text { carbonate }\end{array}$ & & $<150$ & & & & & \\
\hline $\begin{array}{l}\text { Goodlett } \\
\text { et al. } 1986 \\
\end{array}$ & $>20$ & $<93.3$ & 100,000 & & $\begin{array}{l}\text { Sandstone } \\
\text { preferred }\end{array}$ & & 100 & $\begin{array}{c}\left(S_{\sigma}-\right. \\
\left.S_{o r}\right)>0.1 \\
\end{array}$ & & & $>25$ & $<9,000$ \\
\hline $\begin{array}{l}\text { Taber } \\
\text { et al. } \\
(1997 a, b) \\
\end{array}$ & $>10$ & $<93.3$ & & & $\begin{array}{l}\text { Sandstone } \\
\text { preferred }\end{array}$ & & $\begin{array}{l}10<\mu_{\circ} \\
<150\end{array}$ & $>0.5$ & & & $>15$ & $<9,000$ \\
\hline $\begin{array}{l}\text { AlBahar } \\
\text { et al. } 2004 \\
\end{array}$ & $>50$ & $<70$ & 100,000 & 1000 & Sandstone & Low & $<150$ & 0.6 & None & None & & \\
\hline & $\begin{array}{l}>100 \text { if } \\
10<\mu_{0}<100\end{array}$ & & $\begin{array}{l}<1,000 \text { if } \\
10<\mu_{0}<10\end{array}$ & & & & & & & & & \\
\hline $\begin{array}{l}\text { Dickson } \\
\text { et al. } 2010\end{array}$ & $\begin{array}{l}>1,000 \text { if } \\
100<\mu_{0}<1,00 \\
0 \mathrm{cP}\end{array}$ & $<76.7$ & $\begin{array}{c}<3,000 \text { if } \\
100<\mu_{0}<1,00 \\
0 \mathrm{cP}\end{array}$ & & & & $\begin{array}{l}10<\mu_{\circ} \\
<1,000\end{array}$ & $>0.3$ & & & $>15$ & $\begin{array}{l}800- \\
9,000\end{array}$ \\
\hline $\begin{array}{l}\text { Limited } \\
\text { projects } \\
\text { (A) } \\
\text { Adasani } \\
\text { and Bai } \\
\text { 2011) } \\
\end{array}$ & 834.1 & 75 & & & Sandstone & & 123.2 & 0.64 & & & 26.5 & $\begin{array}{c}4,221 \\
9\end{array}$ \\
\hline $\begin{array}{l}\text { Saleh et } \\
\text { al. } 2014 a\end{array}$ & $>10$ & $<98.9$ & & & $\begin{array}{c}\text { Sandstone } \\
\text { and } \\
\text { carbonate }\end{array}$ & & $<5,000$ & $>0.21$ & & & $>12$ & \\
\hline $\begin{array}{l}\text { Saleh et } \\
\text { al. 2014b }\end{array}$ & 139 & 43.9 & 6,500 & & & & 5 & & & & & \\
\hline $\begin{array}{l}\text { Polymer } \\
\text { projects }\end{array}$ & 116.0 & 46.1 & $\begin{array}{c}20,500 \\
\left(39,750^{*}\right) \\
\end{array}$ & $\begin{array}{c}110 \\
\left(326^{\star}\right)\end{array}$ & $\begin{array}{c}\text { Majority } \\
\text { sandstone }\end{array}$ & Low & 9.15 & 0.52 & $\begin{array}{c}\text { Generally } \\
\text { none }\end{array}$ & $\begin{array}{c}\text { Generally } \\
\text { none }\end{array}$ & 32 & 3,486 \\
\hline $\begin{array}{l}\text { Proposed } \\
\text { in this } \\
\text { paper }\end{array}$ & 50 & $<93.3$ & $<50,000$ & $<100$ & Sandstone & Low & $<150$ & $\begin{array}{c}\left(S_{\sigma}\right. \\
\left.S_{o r}\right)>0.1\end{array}$ & Weak & Weak & NC & NC \\
\hline
\end{tabular}

Figura 14 - Resumo sobre os critérios de seleção para injeção de polímeros (SHENG, 2015).

\section{4}

\section{Estabilidade de Polímeros}

Fazer com que a solução mantenha suas características originais desde o processo de preparo da solução até às condições encontradas nos reservatórios é um dos principais desafios no processo de injeção de polímeros. A degradação polimérica promove a quebra das moléculas e a alteração de suas propriedades através de três maneiras: degradação química, biológica e mecânica (SORBIE, 1991; BENTO 2016; ROSA, 2006). 
A razão central para se evitar a degradação polimérica é a manutenção da viscosidade da solução que será injetada, porém esse efeito pode, do mesmo modo, gerar consequências nas regras de retenção dos polímeros no meio poroso (SORBIE, 1991).

\subsection{1}

\section{Degradação Química}

A degradação química é o mecanismo que mais afeta a estabilidade dos polímeros. Trata-se de uma propriedade intrínseca de todo polímero. Mesmo operando em condições livres de agentes agressores, não há como eliminar por completo esse problema. Ela pode ser originada por reações de oxidação ou redução, que acontecem a curto prazo, e por hidrólise ou precipitação, que são ações de longo prazo (SORBIE, 1991).

A presença de agentes contaminantes, como oxigênio e íons de ferro, e temperaturas elevadas podem contribuir consideravelmente para o processo de degradação do polímero.

Há uma relação entre oxigênio dissolvido e temperatura de exposição da solução trazida por Sheng (2011). Segundo o autor, em baixas temperaturas a presença de oxigênio dissolvido não afeta de maneira significativa a viscosidade da solução, com isso a solução ficaria estável por um intervalo maior. Porém, em casos de temperaturas mais elevadas a menor quantidade de oxigênio dissolvido é capaz de causar a degradação da solução. Na presença desses contaminantes, a meia-vida dos polímeros a $50^{\circ} \mathrm{C}, 70^{\circ} \mathrm{C}$ e $90^{\circ} \mathrm{C}$ são $117 \mathrm{~h}, 20 \mathrm{~h}, 2.6 \mathrm{~h}$, respectivamente (SHENG, 2010; LUO et al., 2016). A Fig. 15 mostra a redução da viscosidade de soluções poliméricas expostas a atmosferas de diferentes composições. 


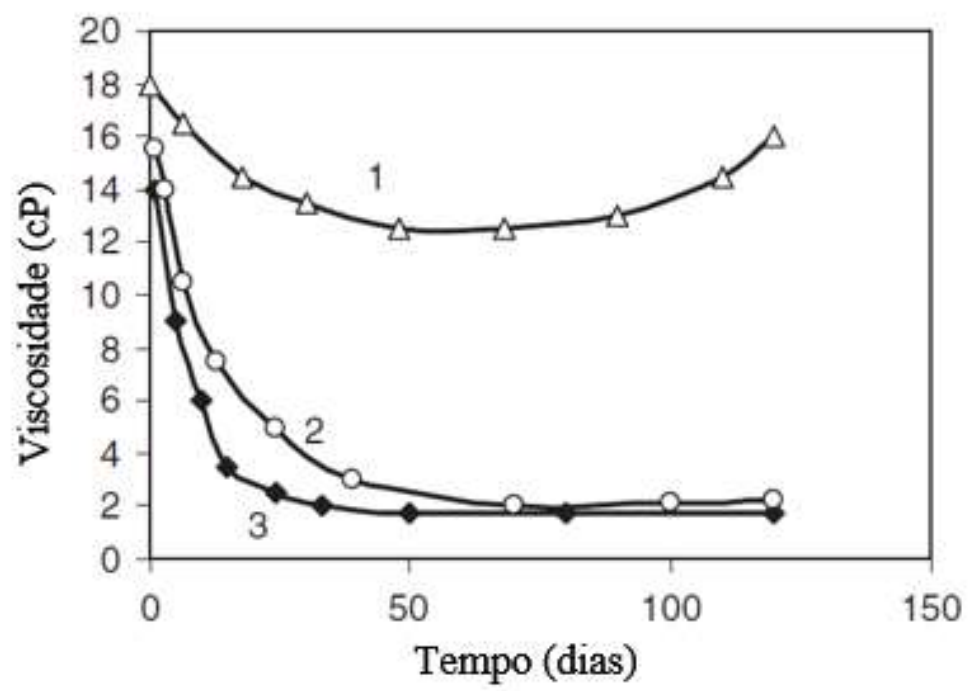

Figura 15 - Efeito da presença de oxigênio em HPAM a $90^{\circ} \mathrm{C}$ : 1, baixo nível de oxigênio; 2, ar; 3, oxigênio (Adaptado de LUO et al., 2006).

Existem alguns métodos para reduzir o teor de oxigênio dissolvido nas soluções. Dentre os mais utilizados estão a utilização de sequestradores de oxigênio, produtos que são misturados à solução e efetuam reações que irão consumir o oxigênio, e o aborbulhamento de gás inerte, como argônio ou nitrogênio.

O oxigênio também é responsável por atuar como agente oxidante, iniciando diversas reações que causam a quebra das moléculas. Um exemplo é a oxidação de $\mathrm{Fe}^{2+}$ em $\mathrm{Fe}^{3+}$, na qual ocorre a liberação de radicais livres $\mathrm{O}^{2-}$, que reagem com as cadeias de HPAM, além disso o $\mathrm{Fe}^{3+}$ também reage com HPAM resultado em um gel insolúvel, responsável pela redução da viscosidade e redução de injetividade devido ao entupimento de poros (RIOS, 2014; BENTO, 2016).

Temperaturas mais elevadas também influenciam no aumento da taxa e grau de hidrólise. O alto grau de hidrólise, maior que $40 \%$, é responsável pela precipitação do polímero, podendo causar redução da viscosidade e prejudicar a sua eficiência. (BENTO, 2016; RIOS, 2014; RYLES, 1983). 


\section{4 .2}

\section{Degradação Mecânica}

A degradação mecânica, que também é responsável pela diminuição da viscosidade da solução, ocorre quando a solução polimérica é submetida a altas velocidades de fluxo. Para vencer as grandes distâncias entre as unidades de operação e o reservatório, os fluidos são injetados através de equipamentos de superfície altamente potentes. Parte da fragmentação da cadeia polimérica pode ocorrer já nesse processo, em bombas, válvulas e tubulações. A outra parcela de grande atuação são as regiões próximas ao poço, onde a velocidade do fluido geralmente é maior (SHENG, 2011). No meio poroso a degradação mecânica pode ocorrer em regiões de permeabilidade baixa, as quais oferecem grandes resistências ao fluxo.

A taxa de quebra dos polímeros é diretamente proporcional à sua massa molar. Por oferecerem maior resistência ao escoamento, moléculas de tamanhos maiores têm uma tendência maior à ruptura (SORBIE 1991; LUO et al., 2006, SHENG, 2011).

Para Maerker (1975, 1976), a degradação mecânica é mais severa em soluções com alto teor de salinidade e com elevada ocorrência de $\mathrm{Ca}^{2+}$, devido ao fato do aumento da força iônica da solução. O autor sugere trabalhar com soluções de dureza reduzida para diminuição dos efeitos de degradação mecânica.

\subsection{3}

\section{Degradação Biológica}

A degradação biológica é mais comum nos biopolímeros, mas também podem ocorrer em polímeros sintéticos. Nesse caso, o fracionamento da cadeia polimérica é realizado pela a ação de bactérias e ocorre durante o processo de estocagem e no reservatório (RIOS, 2014; SHENG 2011).

Assim como na degradação química, há a possibilidade de prevenir a ocorrência desse fato através da adição de biocidas. O principal biocida referenciado pelos autores é o Formaldeído, que, ao ser misturado à solução em proporções corretas (500 a 2000 ppm), pode inibir a ação das bactérias. 


\section{5}

\section{Mecanismos de Retenção de Polímeros}

Durante o processo de injeção de polímeros nas rochas reservatório, além do melhor deslocamento causado pelo aumento da viscosidade da solução, ocorrem alguns outros fatores que irão influenciar na recuperação final do óleo. Um deles é o acúmulo do polímero na formação durante o escoamento, mais conhecido como retenção. Os mecanismos de retenção podem ser divididos em três tipos: retenção hidrodinâmica, aprisionamento mecânico e adsorção (SZABO, 1975; DOMINGUEZ \& WILLHITE, 1977; MEISTER, 1980). A Fig. 16 traz, em escala de poro, os mecanismos citados acima.

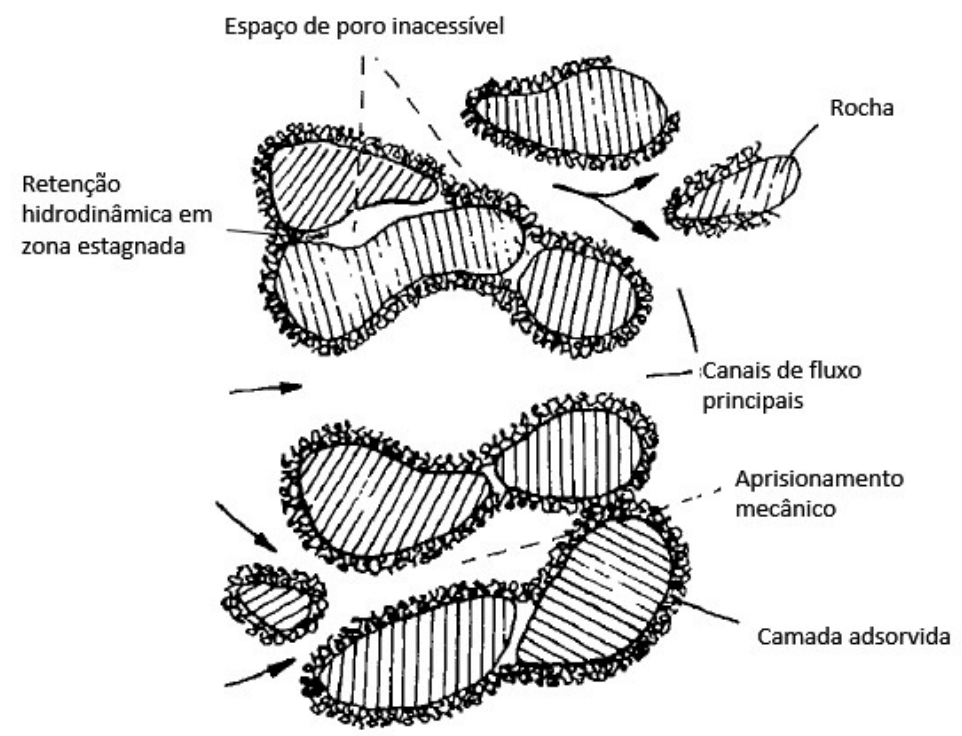

Figura 16 - Mecanismos de retenção polimérica (Adaptado de SZABO, 1975).

Os mecanismos de aprisionamento mecânico e retenção hidrodinâmica ocorrem somente em regimes de fluxo, enquanto que a adsorção pode ser observada também em processos estáticos (SORBIE, 1991). 


\subsection{1}

\section{Retenção Hidrodinâmica}

Esse é o mecanismo que tem menor contribuição na retenção dentre os três citados anteriormente, é também o menos estudado (SORBIE, 1991). A contribuição da retenção hidrodinâmica foi percebida em estudos de fluxo em meios porosos, nos quais acredita-se que forças hidrodinâmicas teriam efeito sobre as moléculas de polímeros, sendo proporcionais ao aumento da taxa de injeção (ZHANG E SERIGHT, 2015). Mesmo após atingir o estado estacionário, o aumento da taxa de injeção causava um acúmulo do polímero nos poros (CHEN, 2016).

Chen et al. (2016) realizaram um estudo com HPAM sobre esse tipo de retenção envolvendo efeitos de taxa de injeção, massa molar e permeabilidade do meio poroso. O estudo concluiu que o grau de retenção hidrodinâmica é diretamente proporcional à massa molar e inversamente proporcional à permeabilidade da amostra. Segundo Huh (1990), a retenção hidrodinâmica está incluída no processo de retenção mecânica. Segundo o autor, esse tipo de retenção é o mais brando que pode ocorrer e é totalmente reversível.

\section{5 .2}

\section{Aprisionamento Mecânico}

O aprisionamento mecânico ocorre quando as gargantas dos poros possuem um tamanho menor que o diâmetro médio das cadeias poliméricas, logo é uma propriedade totalmente dependente da distribuição do tamanho de poro da formação. A escolha correta do polímero ou do tipo de tratamento a ser empregado é fundamental para minimizar o acontecimento desse tipo de barreira. Formações com valores menores de permeabilidades são mais propensas a sofrer esse tipo de fenômeno (SZABO, 1975, DOMINGUEZ \& WILLHITE, 1977, SHENG, 2011).

No meio poroso, a retenção mecânica ocorre frequentemente em áreas próximas ao local de injeção, ou seja, próximo às paredes do poço, em operações de campo, e na entrada das amostras, em experimentos laboratoriais. A distribuição do aprisionamento 
mecânico nesses casos cai exponencialmente ao longo da amostra. Esse efeito ocasiona uma série de consequências como a filtração da solução, que irá causar um diferencial entre as concentrações encontradas no efluente e a na entrada da amostra, podendo levar vários volumes porosos injetados para se igualarem. Outro resultado seria o bloqueio total da formação, ocasionando sérios prejuízos.

Gogarty (1967) realizou um estudo sobre o tamanho médio das moléculas de HPAM e concluiu que os valores variam de 0.4 a $2 \mu \mathrm{m}$. Já Dominguez e Willhite (1977) deduziram através da análise de distribuição de poros, com experimentos utilizando o porosímetro de mercúrio, que aproximadamente $14 \%$ dos poros são retentores das cadeias poliméricas de tamanho médio de $1 \mu \mathrm{m}$.

Dados experimentais de Gogarty (1967) e Domingues e Willhite (1977), mostraram a dominância do mecanismo de retenção mecânica em certos tipos de amostra. Foram realizados testes estáticos e de fluxo para diferenciar a contribuição de cada fator. Ambos mostraram que a quantidade de material polimérico acumulado nas amostras foi muito maior quando houve a injeção da solução através do meio poroso. Uma ocorrência similar nos experimentos foi o atraso na uniformidade dos valores de concentração da solução na entrada e saída da amostra, com alguns casos levando até 10 volumes porosos injetados (SORBIE, 1991).

Huh (1990) observou que o aprisionamento mecânico também pode ocorrer da seguinte maneira: uma molécula de polímero tenta passar por um canal de menor diâmetro que seu raio, nesse processo a molécula acaba sendo adsorvida pelas paredes do poro. Mesmo com o bloqueio parcial, o solvente ainda continua fluindo através dessa garganta, trazendo mais polímero e ocasionando o acúmulo progressivo.

Existem algumas técnicas para se evitar esses tipos de problemas citados acima, como a filtragem da solução polimérica com a utilização de malhas consoantes com a distribuição de poros da formação. Outra maneira seria o pré-cisalhamento das cadeias, o que reduziria o seu tamanho (SHENG, 2011). 


\subsection{3}

\section{Adsorção}

A adsorção, juntamente com o aprisionamento mecânico, representa a maior causa de retenção polimérica em meios porosos. Esse mecanismo é um dos assuntos mais estudados sobre a técnica de injeção de polímeros para recuperação de óleo. Os dois mecanismos que foram mencionados anteriormente são possíveis de serem evitados de alguma forma, mas para o caso da adsorção polimérica, geralmente, somente a troca do polímero modificaria o processo (SORBIE, 1991).

A adsorção polimérica na recuperação de petróleo ocorre através da interação entre as moléculas do polímero, o solvente utilizado e as paredes da rocha, que causa a fixação dessas moléculas à superfície da matriz porosa. A quantidade de material polimérico retido na rocha por adsorção pode ser obtida através de ensaios estáticos ou dinâmicos.

A responsabilidade desse fenômeno é atribuída às pontes de hidrogênio e por ligações de Van der Walls. Por apresentar uma irreversibilidade muito alta, se torna necessário saber o grau do dano de formação que cada substância é capaz de causar. A seguir estão alguns fatores responsáveis pelo processo de adsorção.

\subsubsection{1}

\section{Fatores que Influenciam a Adsorção}

Os fatores que governam a adsorção de polímeros já foram estudados por diferentes autores desde o início da utilização de polímeros na indústria do petróleo. Szabo et al. (1981) confeccionaram um resumo dos trabalhos realizados na década anterior no Laboratório de Pesquisas em Engenharia de Petróleo da Academia Húngara de Ciências envolvendo os fatores que influenciam a adsorção de poliacrilamida em meios porosos. Dentre os assuntos abordados estão: grau de hidrólise, massa molar, concentração da solução polimérica e a composição química dos fluidos e do meio poroso. 
- Grau de hidrólise - Como dito anteriormente no texto, o nível de adsorção é inversamente proporcional ao grau de hidrólise. A redução da adsorção tem relação com as interações das cargas presentes na superfície com as dos grupos carboxílicos do polímero. Quanto maior o grau de hidrólise, maior será a presença desses grupos que contêm cargas negativas, assim como a superfície de sílica. Porém há um limite no grau de hidrólise para se atingir o menor nível de adsorção como é mostrado na Fig. 17 (SORBIE, 1991; LAKATOS, 1981; SHENG 2011).

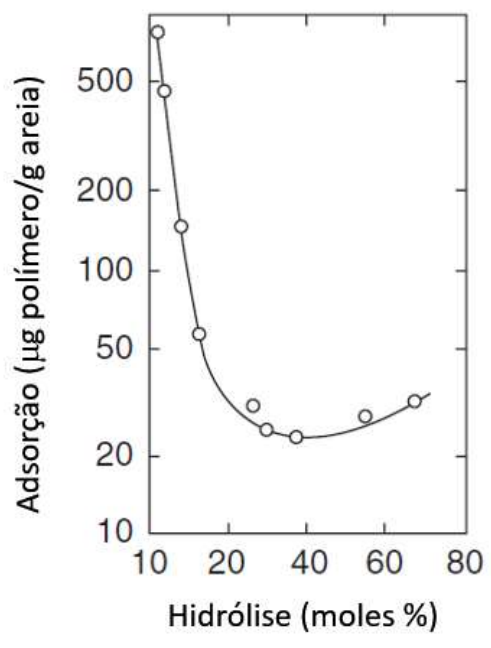

Figura 17 - Adsorção de HPAM para diferentes graus de hidrólise (Adaptado de MACWILLIANS, 1973).

- Massa molar média - Usualmente, polímeros com maiores massas molares tendem a apresentar um nível maior de adsorção. (SHENG, 2010; LIPATOV AND SERGEEVA, 1974). Entretanto, há um limite de adsorção que é independente da massa molar no qual o nível de material adsorvido tende a estabilizar (GRAMAIN E MYARD, 1981).

- Concentração da solução polimérica - O processo de adsorção não possui uma relação muito grande com a concentração da solução polimérica. A Fig. 18 mostra que os valores críticos de adsorção podem ser rapidamente atingidos com o aumento da concentração da solução (SHENG, 2011). 


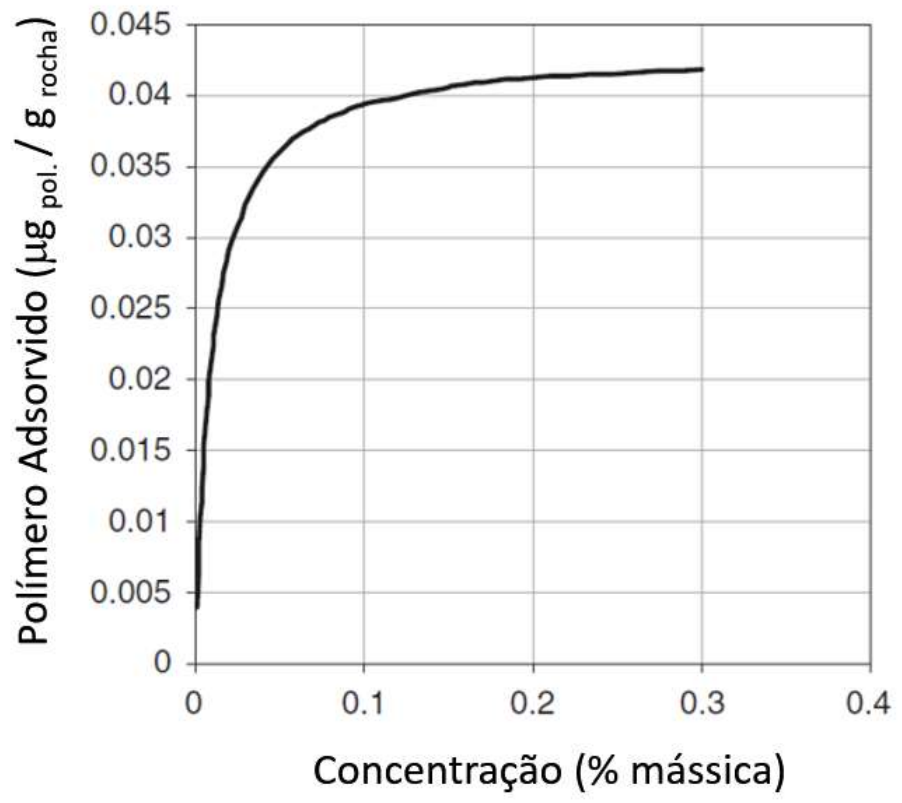

Figura 18 - Relação entre adsorção e concentração da solução polimérica (Adaptado de SHENG, 2010.)

Efeitos de salinidade - A concentração de cátions mono e bivalentes produz um efeito nas cadeias poliméricas, sendo responsável por sua contração. Quanto maior a salinidade, maior será a contração da molécula, diminuindo, dessa forma, seu diâmetro equivalente e a repulsão entre os grupos carboxílicos e a superfície da rocha.

Composição do meio poroso - O grau de adsorção em carbonatos é muito maior que em arenitos. Esse fator pode ser atribuído a forte interação entre os grupos carboxílicos da solução de HPAM e os íons $\mathrm{Ca}^{2+}$ da superfície (SHENG, 2010; SMITH, 1970; SZABO, 1979; LAKOTOS et al., 1979). 


\section{4}

\section{Procedimento Experimental}

Neste capítulo encontram-se todas as informações referentes aos protocolos utilizados durante a realização dos experimentos. O trabalho foi realizado em duas principais partes, que serão abordadas separadamente nesta seção. A primeira etapa tratou de quantificar o material retido nas amostras através do processo de adsorção. $\mathrm{Na}$ segunda parte, foram realizados os procedimentos de recuperação de óleo presente na rocha utilizando-se: água com composição similar a do campo de Peregrino, solução composta de água e glicerina e solução polimérica.

A escolha da solução salina de composição similar à da água de Peregrino é em virtude desse estudo estar relacionado à uma pesquisa que já estava em andamento no laboratório. Nesse trabalho, foram realizadas diversas análises sobre a adsorção de polímeros em meios porosos simulando os processos ocorridos nas operações de produção do campo de Peregrino. Porém, o presente trabalho não visa estabelecer nenhuma relação com as características encontradas nesse campo. Tanto as rochas quanto os fluidos utilizados aqui foram escolhidos de maneira a otimizar o estudo dos processos de retenção polimérica e suas consequências durante os processos de recuperação de óleo.

Todos os processos de preparação dos fluidos utilizados, bem como das amostras de rocha, também serão abordados neste capítulo. 


\section{1}

\section{Material Utilizado}

\subsection{1}

\section{Fluidos}

Durante a realização dos experimentos, foram utilizados três tipos diferentes de soluções:

- Água com composição similar a do campo de Peregrino²;

- Solução polimérica;

- Solução composta de água e glicerina com a mesma viscosidade da solução polimérica.

Os equipamentos utilizados para preparo e caracterização dos fluidos foram:

1. Reômetro Rotacional - Discovery HR-3 - TA INSTRUMENTS

2. Viscosímetro Capilar - Viscoterm 15 - LAUDA

3. Balança Analítica - Adventure Pro - OHAUS

4. Balança Analítica - Q500L210C - QUIMIS

5. Bomba tipo Seringa - 500D - TELEDYNE ISCO

6. Bomba à Vácuo - R-300 - BOECO

7. Agitador magnético - PC-420D-CORNING

8. Densímetro - DMA4200M - ANTON PAAR

9. Manômetro - DPGW-07 - DWYER INSTRUMENTS INC

As concentrações das soluções salina e polimérica estão definidas em volume, já para a solução aquosa de glicerina foi utilizado a concentração em massa.

2 A solução salina com composição similar à da água de formação do campo de Peregrino será referenciada nesse trabalho como Água de Peregrino. 


\subsubsection{1}

\section{Água de Peregrino}

A água utilizada nos experimentos é uma solução salina que reproduz a composição e as propriedades da água encontrada no campo de Peregrino, localizado na parte sudoeste da Bacia de Campos. A composição dessa salmoura foi fornecida pela empresa Equinor que opera no campo, e está descrita na Tabela 1.

\begin{tabular}{lcc}
\hline \multicolumn{1}{c}{ Sal } & $\begin{array}{c}\text { Concentração } \\
(\mathbf{g} / \mathbf{L})\end{array}$ & $\mathbf{m m o l} / \mathbf{L}$ \\
\hline $\mathrm{NaCl}$ & 86,6 & 1481,86 \\
\hline $\mathrm{CaCl} 2 * 2 \mathrm{H} 2 \mathrm{O}$ & 10,0 & 68,02 \\
\hline $\mathrm{MgCl} 2 * 6 \mathrm{H} 2 \mathrm{O}$ & 6,30 & 30,99 \\
\hline $\mathrm{KCl}$ & 0,60 & 8,05 \\
\hline $\mathrm{Na} 2 \mathrm{SO} 4$ & 1,30 & 9,15 \\
\hline $\mathrm{TDS}=99000 \mathrm{mg} / \mathrm{L}$ & & \\
\hline
\end{tabular}

Tabela 1 - Composição da água de Peregrino.

A água foi utilizada em duas diferentes concentrações. Para o preparo da solução polimérica e da solução com glicerina, foi usada com sua concentração total (100.000 ppm). Para os processos de injeção de água, houve uma diluição para $70 \%$ da sua concentração inicial. O principal motivo da diluição foi para promover uma diferença de salinidade entre as soluções, que serviu como traçador para identificar o avanço dos fluidos através da medida de condutividade, como foi explicitado no capítulo 2. Durante a leitura do texto, a solução salina diluída será citada com os termos “água” ou "água de Peregrino".

As medidas de densidade da água de Peregrino foram obtidas através do densímetro HT/HP. Para cálculo de viscosidade, utilizou-se o viscosímetro capilar, com o capilar de vidro Ubbelohde 0C. A Tabela 2 traz os valores de densidade, viscosidade cinemática e viscosidade dinâmica das soluções salinas à temperatura de $40^{\circ} \mathrm{C}$. 


\begin{tabular}{cccc}
\hline Amostra & $\begin{array}{c}\text { Densidade } \\
(\mathbf{g} / \mathbf{c m} 3)\end{array}$ & $\begin{array}{c}\text { Viscosidade Cinemática } \\
(\mathbf{m m 2} / \mathbf{s})\end{array}$ & $\begin{array}{c}\text { Viscosidade Dinâmica } \\
(\mathbf{c P})\end{array}$ \\
\hline Água de Peregrino & 1,0374 & 0,7389 & 0,7666 \\
\hline
\end{tabular}

Tabela 2 - Reologia Água de Peregrino.

Após o preparo, as soluções eram filtradas em filtro de papel com malha de $20-25 \mu \mathrm{m}$.

\subsubsection{2}

\section{Solução Polimérica}

O tipo de polímero usado nos experimentos foi a poliacrilamida parcialmente hidrolisada (HPAM) com denominação AN125VHM, fabricada e fornecida pela empresa SNF-Floeger. Segundo as informações fornecidas pela empresa, o polímero possui peso molecular entre 10 - 12 milhões g/mol e o seu grau de hidrólise é de $25 \%$.

O polímero, que se encontrava originalmente em pó, teve o seguinte processo de preparo.

\subsubsection{1}

\section{Preparo da solução polimérica}

O preparo da solução polimérica foi dividido em 4 partes e realizado de acordo com os procedimentos descritos na norma API-RP-63.

1. Mistura - A norma API-RP-63 (1990) recomenda o preparo inicial de uma solução polimérica de alta concentração (5.000ppm), também conhecida como solução mãe, para posteriormente ser diluída para a concentração estabelecida no teste a ser realizado. Com o auxílio de um agitador magnético, deve-se criar 
um vórtice com $75 \%$ da altura total do fluido contido no béquer. Lentamente, adiciona-se o polímero em pó no interior do vórtice, cuidando para não ocasionar uma grande aglomeração. Após a adição do polímero, deve-se reduzir a rotação para 80-100 RPM, a fim de evitar a degradação mecânica do polímero. O processo de mistura deve durar por, no mínimo, $12 \mathrm{~h}$.

2. Diluição - Após o preparo da solução mãe, o polímero deve ser diluído adicionando-se mais solvente até atingir a concentração desejada. O tempo mínimo de mistura para as diluições é de 1 hora. Recomenda-se que a rotação durante o processo de diluição seja mantida entre 80-100 RPM.

3. Filtração - A filtração da solução polimérica deve ser realizada para verificar se o produto final está satisfatório e pode ser utilizado. De acordo com o protocolo fornecido pela SNF-Floeger e pela norma API-RP-63, uma solução polimérica com concentração de 1.000 ppm, deve ser submetida a passagem por um filtro de $5 \mu \mathrm{m}$ com um diferencial de pressão de 2 bar e apresentar uma taxa de filtragem constante. Para a realização da filtragem da solução, foram utilizados: um cilindro de 1L de acrílico, para armazenamento da solução; um filtro de seringa de $5 \mu \mathrm{m}$; um manômetro, para acompanhamento da pressão; uma proveta graduada de $1 \mathrm{~L}$; uma bomba do tipo seringa para pressurizar o sistema; e um cronômetro para controlar o tempo dos volumes produzidos, como mostrado na Fig. 19. A vazão de produção foi medida para o cálculo da taxa de filtragem (TF), que é dada pela a Eq.13.

$$
T F=\frac{t_{300}-t_{200}}{t_{200}-t_{100}}
$$

Sendo $t_{300}, t_{200}$ e $t_{100}$ os tempos de produção para 300, 200 e 100 $\mathrm{mL}$, respectivamente. 


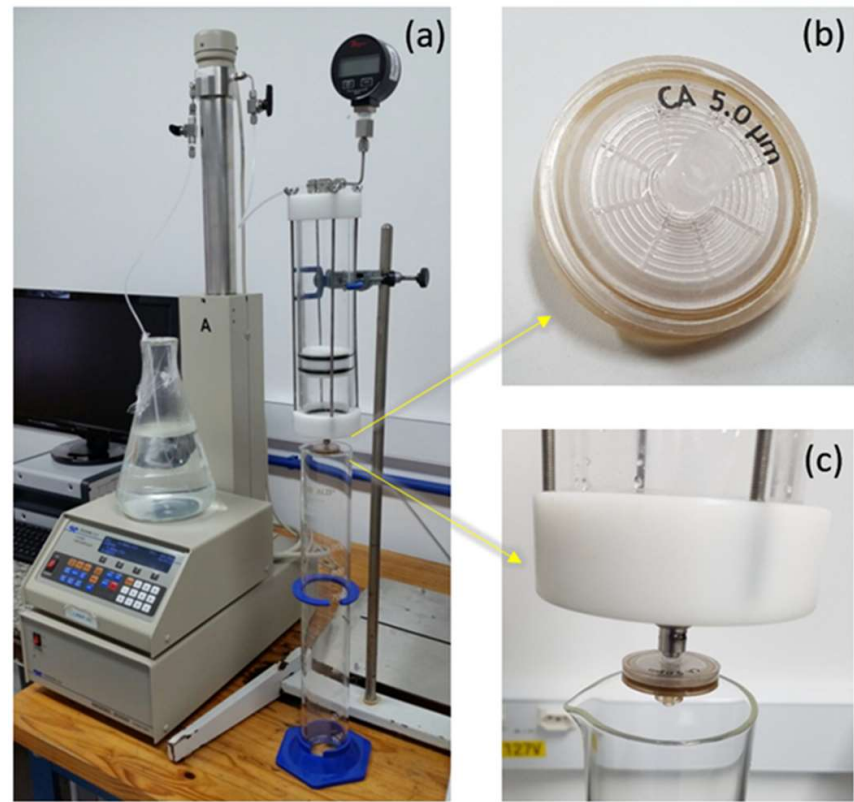

Figura 19 - a) Sistema de filtração da solução polimérica. b) e c) Detalhe do filtro de $5 \mu \mathrm{m}$.

4. Injeção de gás inerte - A última etapa do preparo da solução polimérica antes da injeção é o borbulhamento de gás argônio. A finalidade é reduzir ao máximo a concentração de oxigênio dissolvido presente na amostra, que é o principal responsável pela degradação química do polímero. O protocolo de injeção do gás foi realizado dentro de um ambiente confinado (glove bag), como mostrado na Fig. 20. Primeiramente, era realizada a troca da atmosfera através de ciclos alternados de aplicação de vácuo e injeção de gás argônio. Em seguida, foi realizada a injeção de gás na solução por um período de 3 horas. Testes preliminares, sem a injeção do gás inerte, mostraram que além da degradação da solução polimérica, houve também a corrosão das partes metálicas do experimento que estavam em contato com as soluções salinas e estavam expostas a altas temperaturas. Como é mostrado na Fig. 21, as amostras eram contaminadas com o óxido resultante dessa reação, alterando por completo os resultados dos experimentos. Devido a esse problema, o procedimento de injeção de argônio também foi adotado para toda solução salina que foi utilizada no experimento. 

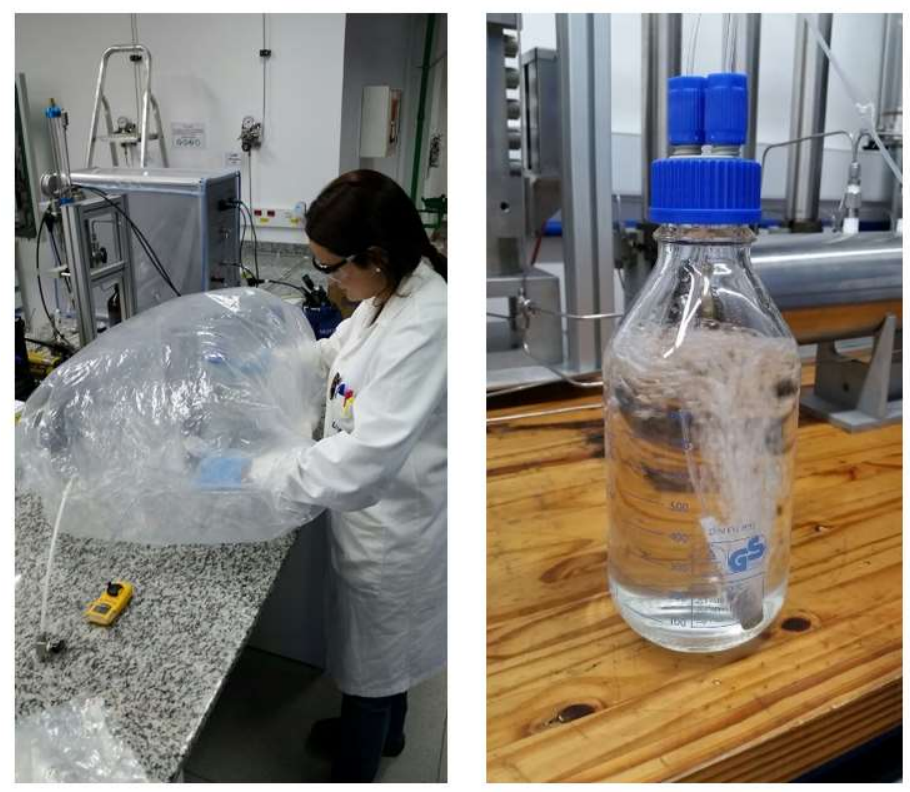

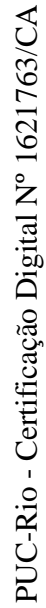

Figura 20 - Procedimento de troca de atmosfera para manipulação da solução polimérica.

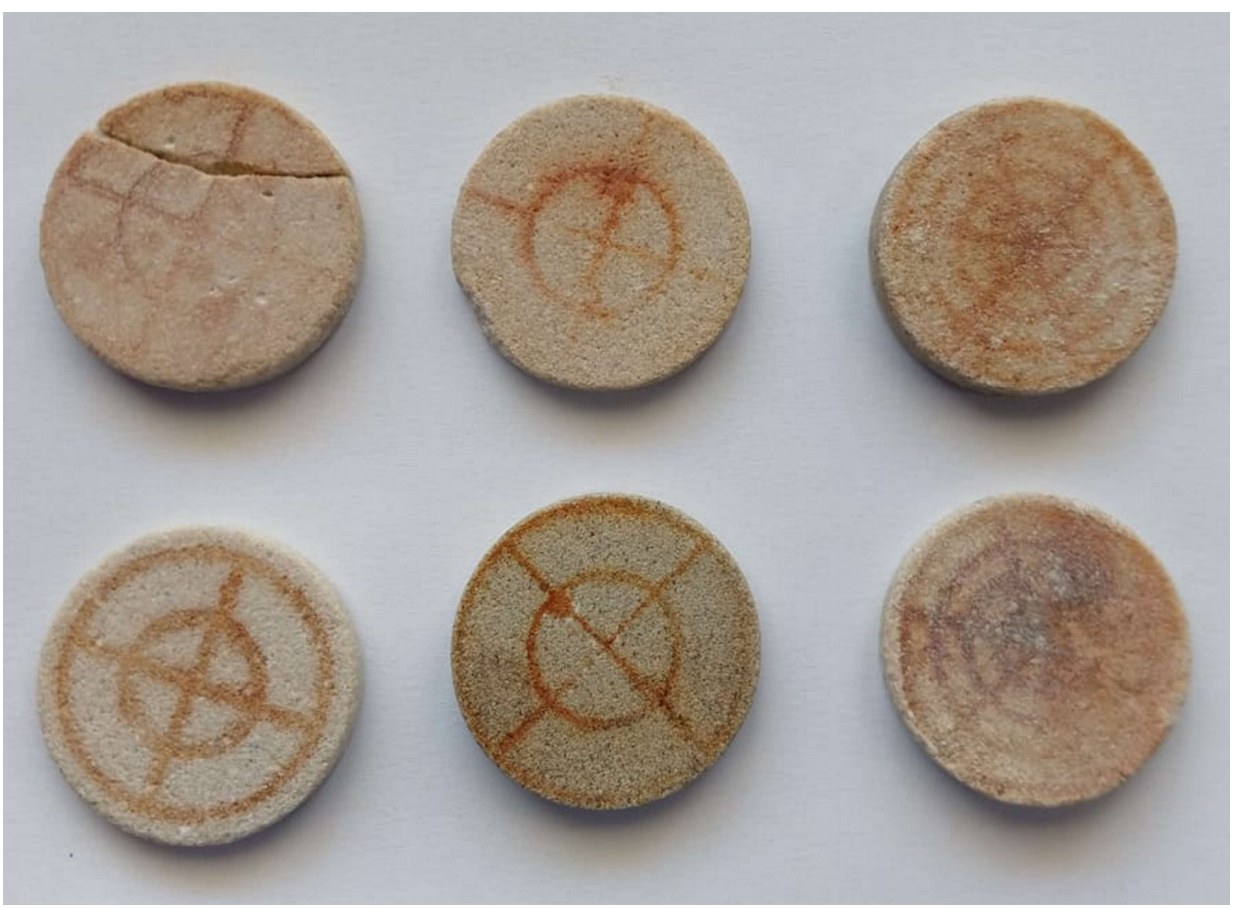

Figura 21 - Face de injeção das amostras manchadas por óxido provenientes das partes metálicas. 


\subsubsection{1}

\section{Reologia da solução polimérica}

A poliacrilamida parcialmente hidrolisada (HPAM) AN125VHM apresenta comportamento de um fluido não Newtoniano com características pseudoplásticas. As Fig. 22 e 23 exibem a caracterização reológica da solução polimérica de 1g/L (1000 ppm) realizada no reômetro rotacional à temperatura de $40^{\circ} \mathrm{C}$. Nessas imagens estão os dados de viscosidade e tensão de cisalhamento para uma faixa de taxa de cisalhamento de $10 \mathrm{~s}^{-1}$ a $1000 \mathrm{~s}^{-1}$. Por razões de confiabilidade dos dados, os testes foram realizados em triplicata. Para a realização desse procedimento foi utilizado o seguinte protocolo:

- Geometria: $50 \mathrm{~mm}$ placas paralelas

- Temperatura: $40^{\circ} \mathrm{C}$

- Taxa de cisalhamento: $1000 \mathrm{~s}^{-1}$ a $10 \mathrm{~s}^{-1}$

- Pontos por década: 6

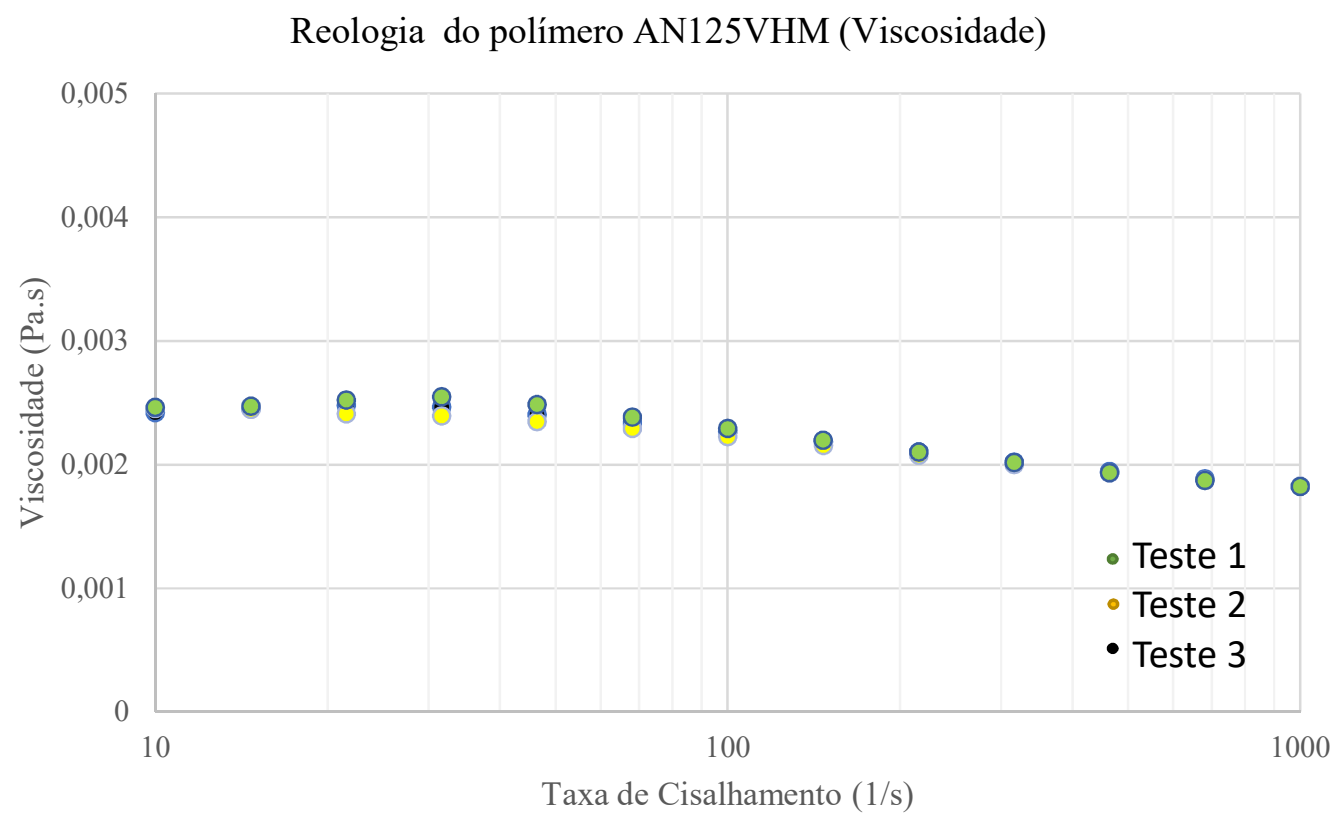

Figura 22 - Caracterização reológica da solução polimérica AN125VHM de 1g/L (1000 ppm) (dados de viscosidade). 


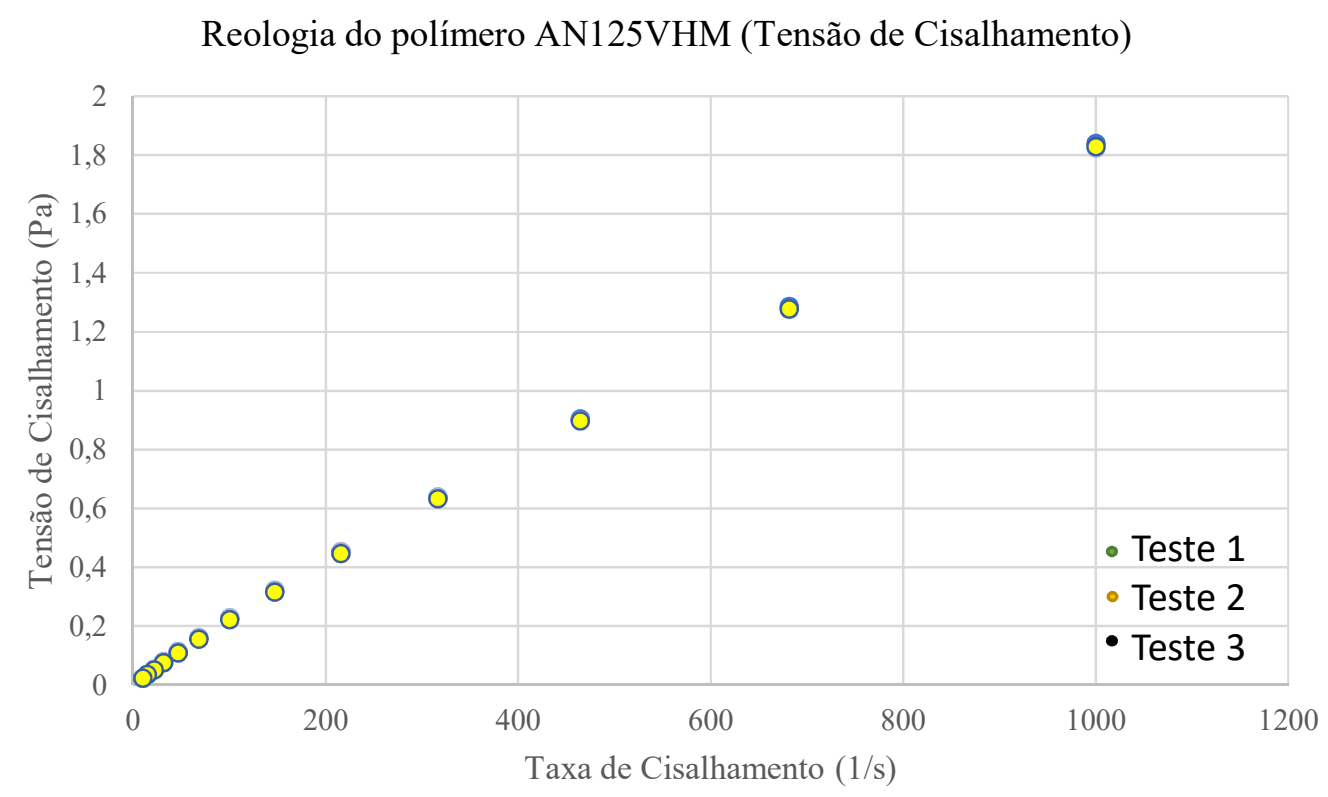

Figura 23 - Caracterização reológica da solução polimérica AN125VHM de 1g/L (1000 ppm) (dados de tensão de cisalhamento).

A partir das Fig. 22 e 23, é possível notar que para valores de taxa de cisalhamento menores que $100 \mathrm{~s}^{-1}$ os valores medidos em cada experimento apresentam uma pequena variação. Isso ocorre em virtude da baixa viscosidade da solução, o que gera um valor de torque muito baixo na geometria do equipamento. Mesmo com esses resultados ligeiramente distintos, pode-se notar que as curvas tendem a um comportamento único.

O modelo reológico mais compatível com as curvas apresentadas foi o modelo de Cross, que apresentou o índice $\mathrm{n}=0,749$ como mostrado na Fig. 24. Esse índice será utilizado em dois diferentes modelos para calcular a taxa de cisalhamento sofrida pelo fluido dentro do meio poroso. A partir da taxa de cisalhamento será possível estimar o valor de viscosidade real da solução polimérica ao passar pela rocha. A Fig. 24 também traz os valores máximos e mínimos de viscosidade que a solução polimérica pode assumir para o seguinte modelo adotado. 


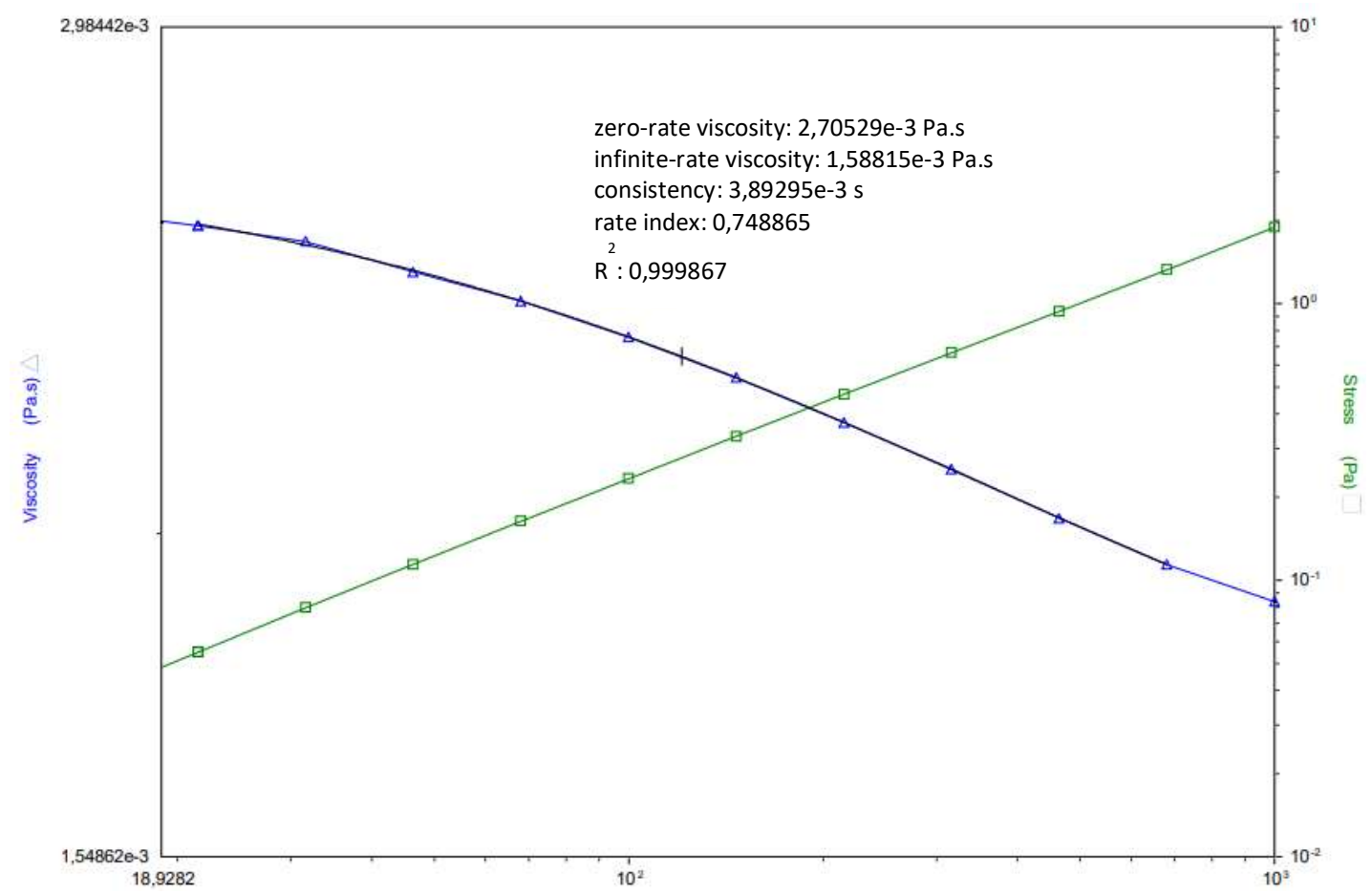

Figura 24 - Análise do ajuste do modelo matemático de Cross e seus devidos índices.

Os valores de viscosidade obtidos no reômetro rotacional foram comparados aos resultados do viscosímetro capilar. De acordo com os cálculos efetuados com as dimensões do capilar de vidro utilizado, o valor da taxa de cisalhamento gerada no escoamento através do capilar foi de, aproximadamente, $1000 \mathrm{~s}^{-1}$. A Tabela 3 exibe os valores de densidade, viscosidade cinemática e viscosidade dinâmica da solução polimérica $\mathrm{AN} 125 \mathrm{VHM}$ de $1 \mathrm{~g} / \mathrm{L}$ à temperatura de $40^{\circ} \mathrm{C}$ e taxa de cisalhamento de $1000 \mathrm{~s}^{-1}$.

\begin{tabular}{cccc}
\hline Amostra & $\begin{array}{c}\text { Densidade } \\
(\mathbf{g} / \mathbf{c m} 3)\end{array}$ & $\begin{array}{c}\text { Viscosidade Cinemática } \\
(\mathbf{m m} \mathbf{m} / \mathbf{s})\end{array}$ & $\begin{array}{c}\text { Viscosidade Dinâmica } \\
\text { (cP) }\end{array}$ \\
\hline AN125VHM & 1,0575 & 1,7950 & 1,8988
\end{tabular}

Tabela 3 - Reologia viscosímetro capilar da solução polimérica AN125VHM 1g/L. 
A Tabela 4 traz os dados obtidos no reômetro rotacional de um dos testes realizados. Nota-se que para o valor de taxa de cisalhamento de $1000^{\mathrm{s}-1}$, o valor da viscosidade é muito similar ao valor obtido no viscosímetro capilar.

\begin{tabular}{ccccccc}
\hline $\begin{array}{c}\text { Stress } \\
\mathbf{( P a )}\end{array}$ & $\begin{array}{c}\text { Shear rate } \\
\left.\mathbf{( s}^{-1}\right)\end{array}$ & $\begin{array}{c}\text { Viscosity } \\
\mathbf{( P a . s )}\end{array}$ & $\begin{array}{c}\text { Step time } \\
(\mathbf{s})\end{array}$ & $\begin{array}{c}\text { Temperature } \\
\left({ }^{\circ} \mathbf{C}\right)\end{array}$ & $\begin{array}{c}\text { Normal } \\
\text { stress }(\mathbf{P a})\end{array}$ & $\begin{array}{c}\text { Torque } \\
(\boldsymbol{\mu N . m )}\end{array}$ \\
\hline $\mathbf{1 , 8 3 9 5 4}$ & 1000,02 & 0,00184 & 51,1837 & 40,047 & 18,378 & 45,1492 \\
\hline $\mathbf{1 , 2 8 6 0 8}$ & 681,334 & 0,001888 & 102,383 & 39,952 & 31,9223 & 31,5651 \\
\hline $\mathbf{0 , 9 0 4 1 6 3}$ & 464,179 & 0,001948 & 153,567 & 40,063 & 44,19 & 22,1915 \\
\hline $\mathbf{0 , 6 3 9 1 5 4}$ & 316,226 & 0,002021 & 204,75 & 40,034 & 50,1906 & 15,6872 \\
\hline $\mathbf{0 , 4 5 3 0 2 3}$ & 215,464 & 0,002103 & 245,903 & 39,993 & 52,6715 & 11,1189 \\
\hline $\mathbf{0 , 3 2 0 8 1 1}$ & 146,797 & 0,002185 & 297,071 & 39,944 & 51,1136 & 7,8739 \\
\hline $\mathbf{0 , 2 2 6 8 6 9}$ & 100,003 & 0,002269 & 338,177 & 40,021 & 49,6579 & 5,5682 \\
\hline $\mathbf{0 , 1 5 9 1 6 9}$ & 68,1332 & 0,002336 & 389,345 & 39,996 & 46,4086 & 3,90659 \\
\hline $\mathbf{0 , 1 1 1 7 3 7}$ & 46,4195 & 0,002407 & 430,467 & 40,041 & 43,7795 & 2,74244 \\
\hline $\mathbf{0 , 0 7 8 0 4 1}$ & 31,6243 & 0,002468 & 471,636 & 40,067 & 41,0755 & 1,91541 \\
\hline $\mathbf{0 , 0 5 3 4 7 3}$ & 21,5466 & 0,002482 & 522,788 & 39,921 & 43,3706 & 1,31242 \\
\hline $\mathbf{0 , 0 3 6 0 6 2}$ & 14,6794 & 0,002457 & 644,156 & 40,033 & 35,2845 & 0,885102 \\
\hline $\mathbf{0 , 0 2 4 2 2 3}$ & 10,0001 & 0,002422 & 765,478 & 40,034 & 22,2242 & 0,594524 \\
\hline
\end{tabular}

Tabela 4 - Dados reômetro rotacional.

Os modelos reológicos utilizados para estimar a taxa de cisalhamento $(\dot{\gamma})$ na solução polimérica dentro da amostra foram os de Christopher e Middleman (1965) e o de Littmann (1988), que são apresentados, respectivamente, nas Eq. 14 e 15.

$$
\begin{aligned}
& \dot{\gamma}=\frac{12}{\sqrt{150}} \frac{3 n+1}{4 n} \frac{v}{\left(k_{p} \Phi\right)^{0.5}} \\
& \dot{\gamma}=\sqrt{2} \frac{3 n+1}{4 n} \frac{v}{\left(k_{p} \Phi\right)^{0.5}}
\end{aligned}
$$


Sendo:

- $\quad n$ - o índice de potência obtido através de análise no reômetro;

. $v$ - a velocidade de Darcy $(\mathrm{m} / \mathrm{s})$

- $k_{e f p}$ - a permeabilidade efetiva da solução polimérica $(\mathrm{mD})$;

- $\Phi$ - a porosidade da amostra.

Os valores de viscosidade calculados a partir da taxa de cisalhamento estimada para o meio poroso pelos modelos citados acima foram comparados com os resultados obtidos diretamente através da lei de Darcy utilizando-se os parâmetros fornecidos durante a injeção das soluções nas amostras. A importância do conhecimento dessa propriedade dos polímeros ao passarem pelo meio poroso é fundamental para a replicação nas amostras de solução de água de Peregrino e glicerina. Os cálculos de taxa de cisalhamento, bem como as quantidades de produtos utilizados na mistura de cada solução, serão apresentados juntamente com os resultados no capítulo 5.

\subsubsection{3}

\section{Solução de água de Peregrino e glicerina}

A glicerina tem origem no óleo vegetal e é um coproduto do processamento de biodiesel. O aumento nacional da produção de biodiesel tem, consequentemente, aumentando a oferta do produto no mercado brasileiro, resultando em novas possibilidades de aplicação. A utilização da glicerina como método de recuperação avançada já é algo presente na indústria do petróleo. Assim como os polímeros, a glicerina pode aumentar a viscosidade da solução aquosa, melhorando a razão de mobilidade entre os fluidos e aumentando a eficiência do varrido. Além desse benefício, a glicerina não apresenta altos níveis de toxicidade, diminuindo os efeitos gerados ao meio ambiente (VELOSO, 2014).

No presente trabalho a solução de água de Peregrino e glicerina foi produzida com a finalidade de aumentar a viscosidade da solução aquosa, igualando-se aos valores da viscosidade aparente encontrados da solução polimérica ao atravessar o 
meio poroso. Logo, cada teste contou com composições diferentes da solução injetada, pois a viscosidade da solução polimérica estava diretamente relacionada com as características de cada amostra e condições experimentais.

A solução de glicerina foi preparada através da diluição da glicerina pura em água de Peregrino 100\%. Para garantir a homogeneidade da solução, realizou-se a mistura com o auxílio do agitador magnético por um período de $2 \mathrm{~h}$. Após esse período, determinou-se a viscosidade do fluido no reômetro rotacional, que apresentou um comportamento de fluido Newtoniano.

\subsubsection{4}

Óleo

O óleo utilizado nos experimentos de recuperação foi o AGECOM 500PS. Trata-se de um óleo de base parafínica de origem mineral. Possui aparência límpida de coloração clara amarelada. As Fig. 25 e 26 trazem a caracterização reológica do óleo AGECOM 500PS, realizada no reômetro rotacional à temperatura de $40^{\circ} \mathrm{C}$. Diferentemente da solução polimérica, o óleo apresenta comportamento de fluido Newtoniano, apresentando um valor de viscosidade praticamente fixo para a faixa de taxa de cisalhamento estudada. 


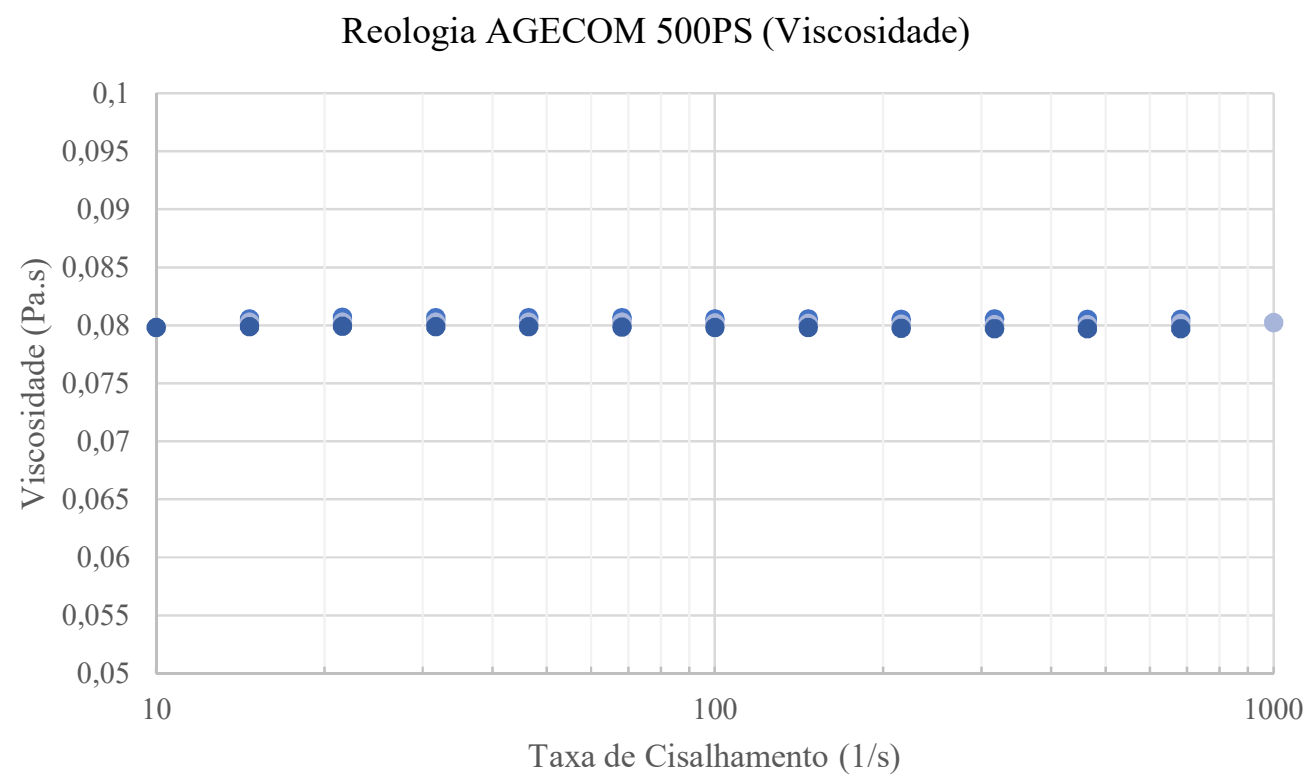

Figura 25 - Caracterização reológica do AGECOM 500PS (Viscosidade).

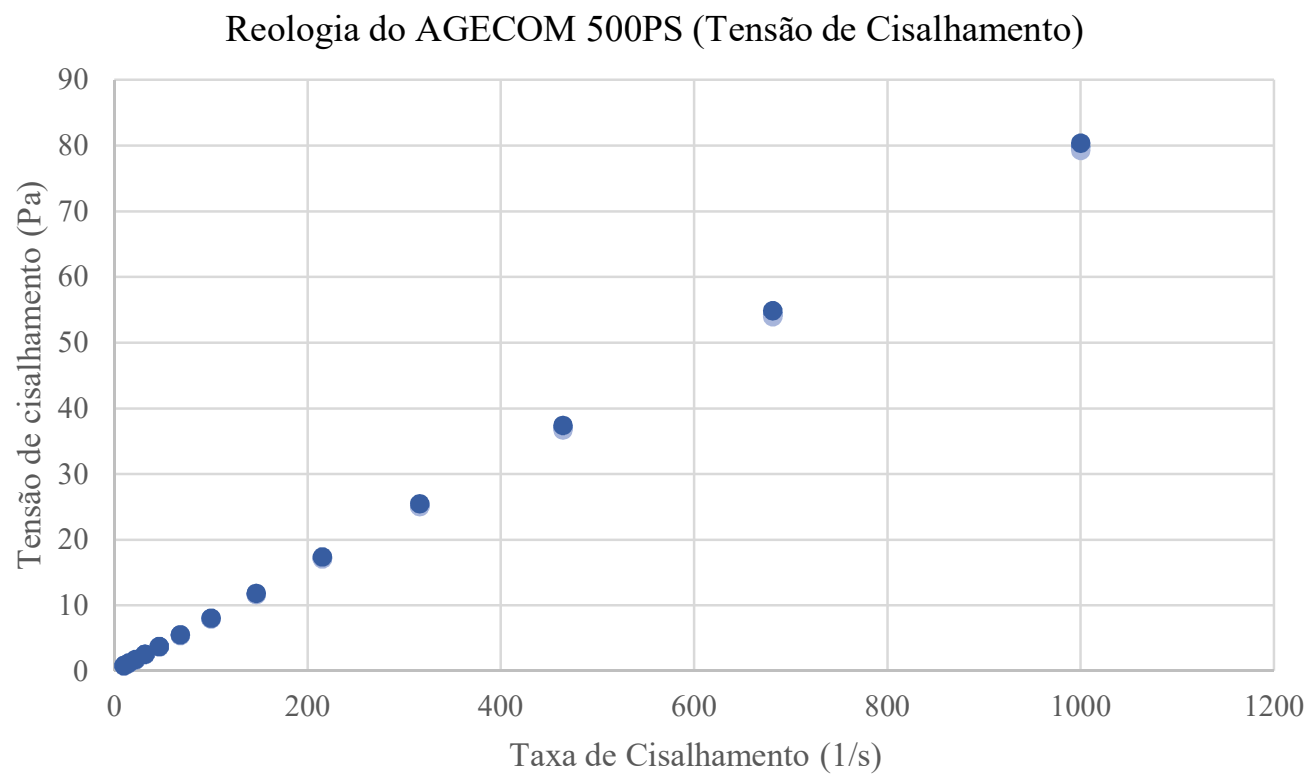

Figura 26 - Caracterização reológica do AGECOM 500PS (Tensão de Cisalhamento).

Assim como foi realizado com a solução polimérica, uma contraprova foi efetuada no viscosímetro capilar. A Tabela 5 mostra os valores de densidade, viscosidade cinemática e viscosidade dinâmica do óleo AGECOM 500PS à temperatura de $40^{\circ} \mathrm{C}$. 


\begin{tabular}{cccc}
\hline Amostra & $\begin{array}{c}\text { Densidade } \\
(\mathbf{g} / \mathbf{c m} 3)\end{array}$ & $\begin{array}{c}\text { Viscosidade Cinemática } \\
(\mathbf{m m} \mathbf{2} / \mathbf{s})\end{array}$ & $\begin{array}{c}\text { Viscosidade Dinâmica } \\
\text { (cP) }\end{array}$ \\
\hline $\mathbf{5 0 0 P S}$ & 0,8725 & 92,7537 & 80,9286 \\
\hline
\end{tabular}

Tabela 5 - Reologia do óleo AGECOM 500PS obtido em viscosímetro capilar.

\subsection{2}

\section{Amostras de Rocha}

Para a realização dos experimentos foram utilizadas amostras de 3 tipos de formações diferentes. As amostras foram adquiridas na empresa Kocurek Industries INC. São provenientes de afloramentos localizados na América do Norte, e possuem características similares com as formações encontradas em rochas reservatório. Foram fornecidas em tarugos de 1,5 polegadas de diâmetro e 12 polegadas de comprimento, que posteriormente foram divididos em 3 pedaços iguais, ficando com tamanhos aproximados de 4 polegadas.

Os equipamentos utilizados para preparo das amostras foram:

1. Paquímetro - 1101-200 - INSIZE

2. Balança - Adventure Pro - OHAUS

3. Bomba a vácuo - R-300 - BOECO

4. Dessecador

5. Estufa - 400/1ND - NOVA ETICA

6. Serra Mármore - MAKITA

Os corpos de prova disponíveis em laboratório para os experimentos são rochas sedimentares do tipo arenito, nos modelos Bentheimer, Gray Berea e Buff Berea. A escolha dessas amostras foi feita para analisar a influência das soluções nos diferentes tipos de rocha. A seguir, nas Tabelas 6, 7, 8 e 9, estão listadas as procedências, características mineralógicas, as dimensões e propriedades petrofísicas de cada amostra. 


\begin{tabular}{cccc}
\hline Características & Buff Berea & Gray Berea & Bentheimer \\
\hline Identificação & SS-104 & SS-103 & SS-102 \\
\hline Formação & Upper Devonian & Upper Devonian & Valaginian \\
\hline Permeabilidade & $150-350 \mathrm{mD}$ & $80-120 \mathrm{mD}$ & $1500-3500 \mathrm{mD}$ \\
\hline Porosidade & $20-22 \%$ & $18-21 \%$ & $23-26 \%$ \\
\hline Confinamento & $3800-4500$ PSI & $6500-8000$ PSI & $3500-4500$ PSI \\
\hline Homogeneidade & SIM & SIM & SIM
\end{tabular}

Tabela 6 - Características das amostras disponíveis para teste (Kocurek Industries INC).

\begin{tabular}{lc}
\hline \multicolumn{2}{c}{ Gray Berea Mineralogia } \\
\hline Sílica & $93,13 \%$ \\
\hline Alumina & $3,86 \%$ \\
\hline Óxido Férrico & $0,11 \%$ \\
\hline Óxido Ferroso & $0,54 \%$ \\
\hline Óxido de Magnésio & $0,25 \%$ \\
\hline Óxido de Cálcio & $0,10 \%$ \\
\hline Tabela 7 - Caracterização mineralógica da Gray Berea (Kocurek Industries INC). \\
\\
\hline \begin{tabular}{l} 
Quartzo (SiO ${ }_{2}$ ) \\
\hline Feldspato Plagioclásio
\end{tabular} \\
\hline Feldspato Potássio & $83,00 \%$ \\
\hline Caulinita & $1,00 \%$ \\
\hline Clorites & $2,00 \%$ \\
\hline Mica e/ou llita & $4,00 \%$ \\
\hline Camada misturada llita>95/Esmectita $<5$ & traço \\
\hline Tabela 8 - Caracterização mineralógica da Buff Berea (Kocurek Industries INC).
\end{tabular}




\begin{tabular}{lc}
\hline \multicolumn{2}{c}{ Bentheimer Mineralogia } \\
\hline Quartzo $\left(\mathrm{SiO}_{2}\right)$ & $95,00 \%$ \\
\hline Feldspato Plagioclásio & traço \\
\hline Feldspato Potássio & $2,00 \%$ \\
\hline Caulinita & $2,00 \%$ \\
\hline Clorites & nd \\
\hline Mica e/ou llita & traço \\
\hline Camada misturada llita>95/Esmectita $<5$ & nd \\
\hline \multicolumn{2}{c}{ Tabela 9 - Caracterização mineralógica da Bentheimer (Kocurek Industries INC). }
\end{tabular}

Não foi possível realizar maiores estudos sobre as propriedades petrofísicas das rochas utilizadas nos experimentos, mas segundo Palombo (2017), que realizou análises de porosimetria em amostras de Bentheimer e Gray Berea, o diâmetro de poro médio para essas formações é de 3533,1 nm e 460,6 nm, respectivamente.

Após o corte, o procedimento de preparo foi basicamente o mesmo. As amostras eram limpas com jatos de ar comprimido, para retirar o excesso de material particulado do corte, e levadas à estufa para secagem. De acordo com a norma APIRP-40 (1998), a temperatura máxima para secagem de arenitos em estufa convencional é de $116^{\circ} \mathrm{C}$. Os valores utilizados para Bentheimer, Gray Berea e Buff Berea foi de $80^{\circ} \mathrm{C}$. O tempo total de permanência dentro da estufa foi de $12 \mathrm{~h}$, para garantir que toda umidade fosse removida.

Em seguida, com as amostras secas, foi medido a massa seca com o auxílio de uma balança de precisão localizada em ambiente controlado. Essa propriedade da rocha é de fundamental importância para o cálculo da quantidade de material adsorvido. Posteriormente, a amostra foi saturada com a solução de água de Peregrino, que já havia sido borbulhada com gás argônio através do seguinte procedimento: a amostra foi posicionada em um béquer, que foi preenchido com a solução salina de modo a cobrir toda a superfície da amostra; esse conjunto foi levado à uma câmara de vácuo, na qual permaneceu por $12 \mathrm{~h}$ para garantir a saturação completa. Após a saturação, 
realizou-se a medição da massa úmida da amostra. Com esses dados, foi possível calcular o volume poroso (VP) da amostra a partir da Eq. 16.

$$
V P=\frac{m_{u}-m_{s}}{\rho_{w}}
$$

Sendo:

- $\quad m_{u}$ - massa úmida da amostra $(\mathrm{g})$;

- $m_{s}$ - massa seca da amostra $(\mathrm{g})$;

- $\rho_{w}$ - densidade da água de Peregrino $\left(\mathrm{g} / \mathrm{cm}^{3}\right)$.

Assim, a amostra estava pronta para a realização do experimento.

\section{2}

\section{Protocolo dos Testes}

Todos os testes foram realizados nas seguintes condições:

- Temperatura: $40^{\circ} \mathrm{C}$;

- Pressão de Confinamento: 1500 PSI (Pressão manométrica);

- Contrapressão (Pressão de Poro): 60 PSI (Pressão manométrica).

\subsection{1}

\section{Procedimentos Primários}

O processo de preparo da bancada experimental é um procedimento vital para o experimento. $\mathrm{O}$ correto funcionamento dos equipamentos que foram utilizados era conferido antes do início de todos os experimentos realizados. A seguir estão listados os itens que eram vistoriados. 
· Calibração do sistema de coleta de dados;

- Calibração das bombas de injeção;

- Limpeza das linhas com água deionizada;

- Estanqueidade do sistema;

- Funcionamento do sistema de resfriamento e aquecimento;

- Funcionamento das válvulas;

- Verificação do reservatório de alimentação das bombas;

- Quantificação do volume morto das linhas ${ }^{3}$.

Por fim, os cilindros eram preenchidos com as soluções, que foram previamente saturadas com a injeção de argônio, e conectados ao sistema para saturação das linhas de injeção. Após todo esse processo, dava-se início ao teste.

\subsection{2}

\section{Adsorção de Polímeros}

\subsubsection{1}

\section{Aparato Experimental}

O sistema de injeção de fluidos em amostras tem a função de simular as condições de pressão e temperatura encontradas nas rochas reservatório. Trata-se de um conjunto completamente ajustável ao tipo de trabalho a ser realizado, podendo oferecer infinitas configurações. Após um longo período de testes e adaptações, chegou-se ao esquema mostrado na Fig. 27. Todas as partes que estavam em contato com as soluções na parte de dentro da estufa foram fabricadas com material não metálico para evitar a oxidação e corrosão.

\footnotetext{
${ }^{3} \mathrm{O}$ volume morto das linhas foi contabilizado e descontado, sempre que preciso, em todos testes realizados.
} 


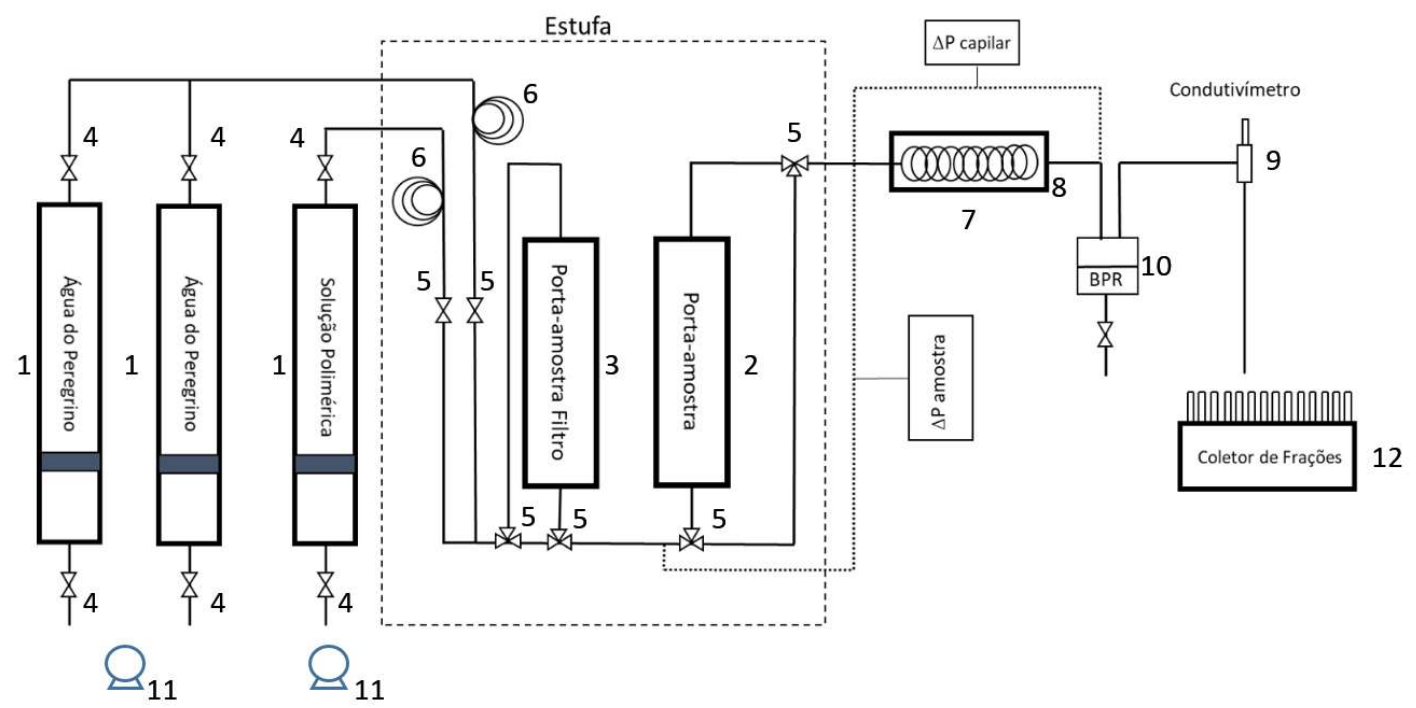

Figura 27 - Esquema do aparato experimental utilizado para os testes de adsorção.

O esquema mostrado acima era composto pelos seguintes itens:

1. Cilindros acumuladores de $500 \mathrm{~mL}$ - Cilindros fabricados em aço inoxidável que exercem a função de pistões de injeção das soluções de trabalho;

2. Porta-amostra - Equipamento fabricado em aço inoxidável com luva interna de borracha nitrílica para acomodar a amostra e aplicar a pressão de confinamento (sobrepeso);

3. Porta-amostra filtro - Possui as mesmas características do porta-amostra principal, mas acomoda uma amostra-filtro, para filtrar e assegurar que a solução polimérica chegará livre de grumos ao corpo de prova.

4. Válvulas de 2 e 3 vias (inox) - Swagelok - Utilizadas para controlar o fluxo das soluções fora da estufa;

5. Válvula de 2 e 4 vias (peek) - Idex - Utilizadas para controlar o fluxo das soluções dentro da estufa;

6. Trocadores de Calor - Serpentinas com 10 metros de comprimento e diâmetro interno de 1/16", fabricadas em nylon, para garantir a troca de calor das soluções dentro da estufa. 
7. Medidor de Concentração - Sistema composto por um tubo de 4 metros de comprimento e diâmetro interno de 1/32" e transdutores de pressão. Utilizado para gerar um diferencial de pressão entre a entrada e saída, que posteriormente será relacionado com a concentração da solução polimérica.

8. Banho termostático - Utilizado para manter a temperatura da serpentina constante $\left(20^{\circ} \mathrm{C}\right)$ e reduzir a temperatura do fluido, promovendo um diferencial de pressão maior.

9. Medidor de Condutividade - $914 \mathrm{pH} /$ conductivity meter (Metrohm) Condutivímetro conectado em linha para medir a condutividade da solução em tempo real.

10. Válvula de contrapressão (BPR): Utilizada para manter a pressão interna do sistema (pressão de poro).

11. Bombas de injeção contínua - 515 HPLC (Waters) - Utilizadas para aplicar pressão de confinamento e deslocar os fluidos armazenados nos acumuladores.

12. Coletor de Frações - FRAC 920 (GE) - Utilizado para coletar frações em tempos regulares dos fluidos produzidos pelo experimento.

13. Estufa - Ethik - Utilizada para manter as condições de temperatura do teste.

14. Transdutores de pressão (Velki) - Utilizados para coletar dados de pressão em determinados pontos do experimento.

\subsubsection{2}

\section{Protocolo do Teste de Adsorção}

Os testes de quantificação de material adsorvido foram realizados nos três tipos de amostras disponíveis, de maneira individual, utilizando-se o Two Slug Method, descrito na subseção 2.3.1.

Com os testemunhos preparados e acondicionados dentro dos porta-amostras, aplicou-se a pressão de confinamento e deu-se início ao processo de aquecimento. Durante esse processo, foi feita a primeira saturação (WF1) com água de Peregrino para remoção de finos decorrentes do corte e até mesmo da própria formação. Após alguns volumes porosos injetados e com os valores de pressão e temperatura estáveis, 
deu-se início ao procedimento de obtenção da permeabilidade absoluta inicial à solução salina através da medição do diferencial de pressão para diferentes vazões impostas.

A partir dessa metodologia, é possível alcançar uma relação entre a vazão e o diferencial de pressão resultante que é expressa pela Lei de Darcy. Visto isso, a Eq. 17 fica da seguinte forma:

$$
k=\frac{\mu L}{A(d P / d Q)}
$$

Sendo $d P / d Q$ a inclinação da reta traçada com os valores de vazão e diferencial de pressão gerados pelo fluxo através da amostra.

Em seguida, realizou-se o procedimento para determinar a capacidade de adsorção de cada amostra, que determina a quantidade máxima de polímero que pode ficar retido na amostra com as condições utilizadas, pois não há qualquer tipo de interação com outro fluido durante a injeção. Os testes foram realizados a uma velocidade constante de $1 \mathrm{~m} /$ dia. A retenção polimérica é proporcional à taxa de injeção (IDAHOSA, 2016), logo, para eliminar essa variável, a vazão durante a injeção dos bancos de solução polimérica e de água de Peregrino não poderiam variar. O protocolo dos testes está resumido na Fig. 28. O volume injetado de cada banco de solução polimérica foi de $10 \mathrm{VP}$, já o volume de água de Peregrino foi de $40 \mathrm{VP}$. 


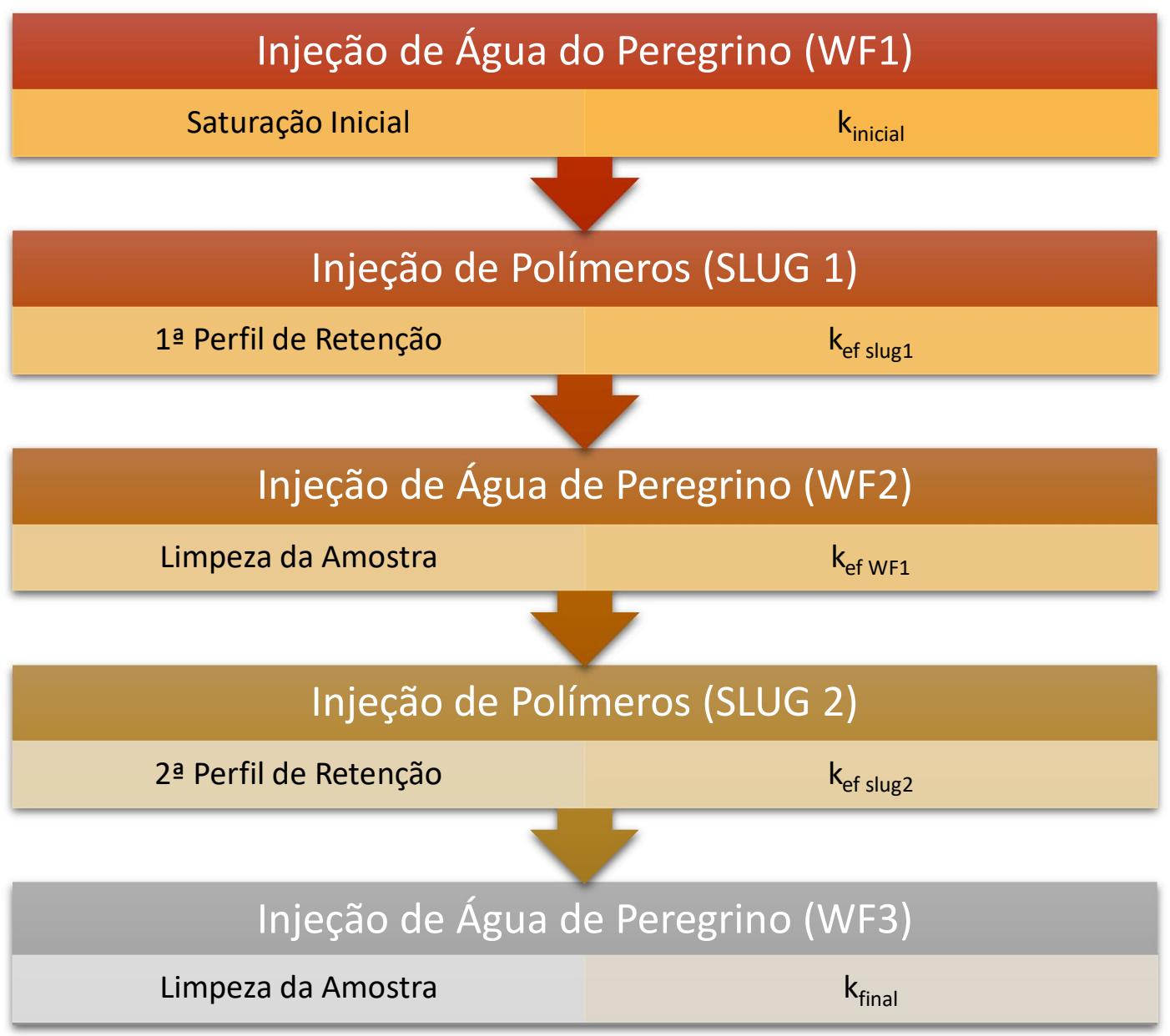

Figura 28 - Esquema do procedimento de adsorção polimérica. 
4.2.3

Recuperação de Óleo com Água de Peregrino, Solução de Glicerina e Solução Polimérica

\subsubsection{1}

\section{Aparato Experimental}

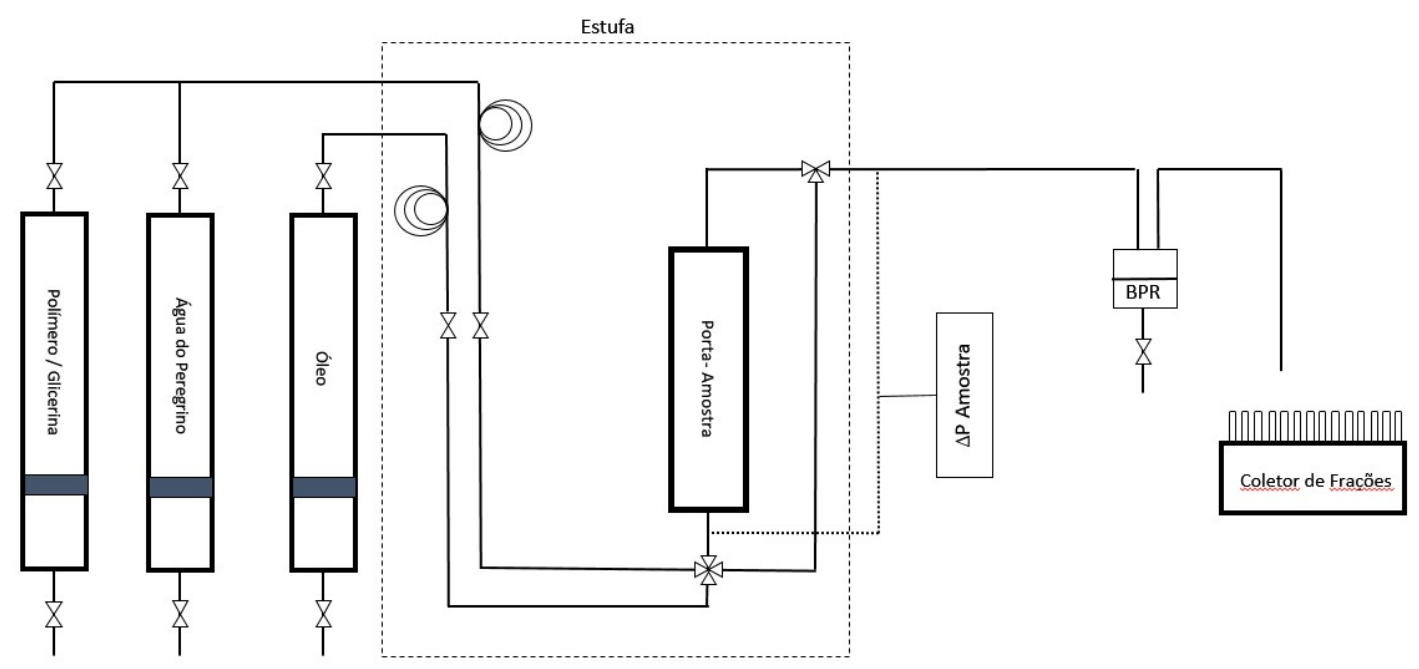

Figura 29 - Esquema do aparato experimental utilizado para os testes de adsorção.

A principal alteração no sistema de injeção utilizado nos testes de recuperação, apresentado na Fig. 29, foi a remoção de alguns equipamentos, tais como: o portaamostra filtro, o sistema de dados de concentração e o sistema de dados de condutividade.

Assim como nos testes de adsorção, o procedimento de recuperação de óleo utilizou mais uma parcela das amostras de Bentheimer, Gray Berea e Buff Berea. A atividade foi executada em sequência com a injeção de 3 tipos de soluções diferentes: água de Peregrino, solução de água de Peregrino com glicerina e solução polimérica. 
O objetivo dessa etapa foi avaliar o deslocamento de óleo ocasionado por cada fluido, compará-los e relacioná-los com os resultados obtidos pelos testes de adsorção e as propriedades dos fluidos injetados.

Igualmente ao protocolo anterior, todo o experimento foi realizado à uma taxa de injeção constante de $1 \mathrm{~m} / \mathrm{d}$, de maneira contínua, para evitar que os fatores relacionados a variação da velocidade do fluido afetassem o seu processo de deslocamento no meio poroso e criassem novas incógnitas.

O experimento foi dividido em 2 etapas e contou com um total de 15 processos de recuperação realizados em 6 amostras diferentes. $\mathrm{Na}$ primeira etapa, foram utilizadas todas as 3 soluções, na seguinte sequência: primeiro a recuperação com água de Peregrino seguida pela recuperação com solução de glicerina e, por fim, a solução polimérica. A segunda fase foi realizada para verificar uma possível influência ocasionada pela injeção da solução de glicerina nas etapas subsequentes, sendo utilizados somente água de Peregrino e solução polimérica. A seguir estão descritos, detalhadamente, o protocolo de cada teste.

\subsubsection{2}

\section{Protocolo 1}

O protocolo 1 é referente à primeira etapa de recuperação de óleo. Com o objetivo de minimizar as possíveis variáveis que poderiam alterar os fatores de recuperação e manter um padrão inicial, as injeções das 3 soluções diferentes foram realizadas de maneira sequencial em cada amostra.

Antes da realização do experimento nas rochas selecionadas para o trabalho, foi feito um teste para verificar se essa metodologia poderia propagar diferenças nos resultados nos processos de injeção subsequentes. O teste foi realizado em uma amostra de rocha Bentheimer e não apresentou nenhuma alteração significativa que pudesse interferir nos resultados finais. Porém, ao executar o experimento em rochas de menor valor de permeabilidade, Gray Berea e Buff Berea, percebeu-se uma modificação nos valores de pressão no processo de injeção de óleo que seguinte. Dessa forma, tornou- 
se necessário a realização de novos testes eliminando a fase de injeção da solução de glicerina e água de Peregrino, assim tornando possível uma comparação mais fiel dos resultados obtidos.

A sequência empregada durante o protocolo 1 foi a seguinte: injeção de água de Peregrino ( $1^{\mathrm{a}}$ embebição), injeção de óleo ( $1^{\mathrm{a}}$ drenagem), injeção de água de Peregrino ( $2^{\mathrm{a}}$ embebição), injeção de óleo ( $2^{\mathrm{a}}$ drenagem), injeção da solução composta de glicerina, injeção de água de Peregrino ( $3^{\mathrm{a}}$ embebição), injeção de óleo ( $3^{\mathrm{a}}$ drenagem), injeção de solução polimérica e injeção de água de Peregrino (4 embebição).

\subsubsection{1}

\section{Fase 1 - $1^{\text {a }}$ Embebição}

Após todos os processos de preparo da bancada experimental e das amostras já citados em itens anteriores, a $1^{\mathrm{a}}$ injeção de água de Peregrino teve como objetivo inicial a saturação final nas condições de temperatura e pressão do teste. Durante essa parte também foi realizada a curva de permeabilidade absoluta inicial dos corpos de prova.

Ao final da primeira embebição, a amostra encontrava-se totalmente saturada com água de Peregrino, $S_{w}=100 \%=S_{w f l}$.

Sendo:

- $S_{w}-$ Saturação de água;

- $S_{w f 1}-$ Saturação de água final da fase 1 .

\subsubsection{2}

\section{Fase $2-1^{\text {a }}$ Drenagem}

A $1^{\text {a }}$ injeção de óleo simula o processo de migração secundária do óleo na formação. Trata-se do percurso que o fluido faz desde a rocha geradora até encontrar uma armadilha geológica, que impedirá seu fluxo contínuo e promoverá a acumulação do óleo na rocha reservatório (THOMAS, 2004, RIOS, 2016). Inicialmente a rocha 
reservatório se encontra completamente saturada com água, que será deslocada pelo óleo até atingir a saturação de água irredutível.

No experimento, a injeção de óleo ocorreu até que a produção de água fosse completamente finalizada e o diferencial de pressão na amostra estivesse constante. Durante a injeção, toda a produção foi recebida pelo coletor de frações para que o volume de cada fluido fosse quantificado.

Ao cessar a produção de água, a amostra encontra-se em um estado equivalente à condição original de um reservatório. Tem-se então a saturação de água imóvel ou conata da formação $\left(S_{w f 2}=1-S_{o f 2}\right)$. Nesse momento, calcula-se a permeabilidade efetiva do óleo $\left(k_{e f o 2}\right)$. A partir desse ponto, as saturações finais de cada fase serão iguais as saturações iniciais da fase seguinte, ou seja, $S_{o f 2}=S_{o i 3}$.

Os volumes finais dessa fase são: $V_{o f 2}=N_{w 2} ; V_{w f 2}=V_{w i 2}-N_{w 2}$.

Sendo:

- $S_{o f 2}$ - Saturação de óleo final da fase 2;

- $S_{w f 2}$ - Saturação de água final da fase 2 (Saturação de água imóvel);

- $S_{o i 3}$ - Saturação de óleo inicial da fase 3;

- $\quad V_{o f 2}-$ Volume de óleo final da fase 2;

- $\quad V_{w i 2}-$ Volume de água inicial da fase 2;

- $\quad V_{w f 2}-$ Volume de água final da fase 2;

- $\quad N_{w 2}$-Produção de água da fase 2;

- $k_{e f o 2}$ - Permeabilidade efetiva a óleo da fase 2.

\subsubsection{3}

\section{Fase 3 - $2^{\mathrm{a}}$ Embebição}

A $2^{\mathrm{a}}$ embebição trata-se da primeira etapa de recuperação de óleo da amostra, através do método convencional de injeção de água. Nessa fase, a saturação inicial de água é igual a saturação de água contada da fase anterior $\left(S_{w i 3}=S_{w f 2}\right)$, e a saturação inicial de óleo é a fração restante $\left(S_{o i 3}=1-S_{w f 2}\right)$. A injeção de água de Peregrino é 
realizada até que a produção de óleo seja nula e o diferencial de pressão estabilize, nesse momento atinge-se a saturação de óleo residual $\left(S_{o r 3}=S_{o f 3}\right)$.

Os volumes finais dessa fase são: $V_{o f 3}=V_{o i 3}-N_{o 3} ; V_{w f 3}=V_{w i 3}+N_{o 3}$.

Após o cessar da produção de óleo e com o diferencial de pressão estável, calcula-se a permeabilidade efetiva à água da amostra $\left(k_{e f w 3}\right)$. O valor de permeabilidade nesse momento é um importante dado de entrada nos modelos de cálculo de taxa de cisalhamento no interior da amostra. Com esse parâmetro é possível calcular a viscosidade que a solução polimérica teria durante a injeção e, desse modo, produzir uma solução composta de glicerina e água de Peregrino com viacosidade similar.

Sendo:

- $S_{w i 3}$ - Saturação de água inicial da fase 3;

- $\quad S_{w f 2}$ - Saturação de água final da fase 2;

- $S_{o i 3}$ - Saturação de óleo inicial da fase 3;

- $S_{o r 3}$ - Saturação de óleo residual da fase 3;

- $S_{o f 3}$-Saturação de óleo final da fase 3;

- $\quad V_{o i 3}$ - Volume de óleo inicial da fase 3;

- $\quad V_{o f 3}-$ Volume de óleo final da fase 3;

- $\quad V_{w i 3}-$ Volume de água inicial da fase 3 ;

- $\quad V_{w f 3}-$ Volume de água final da fase 3;

- $\quad N_{o 3}$-Produção de óleo da fase 3;

- $\quad k_{\text {efw3 }}$ - Permeabilidade efetiva à água da fase 3 .

\subsubsection{4}

\section{Fase 4 - $2^{\mathrm{a}}$ Drenagem}

A $2^{\mathrm{a}}$ injeção de óleo tem como objetivo principal deslocar a água móvel que se encontra na amostra resultante do processo de recuperação realizado anteriormente, e 
tentar restabelecer o cenário original do reservatório. As condições iniciais das duas fases não necessariamente serão as mesmas devido a impossibilidade de se reverter por completo os processos de saturação. Porém, é possível a retomada de condições semelhantes para a realização de novos testes.

A saturações iniciais dessa fase são: $S_{w i 4}=S_{w f 3} ; S_{o i 4}=S_{o f 3}$.

Novamente, a injeção de óleo ocorre até o fim da produção de água e estabilização das pressões, quando é possível o cálculo da permeabilidade efetiva a óleo dessa fase $\left(k_{\text {efo }}\right)$.

Os volumes finais dessa fase são: $V_{o f 4}=V_{o i 4}+N_{w 4} ; V_{w f 4}=V_{w i 4}-N_{w 4}$.

Sendo:

- $\quad S_{w i 4}$ - Saturação de água inicial da fase 4;

- $S_{w f 3}$ - Saturação de água final da fase 3;

- $S_{o i 4}$-Saturação de óleo inicial da fase 4;

- $\quad V_{o i 4}-$ Volume de óleo inicial da fase 4;

- $\quad V_{o f 4}-$ Volume de óleo final da fase 4;

- $\quad V_{w i 4}$ - Volume de água inicial da fase 4;

- $\quad V_{w f 4}-$ Volume de água final da fase 4 ;

- $\quad N_{w 4}$ - Produção de água da fase 4;

- $\quad k_{\text {efo } 4}$ - Permeabilidade efetiva a óleo da fase 4 .

\subsubsection{5}

\section{Fase 5 - Injeção de Solução Composta de Glicerina}

A partir dessa fase, já ocorre a implementação dos mecanismos de recuperação avançada. De maneira a tentar reproduzir os experimentos o mais fiel possível à realidade das operações, foram injetados bancos de 4 volumes porosos das soluções composta de glicerina e soluções poliméricas. Esses bancos foram, posteriormente, deslocados por água de Peregrino até completar o limite de injeção estabelecido por cada fase de aproximadamente 15 volumes porosos. 
A saturações iniciais de fase são: $S_{w i 5}=S_{w f 4} ; S_{o i 5}=S_{o f 4}$.

Sendo:

- $\quad S_{w i 5}$ - Saturação de água inicial da fase 5;

- $S_{w f 4}$ - Saturação de água final da fase 4;

- $S_{o i 5}$-Saturação de óleo inicial da fase 5;

- $S_{o f 4}$-Saturação de óleo final da fase 4.

Os dados de produção foram contabilizados ao fim da próxima fase, na qual o processo de recuperação foi finalizado.

\subsubsection{6}

\section{Fase 6 - $3^{\text {a Embebição }}$}

A $3^{\mathrm{a}}$ injeção de água de Peregrino foi realizada para deslocar o banco de solução aquosa de glicerina que havia sido injetado e continuar a recuperação de óleo. Durante essa fase, foram injetados aproximadamente 11 volumes porosos de água.

Após a injeção do volume estabelecido, foi realizado o balanço de tudo que foi produzido e armazenado pelo coletor de frações e calculado o novo valor da permeabilidade efetiva à água da presente fase $\left(k_{\text {efwo }}\right)$.

Os volumes finais dessa fase são: $V_{o f 6}=V_{o i 6}-N_{o 5 / 6} ; V_{w f 6}=V_{w i 6}+N_{o 5 / 6}$.

Sendo:

- $\quad V_{\text {oir }}-$ Volume de óleo inicial da fase 6;

- $\quad V_{o f 6}-$ Volume de óleo final da fase 6;

- $\quad V_{w i 6}-$ Volume de água inicial da fase 6;

- $\quad V_{w f 6}$ - Volume de água final da fase 6;

- $N_{o 5 / 6}$ - Produção de óleo das fases 5 e 6;

- $\quad k_{\text {efw }}$ - Permeabilidade efetiva à água da fase 6 . 


\subsubsection{7}

\section{Fase 7 - $3^{a}$ Drenagem}

A $3^{\mathrm{a}}$ injeção de óleo teve, basicamente, a mesma função das duas que foram efetuadas anteriormente. As saturações iniciais dessa fase são: $S_{w i 7}=S_{w f \sigma ;} S_{o i 7}=S_{o f \sigma}$.

Com a obtenção das novas condições de saturação, calculou-se a permeabilidade efetiva a óleo da amostra para essa fase $\left(k_{e f w}\right)$. Após isso, a amostra encontra-se pronta para um novo procedimento de recuperação.

Os volumes finais dessa fase são: $V_{o f 7}=V_{o i 7}+N_{w 7} ; V_{w f 7}=V_{w i 7}-N_{w 7}$.

Sendo:

- $\quad S_{w i 7}$ - Saturação de água inicial da fase 7;

- $S_{w f 6}$ - Saturação de água final da fase 6;

- $S_{o i 7}$-Saturação de óleo inicial da fase 7;

- $S_{o f 6}$ - Saturação de óleo inicial da fase 6;

- $\quad V_{o i 7}-$ Volume de óleo inicial da fase 7;

- $\quad V_{o f 7}-$ Volume de óleo final da fase 7;

- $\quad V_{w i 7}$ - Volume de óleo inicial da fase 7;

. $\quad V_{w f 7}-$ Volume de óleo final da fase 7;

- $\quad N_{w 7}$ - Produção de água da fase 7 ;

- $k_{e f o 7}$ - Permeabilidade efetiva a óleo da fase 7.

\subsubsection{8}

\section{Fase 8 - Injeção de Solução Polimérica}

A injeção de solução polimérica foi a última metodologia a ser utilizada, visto que esse procedimento tem uma maior capacidade de produzir mudanças nas características originais do meio poroso.

Nessa fase o volume injetado foi de 4 volumes porosos, assim como foi realizado com a solução composta de glicerina. As saturações iniciais dessa fase são: $S_{w i 8}=S_{w f 7} ; S_{\text {oi8 }}=S_{\text {of } 7}$. 
Sendo:

- $S_{w i 8}$ - Saturação de água inicial da fase 8 ;

- $\quad S_{w f 7}$ - Saturação de água final da fase 7;

- $S_{o i 8}$-Saturação de óleo inicial da fase 8;

- $\quad S_{o f 7}-$ Saturação de óleo final da fase 7.

\subsubsection{9}

\section{Fase 9 - 4 $^{\mathrm{a}}$ Embebição}

A $4^{\mathrm{a}}$ injeção de água de Peregrino foi executada para deslocar o banco de solução polimérica através da rocha, removendo, posteriormente, parte do material que não foi adsorvido. Ao final desse processo, calculou-se os volumes produzidos e a permeabilidade efetiva da amostra $\left(k_{e f w}\right)$.

Os volumes finais dessa fase são: $V_{o f g}=V_{o i 9}-N_{o 8 / 9} ; V_{w f 9}=V_{w i 9}+N_{o 8 / 9}$.

De posse da nova permeabilidade foi possível calcular o fator de redução de permeabilidade, fato de resistência residual (FRR).

Sendo:

. $\quad V_{o i 9}-$ Volume de óleo inicial da fase 9;

- $\quad V_{o f 9}-$ Volume de óleo final da fase 9;

- $\quad V_{w i 9}-$ Volume de água inicial da fase 9;

- $\quad V_{w f 9}$ - Volume de água final da fase 9;

- $\quad N_{o 8 / 9}$ - Produção de óleo das fases 8 e 9;

- $\quad k_{e f w} 9$ - Permeabilidade efetiva à água da fase 9 .

A seguir, encontra-se o esquema ilustrativo do protocolo 1 de recuperação de óleo na Fig. 30. 


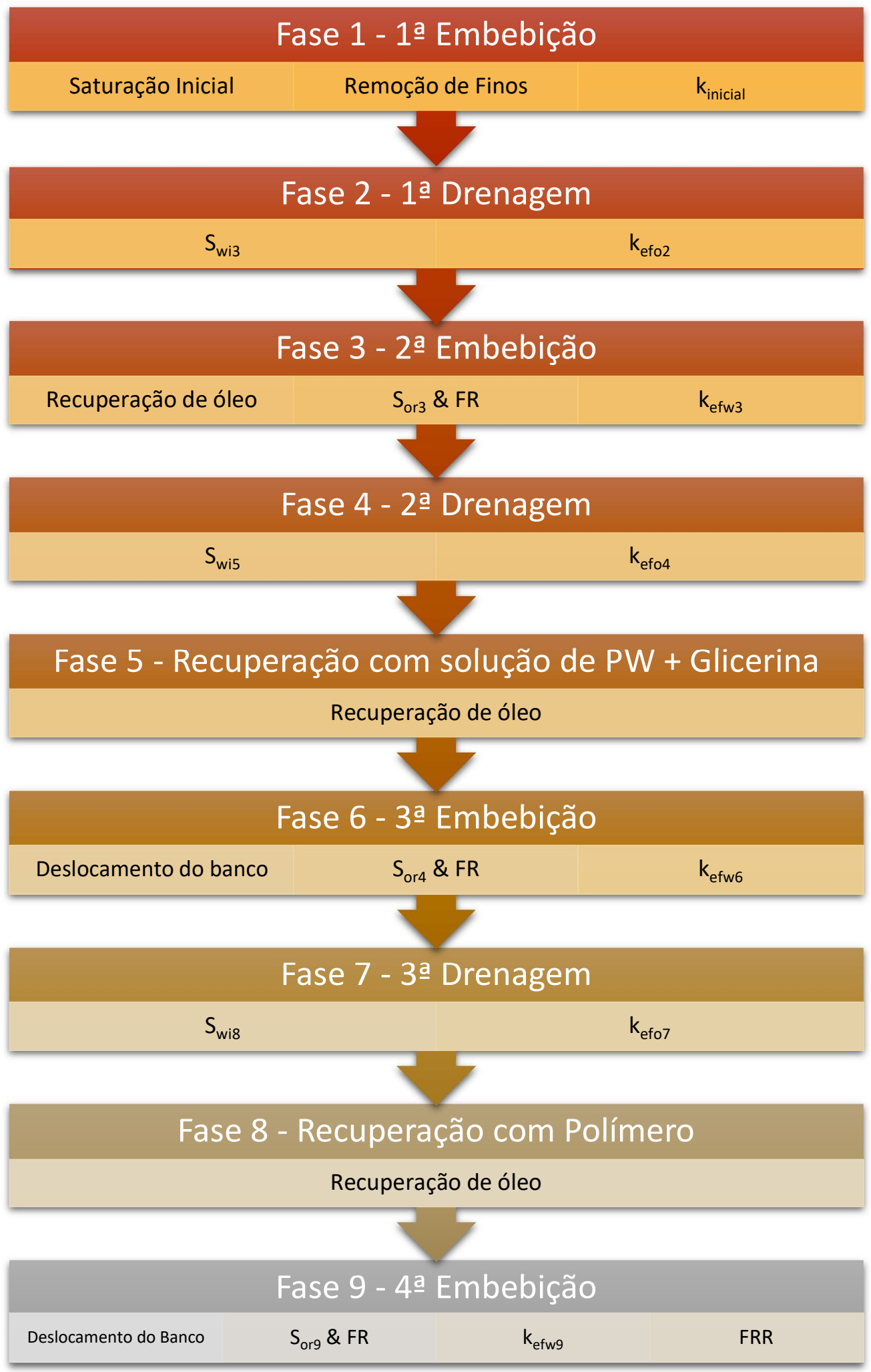

Figura 30 - Esquema do protocolo 1 de recuperação de óleo. 


\subsubsection{3}

\section{Protocolo 2}

O protocolo 2, referente à segunda etapa do processo de recuperação de óleo, foi realizado de maneira similar ao protocolo 1, porém sem as fases 5, 6 e 7, referentes ao processo de injeção de solução de glicerina. Logo, o protocolo ficou resumido ao esquema apresentado na Fig. 31.

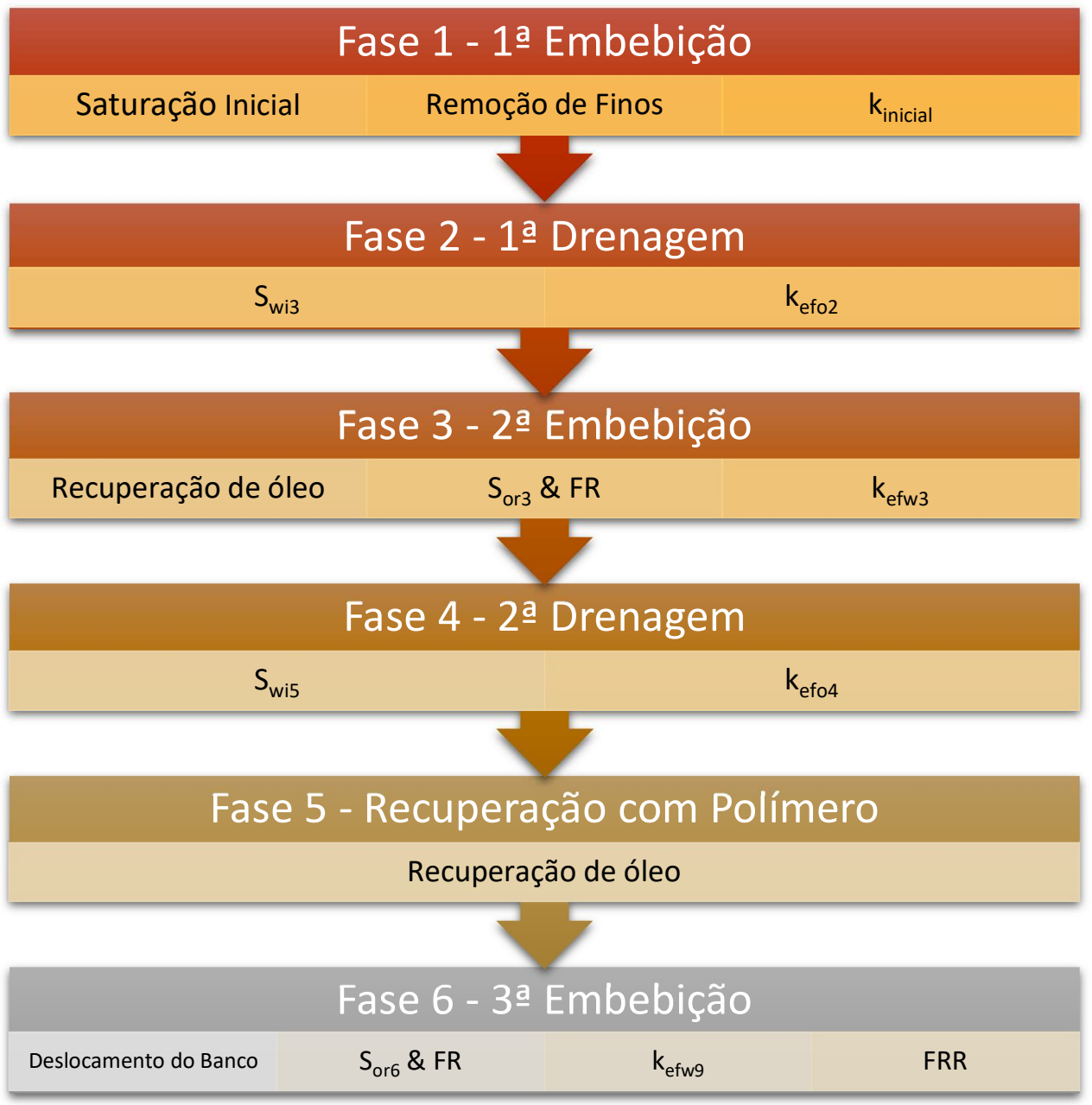

Figura 31 - Esquema do protocolo 2 de recuperação de óleo. 


\section{5}

\section{Resultados e Discussões}

Neste capítulo serão apresentados os resultados dos 3 procedimentos realizados durante a execução deste trabalho: adsorção polimérica, recuperação de óleo utilizando o protocolo 1 e recuperação de óleo através do protocolo 2 .

\section{1}

\section{Resultados dos Procedimentos de Adsorção}

A análise dos resultados será iniciada com os procedimentos de quantificação de material polimérico retido na amostra. Nesses testes foram utilizados apenas a solução salina e a solução polimérica. Como dito anteriormente, não há interferência de nenhum outro fluido durante a realização dessa técnica, logo, acredita-se que esse seria o cenário ideal para verificar o potencial de adsorção de cada corpo de prova nas condições preestabelecidas.

\subsection{1}

\section{Gray Berea (GBT2)}

Seguindo o protocolo de preparo descrito no capítulo 4, após o parcelamento, as amostras seguiam para o processo de caracterização. A Tabela 10 traz as características de propriedades petrofísicas da amostra de Gray Berea GBT2.

\begin{tabular}{cc}
\hline Código da Amostra & GBT2 \\
\hline Procedência & Gray Berea \\
\hline Diâmetro $(\mathrm{cm})$ & 3,787 \\
\hline
\end{tabular}




\begin{tabular}{cc}
\hline Área $\left(\mathrm{cm}^{2}\right)$ & 11,264 \\
\hline Comprimento $(\mathrm{cm})$ & 9,886 \\
\hline Volume $\left(\mathrm{cm}^{3}\right)$ & 111,353 \\
\hline Amostra seca $(\mathrm{g})$ & 236,10 \\
\hline Amostra Úmida $(\mathrm{g})$ & 257,90 \\
\hline Volume Poroso $(\mathrm{mL})$ & 20,87 \\
\hline Porosidade & 18,75 \\
\hline
\end{tabular}

Tabela 10 - Características e propriedades petrofísicas da amosta GBT2.

Essa formação, Gray Berea, é a de menor valor de permeabilidade dentre as que foram utilizadas nesse estudo, com média de $60 \mathrm{mD}$ para procedimentos realizados com solução salina.

A Fig. 32 mostra os pontos obtidos durante a realização das curvas de determinação de permeabilidade absoluta inicial e final, bem como as retas e equações ajustadas. $\mathrm{O}$ coeficiente angular das retas fornecem o parâmetro $(d P / d Q)$ necessário na Eq. 17 para o cálculo da permeabilidade.

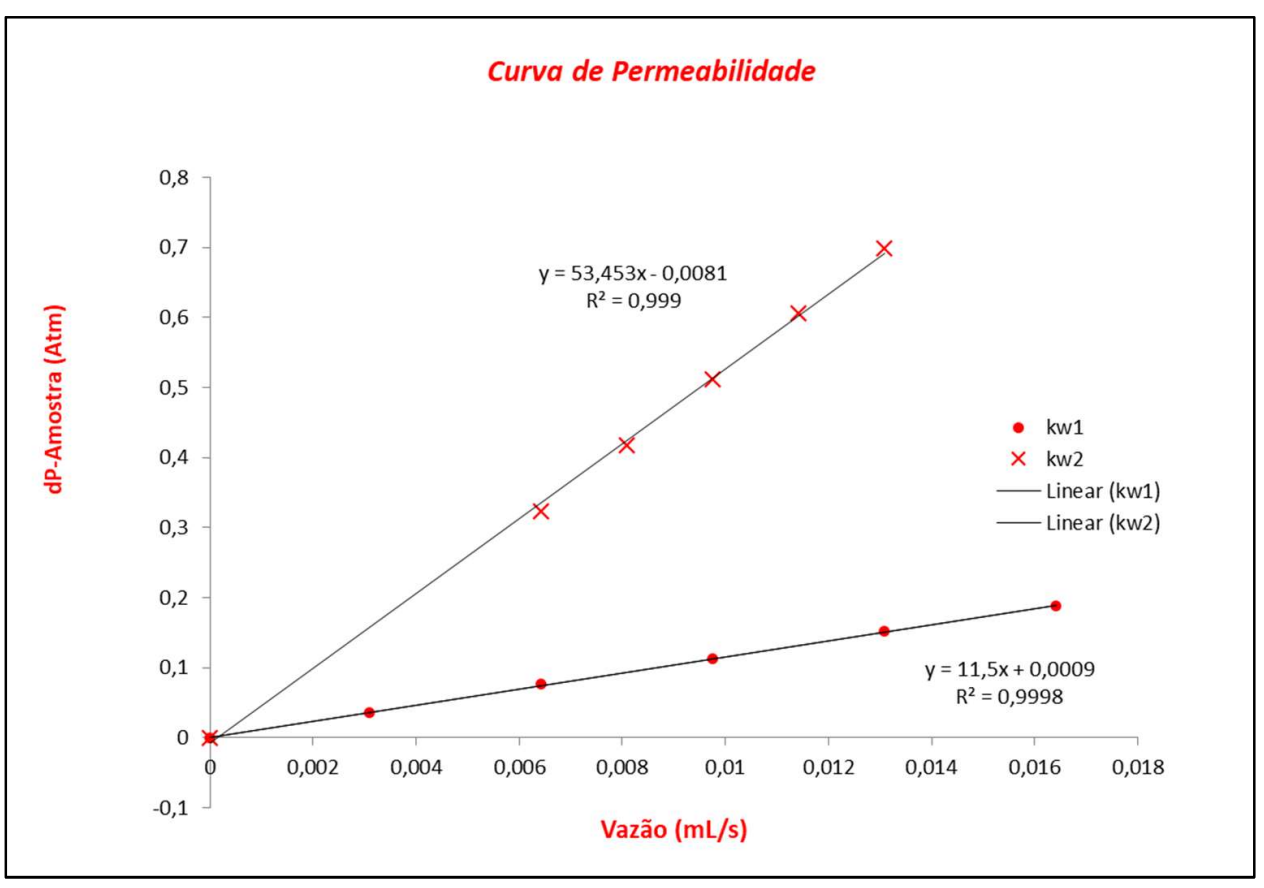

Figura 32 - Curva de permeabilidade da amostra GBT2. 
Usualmente, o Two Slug Method utiliza somente os valores de permeabilidade inicial e final, ou seja, antes da injeção de solução polimérica e após a injeção dos dois slugs, para cálculo do fator de resistência residual (FFR). Porém é possível notar na Fig. 33, que o valor do diferencial de pressão através da amostra não se estabiliza durante a injeção de solução polimérica (curvas amarela e vermelha).

Segundo Sorbie (1991), a não estabilização é um indicativo que está ocorrendo algum processo de retenção polimérica, que nesse caso provavelmente foi ocasionado pelo aprisionamento mecânico das cadeias de polímeros na rocha. Acredita-se que para esse teste a causa tenha sido a baixa permeabilidade do meio poroso. Esse fator ocorreu durante a injeção dos dois bancos de solução poliméricas.

Durante a injeção do primeiro slug, ocorreu a combinação de dois mecanismos de retenção, o de adsorção e o de aprisionamento mecânico. Nota-se através da Fig. 33 que a curva amarela tende a uma possível estabilização, que pode não ter acontecido justamente em virtude do processo de aprisionamento. Na injeção do segundo slug, acredita-se que as paredes do meio poroso já estariam saturadas, com isso o processo de adsorção é considerado como nulo. Observando a curva vermelha da Fig. 33, percebe-se um crescimento do diferencial de pressão através da amostra ainda mais acentuado que o ocorrido na curva amarela. Dessa vez, é possível considerar que a retenção, causada apenas por aprisionamento mecânico, ocorre de maneira mais intensa em razão de a permeabilidade da amostra ser ainda menor devido a retenção ocorrida no primeiro slug.

Em decorrência disso, foi necessário o cálculo de uma permeabilidade intermediária, que é relativa ao momento da segunda injeção de água de Peregrino (WF2) cujo diferencial de pressão através da amostra estivesse constante. Através dessa nova permeabilidade, acredita-se que as ações causadas pelo processo de adsorção possam ser melhor isoladas.

Utilizando-se a Eq. 17 para o cálculo das permeabilidades inicial e final, e a Lei de Darcy para a intermediária, tem-se: 


\begin{tabular}{ll}
\hline Permeabilidade Absoluta Inicial $\left(\mathrm{k}_{1}\right)$ & $58,46 \mathrm{mD}$ \\
\hline Permeabilidade Absoluta Final $\left(\mathrm{k}_{2}\right)$ & $12,58 \mathrm{mD}$ \\
\hline Permeabilidade Absoluta Intermediária $\left(\mathrm{k}_{\text {int }}\right)$ & $23,62 \mathrm{mD}$ \\
\hline
\end{tabular}

Tabela 11 - Permeabilidade inicial, intermediária e final da amostra GBT2.

A Fig. 33 mostra o comportamento do diferencial de pressão durante a realização do Two Slug Method. É notável o aumento do valor da pressão necessária para atravessar o meio poroso durante a segunda e terceira injeção de água, curvas azul e verde, respectivamente. $\mathrm{O}$ teste foi realizado à vazão constante durante a injeção de todas as soluções, com isso, o único contribuinte possível para esse aumento seria a redução da área disponível para passagem do fluido, que teria ocorrido pela retenção polimérica.

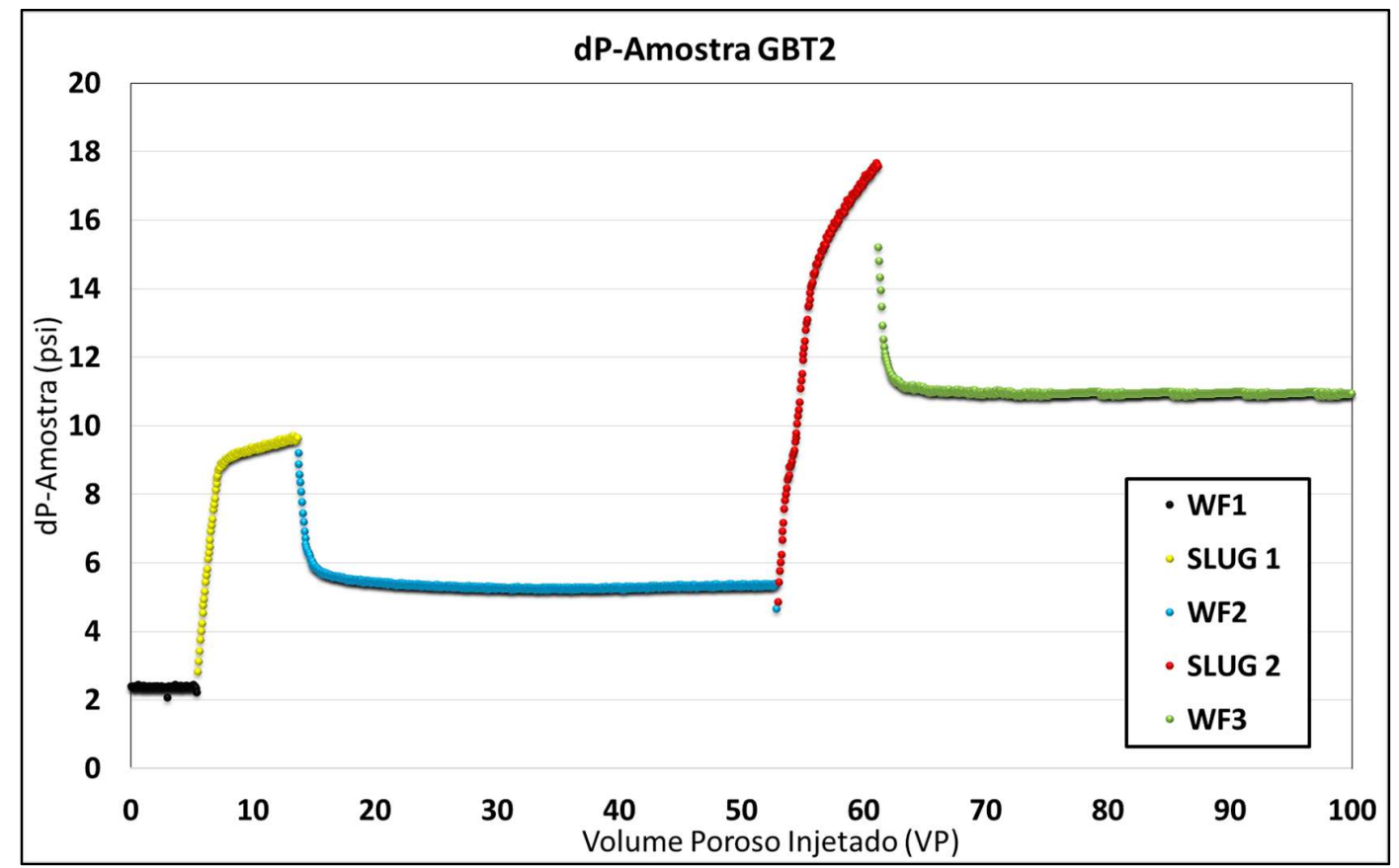

Figura 33 - Diferencial de pressão através da amostra GBT2.

Com os valores de permeabilidade foi possível calcular o fator de resistência residual (FFR) para as etapas intermediária e final. Não foi possível calcular o fator de resistência (FR) em razão da não estabilização do diferencial de pressão durante a 
injeção da solução polimérica. Percebe-se a partir dos valores de FFR que o grau de retenção polimérica durante a injeção dos dois slugs foi bastante alto, pois a redução da permeabilidade foi muito elevada.

$$
\begin{gathered}
F F R_{\text {int }}=2,48 \\
F F R_{\text {final }}=4,65
\end{gathered}
$$

A Fig. 34 mostra os perfis de diferencial de pressão através do capilar normalizados dos slugs 1 e 2 e condutividade (traçador) obtidos no efluente da amostra. Como é possível notar, a concentração da solução pós-amostra (proporcional à diferença de pressão) inicia o aumento após 1,5 volume porosos (VP) injetados, e volta a ser o mesmo que o inicial somente após a injeção de 4 VP, reforçando a suspeita de aprisionamento mecânico.

Percebe-se também que após, aproximadamente, 0,75 VP injetados ocorre um início de elevação da curva de diferencial de pressão, no mesmo momento das curvas de condutividade. Não há nenhum registro sobre isso na literatura, mas acredita-se que esse sinal seria da solução polimérica filtrada pelos poros da formação. Nesse contexto, a solução estava composta apenas pelas cadeias poliméricas de menor tamanho e algumas poucas cadeias maiores que estariam passando através de canais de maior tamanho presentes na amostra. Após o bloqueio de todos os poros menores a solução passaria então somente pelos capilares mais largos e o processo de filtração terminaria. Esse fenômeno é citado por Sorbie (1991), entretanto não há nenhuma representação das curvas de pressão.

O episódio citado no parágrafo anterior não ocorreu na curva que representa a injeção do segundo banco de solução polimérica. Desse modo, é possível notar a irreversibilidade dos danos causados na formação pela retenção polimérica e o quão importante é o entendimento desse fator. 
Através dessas curvas de diferencial de pressão e condutividade é possível determinar a quantidade de material polimérico adsorvido (retido) na amostra e o volume de poro inacessível, que são mostrados na Tabela 12.

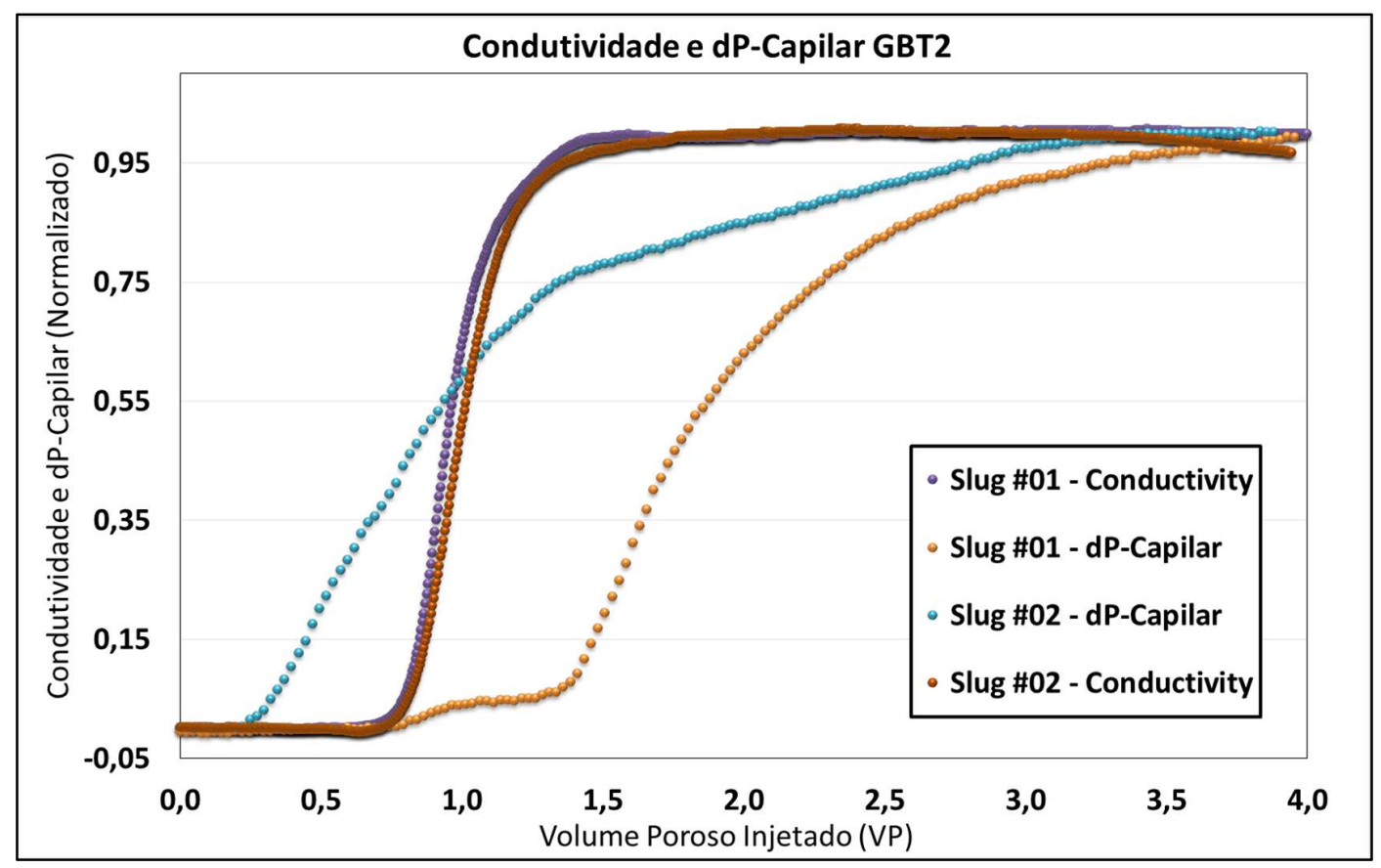

Figura 34 - Perfis de condutividade e diferencial de pressão no capilar pós-amostra GBT2.

\begin{tabular}{lc}
\hline Material Adsorvido $(\boldsymbol{\Gamma})$ & $82,98 \mu \mathrm{g} / \mathrm{g}$ \\
\hline Volume de Poro Inacessível & $2,78 \mathrm{~mL}$ \\
\hline
\end{tabular}

Tabela 12 - Valores de material polimérico adsorvido e volume de poro inacessível da amostra BBT3.

O valor de $2,78 \mathrm{~mL}$ equivale a $13,32 \%$ do volume poroso da amostra. 


\section{1 .2}

\section{Buff Berea (BBT2)}

A Tabela 13 traz as propriedades petrofísicas da amostra BBT2 após o corte.

\begin{tabular}{cc}
\hline Código da Amostra & BBT2 \\
\hline Procedência & Buff Berea \\
\hline Diâmetro $(\mathrm{cm})$ & 3,792 \\
\hline Área $\left(\mathrm{cm}^{2}\right)$ & 11,293 \\
\hline Comprimento $(\mathrm{cm})$ & 9,781 \\
\hline Volume $\left(\mathrm{cm}^{3}\right)$ & 110,461 \\
\hline Amostra Seca $(\mathrm{g})$ & 231,30 \\
\hline Amostra Úmida $(\mathrm{g})$ & 254,30 \\
\hline Volume Poroso $(\mathrm{mL})$ & 22,03 \\
\hline Porosidade & 19,94
\end{tabular}

Tabela 13 - Características e propriedades petrofísicas da amostra BBT2.

A Fig. 35 exibe as curvas de permeabilidades da amostra BBT2, procedimentos realizados durante a primeira e última injeção de água de Peregrino.

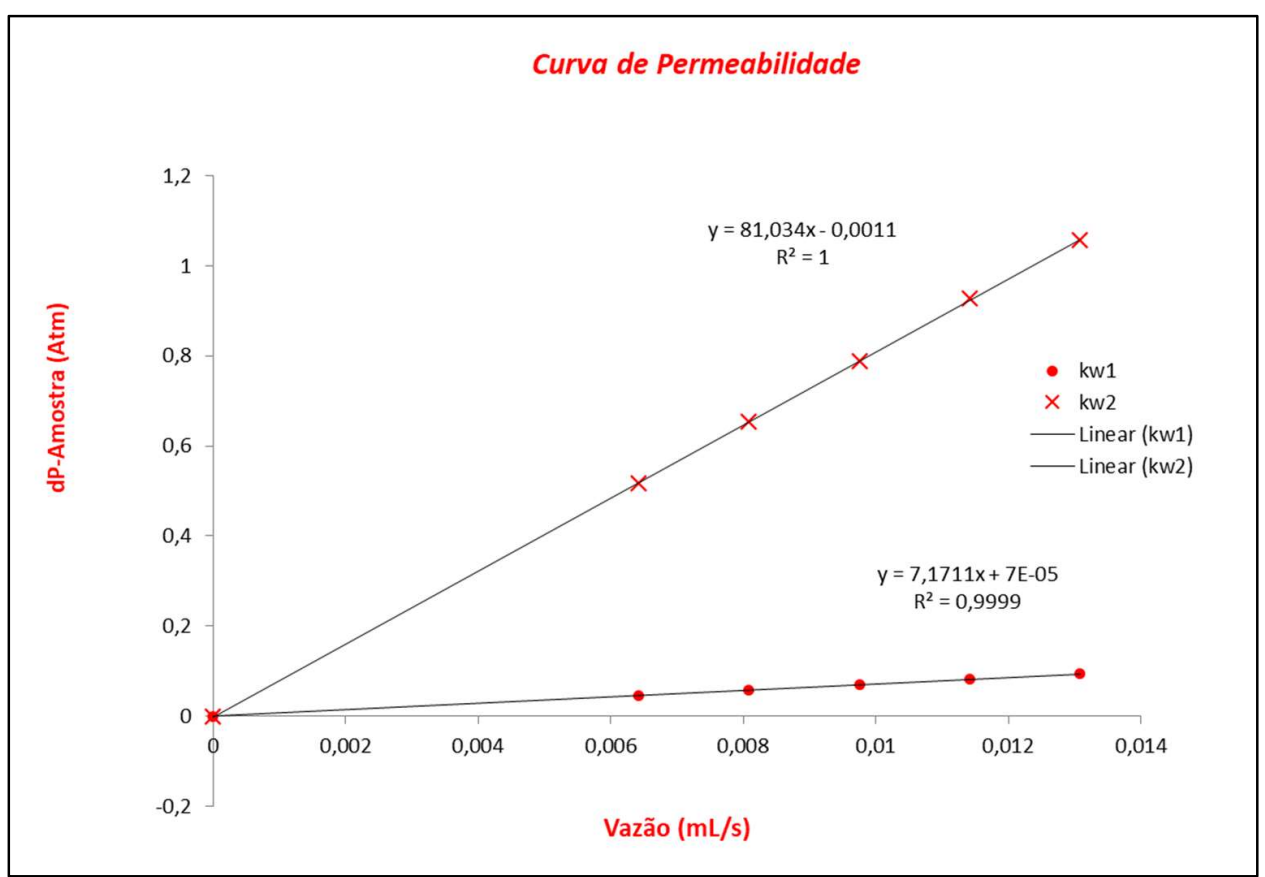

Figura 35 - Curvas de permeabilidade absoluta inicial e final da amostra BBT2. 
Assim como ocorreu na amostra GBT2, é possível notar, através da Fig. 36, que houve novamente material retido por ações mecânicas. Mesmo com o valor de permeabilidade inicial um pouco maior que da amostra anterior, o grau de redução de permeabilidade e o de retenção calculado pelos perfis de diferencial de pressão apresentaram-se maiores que para a amostra de Gray Berea. Em razão disso, assim como foi realizado no teste com a amostra de Gray Berea, escolheu-se calcular o fator de resistência residual com os valores de permeabilidade inicial, intermediária e final para verificar a influência das duas injeções.

Além da baixa permeabilidade, outro fator que pode explicar essa ocorrência é a caracterização mineralógica das amostras. A Tabela 8 mostra que o percentual de argilo-minerais como a Ilita, Esmectita e Caulinita encontrado na formação Buff Berea é maior que na formação de Gray Berea, e como mostrado anteriormente esse é um fator extremamente relevante no grau de retenção polimérica.

\begin{tabular}{lc}
\hline Permeabilidade Absoluta Inicial $\left(\mathrm{k}_{1}\right)$ & $92,51 \mathrm{mD}$ \\
\hline Permeabilidade Absoluta Final $\left(\mathrm{k}_{2}\right)$ & $8,17 \mathrm{mD}$ \\
\hline Permeabilidade Absoluta Intermediária $\left(\mathrm{k}_{\text {int }}\right)$ & $12,08 \mathrm{mD}$ \\
\hline
\end{tabular}

Tabela 14 - Valores de permeabilidades da amostra BBT2.

A Tabela 14 traz os valores das permeabilidades para as 3 diferentes injeções de água de Peregrino. A partir dela nota-se que grande parte da retenção ocorreu durante a injeção do primeiro banco de solução polimérica, restando uma pequena variação na realização do segundo slug. Desse modo, acredita-se que o mecanismo de adsorção teve uma influência muito maior que o de aprisionamento mecânico.

Os comportamentos dos perfis de diferencial de pressão dos dois bancos de solução polimérica mostrados na Fig. 36 apresentam comportamentos parecidos, que tendem a estabilização, porém, em nenhum dos dois slugs foi possível alcançá-la. Notase que, diferente do perfil apresentado no teste com Gray Berea, a segunda injeção não foi muito afetada, mesmo com um valor muito baixo de permeabilidade. 


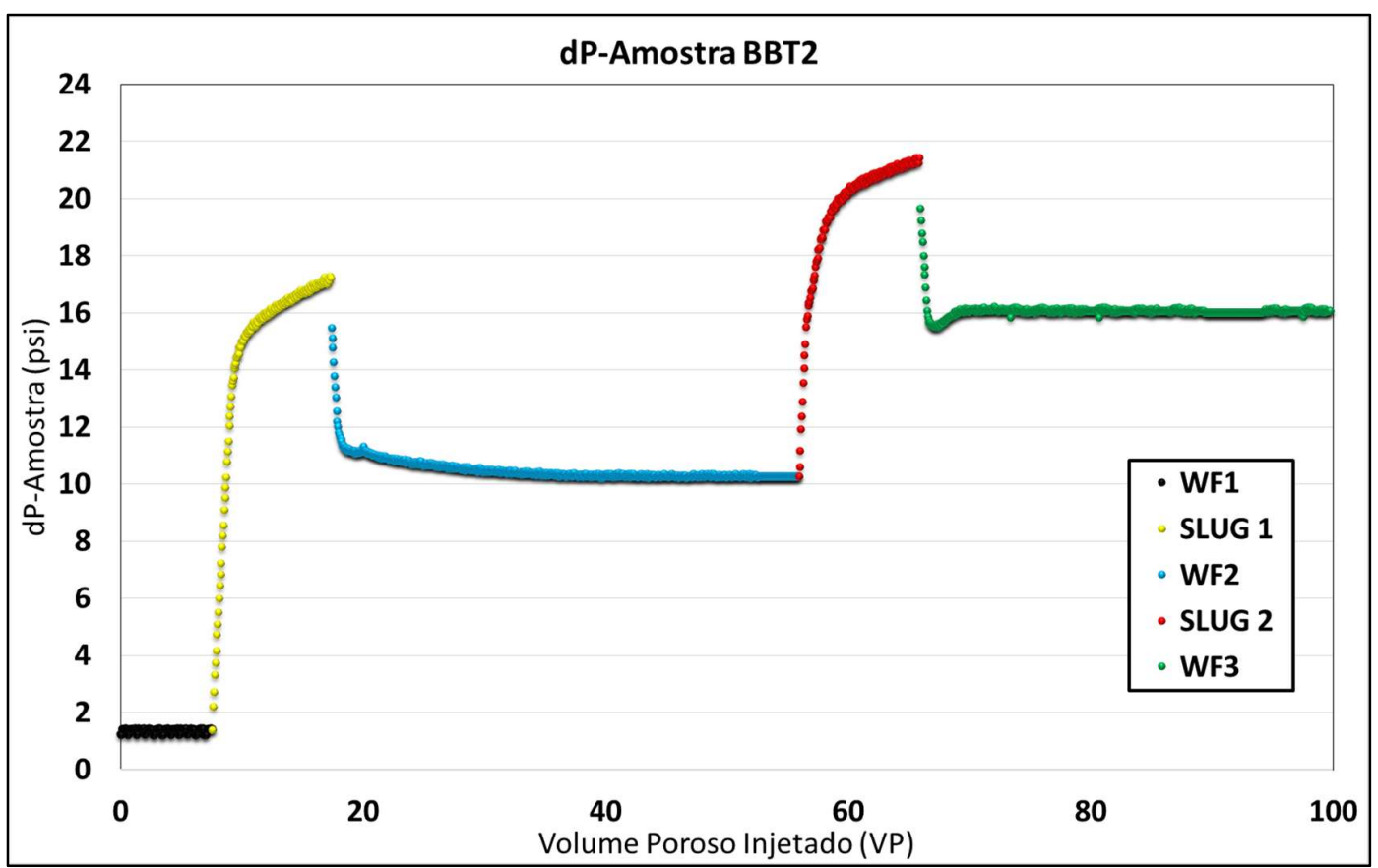

Figura 36 - Diferencial de pressão através da amostra BBT2.

$$
\begin{gathered}
F F R_{\text {int }}=7,66 \\
F F R_{\text {final }}=11,3
\end{gathered}
$$

Os valores do fator de resistência residual calculados com a fase intermediária e fase final são diferentes, porém a razão entre eles é menor que a do teste realizado com a amostra de Gray Berea. Acredita-se que esse pode ser mais um indicativo que para essa formação as ações causadas pela composição de minerais da rocha tenham maior influência que àquelas causadas pela baixa permeabilidade.

A partir da Fig. 37, nota-se novamente um atraso na uniformidade dos valores de concentração da solução polimérica entre a entrada e saída do corpo de provas. É possível também observar o fenômeno da filtração da solução polimérica, porém com um patamar um pouco menor. 


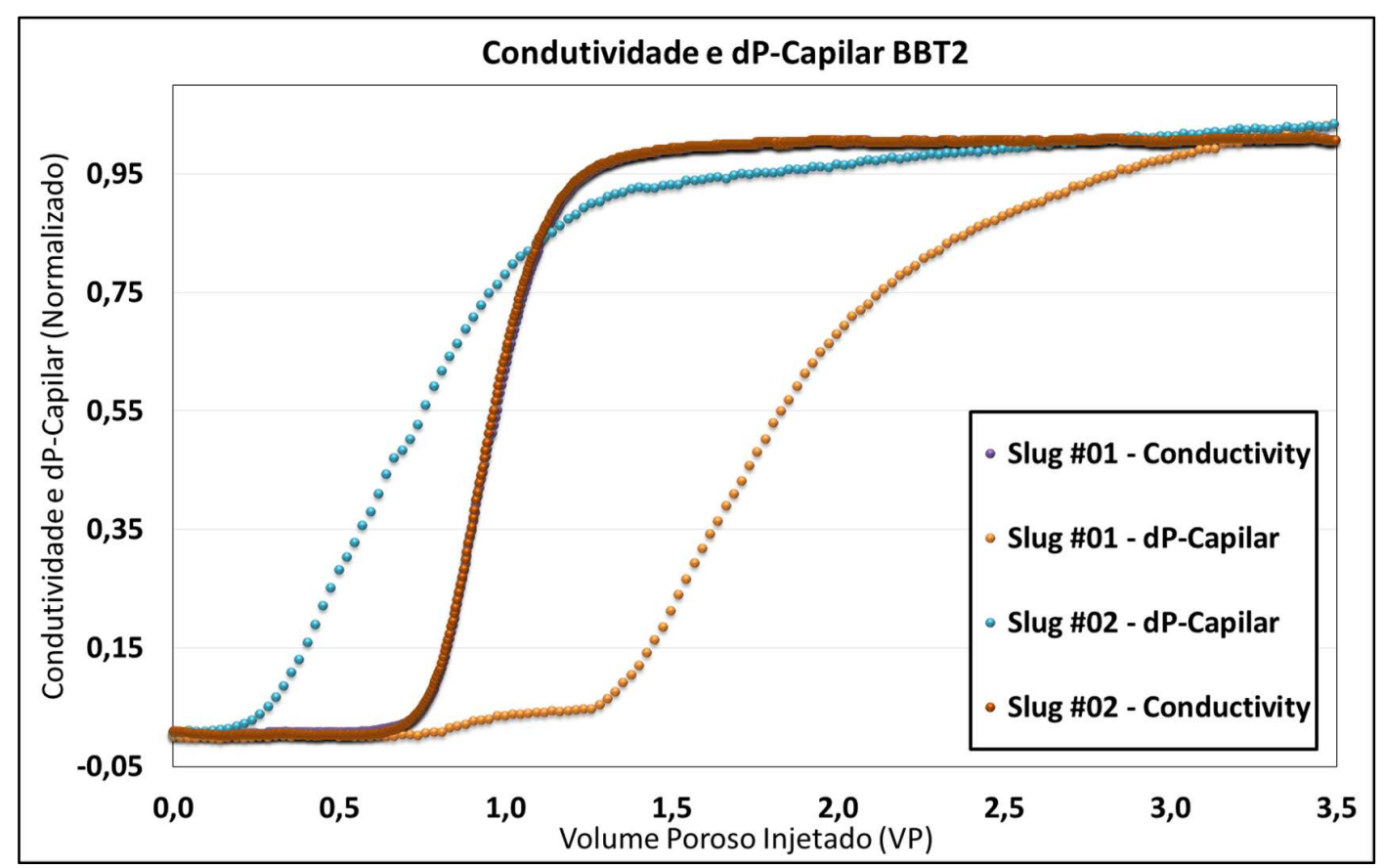

Figura 37 - Perfis de condutividade e diferencial de pressão no capilar pós-amostra BBT2.

\begin{tabular}{lc}
\hline Material Adsorvido $(\boldsymbol{\Gamma})$ & $101,82 \mu \mathrm{g} / \mathrm{g}$ \\
\hline Volume de Poro Inacessível & $5,13 \mathrm{~mL}$ \\
\hline
\end{tabular}

Tabela 15 - Valores de material polimérico adsorvido e volume de poro inacessível da amostra BBT2.

O valor de 5,13 mL equivale a 23,29\% do volume poroso da amostra. O volume de poro inacessível é uma outra maneira de quantificar o dano sofrido pela formação em virtude da injeção de polímeros. Para a amostra de Buff Berea, o percentual de poros bloqueados por ações de retenção foi muito maior que o ocorrido na amostra de Gray Berea. Dessa maneira, o mecanismo de adsorção polimérica parece contribuir de forma mais significativa que o aprisionamento mecânico na determinação desse parâmetro. 


\section{1 .3}

\section{Bentheimer (BHT3)}

A Tabela 16 traz as características e propriedades petrofísicas da amostra BHT3.

\begin{tabular}{cc}
\hline Código da Amostra & BHT3 \\
\hline Procedência & Bentheimer \\
\hline Diâmetro $(\mathrm{cm})$ & 3,792 \\
\hline Área $\left(\mathrm{cm}^{2}\right)$ & 11,293 \\
\hline Comprimento $(\mathrm{cm})$ & 10,155 \\
\hline Volume $\left(\mathrm{cm}^{3}\right)$ & 114,685 \\
\hline Amostra Seca $(\mathrm{g})$ & 221,80 \\
\hline Amostra Úmida $(\mathrm{g})$ & 248,90 \\
\hline Volume Poroso $(\mathrm{mL})$ & 25,96 \\
\hline Porosidade & 22,63 \\
\hline
\end{tabular}

Tabela 16 - Características e propriedades petrofísicas da amostra BHT3.

Essa formação apresenta um valor de permeabilidade muito maior que as amostras utilizadas anteriormente. Desse modo, acredita-se que o aprisionamento mecânico ocorrido nos testes com Gray Berea e Buff Berea não aconteceu durante a realização da injeção de solução polimérica do presente procedimento.

A Tabela 17 mostra os valores calculados das permeabilidades absolutas relativas às 3 injeções de água de Peregrino. A Fig. 38, mostra as curvas de permeabilidade absoluta da amostra BHT3. 


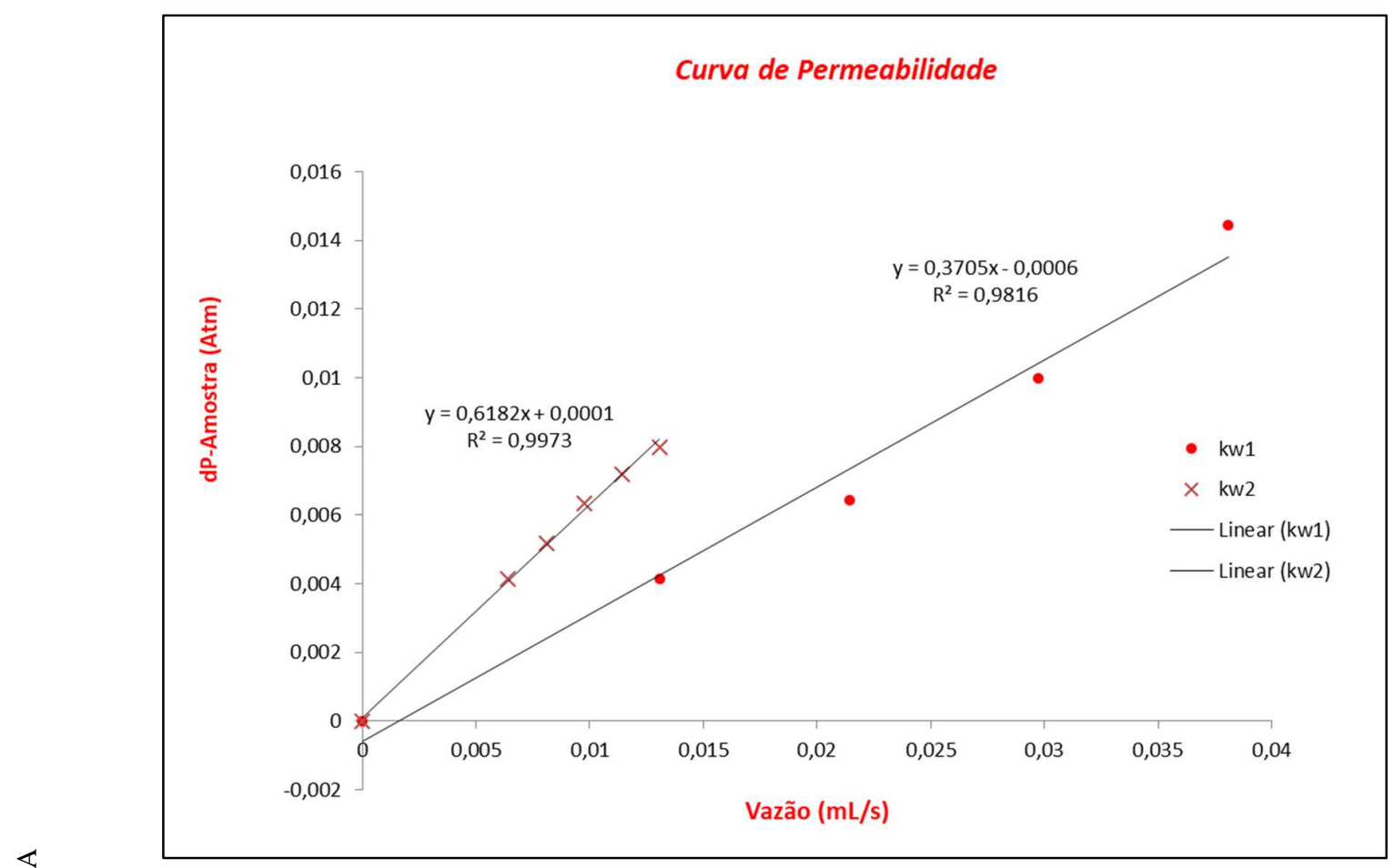

Figura 38 - Curvas de permeabilidade absoluta inicial e final da amostra BHT3.

\begin{tabular}{ll}
\hline Permeabilidade Absoluta Inicial $\left(\mathrm{k}_{1}\right)$ & $1859,06 \mathrm{mD}$ \\
\hline Permeabilidade Absoluta Final $\left(\mathrm{k}_{2}\right)$ & $1114,17 \mathrm{mD}$ \\
\hline Permeabilidade Absoluta Intermediária $\left(\mathrm{k}_{\text {int }}\right)$ & $1705,62 \mathrm{mD}$ \\
\hline
\end{tabular}

Tabela 17 - Valores de permeabilidade absoluta da amostra BHT3.

Durante a realização da terceira injeção de água de Peregrino, verificou-se que ao final da etapa o diferencial de pressão apresentou um leve aumento, como pode ser verificado na Fig. 39. Ao retirar a amostra, foi observado uma mancha de óxido na face de injeção da mesma, indicando a ocorrência de oxidação. Essa suspeita foi confirmada ao abrir o cilindro acumulador de água de Peregrino, o qual apresentava um ponto de oxidação na parede. Como explicado no capítulo anterior, a oxidação provoca o entupimento dos poros da amostra e, consequentemente, a diminuição do valor de permeabilidade. Em virtude disso, escolheu-se calcular novamente os fatores de 
redução residual para as 3 fases de injeção de água, assim como foi feito nos testes anteriores.

$$
\begin{gathered}
F F R_{\text {int }}=1,09 \\
F F R_{\text {final }}=1,67
\end{gathered}
$$

Nota-se a partir dos valores de permeabilidade e FFR que para a amostra de Bentheimer o grau de retenção polimérica é muito baixo. Acredita-se que devido à alta permeabilidade inicial, a retenção tenha ocorrido majoritariamente em razão do mecanismo de adsorção.

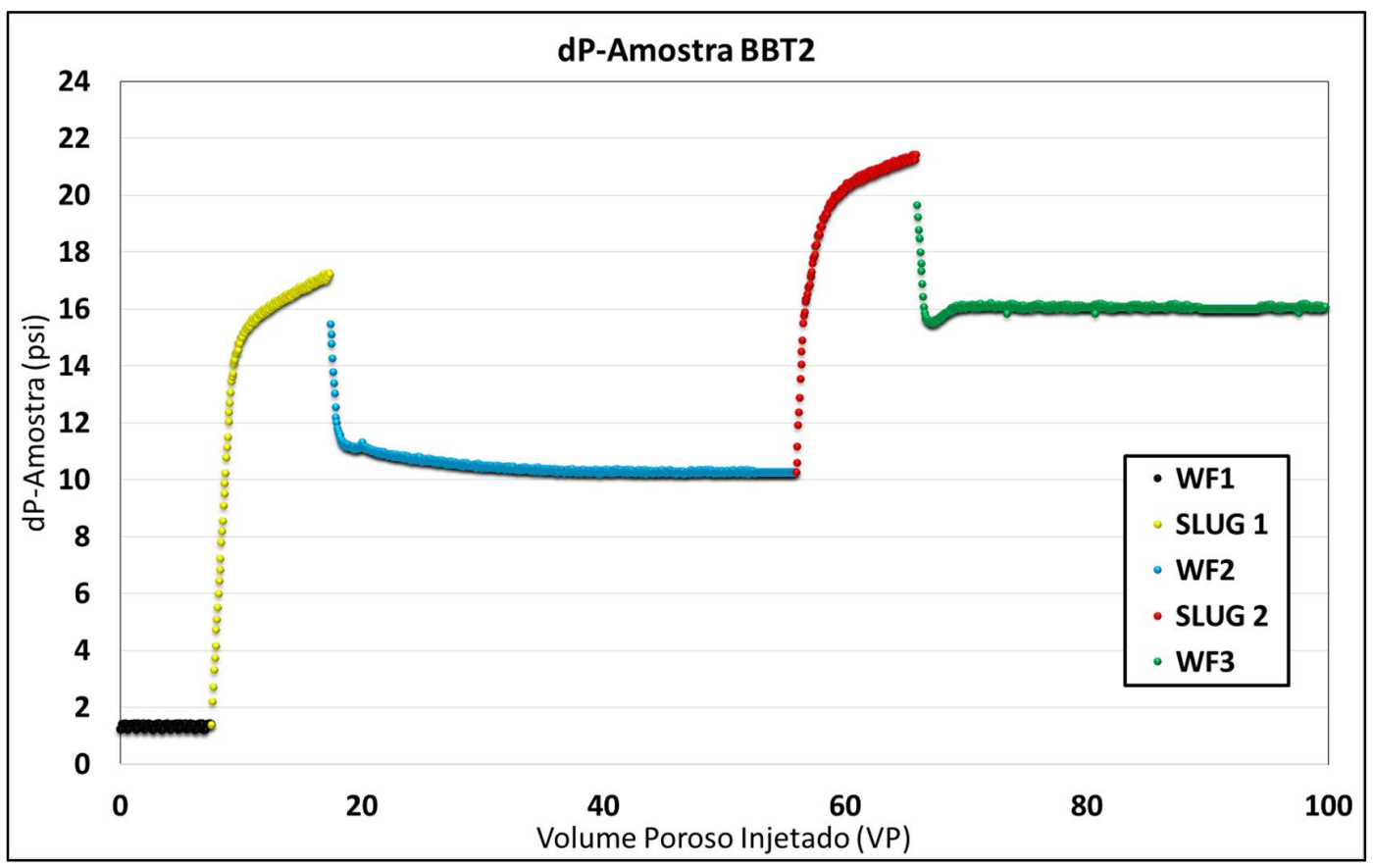

Figura 39 - Diferencial de pressão através da amostra BHT3.

A Fig. 39 mostra que os perfis de diferencial de pressão durante as injeções dos dois bancos de solução polimérica apresentaram um comportamento de estabilização, 
com isso, tornou-se possível o cálculo do fator de resistência (FR). Através da Fig. 39, é possível notar também a uniformidade nos valores de pressão tanto para a segunda, quanto para a terceira injeção de água de Peregrino. Os valores de estabilização dessas fases encontram-se no mesmo patamar, indicando a baixa probabilidade de ocorrência de retenção polimérica durante a injeção do segundo banco de solução polimérica.

Em cenários como esse, espera-se que os benefícios da utilização da solução polimérica estariam mais associados a ações viscosas, ou seja, o incremento na viscosidade da solução ocasionado pela adição do polímero teria mais responsabilidade na recuperação do óleo que as ações de retenção. $\mathrm{O}$ valor apresentado pelo fator de resistência corrobora a teoria apresentada, pois tem praticamente o mesmo valor da razão de viscosidade entre os fluidos.

$$
F R=3,57
$$

A Fig. 40 mostra o comportamento normal dos perfis de pressão sem a ocorrência do aprisionamento mecânico. Percebe-se através do slug 1 que o comportamento de subida é único, diferente daqueles apresentados anteriormente, nos quais ocorreram o processo de filtração da solução. Nesse caso, o Two Slug Method pode ser aplicado sem maiores problemas.

Além da alta permeabilidade, a caracterização das rochas, apresentada no capítulo 4, mostrou que diâmetro médio de garganta de poros das amostras de Bentheimer são maiores em relação às demais rochas utilizadas anteriormente. Essa propriedade resulta em uma área superficial de parede menor, gerando uma menor possibilidade de adsorção. Logo, os valores obtidos nesse teste parecem ser satisfatórios.

Os valores de massa adsorvida e volume de poro inacessível estão apresentados na Tabela 18. 


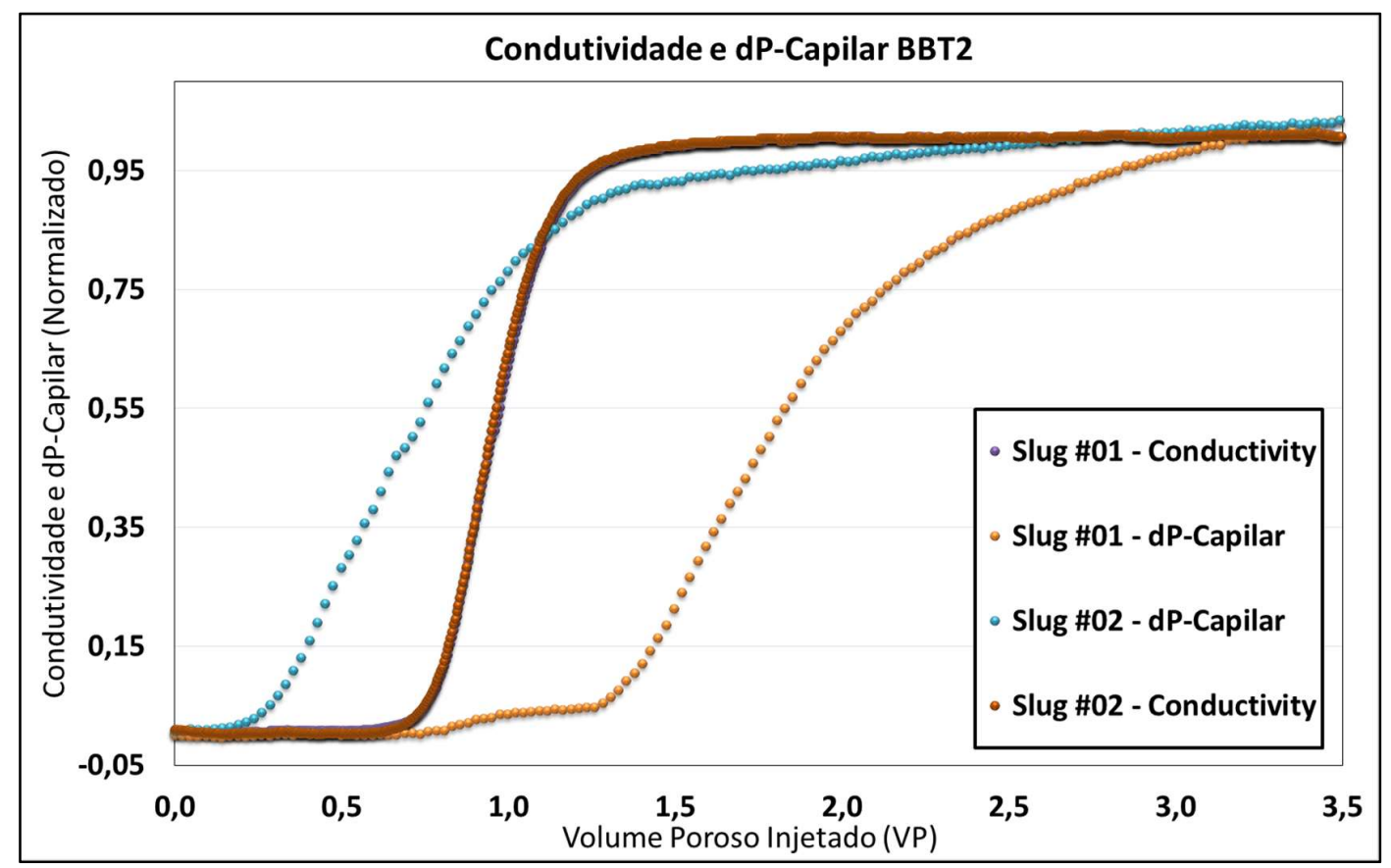

Figura 40 - Perfis de condutividade e diferencial de pressão no capilar pós-amostra BHT3.

\begin{tabular}{lc}
\hline Material Adsorvido $(\boldsymbol{\Gamma})$ & $19,13 \mu \mathrm{g} / \mathrm{g}$ \\
\hline Volume de Poro Inacessível & $0,63 \mathrm{~mL}$ \\
\hline
\end{tabular}

Tabela 18 - Valores de material polimérico adsorvido e volume de poro inacessível da amostra BHT3.

O valor de $0,63 \mathrm{~mL}$ equivale a $2,43 \%$ do volume poroso da amostra. As consequências causadas por essa baixa modificação nas características do meio poroso não devem proporcionar mudanças relevantes nos processos de recuperação, reforçando o pensamento que para amostras com essas propriedades, o aumento da viscosidade da solução causado pela a adição de polímeros seria o maior responsável por alterações nos processos de recuperação de óleo. 


\section{2}

\section{Recuperação de Óleo - Protocolo 1}

Realizados os testes de adsorção nas amostras, era vez de passar para a próxima etapa: aplicar os procedimentos de recuperação avançada e relacionar os resultados obtidos nos testes.

O planejamento inicial era realizar os testes de recuperação utilizando as 3 soluções aquosas em sequências de drenagens e embebições. Porém, as rochas de menores permeabilidades mostraram resultados diferentes dos testes realizados anteriormente para verificar a funcionalidade dessa metodologia. Notou-se que após a injeção da solução de glicerina, o diferencial de pressão nessas amostras durante uma nova injeção de óleo apresentou valores muito elevados. Isso possivelmente foi causado pela maior viscosidade da solução e a impossibilidade de sua remoção total com os volumes de injeção pré-estabelecidos. Viu-se então a necessidade de realização de uma nova bateria de testes, eliminando a etapa de injeção de solução de glicerina, que será explicada no protocolo 2 .

\section{2 .1}

\section{Gray Berea (GBT3)}

A Tabela 19 traz as propriedades e características petrofísicas da amostra GBT3.

\begin{tabular}{cc}
\hline Código da Amostra & GBT3 \\
\hline Procedência & Gray Berea \\
\hline Diâmetro $(\mathrm{cm})$ & 3,792 \\
\hline Área $\left(\mathrm{cm}^{2}\right)$ & 11,293 \\
\hline Comprimento $(\mathrm{cm})$ & 10,024 \\
\hline Volume $\left(\mathrm{cm}^{3}\right)$ & 113,205 \\
\hline Amostra Seca $(\mathrm{g})$ & 241,00 \\
\hline Amostra Úmida $(\mathrm{g})$ & 262,00 \\
\hline Volume Poroso $(\mathrm{mL})$ & 20,11 \\
\hline Porosidade & 17,77 \\
\hline
\end{tabular}


Durante a fase 1, após a saturação da amostra, deu-se início ao procedimento de obtenção da permeabilidade absoluta inicial da amostra. Os pontos de diferencial de pressão relacionados às diferentes vazões estão expostos na Fig. 41 . O valor de permeabilidade absoluta para essa amostra realizado com água de Peregrino foi de $65,82 \mathrm{mD}$, muito próximo ao calculado para a amostra GBT2.

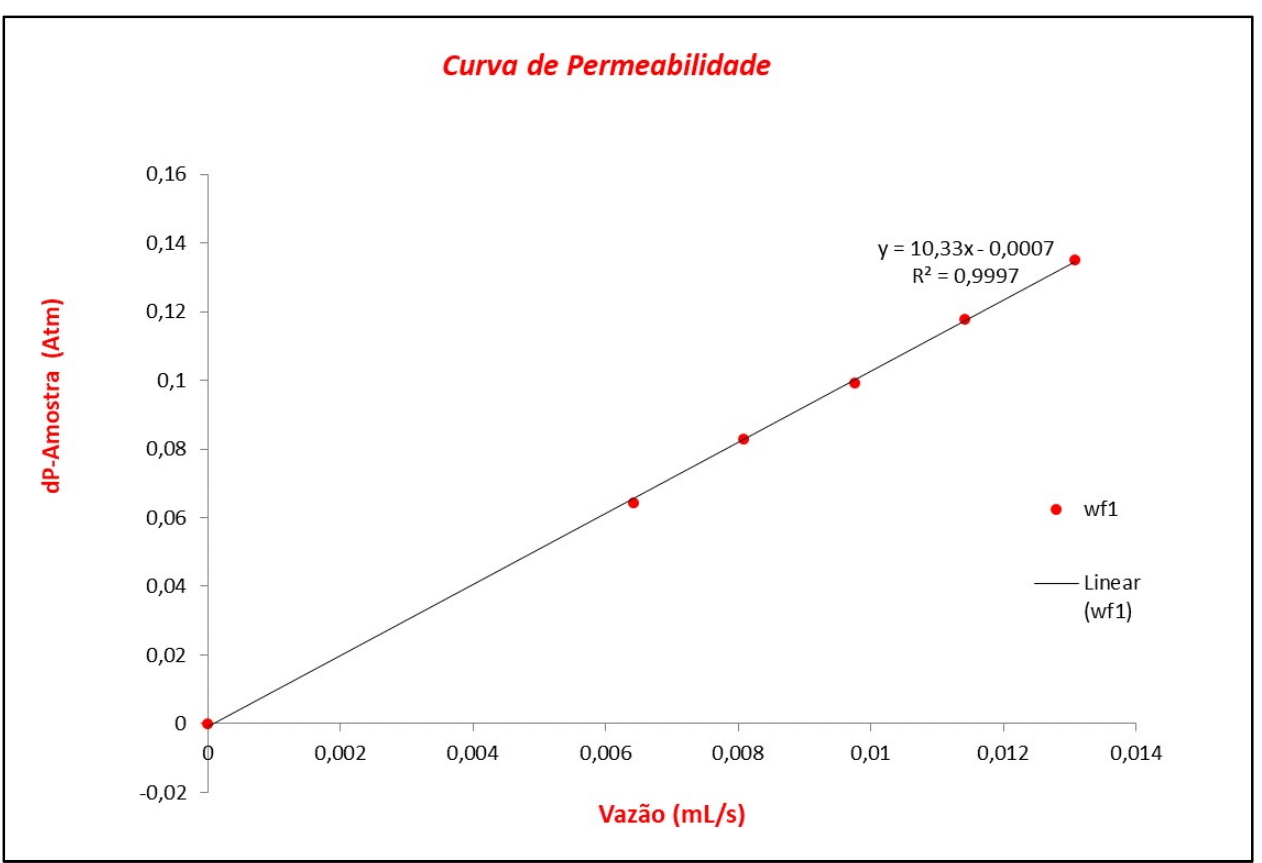

Figura 41 - Curva de permeabilidade absoluta inicial da amostra GBT3. 


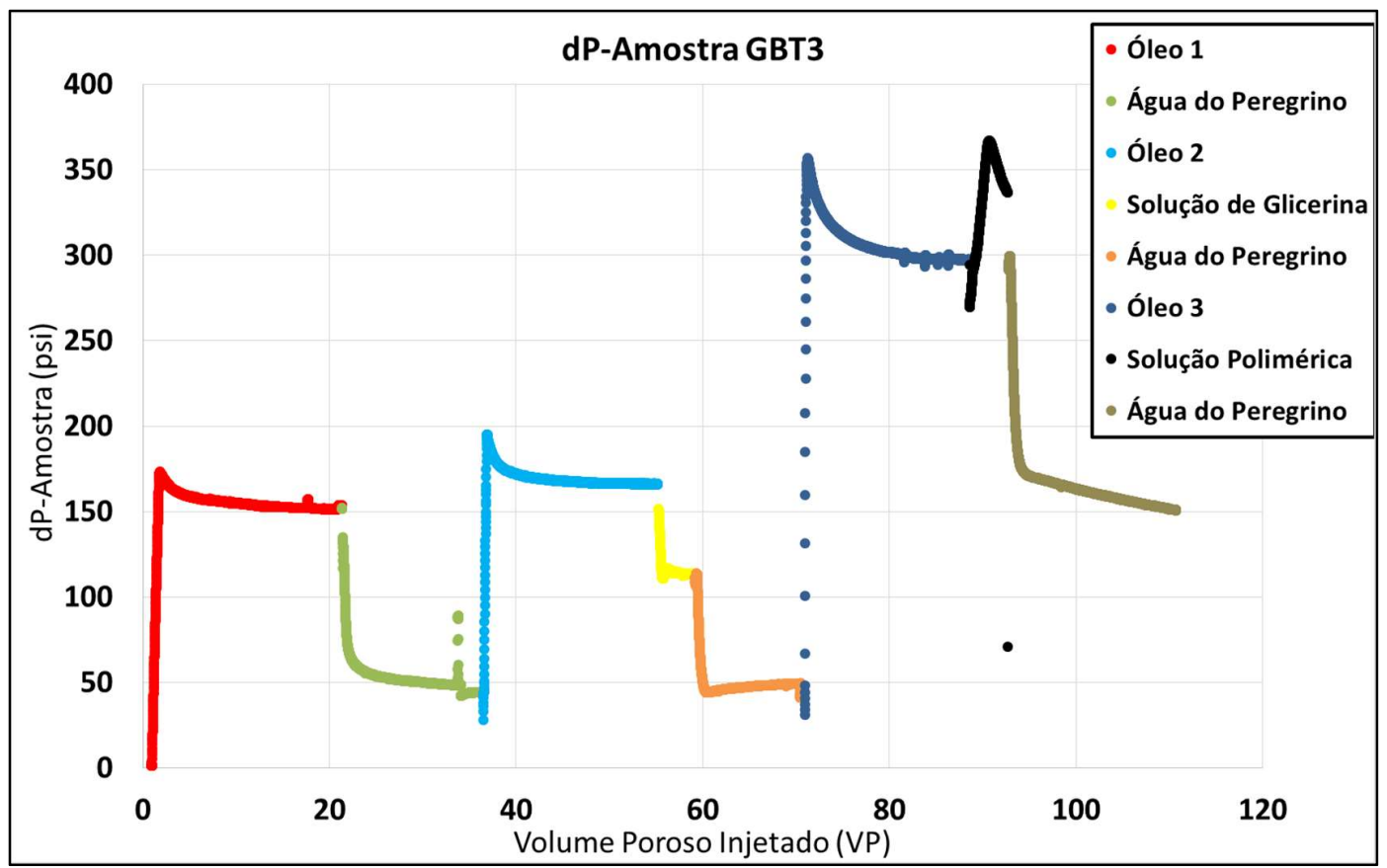

Figura 42- Diferencial de pressão através da amostra GBT3.

Após a determinação da permeabilidade, iniciou-se a fase 2, de injeção de óleo, para obtenção da saturação de água conata e permeabilidade efetiva a óleo. A Tabela 20 traz os valores referentes à fase 2, que está representada pela curva vermelha na Fig. 42.

Ao final da fase 2, com a produção de água nula, calculou-se os valores dos parâmetros que iriam iniciar a próxima fase. Nessa fase, a produção de água foi quantificada e associada com o volume de óleo que ficou acumulado na amostra. Notase que o valor da permeabilidade efetiva a óleo é maior que o calculado para permeabilidade absoluta à água. Isso pode ser explicado pela molhabilidade da amostra, como ela é preferencialmente molhável à água, a camada de água que contorna as paredes do meio poroso facilitaria o escoamento do óleo. Esse fenômeno se repetiu em todas os testes realizados. 


\begin{tabular}{lllll}
\hline Parâmetro & \multicolumn{2}{c}{ Inicial } & \multicolumn{2}{c}{ Final } \\
\hline Volume de água $(\mathrm{mL})$ & $\left(\mathrm{V}_{\mathrm{wi} 2}\right)$ & $\mathbf{2 0 , 1 1}$ & $\left(\mathrm{V}_{\mathrm{wf} 2}\right)$ & $\mathbf{3 , 2 1}$ \\
\hline Volume de óleo $(\mathrm{mL})$ & $\left(\mathrm{V}_{\mathrm{oi} 2}\right)$ & $\mathbf{0}$ & $\left(\mathrm{V}_{\mathrm{of} 2}\right)$ & $\mathbf{1 6 , 9 0}$ \\
\hline Saturação de água $(\%)$ & $\left(\mathrm{S}_{\mathrm{wi} 2}\right)$ & $\mathbf{1 0 0}$ & $\left(\mathrm{S}_{\mathrm{wf} 2}\right)$ & $\mathbf{1 5 , 9 4}$ \\
\hline Saturação de óleo $(\%)$ & $\left(\mathrm{S}_{\mathrm{oi} 2}\right)$ & $\mathbf{0}$ & $\left(\mathrm{S}_{\mathrm{of} 2}\right)$ & $\mathbf{8 4 , 0 6}$ \\
\hline Volume de água produzida $(\mathrm{mL})$ & & & $\left(\mathrm{N}_{\mathrm{w} 2}\right)$ & $\mathbf{1 6 , 9 1}$ \\
\hline Permeabilidade efetiva ao óleo $(\mathrm{mD})$ & & & $\left(\mathrm{K}_{\mathrm{ef} 22}\right)$ & $\mathbf{9 0 , 2 4}$ \\
\hline
\end{tabular}

Tabela 20 - Dados da fase 2 (injeção de óleo) da amostra GBT3.

A fase 3 é referente ao primeiro processo de recuperação, no qual utilizou-se apenas água de Peregrino. O valor inicial disponível de óleo na amostra era de 16,90 $\mathrm{mL}$, dos quais foram produzidos $5,47 \mathrm{~mL}$. A recuperação final foi de 32,39\%. Esse valor é esperado para injeção de água sem aditivos, devido à alta razão de mobilidade entre os fluidos.

Essa etapa está representada pela curva verde na Fig. 42 e seus valores estão dispostos na Tabela 21.

\begin{tabular}{lcccr}
\hline Parâmetro & \multicolumn{2}{c}{ Inicial } & \multicolumn{2}{c}{ Final } \\
\hline Volume de água $(\mathrm{mL})$ & $\left(\mathrm{V}_{\text {wi3 }}\right)$ & $\mathbf{3 , 2 1}$ & $\left(\mathrm{V}_{\mathrm{wf} 3}\right)$ & $\mathbf{8 , 6 8}$ \\
\hline Volume de óleo $(\mathrm{mL})$ & $\left(\mathrm{V}_{\mathrm{oi}}\right)$ & $\mathbf{1 6 , 9 0}$ & $\left(\mathrm{V}_{\mathrm{of} 3}\right)$ & $\mathbf{1 1 , 4 3}$ \\
\hline Saturação de água $(\%)$ & $\left(\mathrm{S}_{\text {wi3 }}\right)$ & $\mathbf{1 5 , 9 4}$ & $\left(\mathrm{S}_{\mathrm{wf} 3}\right)$ & $\mathbf{4 3 , 1 6}$ \\
\hline Saturação de óleo $(\%)$ & $\left(\mathrm{S}_{\mathrm{oi} 3}\right)$ & $\mathbf{8 4 , 0 6}$ & $\left(\mathrm{S}_{\mathrm{of} 3}\right)$ & $\mathbf{5 6 , 8 4}$ \\
\hline Volume de óleo produzido $(\mathrm{mL})$ & & & $\left(\mathrm{N}_{\mathrm{o} 3}\right)$ & $\mathbf{5 , 4 7}$ \\
\hline Permeabilidade efetiva à água $(\mathrm{mD})$ & & & $\left(\mathrm{K}_{\mathrm{efw} 3}\right)$ & $\mathbf{2 , 6 8}$ \\
\hline Fator de recuperação de óleo $(\%)$ & & & & $\mathbf{3 2 , 3 9}$ \\
\hline
\end{tabular}

Tabela 21 - Dados da fase 3 (injeção de água) da amostra GBT3.

Na fase 4 realizou-se uma nova injeção de óleo para deslocar a água móvel da amostra e restabelecer as condições iniciais do reservatório. A saturação final de óleo 
ao final desse procedimento ficou um pouco menor que a saturação da fase 2 , resultando em uma permeabilidade efetiva um pouco menor.

A curva azul da Fig. 42 representa essa etapa. A Tabela 22 detalha os valores iniciais e finais do processo.

\begin{tabular}{llllr}
\hline Parâmetro & \multicolumn{2}{c}{ Inicial } & \multicolumn{2}{c}{ Final } \\
\hline Volume de água $(\mathrm{mL})$ & $\left(\mathrm{V}_{\mathrm{wi} 4}\right)$ & $\mathbf{8 , 6 8}$ & $\left(\mathrm{V}_{\mathrm{wf} 4}\right)$ & $\mathbf{3 , 2 4}$ \\
\hline Volume de óleo $(\mathrm{mL})$ & $\left(\mathrm{V}_{\mathrm{oi} 4}\right)$ & $\mathbf{1 1 , 4 3}$ & $\left(\mathrm{V}_{\mathrm{of} 4}\right)$ & $\mathbf{1 6 , 8 8}$ \\
\hline Saturação de água $(\%)$ & $\left(\mathrm{S}_{\mathrm{wi}}\right)$ & $\mathbf{4 3 , 1 6}$ & $\left(\mathrm{S}_{\mathrm{wf} 4}\right)$ & $\mathbf{1 6 , 0 9}$ \\
\hline Saturação de óleo $(\%)$ & $\left(\mathrm{S}_{\mathrm{oi} 4}\right)$ & $\mathbf{5 6 , 8 4}$ & $\left(\mathrm{S}_{\mathrm{of} 4}\right)$ & $\mathbf{8 3 , 9 1}$ \\
\hline Volume de água produzida $(\mathrm{mL})$ & & & $\left(\mathrm{N}_{\mathrm{w} 4}\right)$ & $\mathbf{5 , 4 4}$ \\
\hline Permeabilidade efetiva ao óleo $(\mathrm{mD})$ & & & $\left(\mathrm{K}_{\mathrm{ef} 4}\right)$ & $\mathbf{8 2 , 2 1}$ \\
\hline
\end{tabular}

Tabela 22 - Dados da fase 4 (injeção de óleo) da amostra GBT3.

Como é possível notar através dos valores da Tabela 23, os valores iniciais da fase 5 não são exatamente os mesmos da fase 3, porém ambos apresentam resultados bastante similares após a saturação com óleo. Na fase 5 é realizado um novo processo de recuperação de óleo, no qual já há a presença de aditivos para aumentar a viscosidade da solução e melhorar a razão de mobilidade.

Nessa etapa, foi realizada a adição de glicerina à água de injeção. A viscosidade que a solução deveria ter foi calculada a partir da permeabilidade efetiva da água após a recuperação realizada na fase 3. A permeabilidade é um dado de entrada nos modelos apresentados no subitem 4.1.1.2.1. Os modelos determinam o valor da taxa de cisalhamento na solução polimérica ao passar pelo meio poroso em questão. De posse da taxa de cisalhamento e dos valores expostos na Tabela 4, é possível chegar ao valor da viscosidade que a solução polimérica teria e produzir uma solução de água de Peregrino com glicerina de mesmo valor. Os valores de taxa de cisalhamento resultantes de cada modelo e as respectivas viscosidades estão apresentados na Tabela 23. 


\begin{tabular}{lll}
\hline Modelo & $\dot{\gamma}\left(\mathrm{s}^{-1}\right)$ & $\mu(\mathrm{cP})$ \\
\hline Littmann & 821,34 & 1,86 \\
\hline Middleman & 561,04 & 1,90 \\
\hline
\end{tabular}

Tabela 23 - Dados reológicos para produção da solução de glicerina para a amostra GBT3.

Para que esse valor de viscosidade fosse obtido foram misturados $165,57 \mathrm{~g}$ de glicerina com 334,64g de água de Peregrino. Uma mistura de aproximadamente $32,13 \%$ em massa. A partir desses valores, nota-se a grande vantagem dos polímeros quando comparado a outros aditivos para aumento da viscosidade de soluções.

Nessa etapa, 16,88mL de óleo estavam disponíveis para serem produzidos. Primeiramente realizou-se a injeção de 4 VP da solução de glicerina durante a fase 5 . Ao final desse volume, a recuperação foi continuada na fase 6 com a injeção de água de Peregrino até completar o volume total pré-estabelecido de 15 VP. O volume de óleo produzido foi de $6,82 \mathrm{~mL}$, resultando em um fator de recuperação de $40,44 \%$. Um acréscimo de $8,05 \%$, quando comparado à injeção de água pura, ocasionado somente pelo aumento da viscosidade da solução e, consequentemente, melhor razão de mobilidade.

A Fig. 42 representa a fase 5 em amarelo e a fase 6 em laranja. A Tabela 24 traz os valores iniciais e finais do processo. Os valores finais são referentes ao final da fase 6.

\begin{tabular}{llllr}
\hline Parâmetro & \multicolumn{2}{c}{ Inicial } & \multicolumn{2}{c}{ Final } \\
\hline Volume de água $(\mathrm{mL})$ & $\left(\mathrm{V}_{\mathrm{wi} / 5 / 6}\right)$ & $\mathbf{3 , 2 4}$ & $\left(\mathrm{V}_{\mathrm{wf} 5 / 6}\right)$ & $\mathbf{1 0 , 0 6}$ \\
\hline Volume de óleo $(\mathrm{mL})$ & $\left(\mathrm{V}_{\mathrm{oi} / 6 / 6}\right)$ & $\mathbf{1 6 , 8 6}$ & $\left(\mathrm{V}_{\mathrm{of} 5 / 6}\right)$ & $\mathbf{1 0 , 0 5}$ \\
\hline Saturação de água $(\%)$ & $\left(\mathrm{S}_{\mathrm{wi} / 6}\right)$ & $\mathbf{1 6 , 0 9}$ & $\left(\mathrm{S}_{\mathrm{wf} 5 / 6}\right)$ & $\mathbf{5 0 , 0 2}$ \\
\hline Saturação de óleo $(\%)$ & $\left(\mathrm{S}_{\mathrm{oi} / 5 / 6}\right)$ & $\mathbf{8 3 , 9 1}$ & $\left(\mathrm{S}_{\mathrm{of} 5 / 6}\right)$ & $\mathbf{4 9 , 9 8}$ \\
\hline Volume de óleo produzido $(\mathrm{mL})$ & & & $\left(\mathrm{N}_{\mathrm{os} / 6}\right)$ & $\mathbf{6 , 8 2}$ \\
\hline Permeabilidade efetiva à água $(\mathrm{mD})$ & & & $\left(\mathrm{K}_{\mathrm{ef} w 5 / 6}\right)$ & $\mathbf{2 , 6 5}$ \\
\hline Fator de recuperação de óleo $(\%)$ & & & & $\mathbf{4 0 , 4 4}$ \\
\hline
\end{tabular}

Tabela 24 - Dados das fases 5 e 6 (injeção de solução aquosa de glicerina seguida de água) da amostra GBT3. 
Assim como na fase 4, a fase 7 teve o objetivo de deslocar a água móvel da amostra a fim de retomar as características do reservatório para um novo ciclo de recuperação.

A Tabela 25 mostra os valores iniciais e finais do processo. Percebe-se que a saturação de óleo final é a maior das obtidas anteriormente nas duas fases de deslocamento de água, uma diferença menor que $1 \%$, porém o valor da permeabilidade efetiva ao óleo é bem menor do que a obtida nos processos de drenagem anteriores. Suspeita-se que o volume de água injetado não tenha sido suficiente para remover completamente a solução de glicerina. Pela Fig. 42, é possível verificar que a curva da segunda injeção de água de Peregrino apresenta um comportamento diferente do que foi apresentado na fase 3. No início da injeção o diferencial de pressão decresce consideravelmente até atingir um valor mínimo, e logo após manifesta um leve aumento. Acredita-se que a água tenha assumido alguns caminhos preferenciais e atravessado a amostra sem ter deslocado por completo a solução de glicerina, a qual foi lentamente removida ao longo do processo de injeção. A fase 7 é representada pela curva roxa na Fig. 42.

\begin{tabular}{llllr}
\hline Parâmetro & \multicolumn{2}{c}{ Inicial } & \multicolumn{2}{c}{ Final } \\
\hline Volume de água $(\mathrm{mL})$ & $\left(\mathrm{V}_{\text {wi7 }}\right)$ & $\mathbf{1 0 , 0 6}$ & $\left(\mathrm{V}_{\mathrm{wf} 7}\right)$ & $\mathbf{3 , 1 3}$ \\
\hline Volume de óleo $(\mathrm{mL})$ & $\left(\mathrm{V}_{\text {oi }}\right)$ & $\mathbf{1 0 , 0 5}$ & $\left(\mathrm{V}_{\text {of }}\right)$ & $\mathbf{1 6 , 9 8}$ \\
\hline Saturação de água $(\%)$ & $\left(\mathrm{S}_{\text {wi7 }}\right)$ & $\mathbf{5 0 , 0 2}$ & $\left(\mathrm{S}_{\mathrm{wf}}\right)$ & $\mathbf{1 5 , 5 9}$ \\
\hline Saturação de óleo $(\%)$ & $\left(\mathrm{S}_{\mathrm{oi}}\right)$ & $\mathbf{4 9 , 9 8}$ & $\left(\mathrm{S}_{\mathrm{of}}\right)$ & $\mathbf{8 4 , 4 1}$ \\
\hline Volume de água produzida $(\mathrm{mL})$ & & & $\left(\mathrm{N}_{\mathrm{w} 7}\right)$ & $\mathbf{6 , 9 2}$ \\
\hline Permeabilidade efetiva ao óleo $(\mathrm{mD})$ & & & $\left(\mathrm{K}_{\text {efo7 }}\right)$ & $\mathbf{4 5 , 9 4}$ \\
\hline
\end{tabular}

Tabela 25 - Dados da fase 7 (injeção de óleo) da amostra GBT3

A última etapa de recuperação de óleo foi realizada com a injeção de solução polimérica. O motivo de deixar essa solução para o fim é o fato dela causar modificações irreversíveis nas características petrofísicas da rocha através do processo de retenção polimérica. Assim como nas fases 5 e 6 , a injeção de polímeros foi 
realizada durante os primeiros 4 VP e em seguida a recuperação avançou com água de Peregrino.

O volume inicial de óleo disponível na amostra era de 16,98 mL. O total de óleo produzido após as duas fases foi de $8,72 \mathrm{~mL}$, resultando em um fator de recuperação de $51,40 \%$. Um acréscimo significativo de produção quando comparado à utilização de água de Peregrino de 19,01\%, e à solução de glicerina de 10,96\%.

As curvas da Fig. 42 que reproduzem o comportamento dessas fases 8 e 9 são a preta e a marrom, respectivamente. A Tabela 26 traz os valores iniciais e finais das fases.

\begin{tabular}{|c|c|c|c|c|}
\hline Parâmetro & \multicolumn{2}{|c|}{ Inicial } & \multicolumn{2}{|c|}{ Final } \\
\hline Volume de água (mL) & $\left(\mathrm{V}_{\text {wi8/9 }}\right)$ & 3,13 & $\left(\mathrm{~V}_{\mathrm{wf8} / 9}\right)$ & 11,86 \\
\hline Volume de óleo (mL) & $\left(\mathrm{V}_{\mathrm{oi} / 9 / 9}\right)$ & 16,98 & $\left(\mathrm{~V}_{\text {of8/9 }}\right)$ & 8,25 \\
\hline Saturação de água (\%) & $\left(\mathrm{S}_{\mathrm{wi} / 9 / 9}\right)$ & 15,59 & $\left(\mathrm{~S}_{\mathrm{wf} 8 / 9}\right)$ & $\mathbf{5 8 , 9 7}$ \\
\hline Saturação de óleo (\%) & $\left(\mathrm{S}_{\mathrm{oi} 8 / 9}\right)$ & 84,41 & $\left(\mathrm{~S}_{\mathrm{of} 8 / 9}\right)$ & 41,03 \\
\hline Volume de óleo produzido (mL) & & & $\left(\mathrm{N}_{\mathrm{o} 8 / 9}\right)$ & 8,72 \\
\hline Permeabilidade efetiva à água (mD) & & & $\left(\mathrm{K}_{\mathrm{efw} 8 / 9}\right)$ & $\mathbf{0 , 8 7}$ \\
\hline Fator de recuperação de óleo (\%) & & & & 51,40 \\
\hline
\end{tabular}

Tabela 26 - Dados das fases 8 e 9 (injeção de solução polimérica seguida de água) da amostra GBT3.

Ao final da fase de injeção de água de Peregrino foi calculado o fator de resistência residual (FFR) considerando as fases 3 e 9. Como é possível notar através da Fig. 42, no final da fase 9 o diferencial de pressão ainda não havia atingido a estabilidade, com isso, acredita-se que o valor de FFR não esteja preciso. O valor calculado foi de 3,08, maior que o valor apresentado no teste de adsorção $(2,48)$. Acredita-se, entretanto, que este valor deveria ser menor devido a influência da fase oleosa no processo.

As Fig. 43 e 44 trazem os dados de produção de óleo e fator de recuperação do teste. Através desses gráficos, observa-se que a produção inicial, nos primeiros 2 volumes porosos injetados, é melhor para os fluidos com viscosidade maiores, dado ao 
efeito de deslocamento tipo pistão que eles são capazes de gerar. Percebe-se também que mesmo para as soluções de valores similares de viscosidade, os efeitos ocasionados pela solução polimérica resultam em uma melhor recuperação do óleo.

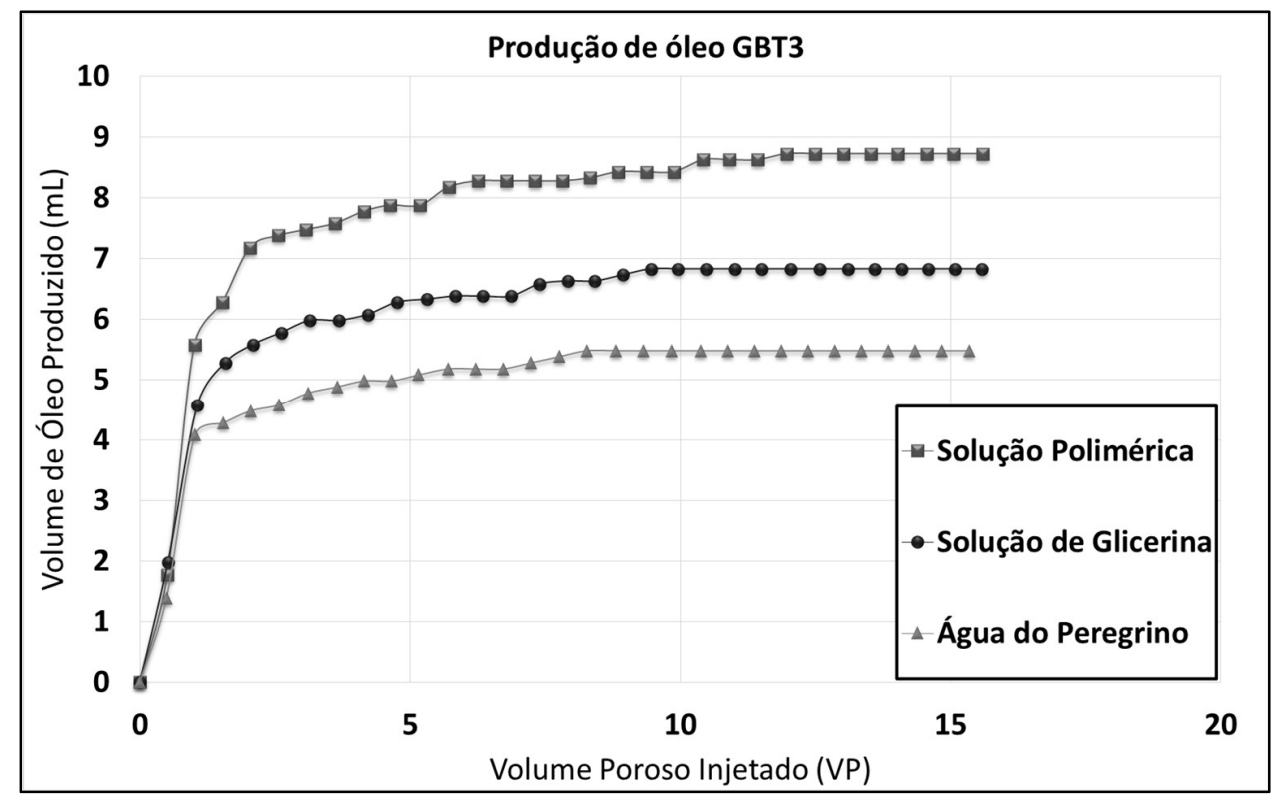

Figura 43 - Curva de volume de óleo produzido com água de Peregrino, solução de glicerina e solução polimérica da amostra GBT3.

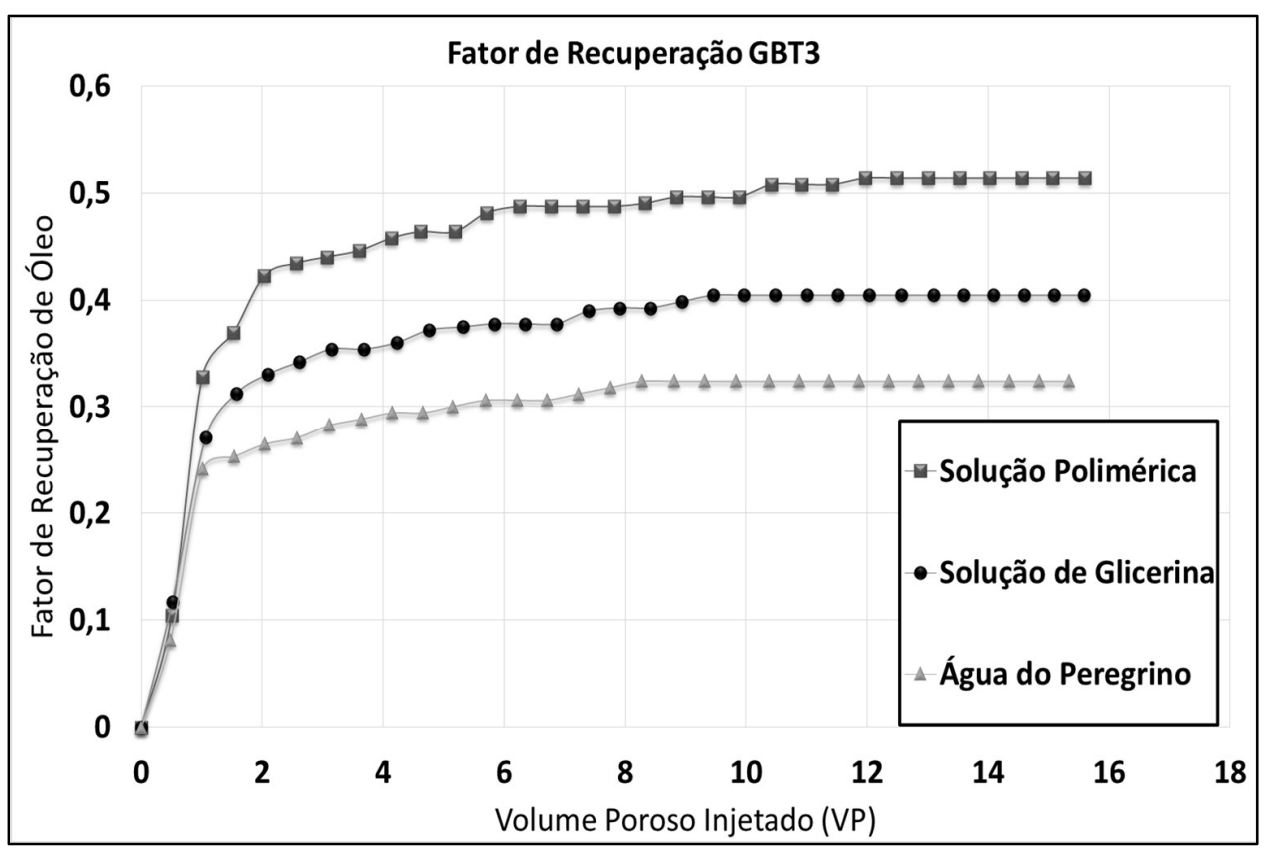

Figura 44 - Curva de fator de recuperação com água de Peregrino, solução de glicerina e solução polimérica da amostra GBT3. 


\section{2 .2}

\section{Buff Berea (BBT3)}

A Tabela 27 traz as características e propriedades petrofísicas da amostra BBT3.

\begin{tabular}{cc}
\hline Código da Amostra & BBT3 \\
\hline Procedência & Buff Berea \\
\hline Diâmetro $(\mathrm{cm})$ & 3,788 \\
\hline Área $\left(\mathrm{cm}^{2}\right)$ & 11,269 \\
\hline Comprimento $(\mathrm{cm})$ & 10,184 \\
\hline Volume $\left(\mathrm{cm}^{3}\right)$ & 114,770 \\
\hline Amostra Seca $(\mathrm{g})$ & 241,30 \\
\hline Amostra Úmida $(\mathrm{g})$ & 264,90 \\
\hline Volume Poroso $(\mathrm{mL})$ & 22,61 \\
\hline Porosidade & 19,69
\end{tabular}

Tabela 27 - Características e propriedades petrofísicas da amostra BBT3.

A fase 1 foi realizada com a saturação final e com o procedimento de determinação da curva de permeabilidade absoluta inicial da amostra. A Fig. 45 mostra os pontos de diferencial de pressão para cada vazão aplicada. Utilizando o coeficiente angular da reta na Eq. 17, chegou-se ao valor da permeabilidade absoluta da formação de $111,46 \mathrm{mD}$. 


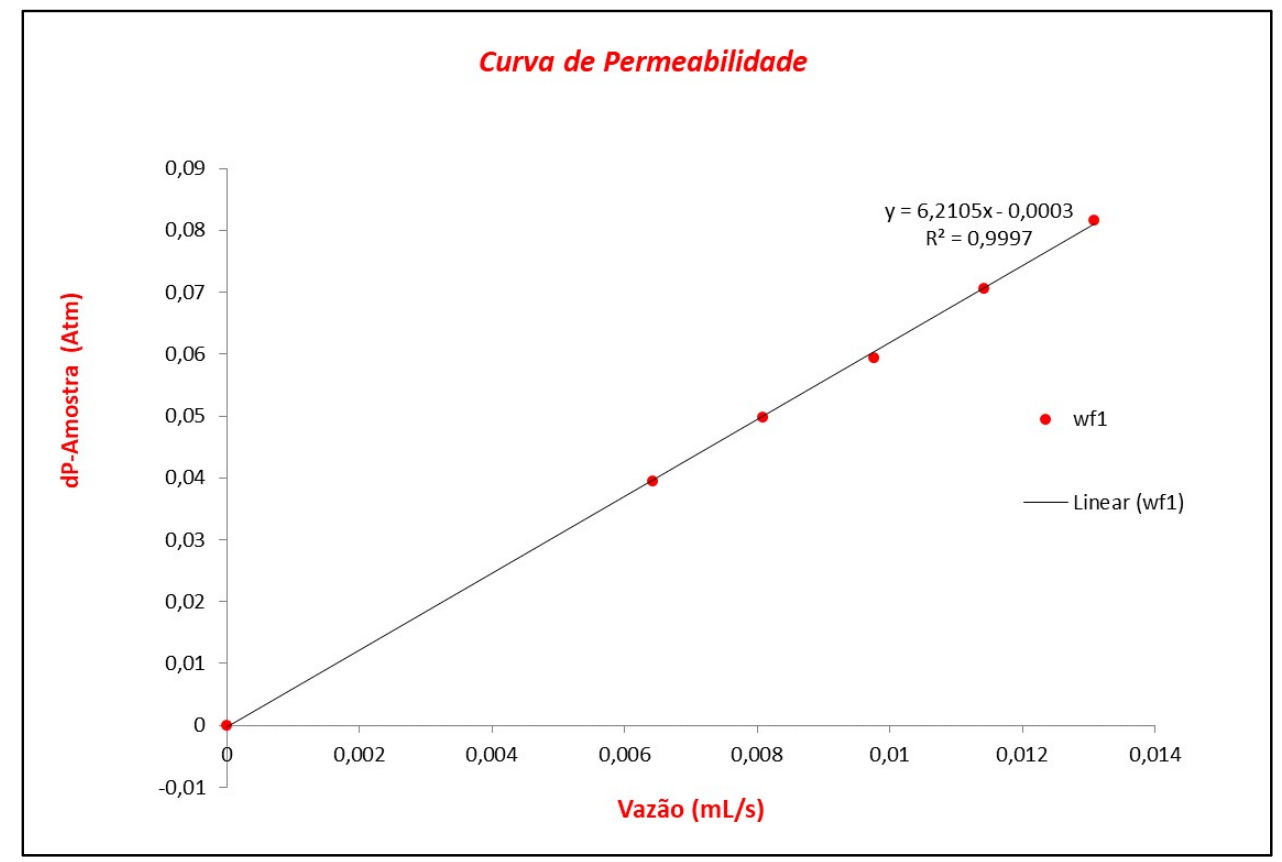

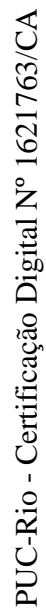

Figura 45- Curva de permeabilidade absoluta inicial da amostra BBT3.

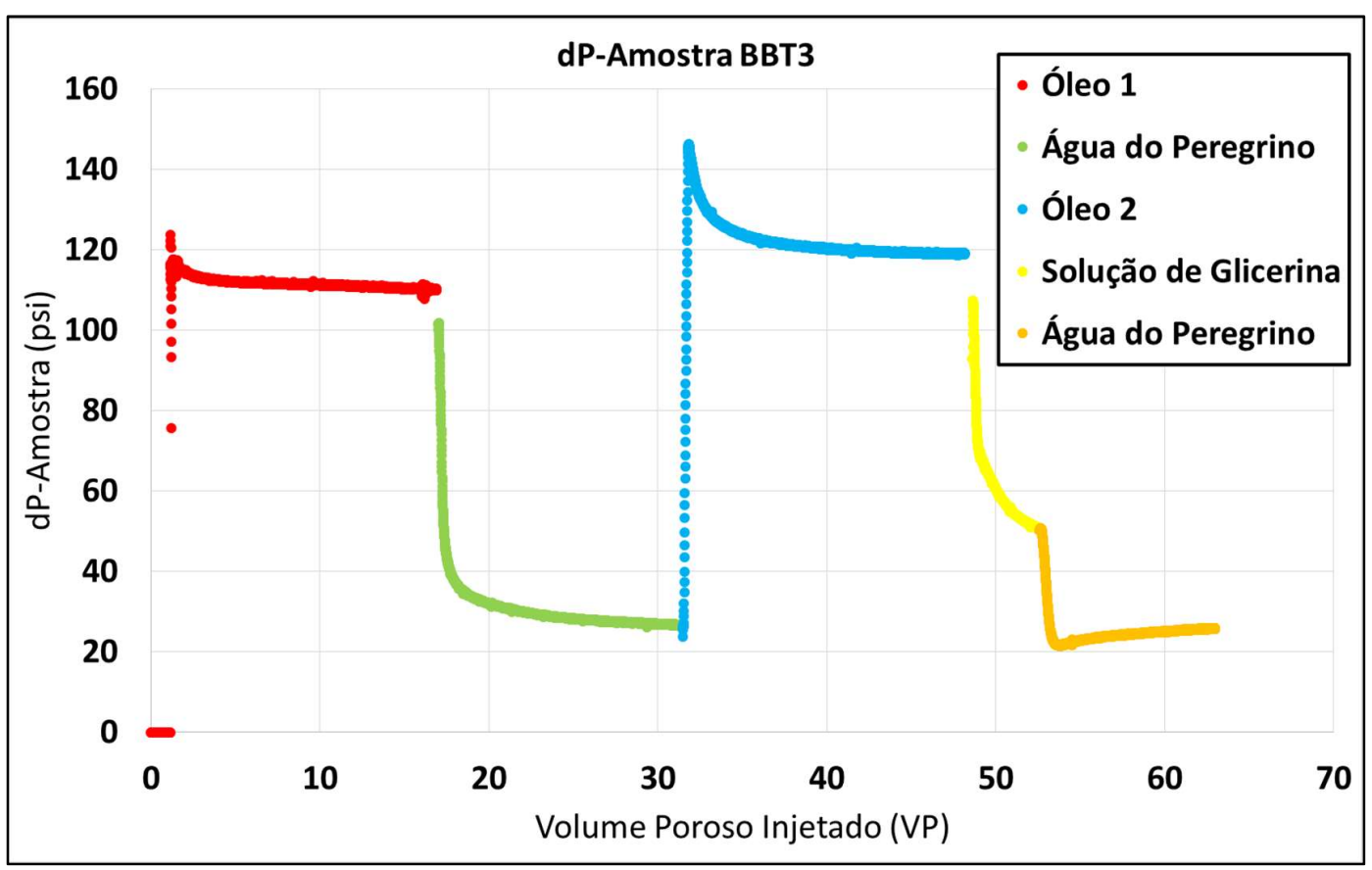

Figura 46 - Diferencial de pressão através da amostra BBT3. 
Terminada a fase 1, deu-se início à injeção de óleo. A Tabela 28 traz os valores iniciais de cada fluido e os resultados do deslocamento da água realizado na fase 2 . Após a produção de toda água móvel que estava contida na amostra, a saturação final de óleo ficou em 74,32\% com um volume de óleo disponível para produção de 16,80 mL. A fase 2 está indicada em vermelho na Fig. 46.

\begin{tabular}{lllll}
\hline Parâmetro & \multicolumn{2}{c}{ Inicial } & \multicolumn{2}{c}{ Final } \\
\hline Volume de água $(\mathrm{mL})$ & $\left(\mathrm{V}_{\mathrm{wi} 2}\right)$ & $\mathbf{2 2 , 6 1}$ & $\left(\mathrm{V}_{\mathrm{wf} 2}\right)$ & $\mathbf{5 , 8 1}$ \\
\hline Volume de óleo $(\mathrm{mL})$ & $\left(\mathrm{V}_{\mathrm{oi} 2}\right)$ & $\mathbf{0}$ & $\left(\mathrm{V}_{\mathrm{of} 2}\right)$ & $\mathbf{1 6 , 8 0}$ \\
\hline Saturação de água $(\%)$ & $\left(\mathrm{S}_{\mathrm{wi} 2}\right)$ & $\mathbf{1 0 0}$ & $\left(\mathrm{S}_{\mathrm{wf} 2}\right)$ & $\mathbf{2 5 , 6 8}$ \\
\hline Saturação de óleo $(\%)$ & $\left(\mathrm{S}_{\mathrm{o} i 2}\right)$ & $\mathbf{0}$ & $\left(\mathrm{S}_{\mathrm{of} 2}\right)$ & $\mathbf{7 4 , 3 2}$ \\
\hline Volume de água produzida $(\mathrm{mL})$ & & & $\left(\mathrm{N}_{\mathrm{w} 2}\right)$ & $\mathbf{1 6 , 8 0}$ \\
\hline Permeabilidade efetiva ao óleo $(\mathrm{mD})$ & & & $\left(\mathrm{K}_{\mathrm{ef} 2}\right)$ & $\mathbf{1 2 5 , 8 5}$ \\
\hline
\end{tabular}

Tabela 28 - Dados da fase 2 (injeção de óleo) da amostra BBT3.

Durante a fase 3 foi realizada a recuperação do óleo com injeção de água de Peregrino. Dos 16,80 mL disponíveis, foram produzidos $4,77 \mathrm{~mL}$, resultando em um fator de recuperação de 28,4\%, ainda menor que o alcançado na amostra de Gray Berea. A Tabela 29 traz os valores iniciais e finais do teste. A curva verde representa a fase 3 na Fig. 46.

\begin{tabular}{llllr}
\hline Parâmetro & \multicolumn{2}{c}{ Inicial } & \multicolumn{2}{c}{ Final } \\
\hline Volume de água $(\mathrm{mL})$ & $\left(\mathrm{V}_{\text {wi3 }}\right)$ & $\mathbf{5 , 8 1}$ & $\left(\mathrm{V}_{\mathrm{wf} 3}\right)$ & $\mathbf{1 0 , 5 8}$ \\
\hline Volume de óleo $(\mathrm{mL})$ & $\left(\mathrm{V}_{\mathrm{oi} 3}\right)$ & $\mathbf{1 6 , 8 0}$ & $\left(\mathrm{V}_{\mathrm{of} 3}\right)$ & $\mathbf{1 2 , 0 3}$ \\
\hline Saturação de água $(\%)$ & $\left(\mathrm{S}_{\text {wi3 }}\right)$ & $\mathbf{2 5 , 6 8}$ & $\left(\mathrm{S}_{\mathrm{wf} 3}\right)$ & $\mathbf{4 6 , 7 9}$ \\
\hline Saturação de óleo $(\%)$ & $\left(\mathrm{S}_{\mathrm{oi} 3}\right)$ & $\mathbf{7 4 , 3 2}$ & $\left(\mathrm{S}_{\mathrm{of} 3}\right)$ & $\mathbf{5 3 , 2 1}$ \\
\hline Volume de óleo produzido $(\mathrm{mL})$ & & & $\left(\mathrm{N}_{\mathrm{o} 3}\right)$ & $\mathbf{4 , 7 7}$ \\
\hline Permeabilidade efetiva à água $(\mathrm{mD})$ & & & $\left(\mathrm{K}_{\mathrm{efw} 3}\right)$ & $\mathbf{4 , 9 2}$ \\
\hline Fator de recuperação de óleo $(\%)$ & & & & $\mathbf{2 8 , 4}$ \\
\hline
\end{tabular}


Ao final da fase 3, de posse do valor de permeabilidade efetiva à água, calculouse a taxa de cisalhamento através dos modelos de Littmann e Middleman para determinar o valor de viscosidade da solução de glicerina. Os valores estão dispostos na Tabela 30.

\begin{tabular}{lcc}
\hline Modelo & $\dot{\gamma}\left(\mathrm{s}^{-1}\right)$ & $\mu(\mathrm{cP})$ \\
\hline Littmann & 575,77 & 1,89 \\
\hline Middleman & 398,90 & 1,99 \\
\hline
\end{tabular}

Tabela 30 - Dados reológicos para produção da solução de glicerina para a amostra BBT3.

Na fase 4 foi realizada uma nova injeção de óleo para deslocar a água móvel da amostra e restaurar as características do reservatório. Dessa vez, foi possível atingir uma saturação de óleo de $80,74 \%$, em torno de $6 \%$ maior que a primeira drenagem, com um volume de óleo acumulado na amostra de 18,25 mL. Os resultados desse procedimento são apresentados na Tabela 31 . A curva azul representa a fase 4 na Fig. 46.

\begin{tabular}{llllr}
\hline Parâmetro & \multicolumn{2}{c}{ Inicial } & \multicolumn{2}{c}{ Final } \\
\hline Volume de água $(\mathrm{mL})$ & $\left(\mathrm{V}_{\mathrm{wi}}\right)$ & $\mathbf{1 0 , 5 8}$ & $\left(\mathrm{V}_{\mathrm{wf} 4}\right)$ & $\mathbf{4 , 3 6}$ \\
\hline Volume de óleo $(\mathrm{mL})$ & $\left(\mathrm{V}_{\mathrm{oi}}\right)$ & $\mathbf{1 2 , 0 3}$ & $\left(\mathrm{V}_{\mathrm{of} 4}\right)$ & $\mathbf{1 8 , 2 5}$ \\
\hline Saturação de água $(\%)$ & $\left(\mathrm{S}_{\mathrm{wi} 4}\right)$ & $\mathbf{4 6 , 7 9}$ & $\left(\mathrm{S}_{\mathrm{wf} 4}\right)$ & $\mathbf{1 9 , 2 6}$ \\
\hline Saturação de óleo $(\%)$ & $\left(\mathrm{S}_{\mathrm{o} i 4}\right)$ & $\mathbf{5 3 , 2 1}$ & $\left(\mathrm{S}_{\mathrm{of} 4}\right)$ & $\mathbf{8 0 , 7 4}$ \\
\hline Volume de água produzida $(\mathrm{mL})$ & & & $\left(\mathrm{N}_{\mathrm{w} 4}\right)$ & $\mathbf{6 , 2 2}$ \\
\hline Permeabilidade efetiva ao óleo $(\mathrm{mD})$ & & & $\left(\mathrm{K}_{\text {efo } 4}\right)$ & $\mathbf{1 1 6 , 5 8}$
\end{tabular}

Tabela 31 - Dados da fase 4 (injeção de óleo) da amostra BBT3.

Um novo protocolo de recuperação foi realizado nas fases 5 e 6 . Para os valores apresentados na Tabela 30, as quantidades de glicerina pura e de água de Peregrino na nova mistura foram $171,05 \mathrm{~g}$ e $328,98 \mathrm{~g}$, respectivamente. 
Inicialmente realizou-se a injeção de 4VP de solução de glicerina, que posteriormente foi deslocada com água de Peregrino até completar o total de 15 VP injetados. Ao final de todo o processo foram recuperados $34,37 \%$ do total de óleo disponível na amostra, um acréscimo de 5,97\% em comparação com a recuperação da fase 3 (injeção de água). Novamente percebe-se um aumento que provavelmente foi decorrente da melhor razão de mobilidade proporcionado pela injeção de um fluido de maior viscosidade. A Tabela 32 traz os valores finais dos procedimentos em conjunto. As fases 5 e 6 estão representadas na Fig. 46 pelas curvas amarela e laranja, respectivamente.

\begin{tabular}{llllr}
\hline Parâmetro & \multicolumn{2}{c}{ Inicial } & \multicolumn{2}{c}{ Final } \\
\hline Volume de água $(\mathrm{mL})$ & $\left(\mathrm{V}_{\mathrm{wi} /} / 6\right)$ & $\mathbf{4 , 3 6}$ & $\left(\mathrm{V}_{\mathrm{wf} 5 / 6}\right)$ & $\mathbf{1 0 , 6 3}$ \\
\hline Volume de óleo $(\mathrm{mL})$ & $\left(\mathrm{V}_{\mathrm{oi} / 5 / 6}\right)$ & $\mathbf{1 8 , 2 5}$ & $\left(\mathrm{V}_{\mathrm{of} 5 / 6}\right)$ & $\mathbf{1 1 , 9 8}$ \\
\hline Saturação de água $(\%)$ & $\left(\mathrm{S}_{\mathrm{wi} / 5 / 6}\right)$ & $\mathbf{1 9 , 2 6}$ & $\left(\mathrm{S}_{\mathrm{wf} 5 / 6}\right)$ & $\mathbf{4 7 , 0 1}$ \\
\hline Saturação de óleo $(\%)$ & $\left(\mathrm{S}_{\mathrm{oi} 5 / 6}\right)$ & $\mathbf{8 0 , 7 4}$ & $\left(\mathrm{S}_{\mathrm{of} 5 / 6}\right)$ & $\mathbf{5 2 , 9 9}$ \\
\hline Volume de água produzida $(\mathrm{mL})$ & & & $\left(\mathrm{N}_{\mathrm{w} 5 / 6}\right)$ & $\mathbf{6 , 2 7}$ \\
\hline Permeabilidade efetiva ao óleo $(\mathrm{mD})$ & & & $\left(\mathrm{K}_{\mathrm{efo} / 6}\right)$ & $\mathbf{5 , 0 9}$ \\
\hline Fator de recuperação de óleo $(\%)$ & & & & $\mathbf{3 4 , 3 7}$ \\
\hline
\end{tabular}

Tabela 32 - Dados das fases 5 e 6 (injeção de solução aquosa de glicerina seguida de água) da amostra BBT3.

Na fase 7, a saturação final de óleo foi de $80,07 \%$, muito próxima a obtida na segunda drenagem, o que resulta em um volume de $18,10 \mathrm{~mL}$ de óleo acumulado na amostra. A Tabela 33 traz os valores iniciais e finais do processo.

Infelizmente não foi possível acompanhar o comportamento do diferencial de pressão através da amostra durante a fase 7 , pois os valores ultrapassaram o limite dos transdutores disponíveis no momento do teste. Acredita-se que o aumento tenha ocorrido novamente pelo mesmo motivo do teste anterior, pois as curvas apresentadas na Fig. 46 apresentam o mesmo comportamento que aquelas mostradas na Figura 42. Ao final dessa etapa, já com o sistema estabilizado, foi possível obter o valor de diferencial de pressão para cálculo da permeabilidade efetiva. 


\begin{tabular}{llllr}
\hline Parâmetro & \multicolumn{2}{c}{ Inicial } & \multicolumn{2}{c}{ Final } \\
\hline Volume de água $(\mathrm{mL})$ & $\left(\mathrm{V}_{\mathrm{wi}}\right)$ & $\mathbf{1 0 , 6 3}$ & $\left(\mathrm{V}_{\mathrm{wf}}\right)$ & $\mathbf{4 , 5 1}$ \\
\hline Volume de óleo $(\mathrm{mL})$ & $\left(\mathrm{V}_{\mathrm{oi}}\right)$ & $\mathbf{1 1 , 9 8}$ & $\left(\mathrm{V}_{\mathrm{of}}\right)$ & $\mathbf{1 8 , 1 0}$ \\
\hline Saturação de água $(\%)$ & $\left(\mathrm{S}_{\mathrm{wi} 7}\right)$ & $\mathbf{4 7 , 0 1}$ & $\left(\mathrm{S}_{\mathrm{wf} 7}\right)$ & $\mathbf{1 9 , 9 3}$ \\
\hline Saturação de óleo $(\%)$ & $\left(\mathrm{S}_{\mathrm{oi} 7}\right)$ & $\mathbf{5 2 , 9 9}$ & $\left(\mathrm{S}_{\mathrm{of}}\right)$ & $\mathbf{8 0 , 0 7}$ \\
\hline Volume de água produzida $(\mathrm{mL})$ & & & $\left(\mathrm{N}_{\mathrm{w} 7}\right)$ & $\mathbf{6 , 1 2}$ \\
\hline Permeabilidade efetiva ao óleo $(\mathrm{mD})$ & & & $\left(\mathrm{K}_{\mathrm{ef} 7}\right)$ & $\mathbf{8 6 , 9 4}$ \\
\hline
\end{tabular}

Tabela 33 - Dados da fase 7 (injeção de óleo) da amostra BBT3.

As fases 8 e 9 (injeção de solução polimérica seguida de água) foram realizadas em seguida. $\mathrm{O}$ volume de óleo recuperado durante as duas fases foi de $8,12 \mathrm{~mL}$, totalizado um fator de recuperação de $44,86 \%$. Esse valor supera o que foi atingido com a injeção de água em 16,46\%, e em 10,49\% o da solução de glicerina.

Igualmente como ocorreu na fase 7 , não foi possível o acompanhamento dos dados de pressão durante a injeção, porém ao final do procedimento, foram adquiridos alguns valores para o cálculo da permeabilidade. O FFR calculado ao final da fase 9 foi de 3,09 , menor que o valor apresentado no processo de adsorção $(7,66)$. A Tabela 34 traz os valores iniciais e finais do processo.

\begin{tabular}{|c|c|c|c|c|}
\hline Parâmetro & \multicolumn{2}{|c|}{ Inicial } & \multicolumn{2}{|c|}{ Final } \\
\hline Volume de água (mL) & $\left(\mathrm{V}_{\text {wi8/9 }}\right)$ & 4,51 & $\left(V_{w f 8 / 9}\right)$ & 12,63 \\
\hline Volume de óleo (mL) & $\left(\mathrm{V}_{\mathrm{oi} 8 / 9}\right)$ & 18,10 & $\left(\mathrm{~V}_{\text {of } 8 / 9}\right)$ & 9,98 \\
\hline Saturação de água (\%) & $\left(\mathrm{S}_{\mathrm{wi} 8 / 9}\right)$ & 19,93 & $\left(\mathrm{~S}_{\mathrm{wf} 8 / 9}\right)$ & 55,86 \\
\hline Saturação de óleo (\%) & $\left(\mathrm{S}_{\mathrm{oi} 8 / 9}\right)$ & 80,07 & $\left(\mathrm{S}_{\mathrm{of} 8 / 9}\right)$ & 44,14 \\
\hline Volume de água produzida $(\mathrm{mL})$ & & & $\left(\mathrm{N}_{08 / 9}\right)$ & 8,12 \\
\hline Permeabilidade efetiva à água (mD) & & & $\left(\mathrm{K}_{\mathrm{efw}} 8 / 9\right)$ & 1,59 \\
\hline Fator de recuperação de óleo $(\mathrm{mL})$ & & & & 44,86 \\
\hline
\end{tabular}

Tabela 34 - Dados das fases 8 e 9 (injeção de solução polimérica seguida de água) da amostra BBT3. 
As Fig. 47 e 48 mostram a evolução das curvas de volume de óleo produzido e seus devidos fatores de recuperação para os 3 testes. Para a amostra de Buff Berea, os efeitos ocasionados na formação parecem ter contribuído ainda mais para a recuperação final de óleo. Porém, para certificar que não houve nenhuma contribuição externa dos processos de injeção realizados anteriormente, os testes foram repetidos com a exclusão da fase de injeção da solução de glicerina. Os resultados estão apresentados ao longo deste capítulo.

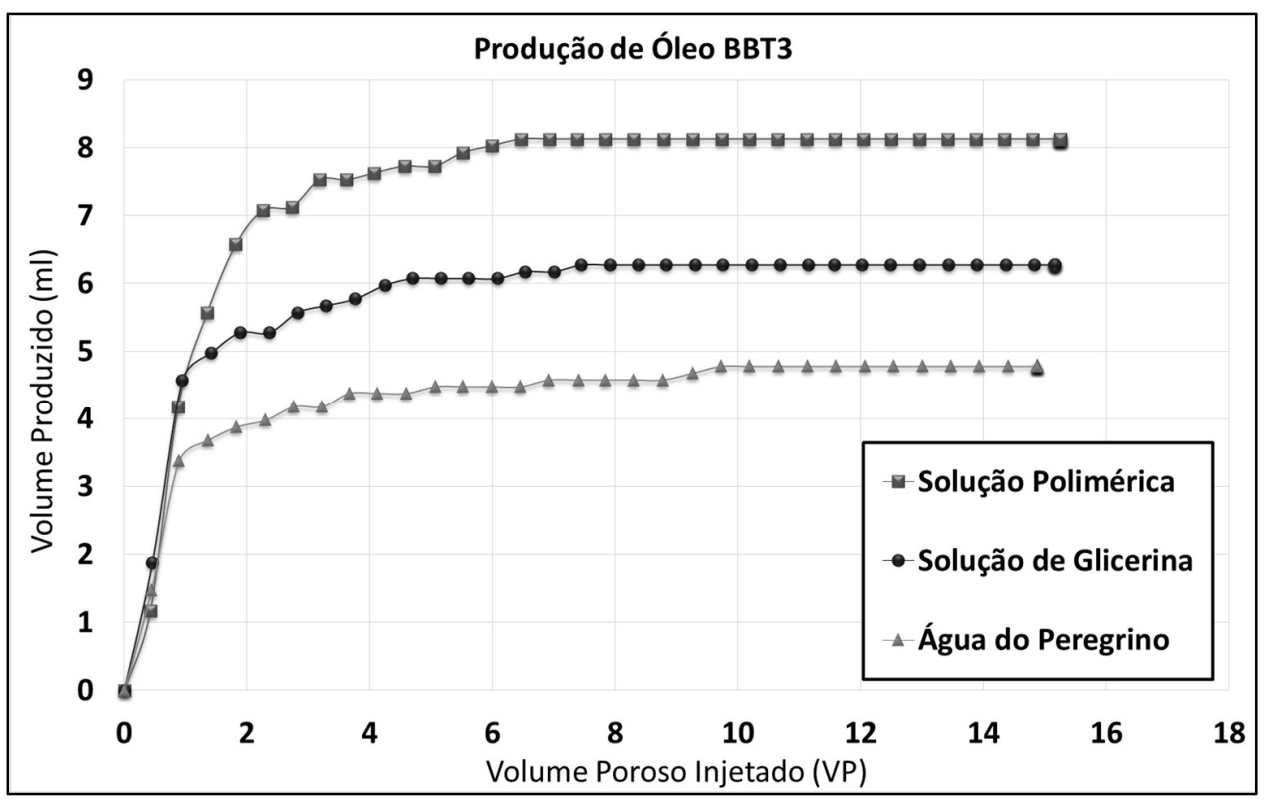

Figura 47 - Curva de volume de óleo produzido com água de Peregrino, solução de glicerina e solução polimérica da amostra BBT3. 


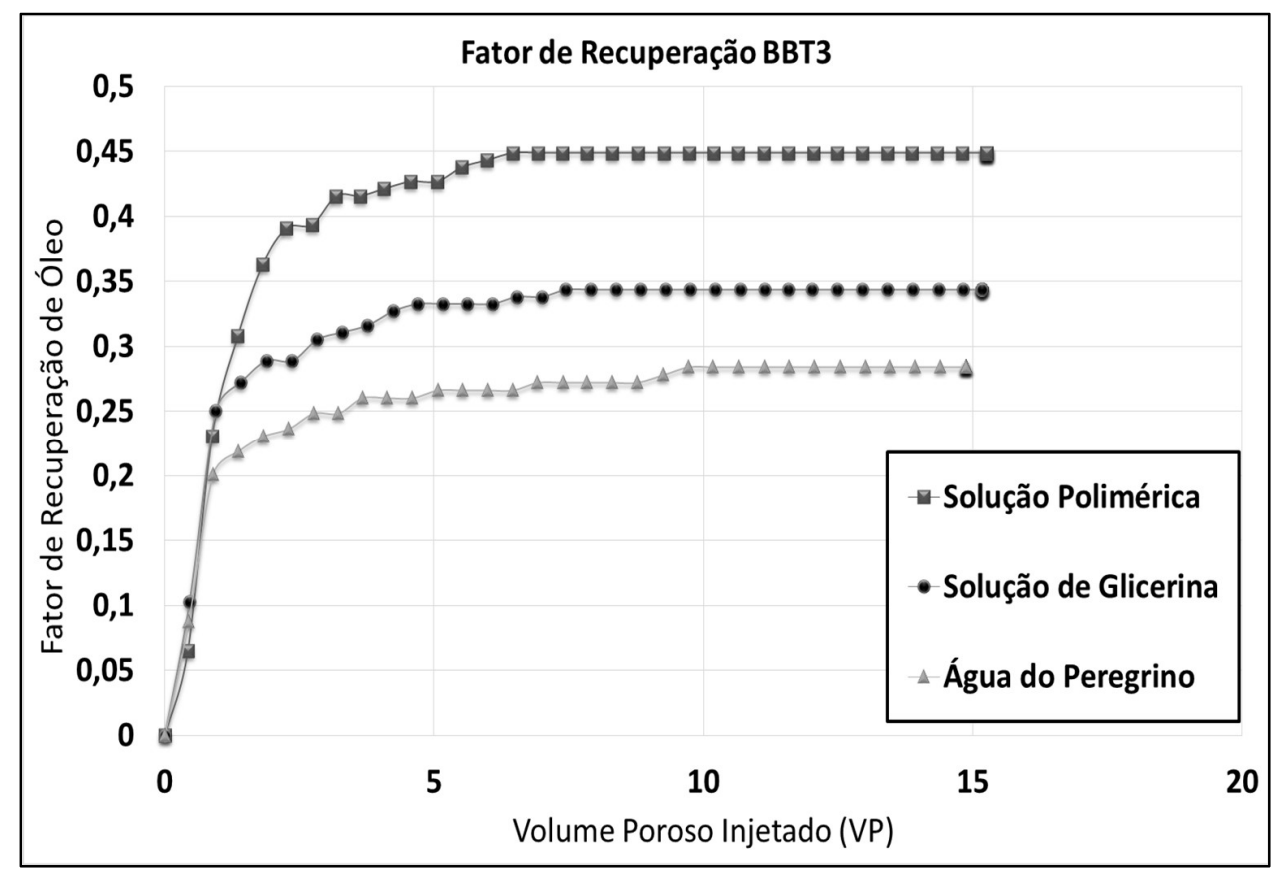

Figura 48 - Curva de fator de recuperação com água de Peregrino, solução de glicerina e solução polimérica da amostra BBT3.

\section{2 .3}

\section{Bentheimer (BHT2)}

A Tabela 35 traz as características e propriedades petrofísicas da amostra BHT2.

\begin{tabular}{cc}
\hline Código da Amostra & BHT2 \\
\hline Procedência & Bentheimer \\
\hline Diâmetro $(\mathrm{cm})$ & 3,792 \\
\hline Área $\left(\mathrm{cm}^{2}\right)$ & 11,293 \\
\hline Comprimento $(\mathrm{cm})$ & 10,155 \\
\hline Volume $\left(\mathrm{cm}^{3}\right)$ & 114,685 \\
\hline Amostra Seca $(\mathrm{g})$ & 227,70 \\
\hline Amostra Úmida $(\mathrm{g})$ & 256,60 \\
\hline Volume Poroso $(\mathrm{mL})$ & 27,68 \\
\hline Porosidade & 24,14 \\
\hline
\end{tabular}

Tabela 35 - Características e propriedades petrofísicas da amostra BHT2 
Na fase 1 foram realizados os procedimentos de saturação e determinação da permeabilidade absoluta inicial da amostra BHT2. Utilizando-se a Eq. 17 e as informações do gráfico, foi possível calcular uma permeabilidade absoluta de 2389,95 $\mathrm{mD}$.

Dispondo de um valor de permeabilidade muito maior que as demais amostras, supõe-se que o comportamento dos perfis de diferencial de pressão não apresente os problemas relacionados com a injeção da solução de glicerina. A Figura 47 confirma esse pensamento através da normalidade nos perfis apresentados. Nota-se que para todas as fases de recuperação, o patamar de estabilização é o mesmo.

A Fig. 49 traz os pontos referentes as diferentes vazões utilizadas e valores de diferencial de pressão resultantes.

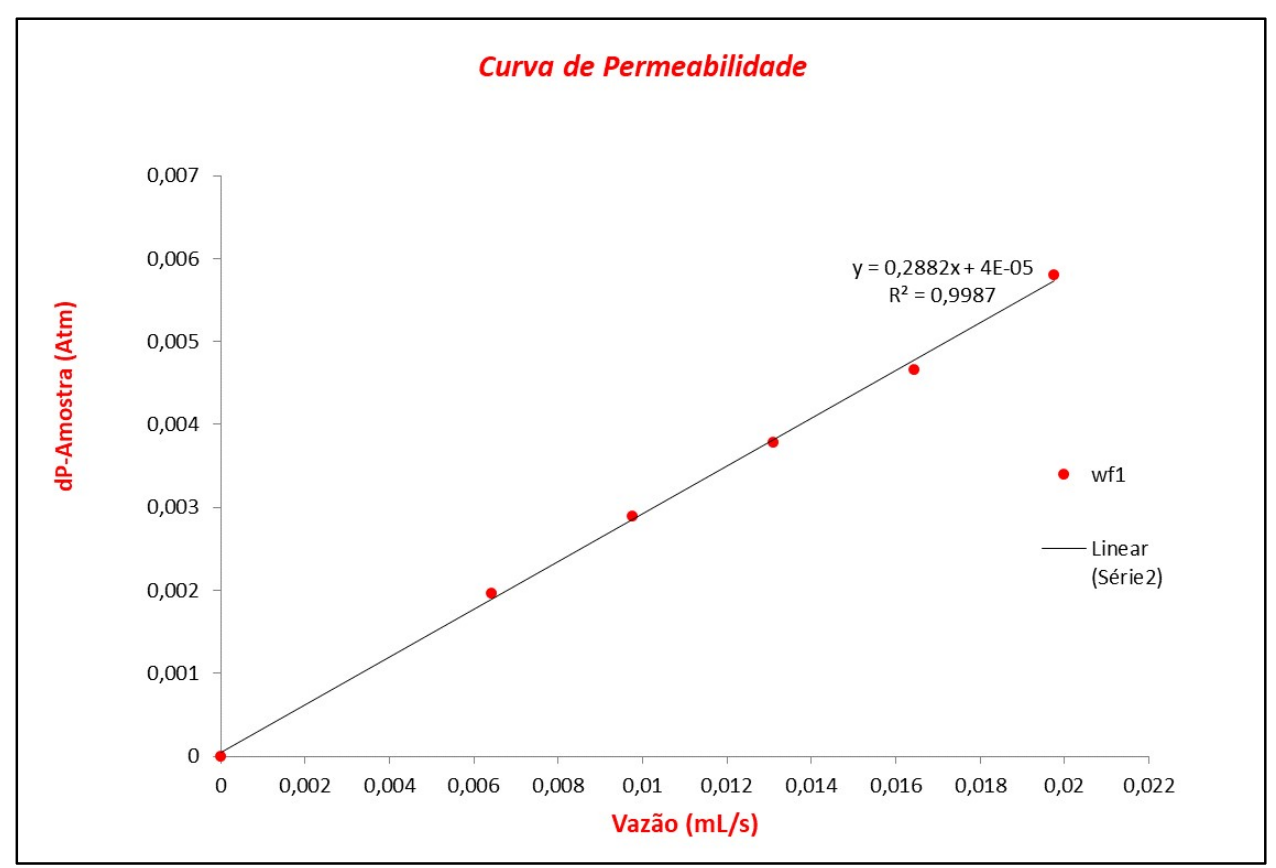

Figura 49 - Curva de permeabilidade absoluta inicial da amostra BHT2. 


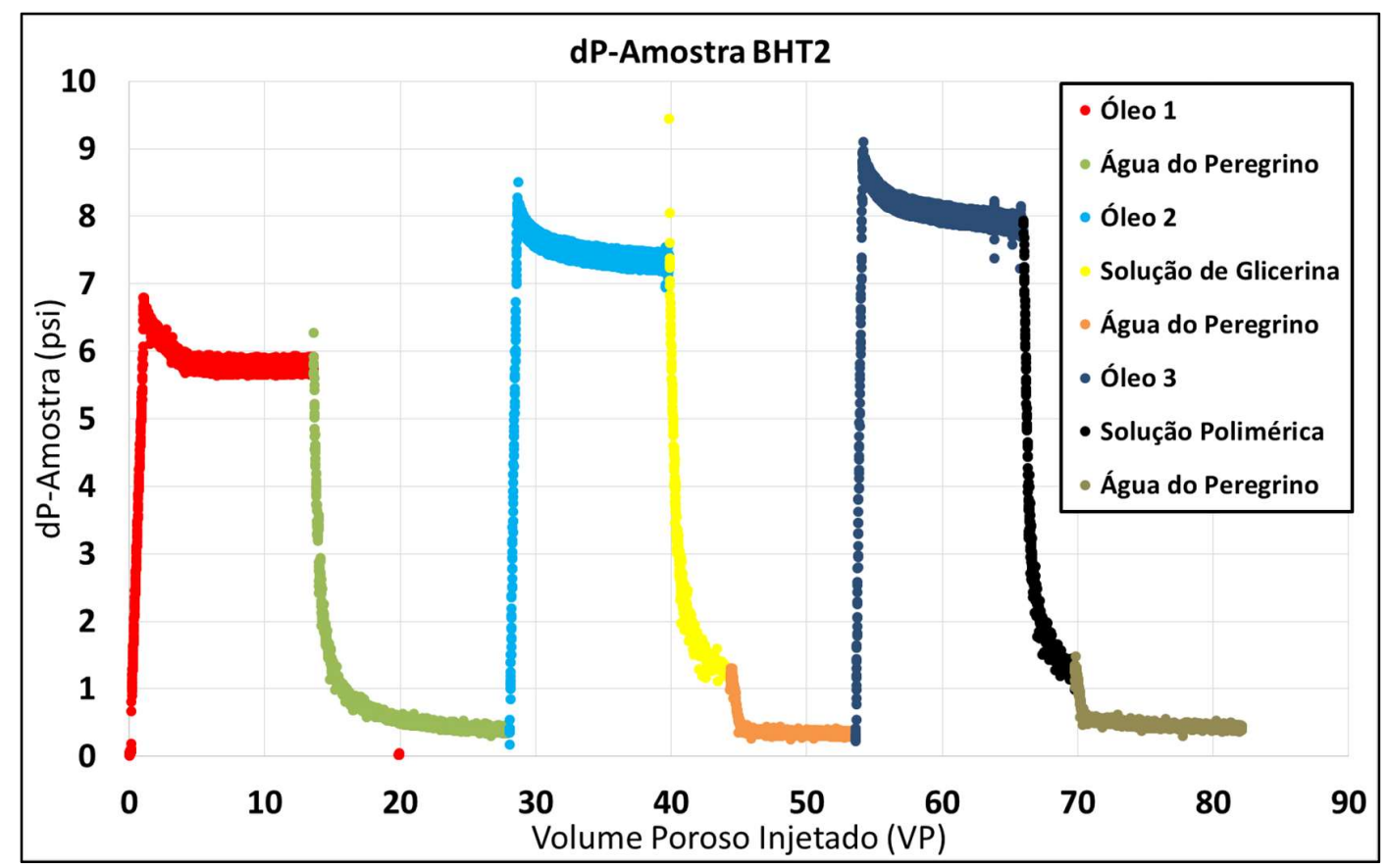

Figura 50 - Diferencial de pressão através da amostra BHT2.

Após a determinação da permeabilidade, iniciou-se a fase 2 (injeção de óleo). A injeção de óleo durou até que a produção de água fosse nula. Nesse momento, foi possível calcular a saturação inicial de óleo e a permeabilidade efetiva a esse fluido. A fase 2 tem seus valores dispostos na Tabela 36, e está representada na Fig. 50 através da curva vermelha.

\begin{tabular}{lllll}
\hline Parâmetro & \multicolumn{2}{c}{ Inicial } & \multicolumn{2}{c}{ Final } \\
\hline Volume de água $(\mathrm{mL})$ & $\left(\mathrm{V}_{\mathrm{wi} 2}\right)$ & $\mathbf{2 7 , 6 8}$ & $\left(\mathrm{V}_{\mathrm{wf} 2}\right)$ & $\mathbf{3 , 7 5}$ \\
\hline Volume de óleo $(\mathrm{mL})$ & $\left(\mathrm{V}_{\mathrm{oi} 2}\right)$ & $\mathbf{0}$ & $\left(\mathrm{V}_{\mathrm{of} 2}\right)$ & $\mathbf{2 3 , 9 2}$ \\
\hline Saturação de água $(\%)$ & $\left(\mathrm{S}_{\mathrm{wi} 2}\right)$ & $\mathbf{1 0 0}$ & $\left(\mathrm{S}_{\mathrm{wf} 2}\right)$ & $\mathbf{1 3 , 5 7}$ \\
\hline Saturação de óleo $(\%)$ & $\left(\mathrm{S}_{\mathrm{o} 2}\right)$ & $\mathbf{0}$ & $\left(\mathrm{S}_{\mathrm{of} 2}\right)$ & $\mathbf{8 6 , 4 3}$ \\
\hline Volume de água produzida $(\mathrm{mL})$ & & & $\left(\mathrm{N}_{\mathrm{w} 2}\right)$ & $\mathbf{2 3 , 6 2}$ \\
\hline Permeabilidade efetiva ao óleo $(\mathrm{mD})$ & & & $\left(\mathrm{K}_{\mathrm{ef} 2}\right)$ & $\mathbf{2 3 9 7 , 2 5}$ \\
\hline
\end{tabular}

Tabela 36 - Dados da fase 2 (injeção de óleo) da amostra BHT2. 
No início da fase 3 (injeção de água), o volume de óleo disponível para produção era de $23,92 \mathrm{~mL}$, dos quais $12,37 \mathrm{~mL}$ foram produzidos com a injeção de água de Peregrino, resultando em um fator de recuperação de 51,72\%. Acredita-se que essa fração elevada de óleo recuperado seja em função da alta permeabilidade da amostra, que torna o deslocamento dos fluidos menos suscetível as ações capilares.

Os dados iniciais e finais dessa etapa estão na Tabela 37. A curva verde da Fig. 50 reproduz o comportamento durante essa primeira recuperação.

\begin{tabular}{llllr}
\hline Parâmetro & \multicolumn{2}{c}{ Inicial } & \multicolumn{2}{c}{ Final } \\
\hline Volume de água $(\mathrm{mL})$ & $\left(\mathrm{V}_{\mathrm{wi} 3}\right)$ & $\mathbf{3 , 7 5}$ & $\left(\mathrm{V}_{\mathrm{wf} 3}\right)$ & $\mathbf{1 6 , 1 3}$ \\
\hline Volume de óleo $(\mathrm{mL})$ & $\left(\mathrm{V}_{\mathrm{oi} 3}\right)$ & $\mathbf{2 3 , 9 2}$ & $\left(\mathrm{V}_{\mathrm{of}}\right)$ & $\mathbf{1 1 , 5 5}$ \\
\hline Saturação de água $(\%)$ & $\left(\mathrm{S}_{\mathrm{wi} 3}\right)$ & $\mathbf{1 3 , 5 7}$ & $\left(\mathrm{S}_{\mathrm{wf}}\right)$ & $\mathbf{5 8 , 2 7}$ \\
\hline Saturação de óleo $(\%)$ & $\left(\mathrm{S}_{\mathrm{oi} 3}\right)$ & $\mathbf{8 4 , 4 3}$ & $\left(\mathrm{S}_{\mathrm{of}}\right)$ & $\mathbf{4 1 , 7 3}$ \\
\hline Volume de óleo produzido $(\mathrm{mL})$ & & & $\left(\mathrm{N}_{\mathrm{o} 3}\right)$ & $\mathbf{1 2 , 3 7}$ \\
\hline Permeabilidade efetiva à água $(\mathrm{mD})$ & & & $\left(\mathrm{K}_{\mathrm{efo} 3}\right)$ & $\mathbf{3 3 6 , 8 6}$ \\
\hline Fator de recuperação de óleo $(\%)$ & & & & $\mathbf{5 1 , 7 2}$ \\
\hline
\end{tabular}

Tabela 37 - Dados da fase 3 (injeção de água) da amostra BHT2.

Com os valores de diferencial de pressão estáveis calculou-se a permeabilidade efetiva à água de injeção. Assim como realizado com as amostras anteriores, determinou-se o valor da taxa de cisalhamento com os diferentes modelos e suas viscosidades, para produção da solução de glicerina.

\begin{tabular}{lcc}
\hline Modelo & $\dot{\gamma}\left(\mathrm{s}^{-1}\right)$ & $\mu(\mathrm{cP})$ \\
\hline Littmann & 1,85 & 2,7 \\
\hline Middleman & 1,28 & 2,7 \\
\hline
\end{tabular}

Tabela 38 - Dados reológicos para produção da solução de glicerina para a amostra BHT2. 
Os valores de taxa de cisalhamento calculados estão abaixo do mínimo utilizado nas análises realizadas no reômetro rotacional, desse modo optou-se em utilizar o valor de máxima viscosidade disponível pelo modelo da Fig. 50. Para essa mistura foram necessários 201,99 g de glicerina pura e 299,49 g de água de Peregrino.

Após o cessar da produção de óleo, foi realizada a retomada da amostra às condições iniciais para um novo procedimento de recuperação. Ao final desse procedimento, a amostra encontrava-se com uma saturação de óleo de 83,36\% de seu volume poroso total.

Os valores iniciais e finais da fase 4 estão na Tabela 39. Na Fig. 50, a curva azul representa a presente fase.

\begin{tabular}{lllll}
\hline Parâmetro & \multicolumn{2}{c}{ Inicial } & \multicolumn{2}{c}{ Final } \\
\hline Volume de água $(\mathrm{mL})$ & $\left(\mathrm{V}_{\mathrm{wi}}\right)$ & $\mathbf{1 6 , 1 3}$ & $\left(\mathrm{V}_{\mathrm{wf} 4}\right)$ & $\mathbf{4 , 6 1}$ \\
\hline Volume de óleo $(\mathrm{mL})$ & $\left(\mathrm{V}_{\mathrm{oi}}\right)$ & $\mathbf{1 1 , 5 5}$ & $\left(\mathrm{V}_{\mathrm{of} 4}\right)$ & $\mathbf{2 3 , 0 7}$ \\
\hline Saturação de água $(\%)$ & $\left(\mathrm{S}_{\mathrm{wi} 4}\right)$ & $\mathbf{5 8 , 2 7}$ & $\left(\mathrm{S}_{\mathrm{wf} 4}\right)$ & $\mathbf{1 6 , 6 4}$ \\
\hline Saturação de óleo $(\%)$ & $\left(\mathrm{S}_{\mathrm{oi} 4}\right)$ & $\mathbf{4 1 , 7 3}$ & $\left(\mathrm{S}_{\mathrm{of} 4}\right)$ & $\mathbf{8 3 , 3 6}$ \\
\hline Volume de água produzida $(\mathrm{mL})$ & & & $\left(\mathrm{N}_{\mathrm{w} 4}\right)$ & $\mathbf{1 1 , 5 2}$ \\
\hline Permeabilidade efetiva ao óleo $(\mathrm{mD})$ & & & $\left(\mathrm{K}_{\text {efo } 4}\right)$ & $\mathbf{1 8 9 8 , 2 5}$ \\
\hline
\end{tabular}

Tabela 39 - Dados da fase 4 (injeção de óleo) da amostra BHT2.

As fases 5 e 6, realizadas em conjunto, recuperaram $12,52 \mathrm{~mL}$ dos $23,07 \mathrm{~mL}$ de óleo disponível na amostra. O fator de recuperação final dessa fase foi $54,28 \%$, um valor não muito diferente daquele obtido apenas com a injeção de água de Peregrino, com um acréscimo de apenas $2,56 \%$.

A Tabela 40 traz os valores iniciais e finais dessas fases e a Fig. 50 representa, através das curvas amarela e laranja, o comportamento da solução de glicerina e da água de Peregrino, respectivamente. 


\begin{tabular}{llllr}
\hline Parâmetro & \multicolumn{2}{c}{ Inicial } & \multicolumn{2}{c}{ Final } \\
\hline Volume de água $(\mathrm{mL})$ & $\left(\mathrm{V}_{\mathrm{wi} /} / 6\right)$ & $\mathbf{4 , 6 1}$ & $\left(\mathrm{V}_{\mathrm{wf} 5 / 6}\right)$ & $\mathbf{1 7 , 1 3}$ \\
\hline Volume de óleo $(\mathrm{mL})$ & $\left(\mathrm{V}_{\mathrm{oi} / 6 / 6}\right)$ & $\mathbf{2 3 , 0 7}$ & $\left(\mathrm{V}_{\mathrm{of} 5 / 6}\right)$ & $\mathbf{1 0 , 5 5}$ \\
\hline Saturação de água $(\%)$ & $\left(\mathrm{S}_{\mathrm{wi} / 6 / 6}\right)$ & $\mathbf{1 6 , 6 4}$ & $\left(\mathrm{S}_{\mathrm{wf} 5 / 6}\right)$ & $\mathbf{6 1 , 8 9}$ \\
\hline Saturação de óleo $(\%)$ & $\left(\mathrm{S}_{\mathrm{oi} 5 / 6}\right)$ & $\mathbf{8 3 , 3 6}$ & $\left(\mathrm{S}_{\mathrm{of} / 6 / 6}\right)$ & $\mathbf{3 8 , 1 1}$ \\
\hline Volume de óleo produzido $(\mathrm{mL})$ & & & $\left(\mathrm{N}_{\mathrm{w} 5 / 6}\right)$ & $\mathbf{1 2 , 5 2}$ \\
\hline Permeabilidade efetiva à água $(\mathrm{mD})$ & & & $\left(\mathrm{K}_{\mathrm{ef} 55 / 6}\right)$ & $\mathbf{4 1 8 , 8 2}$ \\
\hline Fator de recuperação de óleo $(\%)$ & & & & $\mathbf{5 4 , 2 8}$ \\
\hline
\end{tabular}

Tabela 40 - Dados das fases 5 e 6 (injeção de solução aquosa de glicerina seguida de água) da amostra BHT2.

$\mathrm{Na}$ fase 7 ocorreu outra injeção de óleo com a mesma finalidade das fases 2 e 4. O volume de óleo acumulado ao final dessa fase foi de $22,02 \mathrm{~mL}$, que resulta em uma saturação de 79,57\%. A Tabela 41 mostra os valores referentes a essa etapa. A Fig. 50 apresenta por meio da curva roxa o diferencial de pressão através da amostra durante o terceiro processo de injeção de óleo.

\begin{tabular}{lllll}
\hline Parâmetro & \multicolumn{2}{c}{ Inicial } & \multicolumn{2}{c}{ Final } \\
\hline Volume de água $(\mathrm{mL})$ & $\left(\mathrm{V}_{\mathrm{wi}}\right)$ & $\mathbf{1 7 , 1 3}$ & $\left(\mathrm{V}_{\mathrm{wf}}\right)$ & $\mathbf{5 , 6 6}$ \\
\hline Volume de óleo $(\mathrm{mL})$ & $\left(\mathrm{V}_{\mathrm{oi}}\right)$ & $\mathbf{1 0 , 5 5}$ & $\left(\mathrm{V}_{\mathrm{of}}\right)$ & $\mathbf{2 2 , 0 2}$ \\
\hline Saturação de água $(\%)$ & $\left(\mathrm{S}_{\mathrm{wi}}\right)$ & $\mathbf{6 1 , 8 9}$ & $\left(\mathrm{S}_{\mathrm{wf}}\right)$ & $\mathbf{2 0 , 4 3}$ \\
\hline Saturação de óleo $(\%)$ & $\left(\mathrm{S}_{\mathrm{oi}}\right)$ & $\mathbf{3 8 , 1 1}$ & $\left(\mathrm{S}_{\mathrm{of}}\right)$ & $\mathbf{7 9 , 5 7}$ \\
\hline Volume de água produzida $(\mathrm{mL})$ & & & $\left(\mathrm{N}_{\mathrm{w}}\right)$ & $\mathbf{1 1 , 4 7}$ \\
\hline Permeabilidade efetiva ao óleo $(\mathrm{mD})$ & & & $\left(\mathrm{K}_{\mathrm{ef}}\right)$ & $\mathbf{1 7 5 5 , 9 0}$
\end{tabular}

Tabela 41 - Dados da fase 7 (injeção de óleo) da amostra BHT2.

Nas fases 8 e 9 foram realizados os últimos processos de recuperação de óleo. O volume inicial de óleo produzido ao final das duas fases foi de 12,77 mL. Esse valor corresponde a um fator de recuperação de $58 \%$, maior valor dentre os 3 métodos aplicados. Mesmo que não tenha sido muito significativo, o valor recuperado através da injeção de solução polimérica apresentou um novo aumento. Possivelmente, isso 
pode ter sido um resultado dos efeitos, ainda que pequenos, da retenção polimérica no processo de deslocamento de óleo do reservatório.

A Tabela 42 traz os valores totais do processo. A Fig. 50 mostra a fase $8 \mathrm{em}$ preto e a fase 9 em marrom.

\begin{tabular}{|c|c|c|c|c|}
\hline Parâmetro & \multicolumn{2}{|c|}{ Inicial } & \multicolumn{2}{|c|}{ Final } \\
\hline Volume de água (mL) & $\left(\mathrm{V}_{\text {wi8/9 }}\right)$ & 5,66 & $\left(\mathrm{~V}_{\mathrm{wf8} / 9}\right)$ & 18,43 \\
\hline Volume de óleo (mL) & $\left(\mathrm{V}_{\mathrm{oi} / 9 / 9}\right)$ & 22,02 & $\left(\mathrm{~V}_{\text {of } 8 / 9}\right)$ & 9,25 \\
\hline Saturação de água (\%) & $\left(\mathrm{S}_{\mathrm{wi} 8 / 9}\right)$ & 20,43 & $\left(\mathrm{~S}_{\mathrm{wf} 8 / 9}\right)$ & 66,58 \\
\hline Saturação de óleo (\%) & $\left(\mathrm{S}_{\mathrm{oi} / 9 / 9}\right)$ & $\mathbf{7 9 , 5 7}$ & $\left(\mathrm{S}_{\mathrm{of} 8 / 9}\right)$ & 33,42 \\
\hline Volume de óleo produzido (mL) & & & $\left(\mathrm{N}_{\mathrm{w} 8 / 9}\right)$ & 12,77 \\
\hline Permeabilidade efetiva à água (mD) & & & $\left(\mathrm{K}_{\mathrm{efo} 8 / 9}\right)$ & 315,30 \\
\hline Fator de recuperação de óleo (\%) & & & & 58,00 \\
\hline
\end{tabular}

Tabela 42 - Dados das fases 8 e 9 (injeção de solução polimérica seguida de água) da amostra BHT2.

De posse dos dados de permeabilidade de todas as fases, determinou-se o fator de resistência residual (FFR) como 1,07, uma modificação mínima, assim como ocorrido no teste de adsorção.

A Fig. 51 mostra a produção de óleo para os 3 procedimentos de recuperação. Ao analisar tal Figura, tem-se a impressão que o volume final produzido permaneceu constante para as 3 etapas, porém é preciso considerar que as saturações iniciais eram diferentes, assumindo valores decrescentes durantes os variados processos. Essa diferença torna-se notável na Figura 49, na qual estão plotadas as curvas de fator de recuperação, que levam em consideração os valores iniciais e finais e de cada processo separadamente.

Através da Fig. 52 é possível notar que o fator de recuperação para as 3 metodologias permanece praticamente o mesmo até a marca de 10 volumes porosos injetados. A partir desse momento, há um pequeno acréscimo na produção para as duas soluções com aditivos. Como o fator de recuperação, somente com a injeção de água 
de Peregrino, já foi bastante elevada devido à alta permeabilidade da formação, o aumento gerado pelas demais soluções tornou-se não muito expressivo. Ainda na Fig. 52, é possível perceber um leve processo de adiantamento da produção ao utilizar as soluções de maior viscosidade, o que poderia ser importante economicamente para o projeto.

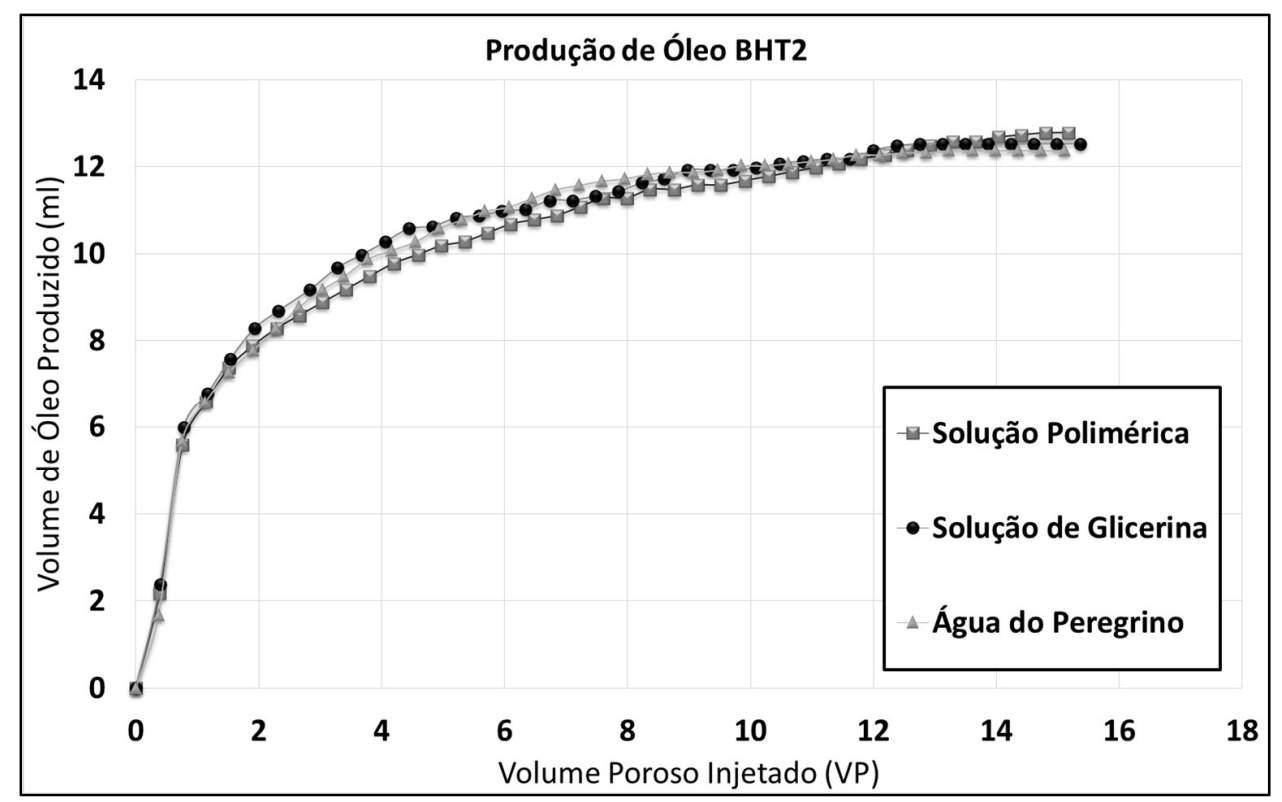

Figura 51 - Curva de volume de óleo produzido com água de Peregrino, solução de glicerina e solução polimérica da amostra BHT2. 


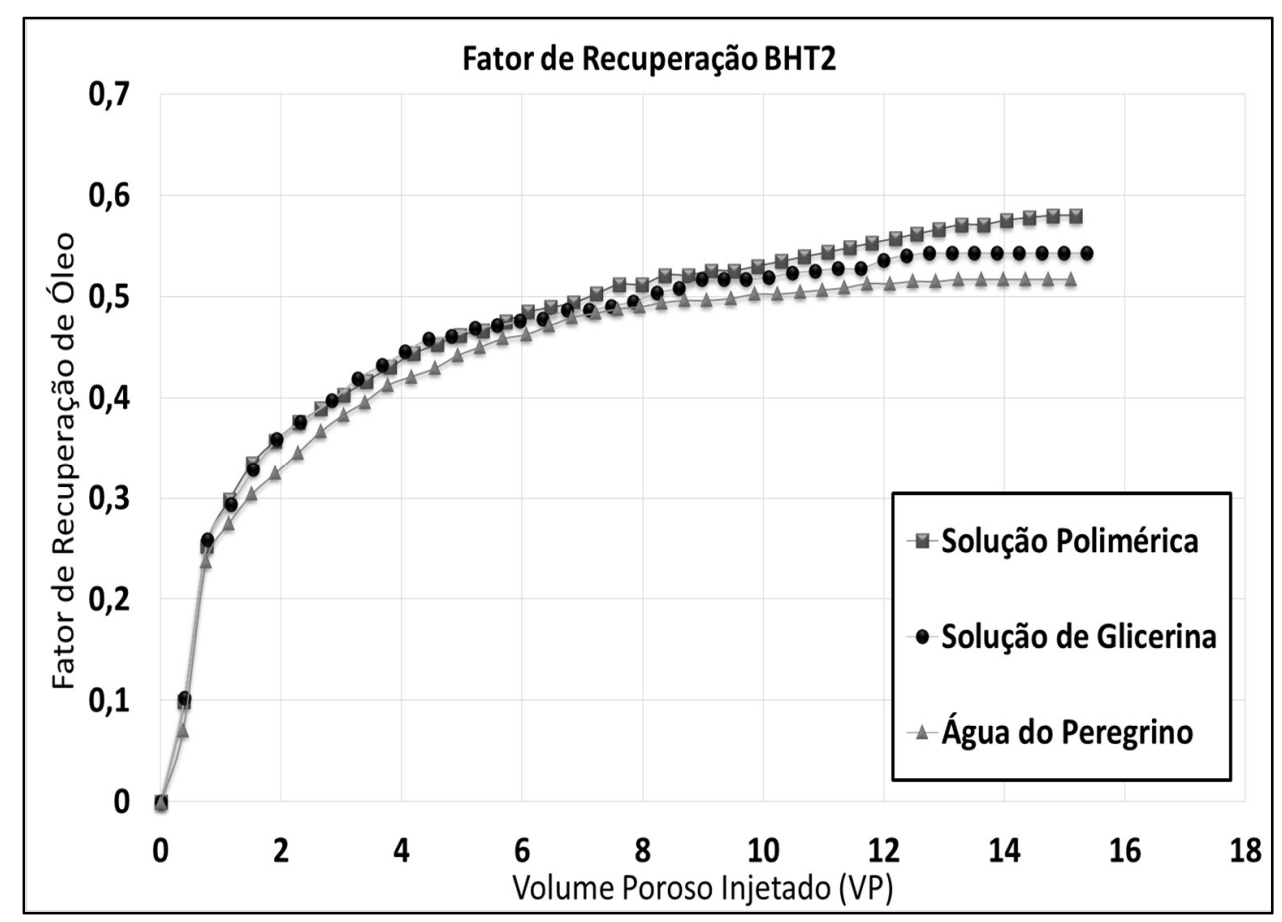

Figura 52 - Curva de fator de recuperação com água de Peregrino, solução de glicerina e solução polimérica da amostra BHT2.

\section{3}

\section{Recuperação de Óleo - Protocolo 2}

Inicialmente o protocolo 2 não seria realizado, porém ao observar-se uma anormalidade muito grande no diferencial de pressão através das amostras de menor permeabilidade após a injeção da solução de glicerina, julgou-se necessário a reprodução dos testes excluindo as fases 5, 6 e 7 para verificar se essas etapas poderiam ter influenciado os resultados das fases seguintes. Desse modo, os testes realizados a partir desse ponto contam apenas com a recuperação de óleo com a utilização de água de Peregrino e solução polimérica seguida de água de Peregrino. 


\subsection{1}

\section{Gray Berea (GBTH3)}

A Tabela 43 traz as características e propriedades petrofísicas da amostra GBTH3.

\begin{tabular}{cc}
\hline Código da Amostra & GBTH3 \\
\hline Procedência & Gray Berea \\
\hline Diâmetro $(\mathrm{cm})$ & 3,792 \\
\hline Área $\left(\mathrm{cm}^{2}\right)$ & 11,293 \\
\hline Comprimento $(\mathrm{cm})$ & 9,508 \\
\hline Volume $\left(\mathrm{cm}^{3}\right)$ & 107,378 \\
\hline Amostra Seca $(\mathrm{g})$ & 229,60 \\
\hline Amostra Úmida $(\mathrm{g})$ & 251,00 \\
\hline Volume Poroso $(\mathrm{mL})$ & 20,50 \\
\hline Porosidade & 19,09 \\
\hline
\end{tabular}

Tabela 43 - Características e propriedades petrofísicas da amostra GBTH3.

Na fase 1 realizou-se a saturação e determinação da permeabilidade absoluta inicial da mostra. Através da equação 17 e dos valores apresentados na Fig. 53, calculou-se uma permeabilidade de $69,66 \mathrm{mD}$, valor muito próximo ao do protocolo 1 . 


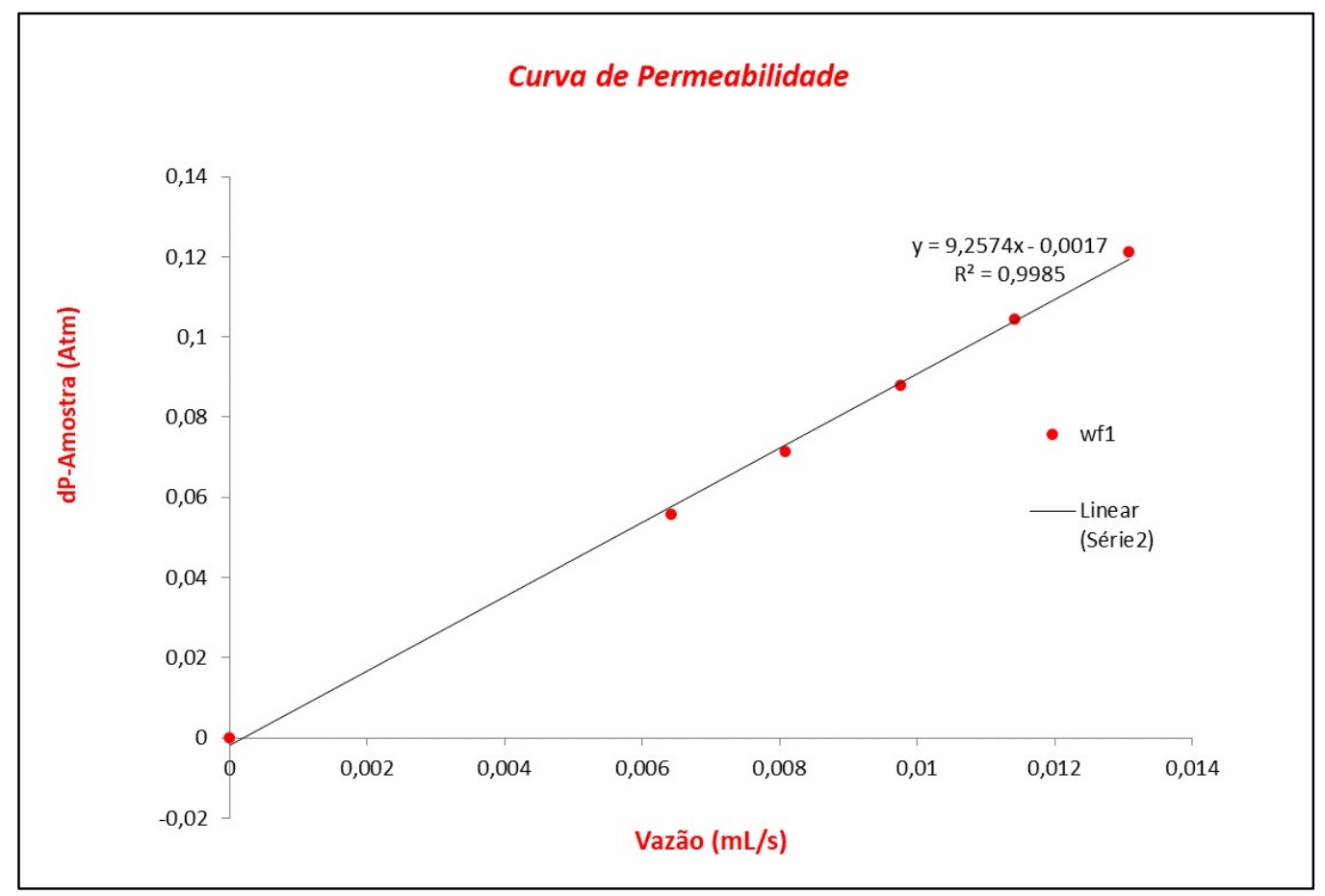

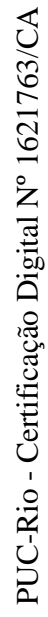

Figura 53 - Curva de permeabilidade absoluta inicial da amostra GBTH3.

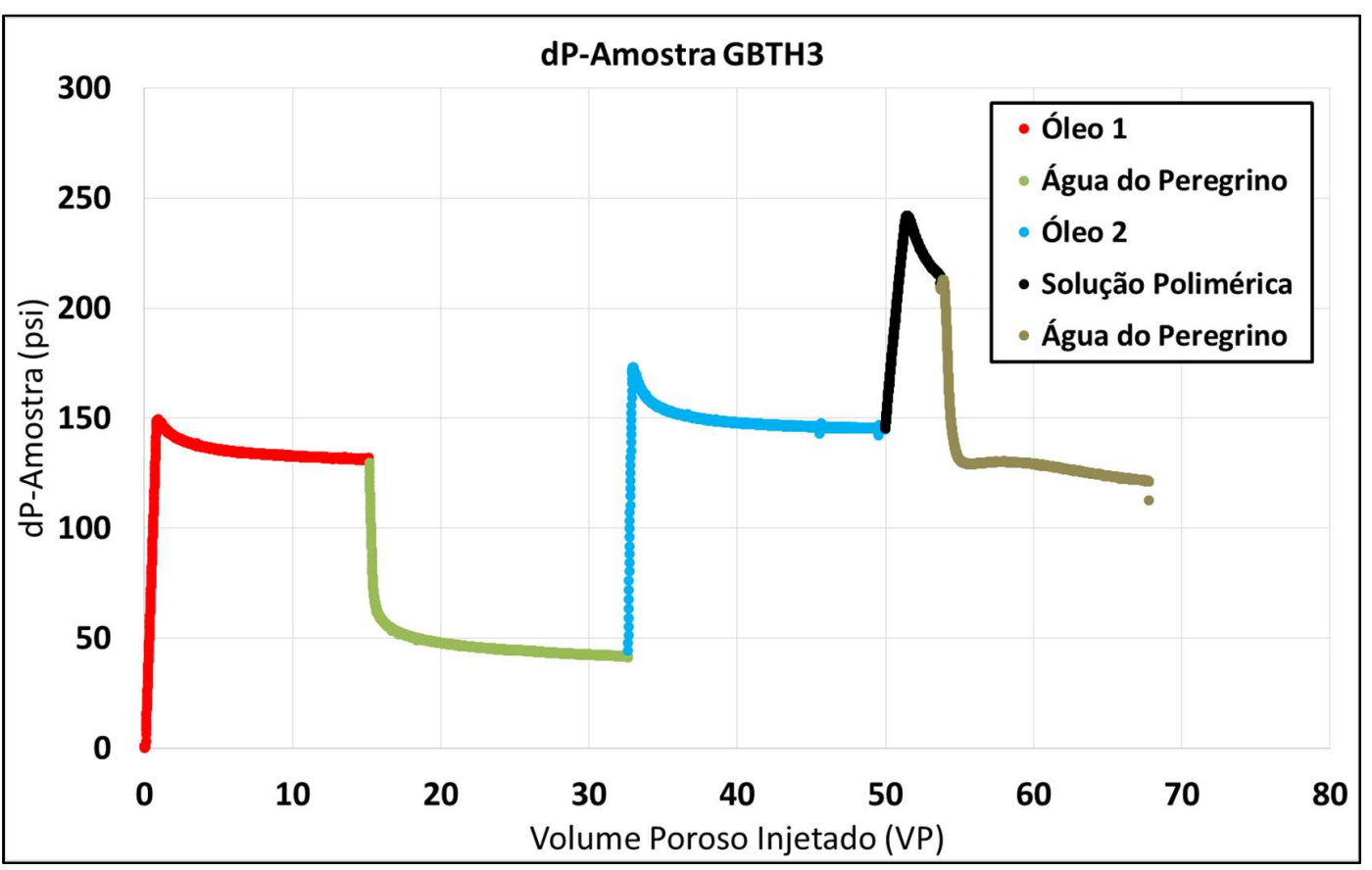

Figura 54 - Diferencial de pressão através da amostra GBTH3. 
Em seguida, iniciou-se o processo de deslocamento da água com a injeção de óleo para preparar a amostra para o primeiro procedimento de recuperação. A saturação de óleo ao final dessa etapa ficou em $80,02 \%$ (aproximadamente $4 \%$ menor que do protocolo 1), que corresponde a um volume disponível para a produção de $16,40 \mathrm{~mL}$. Os valores iniciais e finais dessa fase estão na Tabela 44. A Fig. 54 ilustra através da curva vermelha a fase 2 .

\begin{tabular}{lllll}
\hline Parâmetro & \multicolumn{2}{c}{ Inicial } & \multicolumn{2}{c}{ Final } \\
\hline Volume de água $(\mathrm{mL})$ & $\left(\mathrm{V}_{\mathrm{wi} 2}\right)$ & $\mathbf{2 0 , 5 0}$ & $\left(\mathrm{V}_{\mathrm{wf} 2}\right)$ & $\mathbf{4 , 1 0}$ \\
\hline Volume de óleo $(\mathrm{mL})$ & $\left(\mathrm{V}_{\mathrm{oi} 2}\right)$ & $\mathbf{0}$ & $\left(\mathrm{V}_{\mathrm{of} 2}\right)$ & $\mathbf{1 6 , 4 0}$ \\
\hline Saturação de água $(\%)$ & $\left(\mathrm{S}_{\mathrm{wi} 2}\right)$ & $\mathbf{1 0 0}$ & $\left(\mathrm{S}_{\mathrm{wf} 2}\right)$ & $\mathbf{1 9 , 9 8}$ \\
\hline Saturação de óleo $(\%)$ & $\left(\mathrm{S}_{\mathrm{oi} 2}\right)$ & $\mathbf{0}$ & $\left(\mathrm{S}_{\mathrm{of} 2}\right)$ & $\mathbf{8 0 , 0 2}$ \\
\hline Volume de água produzida $(\mathrm{mL})$ & & & $\left(\mathrm{N}_{\mathrm{w} 2}\right)$ & $\mathbf{1 6 , 4 1}$ \\
\hline Permeabilidade efetiva ao óleo $(\mathrm{mD})$ & & & $\left(\mathrm{K}_{\mathrm{efo} 2}\right)$ & $\mathbf{9 8 , 5 9}$ \\
\hline
\end{tabular}

Tabela 44 - Dados da fase 2 (injeção de óleo) da amostra GBTH3.

$\mathrm{Na}$ fase 3 foi realizado o primeiro processo de recuperação do óleo presente na amostra, fazendo uso apenas de água de Peregrino. Dos 16,40 mL de óleo acumulados na amostra, somente 5,17 mL foram recuperados. Essa fração é equivalente a 31,45\% do volume total e é bastante similar aos $32,39 \%$ obtidos na amostra GBT3. A Tabela 45 mostra os valores dessa fase, que está representada pela curva verde na Fig. 54.

\begin{tabular}{llllr}
\hline Parâmetro & \multicolumn{2}{c}{ Inicial } & \multicolumn{2}{c}{ Final } \\
\hline Volume de água $(\mathrm{mL})$ & $\left(\mathrm{V}_{\mathrm{wi} 3}\right)$ & $\mathbf{4 , 1 0}$ & $\left(\mathrm{V}_{\mathrm{wf} 3}\right)$ & $\mathbf{9 , 2 7}$ \\
\hline Volume de óleo $(\mathrm{mL})$ & $\left(\mathrm{V}_{\mathrm{oi} 3}\right)$ & $\mathbf{1 6 , 4 0}$ & $\left(\mathrm{V}_{\mathrm{of} 3}\right)$ & $\mathbf{1 1 , 2 3}$ \\
\hline Saturação de água $(\%)$ & $\left(\mathrm{S}_{\text {wi3 }}\right)$ & $\mathbf{1 9 , 9 8}$ & $\left(\mathrm{S}_{\mathrm{wf} 3}\right)$ & $\mathbf{4 5 , 2 1}$ \\
\hline Saturação de óleo $(\%)$ & $\left(\mathrm{S}_{\mathrm{oi} 3}\right)$ & $\mathbf{8 0 , 0 2}$ & $\left(\mathrm{S}_{\mathrm{of} 3}\right)$ & $\mathbf{5 4 , 7 2}$ \\
\hline Volume de óleo produzido $(\mathrm{mL})$ & & & $\left(\mathrm{N}_{\mathrm{w} 3}\right)$ & $\mathbf{5 , 1 7}$ \\
\hline Permeabilidade efetiva à água $(\mathrm{mD})$ & & & $\left(\mathrm{K}_{\mathrm{efw} 3}\right)$ & $\mathbf{2 , 9 7}$ \\
\hline Fator de recuperação de óleo $(\%)$ & & & & $\mathbf{3 1 , 5 4}$ \\
\hline
\end{tabular}


A fase 4 foi responsável pelo restabelecimento das condições da amostra para um novo processo de recuperação, para isso, injetou-se óleo até que a produção de água fosse nula. Dessa vez, a saturação final de óleo subiu para $88,07 \%$, oferecendo um volume de $18,06 \mathrm{~mL}$ de óleo para produção. A Tabela 46 traz os valores iniciais e finais da fase 4. A curva azul representa essa fase na Fig. 54.

\begin{tabular}{llllr}
\hline Parâmetro & \multicolumn{2}{c}{ Inicial } & \multicolumn{2}{c}{ Final } \\
\hline Volume de água $(\mathrm{mL})$ & $\left(\mathrm{V}_{\mathrm{wi}}\right)$ & $\mathbf{9 , 2 7}$ & $\left(\mathrm{V}_{\mathrm{wf} 4}\right)$ & $\mathbf{2 , 4 4}$ \\
\hline Volume de óleo $(\mathrm{mL})$ & $\left(\mathrm{V}_{\mathrm{oi}}\right)$ & $\mathbf{1 1 , 2 3}$ & $\left(\mathrm{V}_{\mathrm{of} 4}\right)$ & $\mathbf{1 8 , 0 6}$ \\
\hline Saturação de água $(\%)$ & $\left(\mathrm{S}_{\mathrm{wi} 4}\right)$ & $\mathbf{4 5 , 2 1}$ & $\left(\mathrm{S}_{\mathrm{wf} 4}\right)$ & $\mathbf{1 1 , 9 3}$ \\
\hline Saturação de óleo $(\%)$ & $\left(\mathrm{S}_{\mathrm{oi} 4}\right)$ & $\mathbf{5 4 , 7 2}$ & $\left(\mathrm{S}_{\mathrm{of} 4}\right)$ & $\mathbf{8 8 , 0 7}$ \\
\hline Volume de água produzida $(\mathrm{mL})$ & & & $\left(\mathrm{N}_{\mathrm{w} 4}\right)$ & $\mathbf{6 , 8 2}$ \\
\hline Permeabilidade efetiva ao óleo $(\mathrm{mD})$ & & & $\left(\mathrm{K}_{\text {efo4 } 4}\right)$ & $\mathbf{8 9 , 1 9}$ \\
\hline
\end{tabular}

Tabela 46 - Dados da fase 4 (injeção de óleo) da amostra GBTH3.

O segundo processo de recuperação foi com a injeção de solução polimérica e água de Peregrino. Ao final dos 15 volumes porosos injetados, foi contabilizada uma recuperação de $8,52 \mathrm{~mL}$ de óleo. Esse valor equivale a um fator de recuperação de $47,22 \%$, que supera em 15,68\% o obtido na fase de injeção de água de Peregrino pura. A Tabela 47 mostra os valores iniciais e finais das fases 5 e 6 , cujos comportamentos estão representados pelas cores preta e marrom na Fig. 54.

\begin{tabular}{lllll}
\hline Parâmetro & \multicolumn{2}{c}{ Inicial } & \multicolumn{2}{c}{ Final } \\
\hline Volume de água $(\mathrm{mL})$ & $\left(\mathrm{V}_{\text {wis/6 }}\right)$ & $\mathbf{2 , 4 4}$ & $\left(\mathrm{V}_{\mathrm{wf} 5 / 6}\right)$ & $\mathbf{1 0 , 9 7}$ \\
\hline Volume de óleo $(\mathrm{mL})$ & $\left(\mathrm{V}_{\mathrm{oi} / 6 / 6}\right)$ & $\mathbf{1 8 , 0 6}$ & $\left(\mathrm{V}_{\mathrm{of} 5 / 6}\right)$ & $\mathbf{9 , 5 3}$ \\
\hline Saturação de água $(\%)$ & $\left(\mathrm{S}_{\mathrm{wi} / 6 / 6}\right)$ & $\mathbf{1 1 , 9 3}$ & $\left(\mathrm{S}_{\mathrm{wf} 5 / 6}\right)$ & $\mathbf{5 3 , 5 1}$ \\
\hline Saturação de óleo $(\%)$ & $\left(\mathrm{S}_{\mathrm{oi} 5 / 6}\right)$ & $\mathbf{8 8 , 0 7}$ & $\left(\mathrm{S}_{\mathrm{of} 5 / 6}\right)$ & $\mathbf{4 6 , 4 9}$ \\
\hline Volume de óleo produzido $(\mathrm{mL})$ & & & $\left(\mathrm{N}_{\mathrm{w} 5 / 6}\right)$ & $\mathbf{8 , 5 2}$ \\
\hline Permeabilidade efetiva à água $(\mathrm{mD})$ & & & $\left(\mathrm{K}_{\mathrm{efw} 5 / 6}\right)$ & $\mathbf{0 , 8 2}$ \\
\hline Fator de recuperação de óleo $(\%)$ & & & & $\mathbf{4 7 , 2 2}$ \\
\hline
\end{tabular}

Tabela 47- Dados das fases 5 e 6 (injeção de solução polimérica seguida de água) da amostra GBTH3. 
Ao comparar-se os valores obtidos no teste da amostra GBT3, o novo fator de recuperação é 4,18\% menor para o mesmo procedimento de injeção de solução polimérica, porém continua sendo $6,78 \%$ maior que o fator de recuperação referente à injeção de solução de glicerina. Possivelmente as etapas relacionadas ao mecanismo de recuperação com injeção de glicerina podem ter exercido alguma influência nas fases de injeção polimérica, ainda assim o resultado do presente teste mostra que o aproveitamento do volume produzido com a utilização de polímeros é maior.

As Fig. 55 e 56 apresentam os dados de produção de óleo acumulada e os fatores de recuperação durante as fases de recuperação. Percebe-se que durante a fase 3, de injeção de água de Peregrino, a produção de óleo tende a cessar mais rapidamente. Acredita-se que a continuidade na produção de óleo durante as fases 5 e 6 seja em decorrência das modificações geradas na formação, que pouco a pouco direciona o fluxo dos fluidos injetados a novos caminhos, ocupando poros que não seriam atingidos somente com a injeção de água.

Ao final do teste foi calculado um valor de RRF, referente aos processos de injeção de água, de 2,90. Esse resultado é ligeiramente maior que o obtido no teste de adsorção, e menor que o valor calculado na amostra GBT3. Repare que a saturação final de óleo das fases 3 e 6 são 68,46\% e 52,78\%, respectivamente. Mesmo com uma saturação menor, o valor final de permeabilidade apresentou-se maior. Acredita-se que isso possa ter sido ocasionado pela retenção das partículas de polímero no meio poroso. Porém, em ambos os testes de recuperação, o volume injetado de água de Peregrino nas fases finais não foi suficiente para atingir uma estabilização nos valores de diferencial de pressão, logo, as comparações realizadas através do parâmetro de FFR podem não ser totalmente fidedignas. 


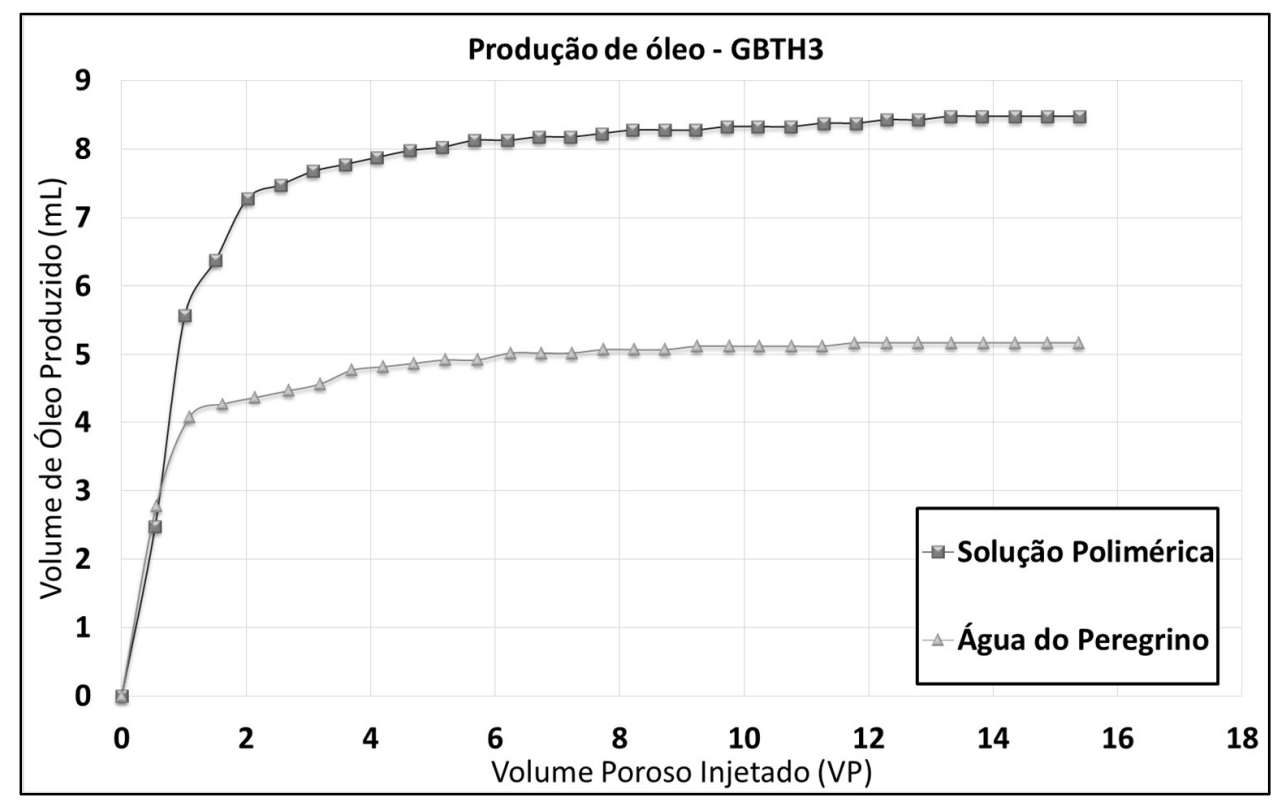

Figura 55 - Curva de volume de óleo produzido com água de Peregrino, solução de glicerina e solução polimérica da amostra GBTH3.

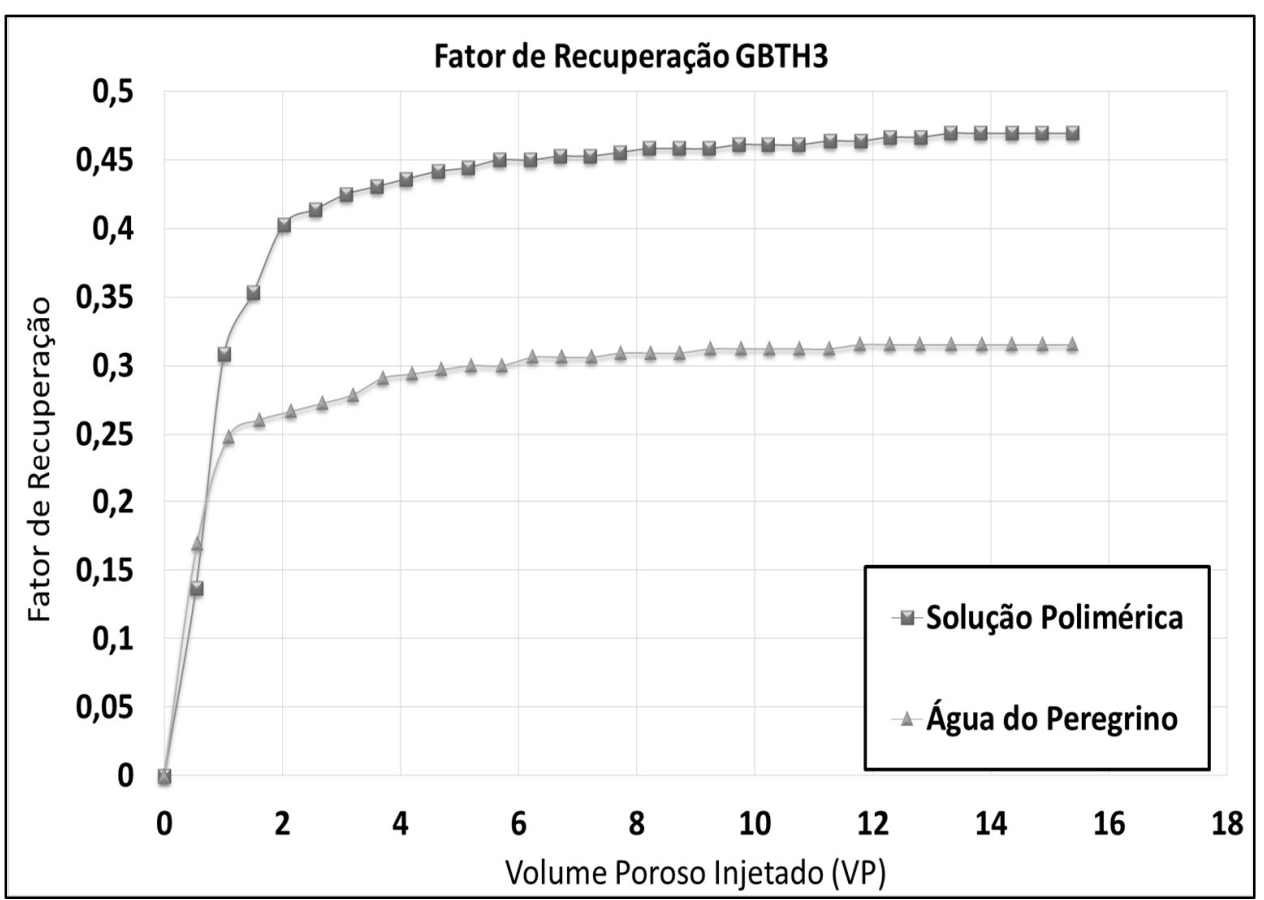

Figura 56 - Curva de fator de recuperação com água de Peregrino e solução polimérica da amostra GBTH3. 


\section{3 .2}

\section{Buff Berea (BB2C)}

A Tabela 48 traz as características e propriedades petrofísicas da amostra $\mathrm{BB} 2 \mathrm{C}$.

\begin{tabular}{cc}
\hline Código da Amostra & BB2C \\
\hline Procedência & Buff Berea \\
\hline Diâmetro $(\mathrm{cm})$ & 3,792 \\
\hline Área $\left(\mathrm{cm}^{2}\right)$ & 11,293 \\
\hline Comprimento $(\mathrm{cm})$ & 10,159 \\
\hline Volume $\left(\mathrm{cm}^{3}\right)$ & 114,725 \\
\hline Amostra Seca $(\mathrm{g})$ & 239,20 \\
\hline Amostra Úmida $(\mathrm{g})$ & 263,60 \\
\hline Volume Poroso $(\mathrm{mL})$ & 23,37 \\
\hline Porosidade & 20,37
\end{tabular}

Tabela 48 - Características e propriedades petrofísicas da amostra BB2C.

Os pontos de diferencial de pressão referentes às diversas vazões injetadas estão dispostos na Fig. 57. Para essa amostra, a permeabilidade absoluta inicial foi calculada em $86,89 \mathrm{mD}$, valor um pouco inferior comparado com as amostras de Buff Berea utilizadas anteriormente (aproximadamente 20\% menor que do protocolo 1). 


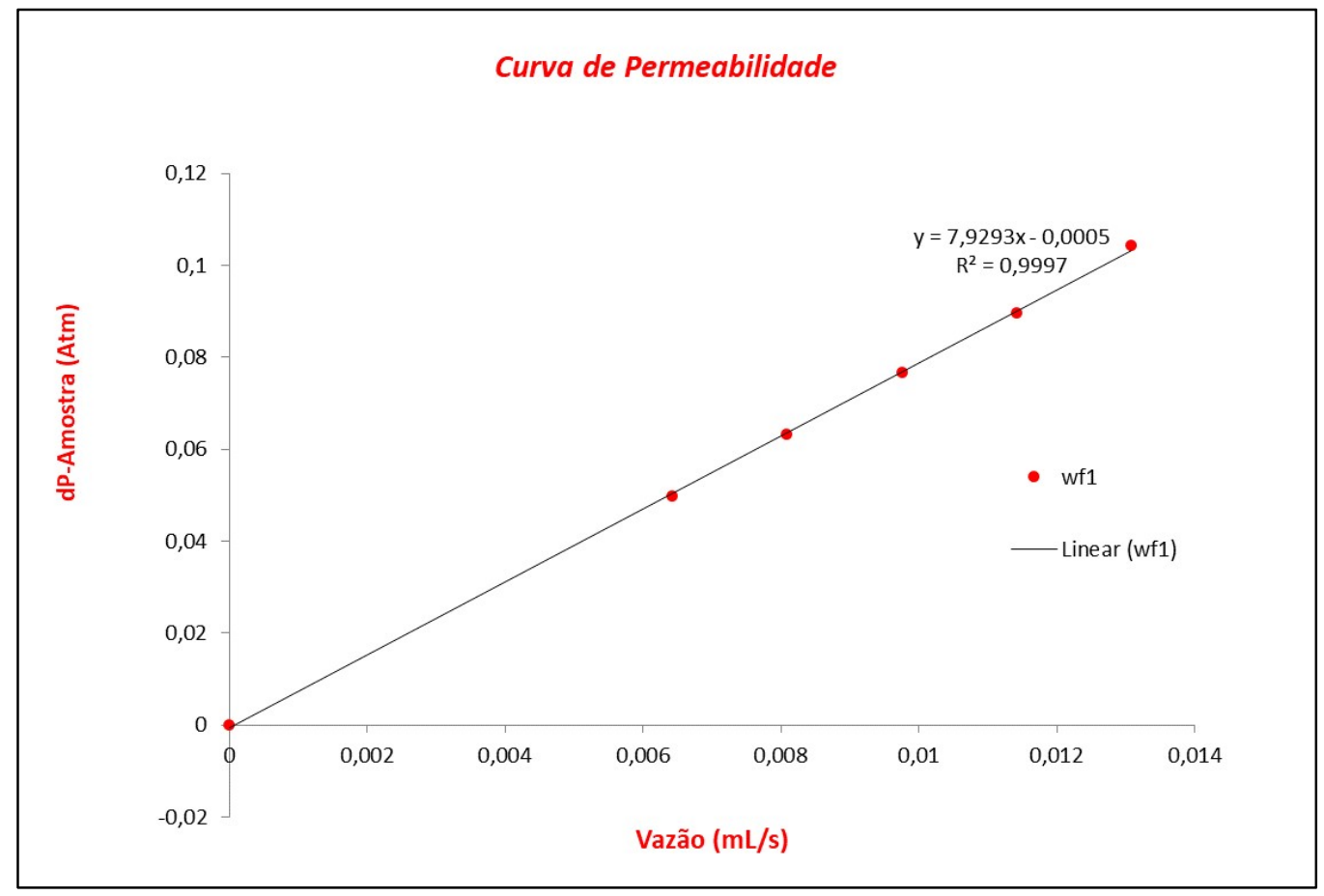

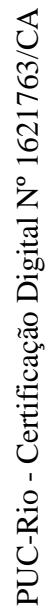

Figura 57 - Curva de permeabilidade absoluta inicial da amostra BB2C.

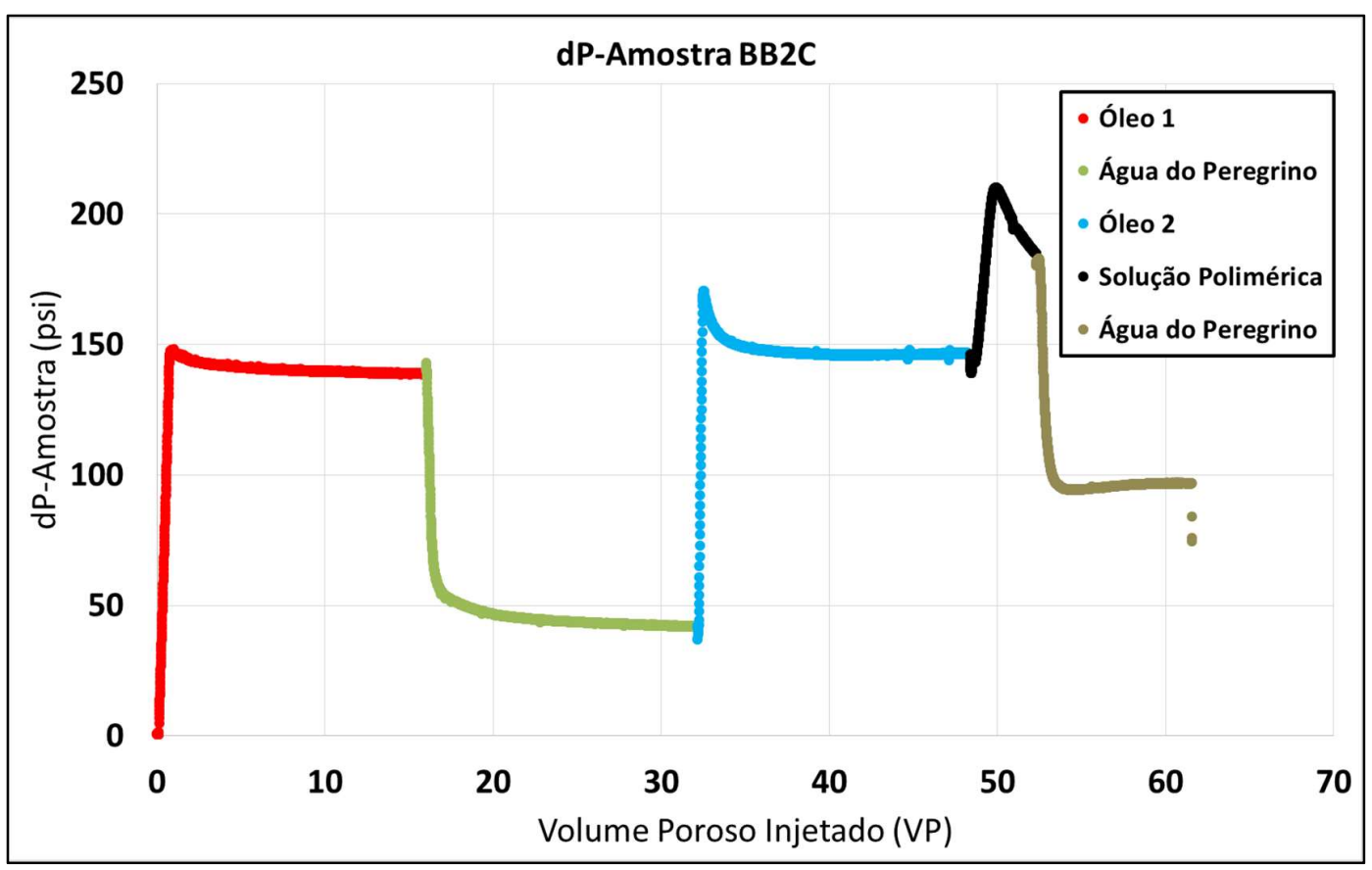

Figura 58 - Diferencial de pressão através da amostra BB2C. 
A etapa seguinte está representada pela curva vermelha na Fig. 58. Tratou-se da injeção de óleo para determinação das saturações dos fluidos para a realização do primeiro processo de recuperação. Ao final, foi calculado um volume de $17,44 \mathrm{~mL}$ de óleo acumulado na amostra. Esse valor representa uma saturação de 74,65\%, muito parecido com o valor obtido para a amostra BBT3 de 74,32\%. A Tabela 49 mostra os valores iniciais e finais da fase 2 .

\begin{tabular}{lllll}
\hline Parâmetro & \multicolumn{2}{c}{ Inicial } & \multicolumn{2}{c}{ Final } \\
\hline Volume de água $(\mathrm{mL})$ & $\left(\mathrm{V}_{\mathrm{wi} 2}\right)$ & $\mathbf{2 2 , 6 1}$ & $\left(\mathrm{V}_{\mathrm{wf} 2}\right)$ & $\mathbf{5 , 9 3}$ \\
\hline Volume de óleo $(\mathrm{mL})$ & $\left(\mathrm{V}_{\mathrm{oi} 2}\right)$ & $\mathbf{0}$ & $\left(\mathrm{V}_{\mathrm{of} 2}\right)$ & $\mathbf{1 7 , 4 4}$ \\
\hline Saturação de água $(\%)$ & $\left(\mathrm{S}_{\mathrm{wi} 2}\right)$ & $\mathbf{1 0 0}$ & $\left(\mathrm{S}_{\mathrm{wf} 2}\right)$ & $\mathbf{2 5 , 3 5}$ \\
\hline Saturação de óleo $(\%)$ & $\left(\mathrm{S}_{\mathrm{oi} 2}\right)$ & $\mathbf{0}$ & $\left(\mathrm{S}_{\mathrm{of} 2}\right)$ & $\mathbf{7 4 , 6 5}$ \\
\hline Volume de água produzida $(\mathrm{mL})$ & & & $\left(\mathrm{N}_{\mathrm{w} 2}\right)$ & $\mathbf{1 7 , 4 4}$ \\
\hline Permeabilidade efetiva ao óleo $(\mathrm{mD})$ & & & $\left(\mathrm{K}_{\mathrm{ef} 2}\right)$ & $\mathbf{9 9 , 7 4}$ \\
\hline
\end{tabular}

Tabela 49 - Dados da fase 2 (injeção de óleo) da amostra BB2C.

A recuperação com água de Peregrino ocorreu durante a fase 3, que recuperou $29,38 \%$ do total de óleo disponível. Esse valor está bastante coerente com o teste anterior, realizado no mesmo tipo de formação, no qual recuperou-se 28,4\%. A Tabela 50 traz os valores característicos desse procedimento e o comportamento do diferencial de pressão está apresentado pela curva verde na Fig. 58.

\begin{tabular}{llllr}
\hline Parâmetro & \multicolumn{2}{c}{ Inicial } & \multicolumn{2}{c}{ Final } \\
\hline Volume de água $(\mathrm{mL})$ & $\left(\mathrm{V}_{\mathrm{wi} 3}\right)$ & $\mathbf{5 , 9 3}$ & $\left(\mathrm{V}_{\mathrm{wf} 3}\right)$ & $\mathbf{1 1 , 0 5}$ \\
\hline Volume de óleo $(\mathrm{mL})$ & $\left(\mathrm{V}_{\mathrm{oi} 3}\right)$ & $\mathbf{1 7 , 4 4}$ & $\left(\mathrm{V}_{\mathrm{of} 3}\right)$ & $\mathbf{1 2 , 3 2}$ \\
\hline Saturação de água $(\%)$ & $\left(\mathrm{S}_{\text {wi3 }}\right)$ & $\mathbf{2 5 , 3 5}$ & $\left(\mathrm{S}_{\mathrm{wf} 3}\right)$ & $\mathbf{4 7 , 2 8}$ \\
\hline Saturação de óleo $(\%)$ & $\left(\mathrm{S}_{\mathrm{oi} 3}\right)$ & $\mathbf{7 4 , 6 5}$ & $\left(\mathrm{S}_{\mathrm{of}}\right)$ & $\mathbf{5 2 , 7 2}$ \\
\hline Volume de óleo produzido $(\mathrm{mL})$ & & & $\left(\mathrm{N}_{\mathrm{o} 3}\right)$ & $\mathbf{5 , 1 2}$ \\
\hline Permeabilidade efetiva à água $(\mathrm{mD})$ & & & $\left(\mathrm{K}_{\mathrm{efw} 3}\right)$ & $\mathbf{3 , 1 6}$ \\
\hline Fator de recuperação de óleo $(\%)$ & & & & $\mathbf{2 9 , 3 8}$ \\
\hline
\end{tabular}


A restauração das condições do reservatório ocorreu através de uma nova injeção de óleo. Ao final dessa etapa a nova saturação de óleo era de 79,14\%. Assim como ocorrido na amostra BBT3, o volume de óleo disponível para a segunda etapa de recuperação foi maior, totalizando-se em 18,49 mL. A Fig. 58 mostra a fase 4 através da curva azul e os valores estão dispostos na Tabela 51.

\begin{tabular}{llllr}
\hline Parâmetro & \multicolumn{2}{c}{ Inicial } & \multicolumn{2}{c}{ Final } \\
\hline Volume de água $(\mathrm{mL})$ & $\left(\mathrm{V}_{\mathrm{wi}}\right)$ & $\mathbf{1 1 , 0 5}$ & $\left(\mathrm{V}_{\mathrm{wf} 4}\right)$ & $\mathbf{4 , 8 8}$ \\
\hline Volume de óleo $(\mathrm{mL})$ & $\left(\mathrm{V}_{\mathrm{oi}}\right)$ & $\mathbf{1 2 , 3 2}$ & $\left(\mathrm{V}_{\mathrm{of} 4}\right)$ & $\mathbf{1 8 , 4 9}$ \\
\hline Saturação de água $(\%)$ & $\left(\mathrm{S}_{\mathrm{wi} 4}\right)$ & $\mathbf{4 7 , 2 8}$ & $\left(\mathrm{S}_{\mathrm{wf} 4}\right)$ & $\mathbf{2 0 , 8 6}$ \\
\hline Saturação de óleo $(\%)$ & $\left(\mathrm{S}_{\mathrm{oi} 4}\right)$ & $\mathbf{5 2 , 7 2}$ & $\left(\mathrm{S}_{\mathrm{of} 4}\right)$ & $\mathbf{7 9 , 1 4}$ \\
\hline Volume de água produzida $(\mathrm{mL})$ & & & $\left(\mathrm{N}_{\mathrm{w} 4}\right)$ & $\mathbf{6 , 1 7}$ \\
\hline Permeabilidade efetiva ao óleo $(\mathrm{mD})$ & & & $\left(\mathrm{K}_{\text {efo4 } 4}\right)$ & $\mathbf{9 4 , 5 8}$ \\
\hline
\end{tabular}

Tabela 51 - Dados da fase 4 (injeção de óleo) da amostra BB2C.

Na quinta e sexta fases foram produzidos $7,57 \mathrm{~mL}$ de óleo durante a injeção das duas fases, resultando em um fator de recuperação de 40,96\%. Novamente um valor inferior ao obtido no protocolo 1 durante a injeção de solução polimérica, porém, outra vez maior que a recuperação realizada com solução de glicerina. As curvas preta e marrom da Fig. 58 representam as fases 5 e 6, respectivamente. A Tabela 52 traz os valores finais do teste.

\begin{tabular}{lcccr}
\hline Parâmetro & \multicolumn{2}{c}{ Inicial } & \multicolumn{2}{c}{ Final } \\
\hline Volume de água $(\mathrm{mL})$ & $\left(\mathrm{V}_{\mathrm{wi} / 5 / 6}\right)$ & $\mathbf{4 , 8 8}$ & $\left(\mathrm{V}_{\mathrm{wf} 5 / 6}\right)$ & $\mathbf{1 2 , 4 5}$ \\
\hline Volume de óleo $(\mathrm{mL})$ & $\left(\mathrm{V}_{\mathrm{oi} / 5 / 6}\right)$ & $\mathbf{1 8 , 4 9}$ & $\left(\mathrm{V}_{\mathrm{of5} / 6}\right)$ & $\mathbf{1 0 , 9 2}$ \\
\hline Saturação de água $(\%)$ & $\left(\mathrm{S}_{\mathrm{wi} / 5 / 6}\right)$ & $\mathbf{2 0 , 8 6}$ & $\left(\mathrm{S}_{\mathrm{wf5} / 6}\right)$ & $\mathbf{5 3 , 2 7}$ \\
\hline Saturação de óleo $(\%)$ & $\left(\mathrm{S}_{\mathrm{oi} 5 / 6}\right)$ & $\mathbf{7 9 , 1 4}$ & $\left(\mathrm{S}_{\mathrm{of} 5 / 6}\right)$ & $\mathbf{4 6 , 7 3}$ \\
\hline Volume de água produzida $(\mathrm{mL})$ & & & $\left(\mathrm{N}_{\mathrm{w} 5 / 6}\right)$ & $\mathbf{7 , 5 7}$ \\
\hline Permeabilidade efetiva ao óleo $(\mathrm{mD})$ & & & $\left(\mathrm{K}_{\mathrm{ef} 55 / 6}\right)$ & $\mathbf{1 , 3 7}$ \\
\hline Fator de recuperação de óleo $(\%)$ & & & & $\mathbf{4 0 , 9 6}$ \\
\hline
\end{tabular}

Tabela 52 - Dados das fases 5 e 6 (injeção de solução polimérica seguida de água) da amostra BB2C. 
Novamente calculou-se o fator de resistência residual para verificar as variações nos valores de permeabilidades. Dessa vez, o resultado obtido foi de 2,30. O valor está próximo à metade do valor estabelecido nos testes de adsorção $(7,66)$. As saturações finais de óleo para as fases 3 e 6 foram 70,62\% e 59,04\%, respectivamente. Pressupõe-se que, assim como explicado no subitem 5.1.2, as características mineralógicas dessa amostra tenham contribuído para um alto nível de retenção polimérica, resultando em uma modificação mais acentuada nos valores de permeabilidade.

Nas Fig. 59 e 60 estão dispostos os processos de volume de óleo produzido e o fator de recuperação durante as fases 3,5 e 6 . Nota-se que mesmo depois dos 4VP injetados de solução polimérica ainda há uma continuidade na recuperação de óleo durante a fase 6 , provavelmente pelo mesmo motivo citado no teste anterior.

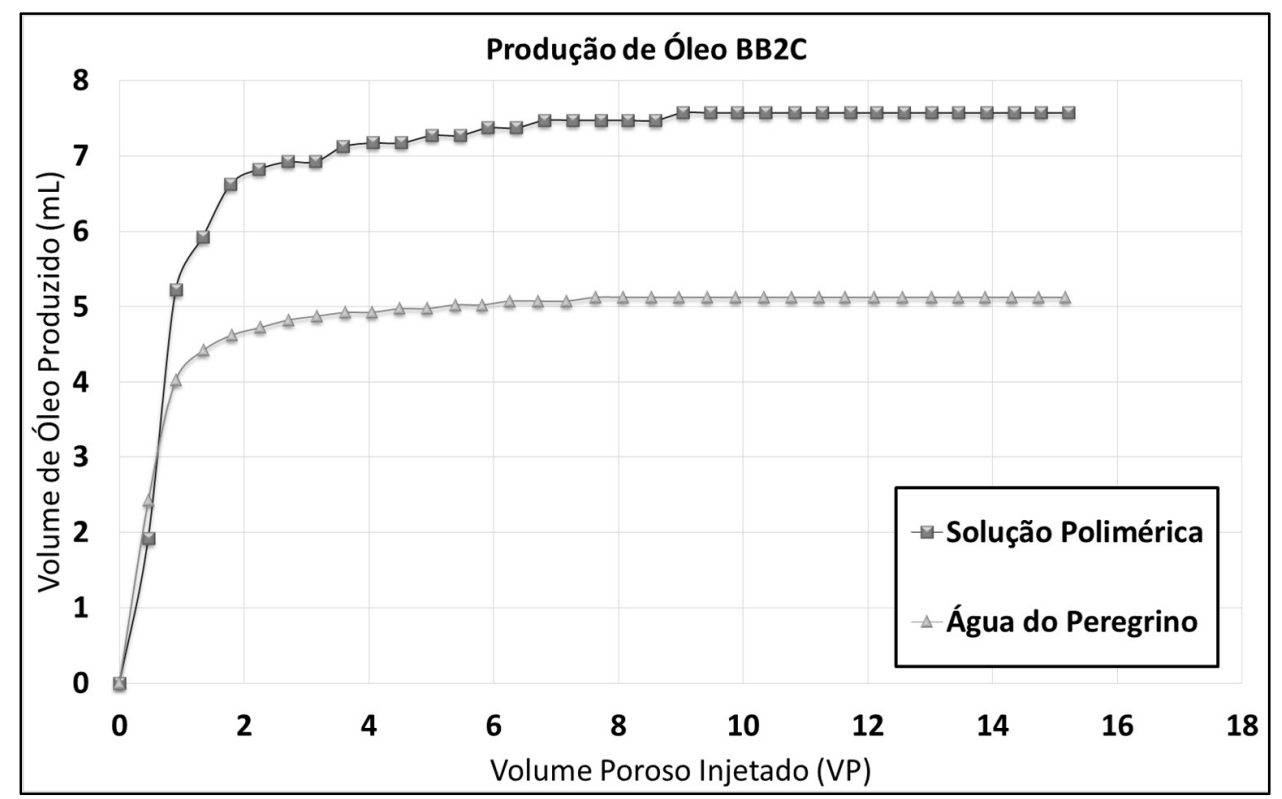

Figura 59 - Curva de volume de óleo produzido com água de Peregrino, solução de glicerina e solução polimérica da amostra BB2C. 


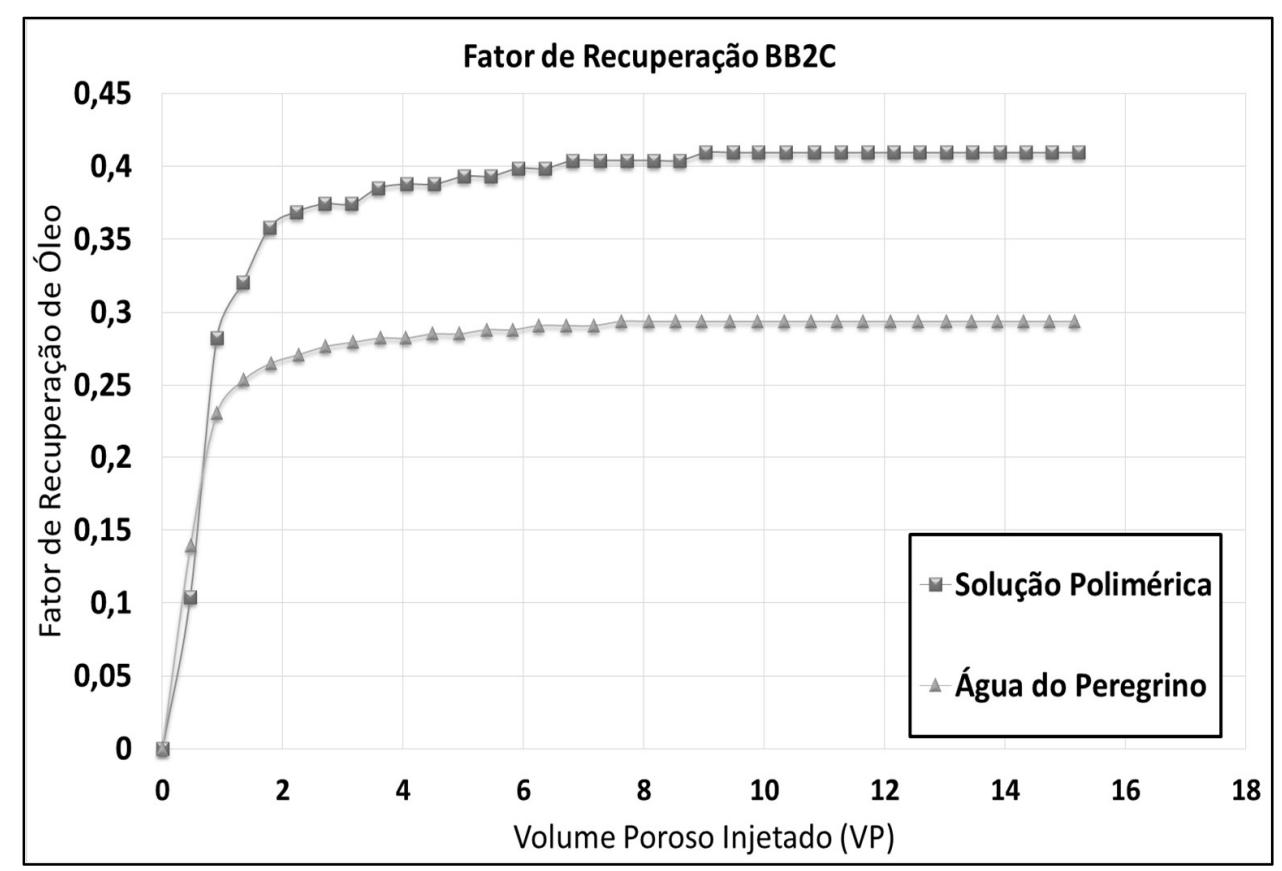

Figura 60 - Curva de fator de recuperação com água de Peregrino e solução polimérica da amostra BB2C.

\section{3 .3}

\section{Bentheimer (BHTH3)}

A Tabela 53 traz as características e propriedades petrofísicas da amostra BHTH3.

\begin{tabular}{cc}
\hline Código da Amostra & BHTH3 \\
\hline Procedência & Behteimer \\
\hline Diâmetro $(\mathrm{cm})$ & 3,824 \\
\hline Área $\left(\mathrm{cm}^{2}\right)$ & 11,483 \\
\hline Comprimento $(\mathrm{cm})$ & 9,816 \\
\hline Volume $\left(\mathrm{cm}^{3}\right)$ & 112,71 \\
\hline Amostra Seca $(\mathrm{g})$ & 221,80 \\
\hline Amostra Úmida $(\mathrm{g})$ & 249,90 \\
\hline Volume Poroso $(\mathrm{mL})$ & 26,92 \\
\hline Porosidade & 23,88 \\
\hline
\end{tabular}

Tabela 53 - Características e propriedades petrofísicas da amostra BHTH3. 
Na fase 1 foi realizada a saturação e determinação da permeabilidade absoluta inicial da amostra. A Fig. 61 mostra os detalhes do procedimento. O valor de permeabilidade calculado foi de $2204,03 \mathrm{mD}$ (aproximadamente $8 \%$ menor que da amostra utilizada no protocolo 1).

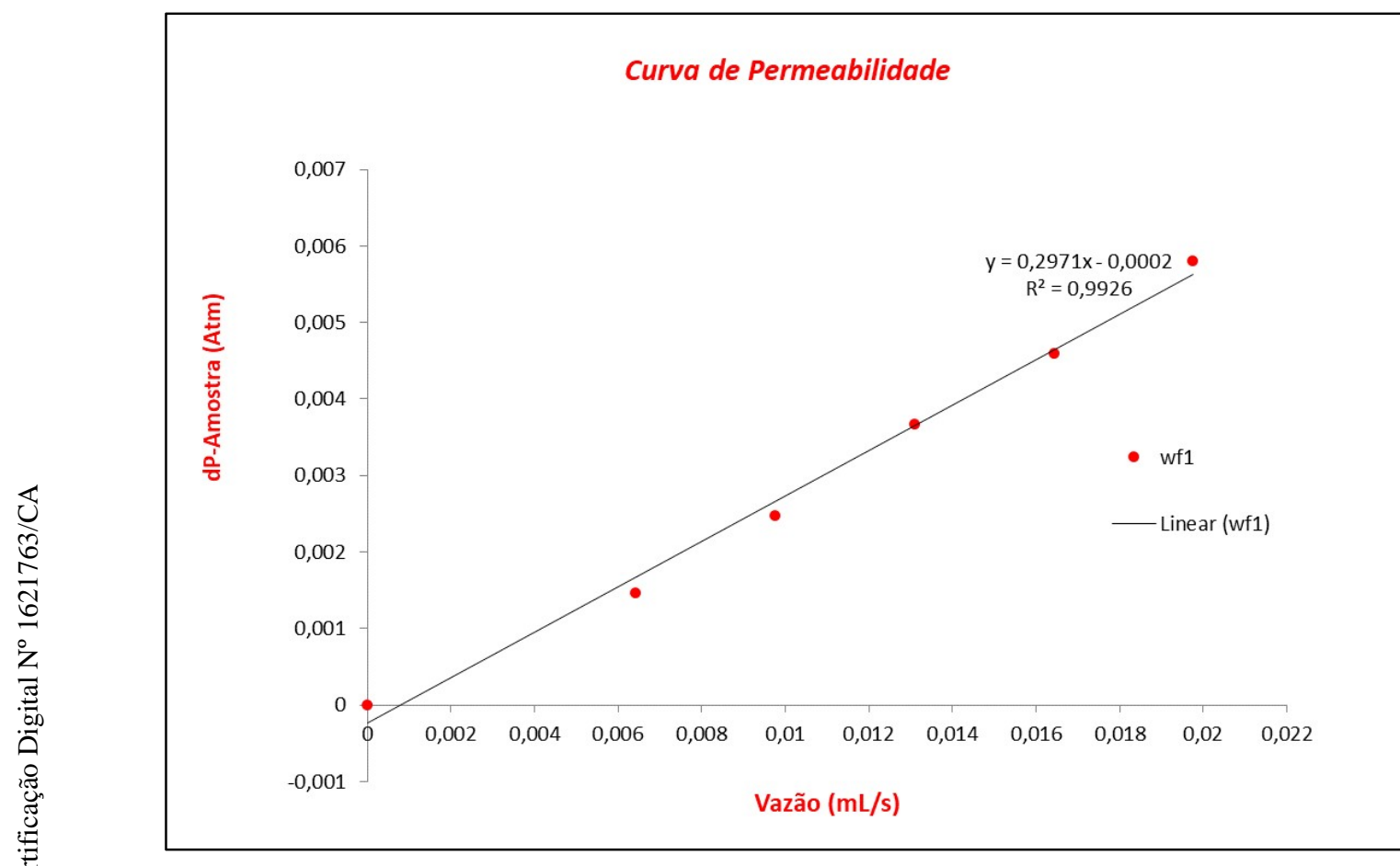

Figura 61 - Curva de permeabilidade absoluta inicial da amostra BHTH3. 


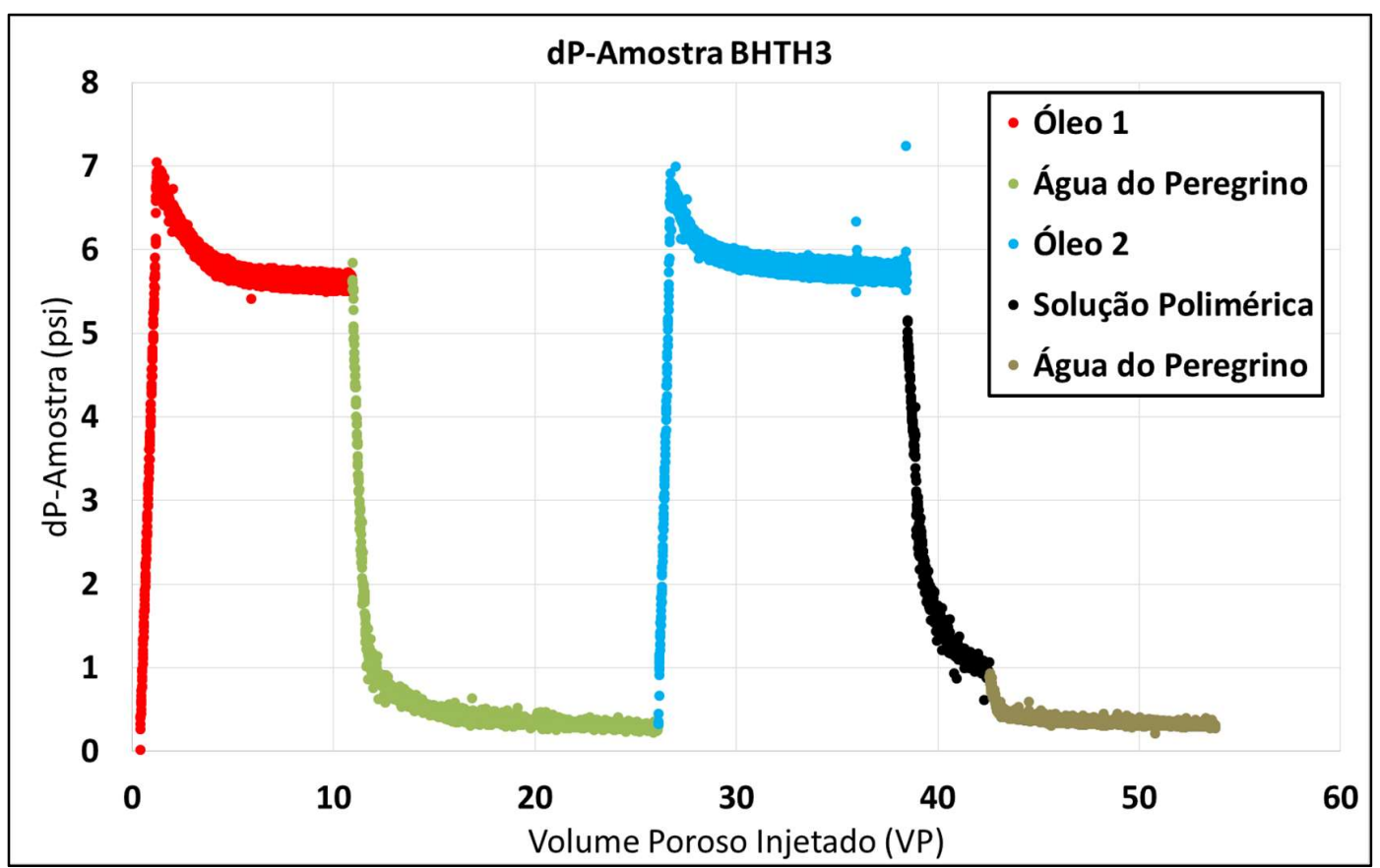

Figura 62 - Diferencial de pressão através da amostra BHTH3.

Em seguida, foi realizada a injeção de óleo para quantificar o volume de água residual da fase 2 e preparar a amostra para o teste de recuperação de óleo. A saturação de óleo no meio poroso para a próxima fase foi de $83,49 \%$. A Fig. 62, apresenta através da curva vermelha, o comportamento dessa fase e a Tabela 54 traz seus valores iniciais e finais.

\begin{tabular}{lllll}
\hline Parâmetro & \multicolumn{2}{c}{ Inicial } & \multicolumn{2}{c}{ Final } \\
\hline Volume de água $(\mathrm{mL})$ & $\left(\mathrm{V}_{\mathrm{wi} 2}\right)$ & $\mathbf{2 6 , 9 2}$ & $\left(\mathrm{V}_{\mathrm{wf} 2}\right)$ & $\mathbf{4 , 4 5}$ \\
\hline Volume de óleo $(\mathrm{mL})$ & $\left(\mathrm{V}_{\mathrm{oi} 2}\right)$ & $\mathbf{0}$ & $\left(\mathrm{V}_{\mathrm{of} 2}\right)$ & $\mathbf{2 2 , 4 7}$ \\
\hline Saturação de água $(\%)$ & $\left(\mathrm{S}_{\mathrm{wi} 2}\right)$ & $\mathbf{1 0 0}$ & $\left(\mathrm{S}_{\mathrm{wf} 2}\right)$ & $\mathbf{1 6 , 5 1}$ \\
\hline Saturação de óleo $(\%)$ & $\left(\mathrm{S}_{\mathrm{oi} 2}\right)$ & $\mathbf{0}$ & $\left(\mathrm{S}_{\mathrm{of} 2}\right)$ & $\mathbf{8 3 , 4 9}$ \\
\hline Volume de água produzida $(\mathrm{mL})$ & & & $\left(\mathrm{N}_{\mathrm{w} 2}\right)$ & $\mathbf{2 2 , 4 7}$ \\
\hline Permeabilidade efetiva ao óleo $(\mathrm{mD})$ & & & $\left(\mathrm{K}_{\text {efo2 } 2}\right)$ & $\mathbf{2 6 1 9 , 2 6}$ \\
\hline
\end{tabular}


O primeiro processo de recuperação de óleo, realizado com injeção de água de Peregrino, recuperou 12,57 mL dos 22,47 mL disponíveis, ou seja, uma fração de $55,95 \%$. Esse valor é ainda maior que o obtido no teste anterior realizado com a Bentheimer BHT2. Esse aumento pode ser um reflexo da maior permeabilidade da amostra. A fase 3 está representada pela curva verde da Fig. 62, e os valores desse procedimento estão na Tabela 55.

\begin{tabular}{lllll}
\hline Parâmetro & \multicolumn{2}{c}{ Inicial } & \multicolumn{2}{c}{ Final } \\
\hline Volume de água $(\mathrm{mL})$ & $\left(\mathrm{V}_{\mathrm{wi} 3}\right)$ & $\mathbf{4 , 4 5}$ & $\left(\mathrm{V}_{\mathrm{wf} 3}\right)$ & $\mathbf{1 7 , 0 2}$ \\
\hline Volume de óleo $(\mathrm{mL})$ & $\left(\mathrm{V}_{\mathrm{oi} 3}\right)$ & $\mathbf{2 2 , 4 7}$ & $\left(\mathrm{V}_{\mathrm{of} 3}\right)$ & $\mathbf{9 , 9 0}$ \\
\hline Saturação de água $(\%)$ & $\left(\mathrm{S}_{\mathrm{wi} 3}\right)$ & $\mathbf{1 6 , 5 1}$ & $\left(\mathrm{S}_{\mathrm{wf} 3}\right)$ & $\mathbf{6 3 , 2 2}$ \\
\hline Saturação de óleo $(\%)$ & $\left(\mathrm{S}_{\mathrm{oi} 3}\right)$ & $\mathbf{8 3 , 4 9}$ & $\left(\mathrm{S}_{\mathrm{of} 3}\right)$ & $\mathbf{3 6 , 7 7}$ \\
\hline Volume de água produzida $(\mathrm{mL})$ & & & $\left(\mathrm{N}_{\mathrm{w} 3}\right)$ & $\mathbf{1 2 , 5 7}$ \\
\hline Permeabilidade efetiva ao óleo $(\mathrm{mD})$ & & & $\left(\mathrm{K}_{\mathrm{ef} 33}\right)$ & $\mathbf{4 6 1 , 8 8}$ \\
\hline Fator de recuperação de óleo $(\%)$ & & & & $\mathbf{5 5 , 9 5}$ \\
\hline
\end{tabular}

Tabela 55 - Dados da fase 3 (injeção de água) da amostra BHTH3.

$\mathrm{Na}$ fase 4, injetou-se novamente óleo para deslocar a água móvel do meio poroso e preparar a amostra para o novo teste. Dessa vez, a saturação de óleo estabilizou-se em 87,02\%, totalizando um volume de 23,42 mL. A curva azul da Fig. 62 representa a fase 4 , e a Tabela 56 traz os valores iniciais e finais dessa etapa.

\begin{tabular}{lllll}
\hline Parâmetro & \multicolumn{2}{c}{ Inicial } & \multicolumn{2}{c}{ Final } \\
\hline Volume de água $(\mathrm{mL})$ & $\left(\mathrm{V}_{\mathrm{wi}}\right)$ & $\mathbf{1 7 , 0 2}$ & $\left(\mathrm{V}_{\mathrm{wf} 4}\right)$ & $\mathbf{3 , 5 0}$ \\
\hline Volume de óleo $(\mathrm{mL})$ & $\left(\mathrm{V}_{\mathrm{oi}}\right)$ & $\mathbf{9 , 9 0}$ & $\left(\mathrm{V}_{\mathrm{of}}\right)$ & $\mathbf{2 3 , 4 2}$ \\
\hline Saturação de água $(\%)$ & $\left(\mathrm{S}_{\mathrm{wi}}\right)$ & $\mathbf{6 3 , 2 2}$ & $\left(\mathrm{S}_{\mathrm{wf} 4}\right)$ & $\mathbf{1 2 , 9 8}$ \\
\hline Saturação de óleo $(\%)$ & $\left(\mathrm{S}_{\mathrm{oi}}\right)$ & $\mathbf{3 6 , 7 7}$ & $\left(\mathrm{S}_{\mathrm{of} 4}\right)$ & $\mathbf{8 7 , 0 2}$ \\
\hline Volume de água produzida $(\mathrm{mL})$ & & & $\left(\mathrm{N}_{\mathrm{w} 4}\right)$ & $\mathbf{1 3 , 5 2}$ \\
\hline Permeabilidade efetiva ao óleo $(\mathrm{mD})$ & & & $\left(\mathrm{K}_{\text {efo4 }}\right)$ & $\mathbf{2 3 0 2 , 9 7}$ \\
\hline
\end{tabular}

Tabela 56 - Dados da fase 4 (injeção de óleo) da amostra BHTH3. 
Durante as fases 5 e 6 foram recuperados $12,87 \mathrm{~mL}$ de óleo, esse valor é equivalente a uma parcela de $54,96 \%$ do volume inicial. Nota-se que o fator de recuperação dessas fases é menor que aquele obtido com a injeção de água de Peregrino. Os comportamentos das fases estão dispostos na Fig. 62 através das curvas preta e marrom. A Tabela 57, mostra os valores iniciais e finais das fases 5 e 6 .

\begin{tabular}{|c|c|c|c|c|}
\hline \multirow{2}{*}{$\begin{array}{l}\text { Parâmetro } \\
\text { Volume de água }(\mathrm{mL})\end{array}$} & \multicolumn{2}{|c|}{ Inicial } & \multicolumn{2}{|c|}{ Final } \\
\hline & $\left(\mathrm{V}_{\text {wi5/6}}\right)$ & 3,50 & $\left(V_{w f 5 / 6}\right)$ & 16,37 \\
\hline Volume de óleo (mL) & $\left(\mathrm{V}_{\mathrm{oi} 5 / 6}\right)$ & 23,42 & $\left(\mathrm{~V}_{\text {of5/6 }}\right)$ & 10,55 \\
\hline Saturação de água (\%) & $\left(\mathrm{S}_{\mathrm{wi} 5 / 6}\right)$ & 12,98 & $\left(\mathrm{~S}_{\mathrm{wf5} / 6}\right)$ & 60,81 \\
\hline Saturação de óleo (\%) & $\left(\mathrm{S}_{\mathrm{oi} 5 / 6}\right)$ & 87,02 & $\left(\mathrm{~S}_{\mathrm{of5} / 6}\right)$ & 39,19 \\
\hline Volume de água produzida $(\mathrm{mL})$ & & & $\left(\mathrm{N}_{\mathrm{w} 5 / 6}\right)$ & 12,87 \\
\hline Permeabilidade efetiva ao óleo (mD) & & & $\left(\mathrm{K}_{\mathrm{efo5} / 6}\right)$ & 387,00 \\
\hline Fator de recuperação de óleo (\%) & & & & 54,96 \\
\hline
\end{tabular}

Tabela 57 - Dados das fases 5 e 6 (injeção de solução polimérica seguida de água) da amostra BHTH3.

O valor do FFR calculado para esse teste foi de 1,19. Valor equivalente ao encontrado para o teste de adsorção e para o primeiro teste de recuperação de óleo nas amostras BHT3 e BHT2, respectivamente.

Através das Fig. 63 e 64 é possível observar uma característica importante relativa às curvas das fases de recuperação de óleo. $\mathrm{O}$ fator de recuperação mostrado na Tabela 57 é um valor absoluto calculado somente no fim de um determinado volume de solução injetado. Porém, ao analisar o desenvolvimento das duas curvas, nota-se que até os 6VP de injeção houve um adiantamento da produção durante a injeção de solução polimérica, igualmente como aconteceu com as soluções de maior viscosidade na amostra BHT2.

Em todos os testes de recuperação realizados foi possível verificar que a partir de um determinado momento, o volume de água injetada para recuperar uma certa quantidade de óleo, torna-se muito elevado. A análise econômica não é o foco do presente trabalho, mas com o mínimo de conhecimento no assunto, pode-se concluir 
que quanto maior for o volume de óleo possível de ser extraído antes de alcançar esse platô, mais interessante e lucrativo será o projeto. Desse modo, acredita-se que a injeção de soluções poliméricas em formações de permeabilidade mais elevadas se encaixa nesse sentido, mesmo mostrando resultados finais não muito interessantes.

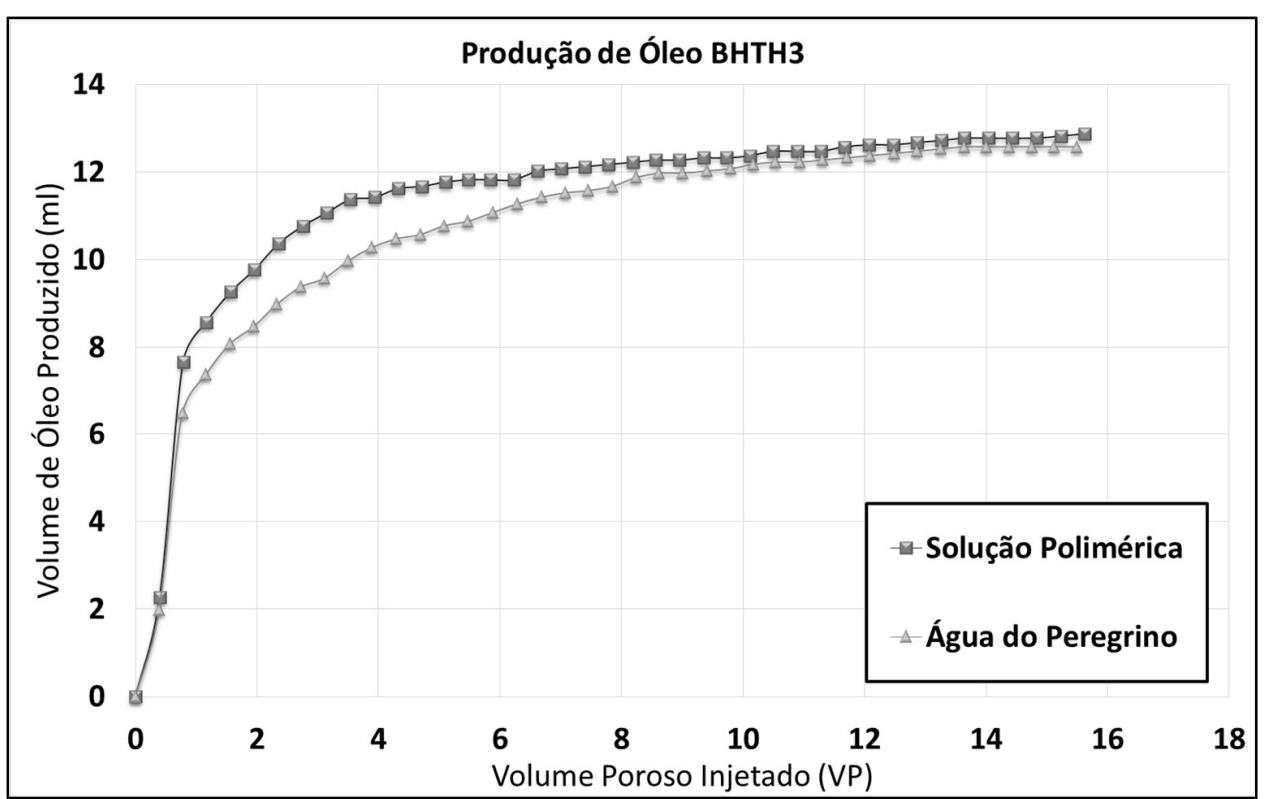

Figura 63 - Curva de volume de óleo produzido com água de Peregrino, solução de glicerina e solução polimérica da amostra BHTH3. 


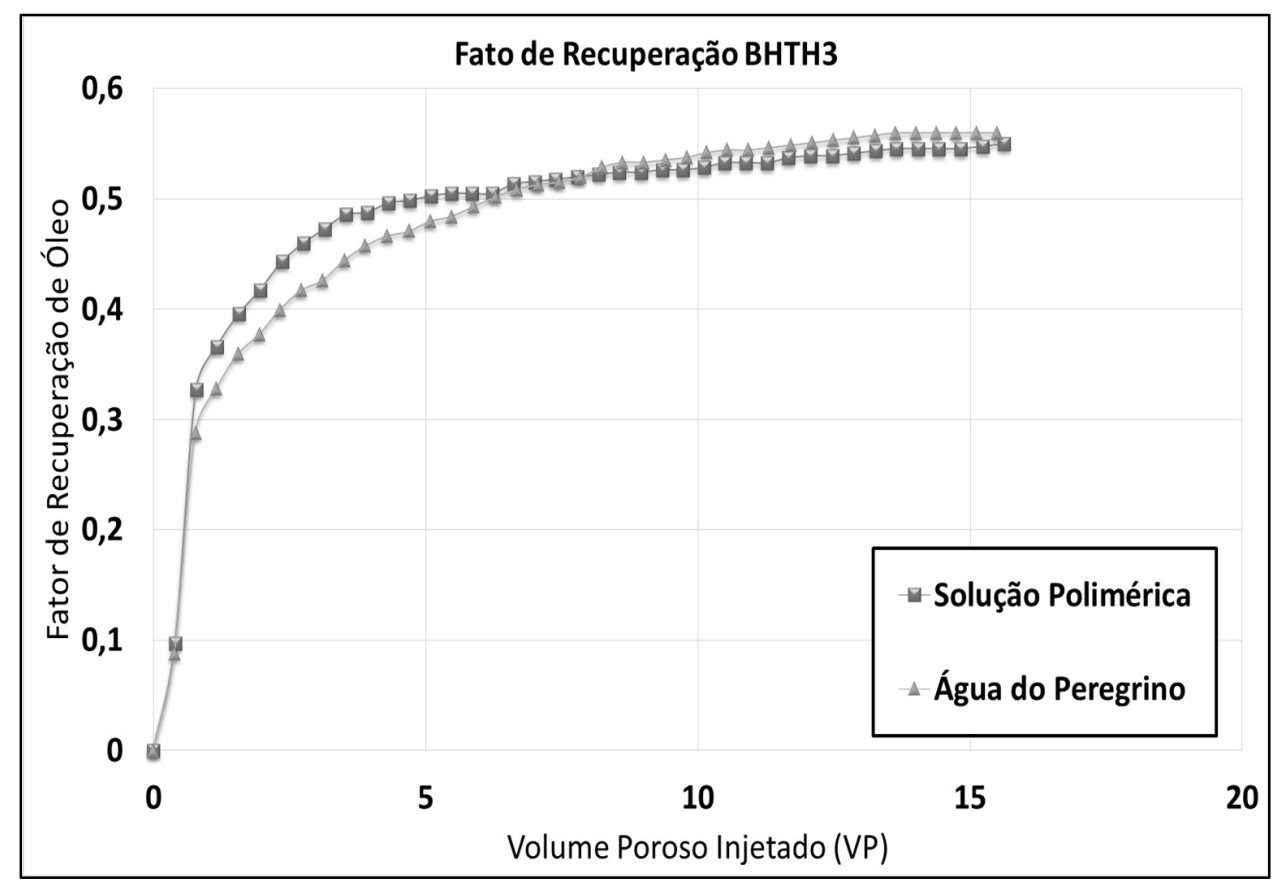

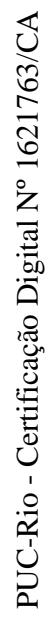

Figura 64 - Curva de fator de recuperação com água de Peregrino e solução polimérica da amostra BHTH3.

Por fim, tabela 58 traz uma síntese dos resultados de todos os testes realizados.

Fator de Recuperação de Óleo (\%)

\begin{tabular}{lcccccc}
\hline Amostra & $\tau(\mu \mathrm{g} / \mathrm{g})$ & VPI $(\%)$ & RRF & PW & Glic + PW & Pol + PW \\
\hline GBT2 & 82,98 & 13,32 & 2,48 & - & - & - \\
\hline BBT2 & 101,82 & 23,29 & 7,66 & - & - & - \\
\hline BHT3 & 19,13 & 2,43 & 1,09 & - & - & - \\
\hline GBT3 & - & - & 3,08 & 32,39 & 40,44 & 51,40 \\
\hline BBT3 & - & - & 3,09 & 28,40 & 34,37 & 44,86 \\
\hline BHT2 & - & - & 1,07 & 51,72 & 54,28 & 58,00 \\
\hline GBTH3 & - & - & 2,90 & 31,54 & - & 47,22 \\
\hline BB2C & - & - & 2,30 & 29,38 & - & 40,96 \\
\hline BHTH3 & - & - & 1,19 & 55,95 & - & 54,96 \\
\hline
\end{tabular}

Tabela 58 - Síntese dos resultados experimentais. 
6

\section{Conclusão}

\section{1}

\section{Conclusão}

No presente trabalho foram testados dois diferentes métodos utilizados durante as operações de recuperação de óleo: a injeção de uma mistura de água do mar com glicerina e a injeção de solução polimérica. Tipicamente, a adição desses dois compostos na água de injeção tem o objetivo central de aumentar a viscosidade da solução, diminuindo, dessa forma, a razão de mobilidade entre os fluidos e melhorando o deslocamento do óleo. Porém, muitos outros fatores relacionados à injeção de soluções poliméricas também estão presentes nesse processo, como a retenção polimérica no meio poroso, que foi o tema central desse estudo.

Primeiramente realizou-se um procedimento para quantificar o material polimérico acumulado nas amostras devido ao mecanismo de adsorção. O Two Slug Method mostrou-se muito útil ao efetuar-se o teste em amostras de alta permeabilidade, porém ao ser empregado em amostras menos permeáveis, o método mostrou-se pouco confiável em consequência da grande quantidade de material aprisionado mecanicamente na amostra.

Em seguida foram realizados os processos de recuperação de óleo nas amostras. Utilizou-se três diferentes técnicas para verificar e comparar a eficácia de cada uma. Inicialmente, realizou-se a injeção de água de Peregrino, para simular o que já é praticado em grande parte dos projetos pela indústria e para ter um parâmetro comum de comparação para as demais metodologias. Em seguida efetuou-se a adição de glicerina e polímero à água do mar. As quantidades de cada produto foram calculadas 
de maneira que ambas as soluções ficassem com o mesmo valor de viscosidade ao atravessarem o meio poroso.

Ainda durante o preparo das soluções, já pôde ser observado uma vantagem significativa dos polímeros devido ao seu poder viscosificante. Para se obter o mesmo valor de viscosidade, foram necessárias quantidades de glicerina até 400 vezes maior que a de polímero, como no caso do teste realizado na formação de Bentheimer.

Durante a realização do primeiro protocolo de recuperação, efetuado com as três fases aquosas, observou-se uma melhora no fator de recuperação ao utilizar a solução de maior viscosidade composta de água do mar e glicerina, porém essa foi ligeiramente ultrapassada pelos valores referentes à recuperação com injeção de solução polimérica. Nas amostras de menor permeabilidade, a diferença entre os dois métodos foi maior que $10 \%$. No segundo protocolo, a diferença no fator de recuperação final entre as duas metodologias foi um pouco menor, mas os resultados continuaram sendo superiores nos procedimentos realizados com polímeros.

Em todos os testes, a injeção de solução polimérica mostrou algum tipo de benefício, seja no fator de recuperação final para as amostras de menor valor de permeabilidade, seja no adiantamento da produção de óleo para as formações mais permeáveis. Esses resultados justificam, a realização deste trabalho e a constante busca em entender os mecanismos que regem as interações das soluções poliméricas em meios porosos.

\section{2}

\section{Sugestões e Recomendações}

Algumas sugestões para futuros experimentos:

- Recomenda-se que ao trabalhar com soluções salinas em temperaturas elevadas (acima de $25^{\circ} \mathrm{C}$ ), todo material que estiver em contato com a solução seja composto de propriedades não metálicas, a fim de evitar a corrosão do mesmo; 
- O oxigênio dissolvido nas soluções pode contribuir significativamente para a degradação do polímero, logo, recomenda-se a utilização de métodos para minimizar esse contaminante como a injeção de gás inerte ou sequestradores de oxigênio;

- Recomenda-se um tratamento prévio de ajuste de molhabilidade nos tubos de produção, a fim de evitar o acumulo de óleo residual nas paredes;

Algumas sugestões de trabalhos futuros:

- Estudar a possibilidade de alteração das características físicas das paredes do meio poroso antes da injeção da solução polimérica, promovendo um ajuste das propriedades que influenciam no processo de adsorção;

- Isolar os fenômenos elásticos, viscosos e os mecanismos de retenção, para classificar as ações de cada um no meio poroso;

- Realizar uma análise econômica dos dados de produção para verificar a viabilidade dos procedimentos;

- Realizar ajustes de modelos numéricos com os dados experimentais disponíveis. 


\section{Referências Bibliográficas}

AL ADASANI, A., BAI, B., Analysis of EOR projects and updated screening criteria. JPT 79 (1-2), 10-24, 2011.

AL-BAHAR, M.A., et al., Evaluation of IOR potential within Kuwait. SPE 88716, Abu Dhabi International Conference and Exhibition, Abu Dhabi, 2004.

AMERICAN PETROLEUM INSTITUTE, Recommended Practices for Evaluation of Polymers Used in Enhanced Oil Recovery Operations. API RP 63, $1^{\text {st }}$ ed., 1990.

AMERICAN PETROLEUM INSTITUTE, Recommended Practices for Core Analysis. API RP 40, $2^{\text {nd }}$ ed., 1998.

ASHBY, M. F., JONES, D. R. H., Engineering Materials 2 - An introduction to microstructures, processing and design. $3^{\text {rd }}$ ed., Oxford, 2006.

BENTO, H. L. I., MORENO, R. B. Z. L., Recuperação avançada de óleo viscoso por injeção de polímeros em diferentes temperaturas, MSc, Universidade Estadual de Campinas, 2015.

BIRD, R. B., ARMSTRONG, R. C., HASSAGER, O. Dynamics of Polymeric liquids. Fluid Mechanics, Vol. 1, New York: Wiley, 1987.

BP, BP Statistical Review of World Energy 2018. Disponível em: <www.bp.com /content/dam/bp/business-sites/en/global/corporate/pdfs/energy-economics/statisticalreview/bp-stats-review-2018-full-report.pdf > . Acesso em 20 dez. 2018.

BRASHEAR, J. P., KUUSKRA, V. A., The potential and economics of enhanced oil recovery. JPT 30, 1231-1239, SPE-6350, 1978.

BUCKLEY, S.E e LEVERETT, M.C: Mechanism of fluid displacement in sands, Trans., AIME146, 107-116, 1942.

CAO, L., Superhydrophobic Surface: Design, Fabrication, and Applications. 2010.

CHALLA, G., Polymer Chemistry - An Introduction. Ellis Horwood, London, 1993.

CHANG, H.L., Polymer flooding technology - yesterday, today and tomorrow. SPE 7043. Fifth Symposium on Improved Methods for Oil Recovery of the Society of Petroleum of AIME, Tulsa, Oklahoma, 1978. 
CHRISTOPHER, R. H., MIDDLEMAN, S., Power-law flow through a packed tube. Industrial \& Engineering Chemistry Fundamentals 4.4, 422-426, 1965.

COSTA, F. C., BALABAN, R. C., Contribuição da poliacrilamida parcialemente hidrolisada em associação com a bentonita em fluidos de perfuração aquosos, MSc, Universidade Federal do Rio Grande do Norte, 2015.

DICKSON, J. L., LEAHY-DIOS, A., WYLIE, P. L., Development of improved hydrocarbon recovery screening methodologies. SPE-129768, Tulsa, USA, 2010.

DOMINGUEZ, J.G., WILLHITE, G.P. Retention and flow characteristics of polymer solutions in porous media. SPE Journal, SPE-5835-PA, v. 17, n. 2, pp. 111121, 1977.

ENGEOLKE, B. S., CARVALHO, M. S., Determinação das curvas de permeabilidade relativa no escoamento de emulsões e óleo, MSc, Pontifícia Universidade Católica do Rio de Janeiro, 2012.

FERREIRA, V.M., SZKLO, A.S, COUTO, P., Avaliação de métodos de recuperação melhorada de petróleo para campos marítimos no Brasil: $O$ caso da Bacia de Campos, MSc, Universidade Federal do Rio de Janeiro, 2016.

FOGAÇA, J., O que são os polímeros? Disponível em: <http://manualdaquimica .uol.com.br/quimica-organica/o-que-sao-ospolimeros.htm>. Acesso em 13 set. 2018.

GOGARTY, W.B., Rheological properties of pseudoplastic fluids in porous media. SPEJ (June), 149-160, 1967.

GOGARTY, W.B., Enhanced oil recovery through the use of chemicals - Part 2. JPT 1767-1775, 1983.

GOODLETT, G. O., et al., The role of screening and laboratory flow studies in EOR process evaluation. SPE-15172, Montana, USA, 1986.

GUTIÉRREZ, J. A. F., CARVALHO, M. S., Information on how viscoelastic polymer solutions behave in porous media and can impact their use in enhanced oil Recovery operation, PhD, Pontifícia Universidade Católica do Rio de Janeiro, 2018.

GRAMAIN, P., MYARD, P., Adsorption studies of polyacrylamides in porous media. Journal of Colloid and Interface Science, 84 (1), 114-126, 1981.

GREEN, D. W., WILlHITE, G. P., Enhanced Oil Recovery, Richardson, Taxis: Society of Petroleum Engineers, SPE Textbook Series Vol. 6. 1998. 
HUH, C., Pope, G.A., Residual oil saturation from polymer floods: Laboratory measurements and theoretical interpretation. SPE 113417, SPE/DOE Improved Oil Recovery Symposium, Tulsa, 2008.

HUSEYNLI, P., KLEPPE, J., Evaluation of polymer flooding for enhanced oil recovery in the Norne Field E-Segment, 2013.

JENNINGS, H. Y., ROGERS, J. H., WEST, T. J., Factors Influencing Mobility Control By Polymer Solutions. SPE 2867, JPT, 391-401, Volume 23, Number 3, 1971.

LAKATOS., I., LAKATOS-SZABO, J., TOTH, J., Factors influencing polyacrylamide adsorption in porous media and their effect on flow behavior. Symposium on Surface Phenomena in EOR, Stockholm, August, Plenum, 1979.

LAKE L. W. Enhanced Oil Recovery. University of Texas at Austin, Prentice Hall: New Jersey, USA, 1989.

LIPATOV, Y.S., SERGEEVA, L.M., Adsorption of Polymers. Wiley, 1974.

LITTMAN, W., Polymer Flooding: Developments in Petroleum Science. No. 24. Elsevier, Amsterdam, 1988.

LOTSCH, T., MULlER, T., PUSCH, G., The Effect of Inaccessible Pore Volume on Polymer Coreflood Experiments. SPE Oilfield and Geothermal Chemistry Symposium, 9-11 March, Phoenix, Arizona, SPE 13590, 1985.

LUO, J.H., LIU, Y.Z., ZHU, P., Polymer solution properties and displacement mechanisms. In: Shen, P.P., Liu, Y.Z., Liu, H.R. (Eds.), Enhanced Oil RecoveryPolymer Flooding. Petroleum Industry Press, pp. 1-72. 2006.

MACWILLIAMS, D.C., ROGERS, J.H., WEST, T.J., Water soluble polymers in petroleum recovery. In: Bikales, N.M. (Ed.), Water Soluble Polymers. Plenum Press, pp. 105-126, 1973.

MAERKER, J.M., Mechanical degradation of partially hydrolyzed polyacrylamide solutions in unconsolidated porous media. SPEJ 172-174, 1976.

MACHADO, F. N. S, ARAUJO, J. F. M., Análise da influência da permeabilidade da formação na recuperação avançada de óleo num projeto de injeção de polímero, BSc, Universidade Federal Fluminense, 2016.

MANRIQUE, E., AHMADI, M., SAMANI, S., Historical and recente observations in polymer floods: an update review. CT\&F - Ciencia, Tecnología y Futuro, 6(5), 17-48, 2017. 
MELO, M. A. et al. Polymer Injection Projects in Brazil: Dimensioning, Field Application and Evaluation. SPE 75194. In: SPE/DOE Improved Oil Recovery Symposium, Tulsa, Oklahoma, 2002.

NPC, Enhanced oil recovery, An analysis of the potential for enhanced oil recovery from known fields in the United States - 1976 to 2000. The National Petroleum Concil, Washington, D.C, 1976.

NPC, Enhanced oil recovery. The National Petroleum Concil, Washington, D.C, 1984.

PALOMBO, L., ULSEN, C., A microtomografia de raios $\mathbf{X}$ e a porosimetria por intrusão de mercúrio na determinação de porosidade e densidade de rochas reservatório. 2017.

PYE, D. J.: Improved Secondary Recovery by Control of Water Mobility. SPE 845. JPT, 911-916, Volume 16, Number 8, 1964.

RIOS, V. S., MORENO, R. B. Z. L., Recuperação de óleo por injeção de polímeros - abordagens experimental, analítica e numérica em pequena escala, MSc, Universidade Estadual de Campinas, 2014.

ROSA, A. J.; CARVALHO, R. S.; XAVIER, J. A. D., Engenharia de Reservatórios de Petróleo, Interciência, 2006.

RYLES, R.G., Elevated temperature testing of motility-control reagentes, Paper SPE 12008 presented at the SPE Annual Technical Conference and Exhibition, 1983.

SALEH, L., WEI, M., BAI, B., Data analysis and novel screening criteria for polymer flooding based on a comprehensive database, SPE-169093-MS, Tulsa, USA, 2014a.

SALEH, L., WEI, M., BAI, B., Data analysis and novel screening criteria for polymer flooding based on a comprehensive database, SPE Res Eval \& Eng 17 (01), SPE-168220-PA, 2014b.

SANDENGEN, K. et al., Qualifying an "Emulsion" Polymer for Field Use-LabScale Assessments on Adsorption and Injectivity. IOR Norway $2017-19^{\text {th }}$ European Symposium on Improved Oil Recovery, Stavanger, Norway, 2017.

SANSONE, E. C., Permeabilidade das rochas, 2014. Disponível em: < edisciplinas.usp.br/pluginfile.php/1678305/mod_resource/content $/ 1 / 07 \% 20$ \%20PMI1673\%20-\%202014\%20-\%20Permeabilidade.pdf $>$. Acesso em 10 jan. 2019. 
SHENG, J.J.: Modern Chemical Enhanced Oil Recovery: Theory and Practice, Elsevier, 2011.

SHENG, J. J., LEONHARDT, B., AZRI, N., Status of polymer-flooding technology, SPE-174541, 2015.

SMITH, F.W., The behavior of partially hydrolyzed polyacrylamide solutions in porous media. JPT 22, 148-156, 1970.

SNF FLOERGER Especificações das Poliacrilamidas, Disponível em: $<$ http://www.snfoil. com/Products.html $>$. Acesso em 17 set. 2017.

SORBIE, K. S., Polymer Improved Oil Recovery. 1.ed. Boca Raton, Blackie, 1991.

STANDNES, D. C., SKJEVRAK, I. Literature review of implemented polymer field projects. Journal of Petroleum Science and Engineering, 122, 761-775, 2014.

STATOIL, Best Practice for laboratory screening of EOR. Appendix B: Laboratory Screening Procedure and Appendix C: Description of "two slug method" for adsorption and IPV, 2015.

SZABO, M.T., Some aspects of polymer retention in porous media using a 14Ctagged hydrolyzed polyacrylamide. SPEJ (August), 323-337, 1975.

SZABO, M.T., An evaluation of water-soluble polymers for secondary oil recovery. parts I and II. JPT (May), 553-570, 1979.

TABER, J.J., MARTIN, F.D., Technical Screening Guide for Enhanced Oil Recovery (SPE- 12069). In: 58th Annual SPE Technical Conference, San Francisco, October 5-8, 1983.

TABER, J.J., MARTIN, F.D., SERIGHT, R.S., EOR Screening Criteria Revisited Part I: Introduction to Screening Criteria and Enhanced Oil Recovery Projects (SPE-35385). SPE Reservoir Engineering 12 (3), 189-198, 1997a.

TABER, J.J., MARTIN, F.D., SERIGHT, R.S., EOR Screening Criteria Revisited Part II: Applications and Impact of Oil Prices (SPE-39234). SPE Reservoir Engineering 12 (3),199-205, 1997 b.

THOMAS, J.E., Fundamentos de Engenharia de Petróleo. Interciência, Rio de Janeiro, 2.ed, 2004.

VIANNA, I. G. P., COUTO, P., DREXLER, S. G., Injeção de diferentes polímeros na simulação de produção de um reservatório, BSc, Universidade Federal do Rio de Janeiro, 2016. 
Veloso, Y., CRuZ, A., MACHADO, L., SAnTANA, A. P. S. C., Método de recuperação avançada de petróleo utilizando injeção de glicerina bruta $\mathrm{e}$ polímeros, 2014.

WILLHITE, G. P., Waterflooding, SPE Textbook series, Vol 3, 1986.

ZHANG, G., SERIGHT, R. S., Hydrodanimic retention and rheology of EOR polymers in porous media, SPE-173728-MS, Texas, USA, 2015. 